\title{
No Oxygen? No Problem! \\ Epigenetic mechanisms of anoxia tolerance in a champion anaerobe, the red-eared slider turtle \\ (Trachemys scripta elegans)
}

\author{
Sanoji Wijenayake
}

B.Sc. University of Ottawa, 2010

M.Sc. Carleton University, 2012

\begin{abstract}
A Thesis Submitted to the Faculty of Graduate Studies and Research in partial fulfillment of the requirements for the degree of
\end{abstract}

\author{
Doctor of Philosophy \\ Department of Biology \\ Carleton University, \\ Ottawa, Ontario, Canada.
}

(C) copyright 2017

Sanoji Wijenayake 
The undersigned herby recommend to the Faculty of Graduate Studies and Research acceptance of this thesis

\title{
No Oxygen? No Problem! \\ Epigenetic mechanisms of anoxia tolerance in a champion anaerobe, the red-eared slider turtle \\ (Trachemys scripta elegans)
}

\author{
Submitted by \\ Sanoji Wijenayake, B.Sc., M.Sc.
}

in partial fulfillment of the requirements for the degree of Doctor of Philosophy

Chair, Department of Biology

Thesis Supervisor

External Examiner

Carleton University 


\begin{abstract}
Red-eared sliders (Trachemys scripta elegans) are champion anaerobes that can
\end{abstract} survive approximately three months of absolute anoxia at $3{ }^{\circ} \mathrm{C}$ and recover with minimal cellular injury. Although various physiological and biochemical adaptations are involved in anoxia tolerance, metabolic rate depression (MRD) is considered to be the most useful response. T.s. elegans can reduce their metabolic rate to $10 \%$ of normoxic values by reducing all energy expensive cellular processes including gene expression. However, adaptations of alternate transcriptional regulatory processes are mostly unknown. In the thesis, epigenetic regulation of anoxia tolerance was investigated by exploring the dynamic changes in DNA methylation/demethylation, histone acetylation/deacetylation, and histone lysine methylation during short-term $(5 \mathrm{~h})$ anoxia and long-term $(20 \mathrm{~h})$ anoxia in several tissues of red-eared sliders. DNA methylation significantly increased in the liver and white skeletal muscle. An increase in DNA methylation could indicate a potential decrease in global gene expression in response to oxygen deprivation in redeared sliders. Correspondingly, a genomic mark of active transcription, DNA demethylation, decreased in the liver and white skeletal muscle. Establishing a unique balance between global and localized DNA methylation could be an important component of anoxia tolerance. Histone lysine methylation was also anoxia responsive in the liver of red-eared sliders, and suggested a target-specific regulation that could potentially aid in the selective upregulation of genes that are necessary for anoxia survival, while suppressing others. Histone acetylation and deacetylation, implicated in MRD of other stress-tolerant animals, illustrated a strong suppression in the liver of red-eared sliders. A strong suppression in histone $\mathrm{H} 3$ acetylation may also indicate an overall decrease in gene 
expression. Overall, this thesis may enhance our understanding of alternate modes of transcriptional regulation during anoxia tolerance and report several epigenetic mechanisms that are involved the hypometabolic response in T.s. elegans.

\section{PREFACE}

Chapter 2: The role of DNA methylation during anoxia tolerance in a freshwater turtle (Trachemys scripta elegans).

- This article was published in the Journal of Comparative Physiology B and was reproduced in whole as part of the Ph.D. thesis (Chapter 2).

- The publisher of this article, Springer, allows the use of published materials in thesis and dissertations. Please see attached Springer copyright document.

- The article should be cited as $\rightarrow$ Wijenayake S., Storey KB. 2016. The role of DNA methylation during anoxia tolerance in a freshwater turtle (Trachemys scripta elegans). J Comp Physiol B. 186(3): 333-42. PMID: 26843075, DOI: 10.1007/s00360-016-0960-x.

- Author contributions:

Sanoji Wijenayake conceived, designed, performed the experiments, analyzed the data, and wrote the paper/chapter.

Kenneth B. Storey contributed reagents, and materials.

Chapter 3: Demethylate that DNA! Dynamic regulation of TET-mediated DNA demethylation in response to anoxia tolerance in a freshwater turtle, Trachemys scripta elegans.

- Awaiting submission, 2019

Chapter 4: The dynamic regulation of histone $\mathrm{H} 3$ acetylation and deacetylation in response to prolonged oxygen deprivation in the champion anaerobe, Trachemys scripa elegans.

- $\quad$ Awaiting submission, 2019

Chapter 5: Regulation of histone lysine methylation in response to anoxia tolerance in a freshwater turtle, Trachemys scripta elegans.

- Submitted to Gene $\rightarrow$ Submission ID: GENE-D-17-01733.

- At the time of final thesis copy submission, the paper was under review.

- Author Contributions:

Sanoji Wijenayake conceived, designed, performed the experiments, analyzed the data, and wrote the paper.

Liam J. Hawkins performed the HMT western immunoblots.

Kenneth B. Storey contributed reagents, and materials. 


\section{ACKNOWLEDGEMENTS}

I would like to start off by thanking my supervisor, Dr. Kenneth B. Storey for everything he has done for me in the past five years. You have not only taught me how to be a great scientist, but also how to be a leader and how to run an organized, functional lab. Thank you for taking a chance on a little "wanna" be scientist who strolled into your office five years ago and asked to study epigenetics and anoxia tolerance. I remember you laughed at me and played the song "Hound Dog" by Big Momma Thorton and asked, "Who is this? If you know who this is, you can come to the lab". You are the best supervisor anybody could ask for Ken and I am really grateful to you and Jan for letting me be a part of the Storey lab. With that said, Ken would not be who he is without Jan. Jan you are the backbone of this lab and thank you for everything you have done for me.

As for the people that were my second family for the past five years; thank you to Shannon for being an amazing mentor and a friend over the years. Thank you to Rashie for being an annoying little sister, I will definitely miss you when I leave. Tony, I don't know how we are Siamese, but I am glad we are and always will be. Hans, we are Skyping once a week and that is that. Also I will fly back for "HaJing" events. BLuu please stop wearing those glasses before you get arrested and thanks for being a great scientific partner and a friend. Cat lady (you know who you are), I hope you never loose your love of cats. Trongy, I will miss your fabric softener stories and keep running 100 $\mathrm{km}$ in less than $3 \mathrm{hr}$. Also thanks to my babies who are now all grown up, Liam, Alex, Sam W, Rasha, and Myriam. Thanks for making me a better teacher and a scientist. To everybody else in the Storey lab, past and present, thank you for everything you have done for me. 
Most importantly, I would like to thank my parents for being my rocks. You have put up with so much over the years and this thesis is just as much yours as it is mine. You are my honorary PhDs. Also, I would not be who I am today without the love of my inlaws, siblings, cousins, aunties, and uncles, who are everything to me. Thank you for always pushing me and being there to catch and yell at me when I fall. I love you more than you know.

Finally, to my husband! I don't think I have enough pages in the thesis to tell you how much you mean to me and how thankful I am to have you in my life. Thank you for always being my biggest cheerleader and supporter. I could not have accomplished this without you. 


\section{TABLE OF CONTENTS}

Title Page $\quad$ i

Acceptance Sheet ii

General Abstract iii

Preface iv

$\begin{array}{lll}\text { Acknowledgements } & \text { v }\end{array}$

Table of Contents vii

List of Abbreviations viii

\begin{tabular}{ll} 
List of Figures & $x$ \\
\hline
\end{tabular}

List of Appendices $\quad$ xiv

$\begin{array}{ll}\text { Chapter } 1 & 15\end{array}$

$\begin{array}{lr}\text { Chapter } 2 & 68\end{array}$

$\begin{array}{lr}\text { Chapter } 3 & 98\end{array}$

$\begin{array}{ll}\text { Chapter } 4 & 135\end{array}$

$\begin{array}{lr}\text { Chapter } 5 & 180\end{array}$

$\begin{array}{lr}\text { Chapter } 6 & 215\end{array}$

$\begin{array}{ll}\text { Appendices } & \mathbf{2 4 1}\end{array}$ 


\section{LIST OF ABBREVIATIONS}

\begin{tabular}{|c|c|}
\hline 2-HG & 2-hydroxyl gluterate \\
\hline 2-OG & 2-oxogluterate \\
\hline $5 \mathrm{caC}$ & 5-carboxylcytosine \\
\hline $5 \mathrm{fC}$ & 5-formylcytosine \\
\hline $5 \mathrm{hmC}$ & 5-hydroxymethylcytosine \\
\hline $5 \mathrm{mC}$ & 5-methylcytosine \\
\hline$\alpha-K G$ & $\alpha$-ketoglutarate \\
\hline AdoHcy & S-adenosyl-L-homocysteine \\
\hline BER & Base excision repair \\
\hline CBP & CREB-binding protein \\
\hline $\mathrm{CH}$ & Cardiac hypertrophy \\
\hline ChIP-seq & Chromatin immunoprecipitation followed by sequencing \\
\hline ChREBP & Carbohydrate responsive element binding protein \\
\hline COBRA & Combined bisulfite restriction analysis \\
\hline DNMT1 & DNA methyltransferase 1 \\
\hline DNMT2 & DNA methyltransferase2 \\
\hline DNMT3a & DNA methyltransferase3a \\
\hline DNTM3b & DNA methyltransferase $3 b$ \\
\hline DTT & Dithiothreitol \\
\hline ECF & Extracellular fluid \\
\hline ETC & Electron transport chain \\
\hline FoxO & Forkhead box proteins \\
\hline GAPDH & Glycelaldehyde-3-phosphate dehydrogenase \\
\hline GCN5L & General control of amino acid synthesis yeast homolog-like \\
\hline GDH & Glutemate dehydrogenase \\
\hline GNAT & Gcn5-related N-acetyltransferases \\
\hline GPox & Glutathione peroxidases \\
\hline GRPs & Glucose regulated proteins \\
\hline GST & Glutathione S-transferases \\
\hline $\mathrm{H}_{2} \mathrm{O}_{2}$ & Hydrogen peroxide \\
\hline $\mathrm{H} 3 \mathrm{~K} 14 \mathrm{ac}$ & Histone $\mathrm{H} 3$ acetyl lysine 14 \\
\hline $\mathrm{H} 3 \mathrm{~K} 18 \mathrm{ac}$ & Histone $\mathrm{H} 3$ acetyla lysine 18 \\
\hline $\mathrm{H} 3 \mathrm{~K} 27 \mathrm{me} 1$ & Histone H3 monomethyl lysine 27 \\
\hline $\mathrm{H} 3 \mathrm{~K} 4 \mathrm{me} 1$ & Histone H3 monomethyl lysine 4 \\
\hline H3K56ac & Histone $\mathrm{H} 3$ acetyl lysine 56 \\
\hline H3K9me3 & Histone $\mathrm{H} 3$ trimethyl lysine 9 \\
\hline H3K9mepan & Histone H3 panmethyl lysine 9 \\
\hline HATs & Histone acetyltransferases \\
\hline $\mathrm{HCO}_{3}^{-}$ & Plasma bicarbonate \\
\hline HDACs & Histone deacetylases \\
\hline HIF-1 & Hypoxia inducible factor 1 \\
\hline
\end{tabular}




$\begin{array}{ll}\text { HP1 } & \text { Heterochromatin protein 1 } \\ \text { HSPs } & \text { Heat shock proteins } \\ \text { JMJs } & \text { Jumonji domain family proteins } \\ \text { KATs } & \text { Lysine acetyltransferases } \\ \text { LDH } & \text { Lactate dehydrogeanse } \\ \text { LSD1 } & \text { Lysine-specific demethylase } \\ \text { MAPK } & \text { Mitogen activated protein kinase } \\ \text { MAT } & \text { Methionine adenosyltransferase } \\ \text { MDB1 } & \text { Methyl-binding protein 1 } \\ \text { MDB2 } & \text { Methyl-binding protein 2 } \\ \text { MRD } & \text { Metabolic rate depression } \\ \text { Ms-SNuPE } & \text { Methylation-sensitive single nucleotide primer extension } \\ \text { MSP } & \text { Methylation-specific PC } \\ \text { NF- } \text { KB }^{-} & \text {Nuclear factor kappa-light-chain-enhancer of activated B cells } \\ \text { O }^{-} & \text {Superoxide anion radicals } \\ \text { OH } & \text { Hydroxyl radical } \\ \text { PCAF } & \text { p300/CBP-associated factor } \\ \text { PK } & \text { Pyruvate kinase } \\ \text { PMSF } & \text { phenylmethylsulfonyl fluoride } \\ \text { PTM } & \text { Post-translational modifications } \\ \text { ROO- } & \text { Peroxide radical } \\ \text { ROS } & \text { Reactive oxygen species } \\ \text { RPA } & \text { Reversible protein acetylation } \\ \text { RPP } & \text { Reversible protein phosphorylation } \\ \text { SAH } & \text { S-adenosylhomocysteine } \\ \text { SAM } & \text { S-adenosylmethionine } \\ \text { SIRTs } & \text { Sirtuins } \\ \text { SOD1 } & \text { Superoxide dismutase1 } \\ \text { STAT } & \text { Signal transducer and activator of transcription } \\ \text { TCA } & \text { Tricarboxylic acid } \\ \text { TETs } & \text { Ten eleven translocation family of proteins } \\ \text { UPR } & \text { Unfolded protein response } \\ \text { UTR } & \text { Untranslated region } \\ & \end{array}$




\section{LIST OF FIGURES}

Fig. 1.1. The duration of anoxia tolerance at different temperatures for which the anoxia tolerant painted turtle (Chrysemys picta bellii) have been observed to recover. The figure was adapted from (Jackson, 2000).

Fig. 1.2. The relationship between blood $\mathrm{pH}$ and plasma lactate concentration during 125 days of anoxic submergence in the Eastern painted turtle (Chrysemys picta picta). Figure adapted from (Jackson, 2000).

Fig. 1.3. Schematic model portraying shell buffering of plasma ions during prolonged exposure to anoxia in the painted turtle (Chrysemys picta bellii). In mechanism 1, calcium, magnesium, and sodium carbonates move from the shell to the blood in response to the accumulation of lactic acid and provide extracellular buffering. In mechanism 2, lactic acid enters the shell, is buffered and stored. The figure was adapted from (Jackson, 2000).

Fig. 1.4. Schematic model portraying shell buffering of plasma ions during prolonged exposure to anoxia in the painted turtle (Chrysemys picta bellii). In mechanism 1, calcium, magnesium, and sodium carbonates move from the shell to the blood in response to the accumulation of lactic acid and provide extracellular buffering. In mechanism 2 , lactic acid enters the shell, is buffered and stored. The figure was adapted from (Jackson, 2000).

Fig. 1.5. Three main stages of hypometabolic response during anoxia exposure in redeared sliders (K. Biggar et al., 2011). Upon exposure to low oxygen, a variety of cellular adjustments take place to reprioritize ATP usage and survive long-term anoxia.

Fig. 1.6. The percent decrease of ATP usage by cellular processes of isolated turtle hepatocytes in response to anoxia. The overall cumulative decrease $(\sim 90 \%)$ is similar to the decrease in ATP usage observed for the whole animal and to the total metabolic rate of hepatocytes. The figure was adapted from (Jackson, 2000).

Fig 1.7. Epigenetics and connection to metabolism. The figure represents the connection between different epigenetic regulators such as DNA methyltransferases (DNMTs), histone methyltransferases (HMTs), lysine specific demethylases (LSD), jumonji domain family (JMJs), methylcytosine deoxygenases (TETs), etc and products of cellular metabolism such as SAM, FAD, O2, 2-HG, Fe(III), and alpha-ketoglutarate. This figure was adapted from (Kohli and Zhang, 2013).

Fig. 2.1. Effect of 5 and $20 \mathrm{~h}$ anoxic submergence on total protein levels of DNMT1, DNMT2, DNMT3a, DNMT3b, MBD1, and MBD2 in liver of T. s. elegans as determined by Western immunoblotting. Data are mean \pm SEM, and $n=3-4$ independent trials on tissue samples from different animals. a Significantly different from the corresponding control $(\mathrm{P}<0.05)$. b Significantly different values from the $5 \mathrm{~h}$ anoxic value. 
Fig. 2.2. Effect of 5 and $20 \mathrm{~h}$ anoxic submergence on total protein levels of DNMT1, DNMT2, DNMT3a, and DNMT3b, MBD1, and MBD2 in heart of T. s. elegans as determined by Western immunoblotting. Other information as in Fig. 2.1

Fig. 2.3. Effect of 5 and $20 \mathrm{~h}$ anoxic submergence on total protein levels of DNMT1, DNMT2, DNMT3a, DNMT3b, MBD1, and MBD2 in white muscle of T. s. elegans as determined by Western immunoblotting. Other information as in Fig. 2.1

Fig. 2.4. Total DNMT enzyme activity (activity was measured as OD/h/mg nuclear protein) in liver, heart, and white muscle of T. s. elegans as determined by EpiQuick DNMT Activity/Inhibition Colorimetric Assay Ultra Kit from Epigentek. Other information as in Fig. 2.1

Fig. 2.5. Relative levels of global DNA methylation (5-mC content) in liver, heart, and white muscle of T. s. elegans as determined by MethylFlash Methylated DNA colorimetric quantification kit from Epigentek. Other information as in Fig 2.1

Fig. 3.1. The relative protein expression levels of TET DNA demethylases and TDG in response to control $5 \mathrm{~h}$ anoxic, and $20 \mathrm{~h}$ anoxic submergence in the liver of T.s. elegans as determined by western immunoblotting. Data are mean \pm SEM and $n=3-4$ biological replicates. One-way ANOVA analysis of variance with a post-hoc Tukey test $(p<0.05)$ was used for data analysis. a significantly different from the control $(p<0.05)$; $\mathbf{b}$ significantly different from $5 \mathrm{~h}$ anoxia $(\mathrm{p}<0.05)$.

Fig. 3.2. Relative expression levels of three methyl-variants of DNA demethylation in response to $5 \mathrm{~h}$ and $20 \mathrm{~h}$ anoxic exposure in the liver of T.s. elegans as determined by DNA dot blotting. Other information as in Figure 3.1.

Fig. 3.3. The relative protein expression levels of TET DNA demethylases and TDG in response to control $5 \mathrm{~h}$ anoxic, and $20 \mathrm{~h}$ anoxic submergence in the white skeletal muscle of T.s. elegans as determined by western immunoblotting. Other information as in Figure 3.1 .

Fig. 3.4. Relative expression levels of three methyl-variants of DNA demethylation in response to $5 \mathrm{~h}$ and $20 \mathrm{~h}$ anoxic exposure in the white skeletal muscle of T.s. elegans as determined by DNA dot blotting. Other information as in Figure 3.1.

Fig. 3.5. The relative protein expression levels of TET DNA demethylases and TDG in response to control $5 \mathrm{~h}$ anoxic, and $20 \mathrm{~h}$ anoxic submergence in the heart of T.s. elegans as determined by western immunoblotting. Other information as in Figure 3.1.

Fig. 3.6. Relative expression levels of three methyl-variants of DNA demethylation in response to $5 \mathrm{~h}$ and $20 \mathrm{~h}$ anoxic exposure in the heart of T.s. elegans as determined by DNA dot blotting. Other information as in Figure 3.1. 
Fig. 3.7. Total TET enzyme activity ( $\mathrm{ng} / \mathrm{h} / \mathrm{mg}$ of nuclear protein) on $5 \mathrm{mC}$ in the liver, white muscle, and heart of T.s. elegans as determined by Epigenase $5 \mathrm{mC}$ hydroxylase TET activity/inhibition assay kit from Epigentek. Other information as in Figure 3.1.

Fig. 4.1. The protein expression level of histone $\mathrm{H} 3$ along with the acetylation levels of four lysine residues on histone $\mathrm{H} 3$ in the liver of T.s. elegans in response to control, $5 \mathrm{~h}$ anoxia, and $20 \mathrm{~h}$ anoxia as determined by western immunoblotting. Data are mean \pm SEM, and $n=3-4$ independent trials on tissue samples from different animals. a Significantly different from the corresponding control $(\mathrm{p}<0.05)$. $\mathrm{b}$ Significantly different values from the $5 \mathrm{~h}$ anoxic value.

Fig. 4.2. The relative protein expression levels of GCN-family of acetyltransferases, HAT1, GCN5L, and PCAF in response to control, $5 \mathrm{~h}$, and $20 \mathrm{~h}$ anoxia in the liver of T.s. elegans. Other information as in Figure 4.1.

Fig. 4.3. The relative protein expression levels of MYST family of acetyltransferases, Tip60, in response to control, $5 \mathrm{~h}$, and $20 \mathrm{~h}$ anoxia in the liver of T.s. elegans. Other information as in Figure 4.1.

Fig. 4.4. The relative protein expression levels of CBP acetyltransferases in response to control, $5 \mathrm{~h}$, and $20 \mathrm{~h}$ anoxia in the liver of T.s. elegans. Other information as in Figure 1.

Fig. 4.5. Total HAT enzymatic activity and nuclear HAT enzymatic activity ( $\mathrm{ng} / \mathrm{h} / \mathrm{mg})$ were measured in the liver of T.s. elegans in response to control, $5 \mathrm{~h}$ anoxia, and $20 \mathrm{~h}$ anoxia as determined by EpiQuik HAT Activity/Inhibition Assay kit from Epigentek. Other information as in Figure 1.

Fig. 4.6. The relative protein expression levels of the nuclear SIRTs, SIRT1, SIRT6, and SIRT7 in response to control, $5 \mathrm{~h}$ anoxia, and $20 \mathrm{~h}$ anoxia, in the liver of T.s.elegans. Other information as in Figure 1.

Fig. 4.7. SIRT enzymatic activity (RFU/min $/ \mathrm{mg}$ ) was measured in the liver of T.s. elegans in response to control, $5 \mathrm{~h}$ anoxia, and $20 \mathrm{~h}$ anoxia as determined by Epigenase Universal SIRT Activity/Inhibition Fluorometric Assay. Other information as in Figure 1.

Fig. 5.1. Histone H3 lysine 4, 9, and 27 residues that are mono, di, or tri methylated by respective histone methyltransferases such as SET7/9, RBBP5, ASH2L, SMYD2, EHMT2, and SUV39H1.

Fig. 5.2. The relative expression of methyl moieties on histone $\mathrm{H} 3$ in response to control, $5 \mathrm{~h}$, and $20 \mathrm{~h}$ anoxia exposure in the liver of T.s. elegans as determined by Western immunoblotting. Data are mean \pm SEM, $n=4$ independent trials on samples from different animals. Data were analyzed using analysis of variance with a post hoc Tukey test $(\mathrm{p}<0.05)$; a Statistically significant from the control, normoxia $(\mathrm{p}<0.05)$. b Statistically significant from $5 \mathrm{~h}$ anoxia $(\mathrm{p}<0.05)$. 
Fig. 5.3. The relative proteins expression levels of five histone $\mathrm{H} 3$ methyltransferases in response to control, $5 \mathrm{~h}$, and $20 \mathrm{~h}$ anoxia exposure in the liver of T.s. elegans as determined by western immunoblotting. Other information as in Figure 2.

Fig. 5.4. Total Histone methyltransferase enzyme activity $(\mathrm{ng} / \mathrm{h} / \mathrm{mg}$ of total soluble protein) on histone $\mathrm{H} 3 \mathrm{~K} 4, \mathrm{H} 3 \mathrm{~K} 9$, and $\mathrm{H} 3 \mathrm{~K} 27$ in the liver of T.s. elegans as determined by Epiquick HKMT activity/inhibition colorimetric assays from Epigentek. Other information as in Figure 2. 


\section{LIST OF APPENDICES}

\begin{tabular}{ll} 
Appendix A & List of publications \\
Appendix B & Communications at scientific meetings \\
Appendix C & Departmental seminars and guest lectures \\
Appendix D & Author contributions \\
Appendix $\mathbf{E}$ & List of antibodies \\
Appendix F & Immunoblotting conditions \\
Appendix G & Steps taken to ensure antibody specificity for immunoblotting \\
Appendix H & Bioinformatics for immunoblotting \\
Appendix I & Western immunoblot image \\
Appendix J & Technical information on cyto-nuclear extractions \\
\hline Appendix K & Enzymatic assays - mechanistic details \\
Appendix L & Thesis defense slides
\end{tabular}


CHAPTER 1

GENERAL INTRODUCTION

"Try to be like a turtle, at ease in your own shell"

- Bill Copeland 


\subsection{Oxygen, the molecule of life}

Oxygen, the second most abundant gas in Earth's atmosphere and is believed to have been incorporated into the electron transport chain (ETC) circa 1-3 billion years ago by primitive eukaryotic ancestors (Embley and Martin, 2006). Since then, oxygen has become a vital component of aerobic ATP production due to its high redox potential and the ability to efficiently accept electrons from reduced metabolic intermediates, such as $\mathrm{NADH}$ and $\mathrm{FADH}_{2}$. Although anaerobic catabolism of glucose in the form of glycolysis is capable of producing some ATP, the amount of ATP that is produced is not sufficient to support multicellular life for an extended period of time $(1 \mathrm{~mol}$ glucose $=$ net production of $2 \mathrm{~mol}$ of ATP). As such, the introduction of oxygen as the final acceptor of electrons in the ETC not only greatly increased the amount of ATP that can be produced by the breakdown of $1 \mathrm{~mol}$ of glucose from $2 \mathrm{~mol}$ of ATP to $36 \mathrm{~mol}$ of ATP (Brand, 2003), but it also enabled eukaryotes to extract greater amount of energy from other macromolecules, such as fatty acids and proteins. Consequently, the ability to extract greater amounts of energy from macromolecules through oxidative phosphorylation has driven life to evolve into higher and more complex forms but with a major dependence on oxygen (Storey, 2007).

Hypoxia (low oxygen) and anoxia (complete lack of oxygen) arises when the metabolic demand for oxygen exceeds the supply, and most vertebrates, in particular humans, are very sensitive to oxygen deprivation and prolonged exposure to hypoxia. Interruption in oxygen supply, if lasting for more than few minutes, halts the ETC residing within the mitochondria, backlogs the tricarboxylic acid (TCA) cycle, and disrupts oxidative phosphorylation, the leading source of ATP production in the cell 
(Milton and Prentice, 2007; Storey, 2007). Consequently, prolonged periods of hypoxia and anoxia can disrupt the regular functioning of so called "ATP sinks" such as protein translation, protein degradation, urea biosynthesis, gluconeogenesis, and various ion motive ATPases (Hochachka and Lutz, 2001a). As such, situations of hypoxia and/or anoxia can rapidly lead to severe tissue damage and inevitable death (Brierley, 1977) to intolerant organisms.

$\mathrm{Na}^{+} / \mathrm{K}^{+}$ATPases that maintain cellular ionic homeostasis are among the first cellular processes to be disrupted by the onset of hypoxia and this can cause the most detrimental damage. The interruption of $\mathrm{Na}^{+} / \mathrm{K}^{+}$ATPase ion channels is particularly damaging since it can lead to a loss in membrane potential difference and a rapid breakdown of critical transmembrane ion gradients, a dangerous rise in intracellular $\mathrm{Ca}^{2+}$ levels, and a constant release of excitatory neurotransmitters (Hochachka and Lutz, 2001a; Storey, 2007). In particular, acute hypoxia and ischemia can be hazardous for neuronal function since neurons are considered to be the most anoxia sensitive of all cells (Brierley, 1977). The breakdown of membrane potential in the brain is followed by the release of excitatory neurotransmitters such as aspartate and glutamate, in which glutamate binds to postsynaptic receptors that regulate calcium channels. The uncontrolled influx of $\mathrm{Ca}^{2+}$ has been shown to activate proteases, lipases, and endonucleases that can in turn destroy neuronal integrity (Milton and Prentice, 2007). Additional neuronal damage can occur during the oxygen reperfusion phase with the sudden influx of reactive oxygen species (ROS), production of nitric oxide, extensive inflammation, and deregulation in the release of excitatory and inhibitory neurotransmitter systems (Berger et al., 2016). Brain is not the only organ that can be affected by acute hypoxia and ischemia. 
As a muscle pump, the heart's ATP requirement far exceeds that of most other organs, with the exception of the brain. Apart from the continual supply of ATP that is required for the mechanical functioning of cardiomyocytes (contract and relax), ATP is also essential for generation and maintenance of repeated action potentials and intracellular $\mathrm{Ca}^{2+}$ homeostasis in the heart (Stecyk et al., 2008a). Under normoxic conditions, the high myocardial ATP demand is supported mainly through oxidative phosphorylation and if the hypoxic episode is short term, cardiomyocytes can solve this problem by 1) matching the increased ATP demand of the cell by increasing glycolysis (this compensation strategy is referred to as the Pasteur effect) (Storey and Storey, 1990a), 2) decreasing mechanical functioning, and 3) selectively suppressing non-contractile physiological process in the heart (Stecyk et al., 2008a). However, if normoxia does not ensue within minutes, intolerant species will not be able to sustain regular cardiac functioning even with maximum anaerobic glycolytic supply (Storey and Storey, 1990a). As such prolonged exposure to anoxia can quickly lead to cardiomyocyte death through apoptosis and necrosis, overall cardiac failure, and ultimately death (Hicks and Wang, 1998; P. Hochachka, 1986; Hochachka et al., 1996).

However, an obligate attachment to oxygen is not universal to all animals and many experience natural situations where their access to oxygen can be cut off for short or long periods of time. For instance, some animals regularly experience situations of interrupted oxygen supply that arise due to 1) variations in oxygen availability of the habitats (i.e. ice-locked lakes with anoxic waters) that deny animals like freshwater turtles access to atmospheric oxygen, and/or 2) feeding behaviors that warrant extended periods of breathhold diving (i.e. apnoic dives) (Hochachka, 1988; Hochachka and Lutz, 2001b; K. Storey 
and Storey, 2004a). Depending on the length of the exposure, both of these situations decrease oxidative phosphorylation, increase oxidative stress, and increase cytotoxicity due to the accumulation of end products such as lactic acid or ethanol (Storey and Storey, 1990a). As such, some of these animals have developed physiological as well as biochemical mechanisms to combat and survive short-term hypoxia. Physiological responses to short-term hypoxia include increased lung ventilation and gas exchange; altered hemoglobin affinity for oxygen; release of stored red blood cells from the spleen; and an increase in heart rate and cardiac pumping of oxygenated blood through the body (Storey and Storey, 2007; K. B. Storey and Storey, 2004). These physiological adaptations serve to increase oxygen uptake and delivery to oxygen sensitive organs for a period of time but are not solutions to long term oxygen deprivation (Storey, 2007; K.

Storey and Storey, 2004a; K. B. Storey and Storey, 2004). Some biochemical responses to oxygen deprivation include an increased breakdown of liver glycogen stores through glycolysis (Pasteur effect) as well as to tap into creatine phosphate reserves in tissues with large phosphagen pools such as the adipocytes (K. Storey and Storey, 2004a; K. B. Storey and Storey, 2004). Often these physiological and biochemical adaptations are sufficient to survive short-term and mild forms of hypoxia, but extended periods of anoxic exposure require a slew of other biochemical adaptations and metabolic reorganization.

\subsection{Anaerobiosis and the “AMAZING" turtle}

Among vertebrates, long-term survival without oxygen is highly developed in some freshwater turtles. Several of these species have very well-developed physiological and biochemical adaptations for living without oxygen, more commonly referred to as 
anaerobiosis (Storey, 2007). For example, freshwater turtles living in northern regions of United States and Canada elude inhospitable, freezing temperatures on land by hibernating at the bottom of ice-locked ponds for the duration of the winter, without accessing the surface to breath. In addition to seasonal anoxic exposure, short-term hypoxia is often a daily occurrence for these turtles due to deep underwater dives in search of food and/or to avoid predation (K. Biggar et al., 2011; Jackson, 2000).

Red-eared sliders (Trachemys scripta elegans), as well as subspecies of Chrysemys picta such as the Western painted turtle (C. p. bellii), and Midland painted turtle (C. p. marginata) have become established vertebrate models for anoxia tolerance research. Although humans cannot live without oxygen for more than a few minutes, sliders and painted turtles are able to survive underwater submergence without oxygen for up to 12-18 weeks at around $3{ }^{\circ} \mathrm{C}$ (Figure1) (Jackson, 1968, 2000; Ultsch and Jackson, 1982 ) and return to normoxic conditions without incurring cellular damage. Brummation temperature of the ponds is one of the main determinants of the anoxia duration in freshwater turtles. In particular, some freshwater turtles have been shown to only tolerate and survive 0.5 days of anoxia at $20^{\circ} \mathrm{C}$, three days at $15^{\circ} \mathrm{C}$, and up to two weeks at $16^{\circ}$ C (Jackson, 2000). Uniquely, hatchlings of C. p. bellii and C. p. marginata are also able to survive whole body freezing during their first winter which they spend in their terrestrial nest; their high anoxia tolerance is crucial to their freeze tolerance (Storey and Storey, 1992). Crucian carp and goldfish also have well developed anoxia tolerance to support winter survival in ice-locked ponds and lakes (Storey and Storey, 1990b).

Some species of freshwater turtles have solved the problem of low oxygen availability by evolving extrapulmonary mechanisms of oxygen uptake such as taking up 
oxygen from the surrounding water across cloacal and/or buccal epithelia (K. Storey and Storey, 2004a; K. B. Storey and Storey, 2004; Ultsch and Jackson, 1982). Because the metabolic rate of ectotherms in cold water is very low, this strategy can meet the full oxygen requirements of the animals for some time. Other turtle species, such as the redeared sliders, however, are facultative anaerobes that can live longer periods (i.e. weeks to months) without oxygen and have developed more extensive and strictly regulated cellular processes to tolerate and survive long-term anoxia.

Some well-known physiological and biochemical adaptations employed by red-eared sliders to combat and survive prolonged anoxic exposure include;

1) Maintaining high glycogen stores in tissues (principally liver and skeletal muscle) (Jackson, 1968; K. Storey and Storey, 2004a; Storey and Storey, 2007, 1990b; K. B. Storey and Storey, 2004; Ultsch and Jackson, 1982).

2) Maintaining a high glycolytic capacity - i.e. high activities of glycolytic enzymes (K. Storey and Storey, 2004a; Storey and Storey, 2007; K. B. Storey and Storey, 2004).

3) Regulate ion channels and neurotransmitter release and production (Brierley, 1977; P. Hochachka, 1986; Milton and Prentice, 2007).

4) Use the calciferous shell to store and buffer protons and lactate that is produced by anaerobic glycolysis and thereby minimize the associated acidosis (Davis and Jackson, 2007; DC Jackson et al., 2000; DC. Jackson et al., 2000; Jackson, 1997; Jackson et al., 2006a).

5) Reduce overall metabolic rate to just $10-20 \%$ of the normoxic condition by temporarily shutting down all unnecessary energy-consuming processes and 
reprioritizing the available ATP to sustain key cellular processes (Hochachka, 1988; Hochachka et al., 1999; Hochachka and Lutz, 2001b; Storey and Storey, 1990a).

Recent studies done on red-eared sliders by the Storey lab has also identified numerous, novel molecular strategies of metabolic rate depression (MRD) and cellular stress response during $5 \mathrm{~h}$ hypoxic and $20 \mathrm{~h}$ anoxic exposure such as;

1) Activation of hypoxia sensing (Hif-1 $\alpha$ ) and other signal transduction pathways such as mitogen activated protein kinase (MAPK) (K. Biggar et al., 2011) in response to anoxia.

2) Up-regulation of antioxidant defenses, unfolded protein response, and the heat shock protein response to minimize ROS damage caused by oxygen reperfusion during oxygen recovery phase (Krivoruchko and Storey, 2013a, 2010a, 2010b).

3) Transcriptional (transcription factor regulation), post-transcriptional (miRNA regulation), and post-translational (phosphorylation, acetylation, and methylation) mechanisms to regulate gene and protein expression in a tissue specific and target-specific manner (Biggar and Storey, 2011, 2015, 2012a, Krivoruchko and Storey, 2013b, 2010c, 2010d; Sanoji Wijenayake and Storey, 2016; Zhang et al., 2013a).

The overall focus of this thesis is to build upon existing research on molecular adaptations that support anoxia-induced metabolic rate depression in red-eared sliders with a principal focus on exploring the role of epigenetics (DNA methylation and demethylation, dynamic histone modifications) in facilitating anoxia tolerance and survival (discussed in chapter 2-4). 


\subsection{Acid-base regulation and prevention of acidosis}

Anoxic turtles accumulate plasma lactate concentrations as high as $150-200 \mathrm{mM}$ after several months of anoxia (Davis and Jackson, 2007; Jackson et al., 2006a), whereas a human excised to exhaustion may only experience an extreme plasma lactate level of 20$25 \mathrm{mM}$ before experiencing acidosis (Figure 2). Lactate accumulation decrease the overall $\mathrm{pH}$ of the plasma and can dissolve bones and shell (Jackson et al., 2001). Blood $\mathrm{pH}$ have been shown to rapidly decrease in anoxia tolerant softshell turtle, Apalone spinifera with increased lactate accumulation, when compared to the anoxia tolerant painted turtle Chrysemys picta; this may be a major factor that limits prolonged anoxia survival in this animal (DC Jackson et al., 2000).

The anoxia-tolerant freshwater turtle are able to cope with these extraordinarily high lactate and proton $\left(\mathrm{H}^{+}\right)$levels by utilizing key physiological defense mechanisms;

1) The first line of defense is the use of extracellular buffering against accumulating $\mathrm{H}^{+}$and lactate. In freshwater turtle species plasma bicarbonate $\left[\mathrm{HCO}_{3}{ }^{-}\right]$range from $35-45 \mathrm{mM}$ (Ultsch and Jackson, 1996) with some chelonian species such as the painted turtle and red-eared sliders having considerably higher concentration of $\mathrm{HCO}_{3}{ }^{-}$in specialized pericardial $(\sim 120$ $\mathrm{mM})$ and peritoneal fluids ( $120 \mathrm{mM})$ that can flush the heart and abdominal cavities (Jackson, 2000; Smith, 1929). However, as the duration of anoxic submergence at $3{ }^{\circ} \mathrm{C}$ prolongs, the amount of lactate and $\mathrm{H}^{+}$buildup far exceeds the extracellular buffering capacity (DC. Jackson et al., 2000; Jackson and Heisler, 1983; Smith, 1929; Ultsch and Jackson, 1996). Thus additional and 
more long-term buffering mechanisms are needed to survive 3-5 months of oxygen deprivation at low temperatures.

2) Acid-base buffering using the turtle shell is a long-term and stable approach to combating acidosis. The turtle's shell is a dynamic structure that not only functions as a protective enclosure for the animal against predation and desiccation, but it also serves as an insertion site for muscle and connective tissues, perfused with blood, grows, remodels, and serves as a major mineral reservoir the turtle can tap into for acid-base regulation (Jackson and Heisler, 1983; Jackson, 2000; Ultsch and Jackson, 1996). Red-eared sliders use the shell to buffer proton and lactate buildup during prolonged anoxia in two ways; 1) $\mathrm{Ca}^{2+}$ and $\mathrm{Mg}^{2+}$ carbonate ions are released from the shell into the extracellular fluid (ECF) and form complexes with proteins and lactate anions to supplement buffering (DC. Jackson et al., 2000; Jackson, 2000) and 2) the shell and bones absorb lactate anions and $\mathrm{H}^{+}$, where natural carbonates act to buffer protons and lactate is stored until normoxic conditions are restored (DC. Jackson et al., 2000; Jackson, 1997; Jackson et al., 1999, 2006a; Jackson and Heisler, 1983) (Figure 3; Figure 4).

Acid-base buffering through carbonate, $\mathrm{Mg}^{2+}$ and $\mathrm{Ca}^{2+}$ release and efficient lactate uptake by the shell accounts for more than $70 \%$ of the total lactic acid buffering in the champion anaerobe, red-eared sliders, during prolonged anoxic exposure. Therefore, by employing these two modes of buffering in combination, the anoxia tolerant freshwater turtle, maintains a stable ECF ion homeostasis, ECF $\mathrm{PCO}_{2}$ that is remarkably the same or even lower than normoxic $\mathrm{PCO}_{2}$ values (Jackson, 2000), and in general avoids lethal 
acidosis that is typically associated with anoxia.

\subsection{Metabolic rate depression}

Under aerobic conditions, most organisms use oxidative phosphorylation as the main source of high yield ATP production in the cell to catabolize all fuels, not only carbohydrates but also lipids and proteins to generate ATP to drive cellular processes. However, one of the main consequences of anoxia is the complete breakdown of oxidative phosphorylation due to the absence of oxygen as the final acceptor of electrons in the ETC. In particular, once blood oxygen levels fall below an arterial $\mathrm{pO}_{2}$ of about 20 Torr in freshwater turtles (Greenway and Storey, 2000), oxidative phosphorylation comes to a halt and oxygen-independent metabolic pathways, such as anaerobic glycolysis becomes the sole source of ATP production in the cell (Hochachka, 1988; Jackson, 1968; K. Storey and Storey, 2004a; Storey and Storey, 1990b). This presents a metabolic situation wherein anaerobic glycolysis becomes the sole source of ATP production and a very high rate of glycolysis would be needed to sustain the ATP requirements of all cell functions. However, even a very high rate of glycolysis cannot produce enough ATP to sustain cellular processes to the level they were under normoxic conditions, and sooner rather than later, glycogen/glucose reserves in all cells (including the huge glycogen reserves in liver) will be consumed and cells will run out of energy (K. Biggar et al., 2011; Brand, 2003). Furthermore, an increased glycolytic rate is also associated with large accumulations of lactic acid with the potential to induce lethal acidosis (discussed in section 1.4) (Jackson, 1997; Storey, 2007). Therefore, using only glycolysis to maintain the same metabolic rate during anoxia as under aerobic conditions is not a feasible option 
for long-term survival by turtles. Therefore, facultative anaerobes, such as red-eared sliders, must put in place strategies to tolerate and survive the negative consequences of running only anaerobic glycolysis to generate ATP. Such strategies include; 1) increase glycogen reserves in the liver and skeletal muscle that can be tapped into to generate ATP, 2) adapt to a high tolerance for large changes in $\mathrm{pH}$ of intracellular and extracellular fluids, 3) utilize shell and bone buffering to combat lactic acid buildup, 4) release inhibitory neurotransmitters such as GABA, taurine, and glycine to reduce neuronal activity and energy consumption in the anoxic turtle brain, and 4) employ a strong reduction of metabolic rate when oxygen levels fall below an arterial $\mathrm{pO}_{2}$ of $\sim 20$ Torr, 5) reprioritize the available ATP to drive necessary cellular processes and repress ATP expensive cellular processes, 6) maintain a long-term hypometabolic state, and 7) prepare for oxygen reperfusion, a rapid increase in metabolic rate, and a global resumption of cellular activities during normoxic recovery by strengthening cytoprotective measures (K. Biggar et al., 2011; Blokhina et al., 2003; Hermes-Lima and Zenteno-Savín, 2002; Jackson, 1968, 2000; Jackson and Heisler, 1983; Jackson and Ultsch, 1982; Jackson et al., 2006a; Lutz and Milton, 2004; Nilsson and Lutz, 1991; Storey and Storey, 2007, 1990b; K. Storey and Storey, 2004a; Ultsch and Jackson, 1996). Red-eared sliders are considered champion anaerobes mainly because they have the ability to suppress, reprioritize, and balance the rate of ATP production and ATP utilization through metabolic rate depression. For example, studies with isolated turtle hepatocytes showed a $94 \%$ decrease in overall ATP turnover during long-term anoxia (Hochachka et al., 1996). 


\subsection{Hypometabolic transition}

Dramatic changes can be seen in the overall ATP turnover during the entrance into hypometabolism in red-eared sliders (Figure 5). Regulation of this entry phase is tightly coordinated through transcriptional, post-transcriptional, and post-translational modifications of cellular enzymes and signal transduction pathways (SP Brooks and Storey, 1993; Greenway and Storey, 2000; K. Storey and Storey, 2004a). For example, multiple cellular processes are strongly suppressed, some very strongly (e.g. protein synthesis, protein degradation, cell cycle, apoptosis, global gene expression, gluconeogenesis, and urea synthesis) and others less so (e.g. regulation of ion motive ATPases) (Figure 6) (Jackson, 1968, 2000). (Hochachka et al., 1996) postulated that under anoxic conditions in liver hepatocytes the ATP demand by protein turnover drops to less than $10 \%$ of normoxic rates, and urea and glucose biosynthesis drop to essentially zero. Although the ATP demand by $\mathrm{Na}^{+} / \mathrm{K}^{+}$ATPases is reduced, the suppression in percentage terms is less than for overall ATP turnover, in order to avoid membrane depolarization. As a result, under anoxic conditions the $\mathrm{Na}^{+}$pumps actually account for $75 \%$ of the total ATP use of the cells when compared to normoxic conditions (Buck et al., 1993) (Figure 6). Moreover, during the entrance period, overall metabolic rate in freshwater turtles is reduced to $10-20 \%$ of the normal aerobic level at the same body temperature whereas glycolytic rate is increased in heart, brain, and skeletal muscles to meet the immediate and rising ATP demands. Recognition and reprioritization of available ATP supply to vital processes during the entrance stage is the difference between long-term survival and rapid cell death. The hypoxia inducible factor (HIF-1) is also activated during the entrance period. HIF-1 is a heterodimeric protein that consists of 
two main subunits, HIF-1 $\alpha$ and HIF-1 $\beta$. The HIF-1 $\alpha$ subunit is localized in the cytoplasm and is only translocated into the nucleus to combine with the HIF-1 $\beta$ subunit under low oxygen conditions (Adams et al., 2009; Ziello et al., 2007). Moreover, HIF-1 is an oxygen-sensing transcription factor that is vital for the induction of hypoxia responsive gene expression (Adams et al., 2009). HIF-1 plays an important role in protecting tissues from hypoxia induced damage by up-regulating selected genes that either enhance oxygen delivery to cells and/or increase non-oxygen dependent ATP supply via anaerobic glycolysis (K. Biggar et al., 2011; Morin and Storey, 2005).

The second phase of anoxia survival in turtles is the anoxia maintenance period, which is the longest hypometabolic period and can last from a few hours, to days, or even 12-18 weeks. In this stage, turtles continue to strongly suppress ATP consuming processes, while up-regulating selected genes and proteins that serve a cytoprotective function such as other transcription factors (e.g. NFאB and Nrf2), antioxidant defenses (AO), the heat shock protein (HSP) response, and the unfolded protein response (UPR) (Krivoruchko and Storey, 2013a, 2010a, 2010b, 2010c). It has been proposed that the constitutively high cytoprotective defenses seen in anoxia tolerant turtles during the maintenance period is a result of natural adaptation, and/or preconditioning for the rapid oxygen reperfusion that follows during the return to normoxia (Willmore and Storey, 1997).

The final phase is the recovery phase in which normoxic conditions are restored. Similar to entering hypometabolism upon exposure to hypoxia, the red-eared sliders must transition out of hypometabolism back to regular metabolic and cellular conditions without incurring cellular damage. However, transitioning back into normoxia is not an 
easy feat, since all metabolically repressed processes must be reactivated step by step, while protecting the cellular environment from damaging reactive oxygen species (ROS) (K. Biggar et al., 2011; K. Storey and Storey, 2004a; Storey and Storey, 1990b). ROS include hydrogen peroxide $\left(\mathrm{H}_{2} \mathrm{O}_{2}\right)$, the superoxide anion radical $\left(\mathrm{O}_{2}{ }^{-}\right)$, the hydroxyl radical $\left(\mathrm{OH}^{-}\right)$, and the peroxide radical (ROO-) (Blokhina et al., 2003; Tribble et al., 1987). The hydroxyl radical is the most highly reactive and least specific in the type of molecules it damages (Krivoruchko and Storey, 2010b). ROS are produced in large quantities when blood oxygen rapidly returns to normoxic levels (Willmore and Storey, 1997). Upon recovery from anoxia, glycolytic ATP production is replaced with oxidative phosphorylation; however, during the extended oxygen deprivation period the electron carriers of the electron transport chain had become reduced. The reintroduction of oxygen brings about an immediate oxidation of these carriers and an overproduction of ROS. Uncontrolled generation of ROS in a short amount of time can cause peroxidation of fatty acids in organelles and plasma membranes, oxidation of enzymes, depolymerization of polysaccharides, and single and double stranded DNA breaks (Blokhina et al., 2003; Tribble et al., 1987). Interestingly, turtles can tolerate an extensive degree of oxidative stress as they have well-developed and characteristically high levels of antioxidant defenses (Krivoruchko and Storey, 2010b; Willmore and Storey, 1997). Red-eared sliders employ an array of enzymatic players to combat ROS damage. These include catalase (a peroxisomal enzyme that plays a major role in the decomposition of $\mathrm{H}_{2} \mathrm{O}_{2}$ to form $\mathrm{H}_{2} \mathrm{O}$ and $\mathrm{O}_{2}$ ), alkyl hydroperoxide reductase, superoxide dismutase (mitochondrial Mn-SOD and cytosolic $\mathrm{Cu} / \mathrm{Zn}-\mathrm{SOD})$, and enzymes that utilize reduced glutathione in their detoxification reactions such as glutathione peroxidases (GPox), and glutathione $S$ - 
transferases (GST) (Hermes-Lima and Zenteno-Savín, 2002; Krivoruchko and Storey, 2010b; Willmore and Storey, 1997). In addition to deploying large amounts of antioxidants, red-eared sliders also use the UPR and HSP responses to combat ROSinduced protein damage and degradation. As reported by (Hochachka et al., 1996), in isolated turtle hepatocytes, over $50 \%$ of ATP was devoted to protein turnover during normoxic conditions, but under anoxia both protein synthesis and protein degradation was reduced by approximately $90 \%$. This must mean that anoxia tolerant freshwater turtles employ cytoprotective mechanisms to enhance, preserve, and protect proteins during long-term anaerobiosis. Correspondingly (Krivoruchko and Storey, 2013a, 2010a) reported a strong tissue-specific expression of HSPs and UPR pathway chaperones (socalled glucose-regulated proteins: GRPs) in response to $5 \mathrm{~h}$ and $20 \mathrm{~h}$ anoxia.

\subsection{Post-transcriptional regulation of anoxia tolerance}

Protein synthesis consumes a very large portion of available ATP turnover in cells under normoxic conditions, with requiring approximately 5 ATP equivalents to form one peptide bond (Cramer et al., 1991). As such, some freshwater turtles have been shown to strongly decrease the amount of ATP usage by protein synthesis to about $6 \%$ during anoxia (Hochachka et al., 1996). Furthermore, according to studies by (SP Brooks and Storey, 1993; Fraser et al., 2001; Land et al., 1993) the rates of protein synthesis in several tissues of freshwater turtles exposed to $3 \mathrm{~h}$ anoxia decreased to below measurable values $(\sim 0 \%)$ a $23{ }^{\circ} \mathrm{C}$. These results are on par with the decreased protein synthesis rates reported in isolated anoxic turtle cardiomyocytes (Bailey and Driedzic, 1997, 1996). Additionally, isolated hepatocytes from painted turtles, also showed a strong reduction in 
the rate of protein synthesis to $8 \%$ of normoxic values after $12 \mathrm{~h}$ of anoxia (Land et al., 1993).

Post-transcriptional inhibition of protein synthesis in response to hypometabolic triggers can be done in three ways; 1) reduce the amount of available mRNA by sequestering mRNA into storage in stress granules, 2) regulate the function of the ribosomal translational machinery, and 3) use miRNA interference to block translation of mature mRNA transcripts (Biggar and Storey, 2015). However, neither the total mRNA content nor mRNA transcript levels of some constitutively-expressed genes were reduced in expression during anoxia exposure and the RNA-to-protein ratio did not significantly change in red-eared slider liver after $12 \mathrm{~h}$ anoxic exposure (Land et al., 1993). Therefore, perhaps the decrease in protein synthesis reported in these tissues in response to anoxia may not be fully controlled by RNA concentration bur rather the translational inhibition of targeted mRNA transcripts via differential regulation of microRNAs (miRNA). These miRNAs are small (18-25 nt), non-coding RNAs that are able to bind with full or partial complementarity to the 3' translated regions (UTR) of target mRNA transcripts. Binding of miRNA to the target mRNA transcripts results in the inhibition of translation or degradation of the target mRNA (Biggar and Storey, 2011, 2015; K. K. Biggar et al., 2011). A recent study by (Selbach et al., 2008) examined the effect of miRNA on protein translation and showed that changes in the expression of a single miRNA can directly affect the translational rate of it's targeted mRNA transcripts. 


\subsection{Post-translational regulation of anoxia tolerance}

Reversible protein phosphorylation (RPP) of cellular enzymes and functional proteins is one of the more universal and effective mechanisms used by cells to make quick but stable changes to enzymatic activity in response to environmental perturbations instead of changing the overall protein expression of target enzymes (Storey, 2007). Similar to other stress-tolerant vertebrates, RPP plays a very important role in the regulation of the hypometabolic response in anoxia tolerant freshwater turtles by coordinating the rates of multiple ATP-producing and ATP-utilizing cellular processes (K. Storey and Storey, 2004a; Storey and Storey, 1990a, 1990b; K. B. Storey and Storey, 2004; Zhang et al., 2013a). In freshwater turtles, RPP has been shown to control several important glycolytic enzymes in an organ-specific manner. For example, early studies by (Brooks and Storey, 1989; Mehrani and Storey, 1995a; Storey, 1996) reported stable changes in kinetic properties of glycogen phosphorylase, PFK, and pyruvate kinase that were consistent with RPP of the enzymes during anoxia. In addition, enzymatic activities and correspondingly the phosphorylation levels of protein kinase $\mathrm{A}$, protein kinase $\mathrm{C}$, and protein phosphatase 1 were differentially regulated in a tissue-specific manner in the anoxic red-eared sliders. RPP of these three enzymes in turn could suppress the activities of multiple downstream enzymes and contribute to overall metabolic reorganization and metabolic rate depression that are characteristics of anoxia tolerance in red-eared sliders (SP Brooks and Storey, 1993; Mehrani and Storey, 1995b, 1995c; Storey, 1996). More recent work by (Bell and Storey, 2012), also reported a significant decrease in the phosphorylated form of liver glutamate dehydrogenase (GDH) in anoxic turtles; GDHI a key enzyme in both nitrogen and carbohydrate metabolism. Furthermore, with the use of ${ }^{32} \mathrm{P}$, (SP Brooks and Storey, 
1993), demonstrated 1.6, 2.4, and 1.3-fold increases in global phosphoprotein levels during anoxia in turtle brain, heart, and liver, respectively.

RPP is also responsible for regulating voltage-gated ion channels such as $\mathrm{Ca}^{2+}, \mathrm{Na}^{+}$, and $\mathrm{K}^{+}$channels as well as membrane receptors such as N-methyl-D-aspartate-type glutamate receptors (Bickler and Buck, 1998; Hochachka et al., 1996; K. Storey and Storey, 2004a). Furthermore, RPP is used to regulate signal transduction pathways such as mitogen-activated protein kinases (MAPKs) (Cowan and Storey, 2003) and the transcription factor nuclear factor kappa-light-chain-enhancer of activated B cells (NFKB) (Krivoruchko and Storey, 2010c) in response to anoxia. DNA binding capability of transcription factors such as p53 (Zhang et al., 2013a), FOXO (Krivoruchko and Storey, 2013b), CREB, and ATF1 (Krivoruchko and Storey, 2013a), STATs (Bansal et al., 2016), as well as overall protein synthesis through Akt/mTOR pathway (personal communication) are also regulated through RPP in response to anoxia in red-eared sliders.

RPP is not the only type of post-translational modification that is used by red-eared sliders under anoxic conditions to regulate cellular processes and to induce a hypometabolic state. Some of the glycolytic enzymes and transcriptional factors mentioned previously can be acetylated, methylated, and/or ubiquitinated to name a few potential modifications. Albeit, these post-translational modifications are not as extensively studied in anoxic turtles as compared to RPP. However, (N. Dawson et al., 2013; Neal J Dawson et al., 2013; Xiong and Storey, 2012) have demonstrated that fructose-1,6-bisphosphate aldolase and lactate dehydrogenase are enzymatically regulated by acetylation during prolonged anoxic exposure in red-eared sliders. 
In summary, red-eared sliders use both physiological, biochemical, posttranscriptional, and post-translational strategies in a stringently regulated and timedependent manner to tolerate $12-18$ weeks of absolute oxygen deprivation at $3{ }^{\circ} \mathrm{C}$ (in nature) and recover with minimal cellular damage. However, a new area of molecular biology has come to the forefront of science in the past decade that introduces an alternative regulatory mechanism that can directly control target-specific as well as global gene expression. As such, the main focus of this thesis is to explore this novel form of gene regulation referred to as epigenetics and its involvement in supporting and/or regulating anoxia tolerance in red-eared sliders.

\subsection{Epigenetic regulation and anoxia tolerance}

Epigenetics has become a subject of deep interest over the past few decades, as it deals with the issue of nurture versus nature. The term epigenetics refers to heritable changes in gene expression and phenotype that arise independent of changes in the primary DNA sequence (Waddington, 2012, 1956). These changes are coordinated via reversible modifications to DNA and post-translational modifications (PTMs) to histone proteins and are highly susceptible to environmental stimuli and stress. As such, epigenetic alterations are more plastic and individualistic than genetic changes. In general, the silencing of DNA or down regulation of selected genes is the combinatorial result of DNA hypermethylation of target promoter regions on genes and amino acidspecific histone methylation, deacetylation, or phosphorylation modifications (Allis and Jenuwein, 2016; Jaenisch and Bird, 2003). Many previous studies have shown that epigenetic mechanisms play a vital role in many, if not all, cellular and physiological 
processes, such as gene expression (Gibney and Nolan, 2010; Jaenisch and Bird, 2003), cell cycle control (Macaluso et al., 2005), growth and development (Bestor and Tycko, 1996; Tost et al., 2009), disease and cancer (Barros and Offenbacher, 2009; van der Maarel, 2008), aging (Calvanese et al., 2009), sex determination (Bestor, 2003; Bestor and Coxon, 1993), genomic immunity, and imprinting (Allis and Jenuwein, 2016; Barlow, 1993; Bartolomei and Tilghman, 1997).

Many physiological and genetic adaptations that confer hypoxia/anoxia survival are interconnected with underlying epigenetic mechanisms in the form of DNA methylation/demethylation and histone modifications (i.e. acetylation, methylation, and phosphorylation). In particular, previous evidence points towards a tight link between short and long-term exposure to cold temperatures and starvation, main characteristics of hibernation, and epigenetic control of metabolic rate depression. (Rouble and Storey, 2015) reported a tissue-specific response of type III HDACs, the Sirtuin (SIRTs) proteins, at different stages of mammalian hibernation, including an interesting correlation between increased SIRT3 protein expression, heightened SIRT enzymatic activity, and decreased acetylation of downstream SIRT3 target SOD2K68 in skeletal muscle of hibernating 13lined ground squirrels. According to the authors, these results may suggest a potential role for SIRT3 in regulating metabolic rate depression and cell protection during hibernation. In addition, (Biggar and Storey, 2014) reported strong evidence for a global suppression of transcription during torpor via DNA methylation and histone $\mathrm{H} 3$ deacetylation in brown adipose tissue of hibernating 13-lined ground squirrels. Epigenetic regulation may also work hand-in-hand with the HIF family or may contribute in a substantial way to the maintenance and regulation of a hypoxia-adapted cellular phenotype long after HIF-1 
activation (K. Biggar et al., 2011). Moreover, several recent studies have recognized positive and negative feedback regulatory loops between metabolic pathways that produce end products such as S-adenosyl-L-methionine (SAM), acetyl-coA, FAD, $\alpha$ ketoglutarate $(\alpha-\mathrm{KG}), \mathrm{Fe}(\mathrm{II})$, and 2-hydroxyglutarate (2-HG) and some of the more important epigenetic regulators such as DNA methyltransferases (DNMTs), TETs (teneleven translocation family of DNA demethylases), lysine methyltransferases (KMTs), lysine-specific demethylases (LSDs), and jumonji domain family proteins (JMJs) (Figure 7). Therefore, it seems that eukaryotes differentially regulate gene expression in response to external cues that in turn regulate metabolic pathways. However, at the same time, several epigenetic regulators that positively or negatively regulate transcription may use the same cofactors that are needed for, or produced by, metabolic reactions (Chiacchiera et al., 2013). For example, cofactors such as SAM and acetyl-CoA are not only produced by metabolic reactions but also used as primary sourced material for DNA methylation and protein acetylation. Since a very comprehensive array of work has already been done on metabolic regulation of anoxia tolerance in red-eared sliders, studying epigenetic regulation during anoxia tolerance in this vertebrate will expand our knowledge and shed light on this potential reciprocal relationship between metabolic regulation and epigenetic controls.

Apart from a preliminary study by (Krivoruchko and Storey, 2010d), on the role of histone deacetylases (HDACs) in turtle anoxia tolerance, the potential involvement of other forms of epigenetic control of DNA and histones (e.g. DNA methylation or demethylation, histone $\mathrm{H} 3$ modification by acetylation or methylation) in aiding anoxia survival has not been extensively studied in the champion anaerobe, the red-eared sliders. 
Nonetheless, it is becoming increasingly apparent that epigenetics can play a crucial role in the cellular response to hypoxia and anoxia. For example, (Krivoruchko and Storey, 2010d) found a tissue-specific pattern of HDAC upregulation in response to $20 \mathrm{~h}$ anoxia, suggesting that type I and II HDACs (HDACs 1-7) may play a significant role in transcriptional silencing of energy expensive cellular processes, which is vital for maintaining a hypometabolic state during prolonged periods of oxygen deprivation.

\subsection{Hypotheses and objectives}

Understanding the epigenetic control of anoxia tolerance using a champion facultative anaerobe as the experimental model is of great importance not only from a comparative and physiological perspective, but also has medical relevance and clinical applications. Whereas most mammalian tissues, especially those of humans, are highly sensitive to oxygen deprivation, an anoxia tolerant vertebrate would be expected to use many different physiological, molecular, and biochemical adaptations to survive anoxia; these could theoretically be induced or used as the basis for therapeutic measures against ischemia/reperfusion injuries that are associated with human heart transplants, neonatal umbilical cord injuries, and strokes. Furthermore, many previous studies have shown a direct link between epigenetic dysregulation and a variety of diseases, including cancer, some neurodegenerative disorders, kidney disease, autoimmune diseases, and several cardiac pathologies including heart failure and cardiac hypertension. As such, my general focus was to map and understand the epigenetic mechanisms surrounding hypoxia and anoxia in T.s. elegans with the aim of finding novel epigenetic mechanisms that someday may bridge the gap between genotype and phenotype and offer innovative therapeutics 
for treating illnesses involving oxygen restriction in humans. In my thesis, I chose to take an epigenetic-based approach to analyzing anoxia tolerance and survival of red-eared slider turtles, T.s. elegans, with particular emphasis on four major areas;

1. DNA methylation

2. DNA demethylation

3. Histone-H3 methylation

4. Histone-H3 acetylation by HATs and deacetylation by type III histone deacetylases (SIRTs).

\section{General Hypothesis:}

The epigenetic regulation of anoxia tolerance in the freshwater turtle, T.s. elegans, is a combinatorial result of increased DNA methylation, decreased DNA demethylation along with site-specific histone modifications in the form of Histone H3-methylation and acetylation/deacetylation.

These four epigenetic areas were explored in three main tissues, liver, heart, and skeletal muscle under control normoxic conditions, $5 \mathrm{~h}$ anoxia exposure (which represents the hypoxic entrance stage), and $20 \mathrm{~h}$ anoxia (which represents a time when anoxiainduced hypometabolism is well established and maintained).

To address this general hypothesis, I investigated four main types of epigenetic regulators that are known to directly control global as well as site-specific gene expression. These four approaches are listed in the following objectives. 


\section{Objective 1: Profiling DNA methylation response during anoxia}

As mentioned before, anoxia survival relies strongly on the suppression of ATP consumption by processes such as gene expression and reprioritization of the ATP use into driving cellular processes that are required for survival such as the HSP response, antioxidant defenses, UPR as well as selected expression of target transcriptional regulators and chromatin modifiers. DNA methylation is a unique transcriptional regulator that can selectively modify gene expression in both a ubiquitous as well as stress-responsive manner. Similar to other epigenetic regulators, DNA methylation also has a metabolic connection in which SAM production and availability directly regulates the abundance of $5 \mathrm{mC}$ on genomic DNA.

DNA methylation is a chemically stable, reversible, and post-replicative modification of the $5^{\text {th }}$ position of cytosine $(5 \mathrm{mC})$ catalyzed by DNA methyltransferases 1, 3a and $3 \mathrm{~b}$ (DNMTs) and methyl-CpG binding proteins (MBD 1, 2 and $\left.\mathrm{MeCP}_{2}\right)($ Bestor and Coxon, 1993; Bestor and Tycko, 1996). A fourth enzyme, DNMT2 has weak methyltransferase activity and is involved instead in methylating the tRNA that carries aspartate in the cytoplasm. However, recent evidence suggests that DNMT2 may also be responsible for methylating non-CpG island cytosines (Kunert et al., 2003). DNMTs utilize SAM as the methyl donor to transfer methyl groups to cytosine bases of both $\mathrm{CpG}$ and non-CpG islands (Bestor et al., 2015; Bird, 2002; Bird and Taggart, 1980). In a nutshell, the mechanism involves the binding of the methyltransferase to the target DNA sequence, reversion of the target cytosine out of the double helix ("base flipping"), formation of a covalent complex with cytosine $\mathrm{C}_{6}$, transfer of the methyl group from SAM to the activated cytosine $\mathrm{C}_{5}$, and release of the bound enzyme by elimination 
(Cheng and Roberts, 2001). Approximately $60-70 \%$ of all CpG sites are hypermethylated with the exception of relatively short regions characterized by high $\mathrm{CpG}$ density (called $\mathrm{CpG}$ islands). $\mathrm{CpG}$ islands are located upstream of promoters and the first exons of housekeeping genes. These $\mathrm{CpG}$ islands are differentially methylated in different tissues at different time points, suggesting a highly dynamic transcriptional regulatory mechanism (Bird, 2002; Bird and Taggart, 1980; Chen and Li, 2006). Hypermethylation of $\mathrm{CpG}$ island promoters correlates with transcriptional silencing by direct interference of transcription factor binding and/or through recruitment of repressive methyl-binding proteins such as MBD1, MBD2 and $\mathrm{MeCP}_{2}$ (Bogdanović and Veenstra, 2009). These proteins bind to methylated $\mathrm{CpG}$ islands and recruit repressive chromatin modifiers (such as histone deacetylases) and remodeling complexes that indirectly prevent the transcriptional machinery from binding to the promoter regions to initiate transcription. Surprisingly, MBD1 and MeCP2 have been shown to bind DNA and induce chromatin compaction independent of DNA methylation (Georgel et al., 2003; Jaenisch and Bird, 2003; Jørgensen et al., 2004; Nikitina et al., 2007).

DNA methylation is a great molecular tool that can be used to selective up and down regulate gene targets in response to anoxia. However, very little is known about the global regulation of DNA methylation in response to anoxia in anoxia-tolerant vertebrates. In the first chapter of this thesis, I examine the global regulation of DNA methylation as well as the dynamic expression and activity of DNMTs in response to anoxia in red-eared sliders.

Chapter 2 tests this hypothesis by exploring the global regulation of DNA methylation in three turtle organs in response to anoxia. The overall aim of this chapter is 
to assess whether prolonged exposure to not only anoxia but a state of hypometabolism, that is known to accompany anoxia in red-eared sliders, may modify global $5 \mathrm{mC}$ levels in the genome. Specifically, this objective was addressed by characterizing the protein expression levels and total enzymatic activity of DNMT1, DNMT2, DNMT3a, and DNMT3b along with expression profiling of MBD1 and MBD2 and measurements of genomic $5 \mathrm{mC}$ levels in liver, white muscle, and heart of red-eared sliders under aerobic control, $5 \mathrm{~h}$ anoxia exposure and $20 \mathrm{~h}$ anoxia exposure. Increased expression of global $5 \mathrm{mC}$ levels and the corresponding DNMTs could indicate a state of global gene repression during the anoxia-induced hypometabolic state in red-eared sliders.

\section{Hypothesis 1:}

Anoxia survival by T.s. elegans may include an overall increase in DNA methylation to support a global repression of gene expression.

\section{Objective 2: Profiling DNA demethylation response during anoxia}

Due to the gene regulatory properties associated with DNA methylation, it is vital to tightly control DNA methylation patterns within the genome during periods of low ATP availability (Kohli and Zhang, 2013). Very little is yet known about the mechanisms that regulate the balance between hyper- and hypo-methylation and despite intense research for the past decade DNA demethylases that directly remove $5 \mathrm{mC}$ groups from the genomic DNA have not been identified. However, recent findings about the teneleven translocation family of proteins (TET 1-3) and thymine DNA glycosylase (TDG1) suggests a potential mechanism for site-specific, reversible demethylation of $5 \mathrm{mC}$ (Kohli and Zhang, 2013; Tahiliani et al., 2009). TET1, TET2, and TET3 are Fe(II) and 2- 
ketogluterate dependent dioxygenases that have the capacity to convert $5 \mathrm{mC}$ residues to 5-hydroxymethyl cytosine $(5 \mathrm{hmC})$ through an oxidation reaction in vivo and in vitro (Hahn et al., 2014; Ito et al., 2010a; Kohli and Zhang, 2013; Tahiliani et al., 2009). TETs can oxidize $5 \mathrm{mC}$ into $5 \mathrm{hmC}$ but the oxidation reaction does not stop there. Subsequently, $5 \mathrm{hmC}$ can proceed to 5 -formylcytosine $(5 \mathrm{fC})$ and then to 5 -carboxylcytosine $(5 \mathrm{caC})$. This pathway is continued further by TDG1, which recognizes $5 \mathrm{caC}$ and carries out base excision repair to remove $5 \mathrm{caC}$ and replace that position with an unmodified cytosine (Hahn et al., 2014; Hill et al., 2014; Kohli and Zhang, 2013; Wu and Zhang, 2014).

\section{Hypothesis 2:}

Anoxia survival by T.s. elegans may include an overall decrease in DNA demethylation to support a global repression of gene expression.

Chapter 3 tests this hypothesis by examining the TET-mediated DNA demethylation response in three turtle organs in response to anoxia. As much as DNA methylation is vital for the maintenance of a hypometabolic state by repressing global gene expression, DNA demethylation may be vital for the expression of genes that are necessary for anoxia survival such as HSPs, antioxidants, UPR, miRNA regulatory machinery, as well as epigenetic regulators. Furthermore, DNA demethylation is of utmost importance during the reoxygenation/anoxia recovery phase in which all repressed cellular processes must return to normoxic levels within a few minutes to hours. Consequently, it is important to not only measure the global expression of DNA methylation in response to anoxia, but also look at the dynamic regulation of DNA demethylation in T.s. elegans. This objective was addressed by measuring genomic expression levels of $5 \mathrm{hmC}, 5 \mathrm{fC}$, and $5 \mathrm{caC}$ along with the protein expression levels of 
TET1-3 and TDG1, and total enzymatic activity of TET enzymes in liver, heart, and white muscle of control, $5 \mathrm{~h}$, and $20 \mathrm{~h}$ anoxic red-eared sliders. Nuclear protein fractionations were used for the total TET enzymatic assay. A global decrease in TETmediated DNA demethylation may be a characteristic of anoxia-induced hypometabolism.

\section{Objective 3: Profiling the "histone code" in response to anoxia}

Within eukaryotic cells about two meters of DNA is packaged into a $20 \mu \mathrm{m}$ nucleus due to the formation of a highly conserved and organized structural polymer, termed chromatin. The nucleosome is the fundamental unit of chromatin and is composed of an octamer of the four core histone proteins $(\mathrm{H} 2 \mathrm{~A}, \mathrm{H} 2 \mathrm{~B}, \mathrm{H} 3$, and $\mathrm{H} 4)$ and one linker protein (H1). Approximately 146 base pairs of DNA wrap twice around each nucleosome, with the globular carboxyl-terminal domains making up the nucleosome scaffold, while the flexible amino-terminal tails protrude outward (Kaplan et al., 2009; Khorasanizadeh et al., 2004). The N-terminal tails are not involved in maintaining the structural integrity of the nucleosomes but they are vital for condensation of chromatin. The core histone Nterminal tails are available for interaction with other histones as well as histone modifying proteins such as HMTs, histone acetyltransferases (HATs), SIRTs, HDACs, and kinases (S. L. Berger, 2002; Peter Cheung et al., 2000). Post-translational modifications of Nterminal tails of the histone proteins alter nucleosome interaction with DNA and depending on the modification type and modification site, increase or decrease accessibility of RNA polymerase II and the transcriptional machinery to the targeted promoter regions. Particularly in the case of histone H3, these posttranslational modifications are closely related to activation and repression of gene transcription (Eva 
Bártová et al., 2008; B. D. Strahl and Allis, 2000; Venkatesh and Workman, 2015). There are three main types of post-translational histone $\mathrm{H} 3$ modifications: acetylation, mono, di, or tri methylation, and phosphorylation but additional histone modifications can include glycosylation, ADP-ribosylation, ubiquitinylation (Ub) and small-ubiquitin like modifiers (SUMO) (Bannister and Kouzarides, 2011; Venkatesh and Workman, 2015). For the purpose of this thesis, dynamic changes in acetylation and methylation were explored in response to anoxia.

\section{Hypothesis 3:}

Post-translational regulation of histone $\mathrm{H} 3$ in the form of lysine methylation and acetylation/deacetylation may regulate gene expression in a site-specific manner in response to anoxia exposure in T.s. elegans.

Chapter 4 tests this hypothesis by exploring four transcriptionally relevant acetylation sites on lysine residues of histone H3 (H3K9, H3K14, HSK18, H3K56) along with the expression levels of the corresponding HATs and the total enzymatic activity of all nuclear HATs in the liver of anoxia tolerant T.s. elegans. Histone acetylation is the most studied post-translational histone modification in which HATs transfer acetyl groups from acetyl-CoA to the lysine amino groups on the N-terminal tails of histones. Histone acetylation appears to promote gene transcription by favoring an open, less compact chromatin conformation that permits binding of the transcriptional machinery to the promoter region of genes (Kuo et al., 1998; Kurdistani et al., 2004). Deacetylation of histone proteins by HDACs works hand in hand with acetylation in regulating gene expression. A previous study done by (Krivoruchko and Storey, 2010d) illustrated a tissue-specific upregulation of the type I and II HDAC response during anoxia in red- 
eared sliders, indicative of a global repression of gene expression. In order to obtain a more comprehensive picture of the regulation of HDACs in response to anoxia and to explore another epigenetic regulator that is dependent on the availability of metabolic intermediates, type III NAD ${ }^{+}$-dependent SIRT levels along with total SIRT activity were measured in liver nuclear fractions of T.s. elegans.

Chapter 5 further tests this hypothesis by evaluating the differential expression of several histone $\mathrm{H} 3$ lysine methyl moieties (H3K4, H3K9, H3K27) that are dynamically modified in response to external stimuli in other vertebrates (Vakoc et al., 2006). The expression levels of the corresponding KMTs that are known to methylate the above residues, as well as total enzymatic activity of all nuclear KMTs that modify H3K4, $\mathrm{H} 3 \mathrm{~K} 9$, and $\mathrm{H} 3 \mathrm{~K} 27$ positions were measured under control, $5 \mathrm{~h}$ and $20 \mathrm{~h}$ anoxic conditions in T.s. elegans tissues. Histone methylation is a stable epigenetic mark that does not change the overall charge on histone tails, but hypermethylation of histone tails at specific lysine and arginine residues does increase the basicity and hydrophobicity of the tails. Therefore, the highly basic and hydrophobic histone subunits will bind stringently to the anionic DNA and create heterochromatin (Lachner et al., 2003). Histone methylation is catalyzed by KMTs using SAM as a co-factor and is highly sensitive to metabolic fluctuations. Furthermore, histone methylation is highly site-specific and depending on the site of mono, di, or tri methylation, gene expression is activated or repressed (S. L. Berger, 2002; Martin and Zhang, 2005; Shi and Whetstine, 2007; Sims et al., 2003). Thus, histone methylation presents the red-eared sliders with a dynamic gene regulatory system that can be used in a coordinated yet easily reversible manner to suppress global gene expression under anoxia while facilitating expression of selected genes. 


\subsection{References}

Adams, J., Difazio, L., Rolandelli, R., Luján, J., Haskó, G., Csóka, B., Selmeczy, Z., Németh, Z., 2009. HIF-1: a key mediator in hypoxia (Review). Acta Physiol. Hung. 96, 19-28. doi:10.1556/APhysiol.96.2009.1.2

Allis, C.D., Jenuwein, T., 2016. The molecular hallmarks of epigenetic control. Nat. Rev. Genet. 17, 487-500. doi:10.1038/nrg.2016.59

Bailey, J.R., Driedzic, W.R., 1997. Protein synthesis under conditions of anoxia and changing workload in ventricle strips from turtle heart. J. Exp. Zool. 278, 273-82.

Bailey, J.R., Driedzic, W.R., 1996. Decreased total ventricular and mitochondrial protein synthesis during extended anoxia in turtle heart. Am. J. Physiol. 271, R1660-7.

Bannister, A.J., Kouzarides, T., 2011. Regulation of chromatin by histone modifications. Cell Res. 21, 381-395. doi:10.1038/cr.2011.22

Bansal, S., Biggar, K.K., Krivoruchko, A., Storey, K.B., 2016. Response of the JAKSTAT signaling pathway to oxygen deprivation in the red eared slider turtle, Trachemys scripta elegans. Gene 593, 34-40. doi:10.1016/j.gene.2016.08.010

Barlow, D., 1993. Methylation and imprinting: From host defense to gene regulation? Science (80-. ). 260, 309-310. doi:10.1126/science.8469984

Barros, S.P., Offenbacher, S., 2009. Epigenetics: Connecting environment and genotype to phenotype and disease. J. Dent. Res. 88, 400-408.

doi: $10.1177 / 0022034509335868$

Bartolomei, M.S., Tilghman, S.M., 1997. Genomic imprinting in mammals. Annu. Rev. Genet. 31, 493-525. doi:10.1146/annurev.genet.31.1.493

Bártová, E., Krejčí, J., Harničarová, A., Galiová, G., Kozubek, S., 2008. Histone 
modifications and nuclear architecture: A review. J. Histochem. Cytochem. 56, 711721. doi:10.1369/jhc.2008.951251

Bell, R., Storey, K., 2012. Regulation of liver glutamate dehydrogenase from an anoxiatolerant freshwater turtle. HOAJ Biol. 1, 1-3. doi:org/10.7243/2050-0874-1-3

Berger, R., Garnier, Y., Jensen, A., 2016. Prinatal brain damage: Underlying mechanisms and neuroprotective strategies. J. Soc. Gynecol. Investig. 9, 319-328. doi:10.1177/107155760200900601

Berger, S.L., 2002. Histone modifications in transcriptional regulation. Curr. Opin. Genet. Dev. 12, 142-148. doi:10.1016/S0959-437X(02)00279-4

Bestor, T., 2003. Cytosine methylation mediates sexual conflict. Trends Genet. 19, 185190.

Bestor, T.H., Coxon, A., 1993. Cytosine methylation; The pros and cons of DNA methylation. Curr. Biol. 3, 384-386. doi:10.1016/0960-9822(93)90209-7

Bestor, T.H., Edwards, J.R., Boulard, M., 2015. Notes on the role of dynamic DNA methylation in mammalian development. PNAS 112, 6796-6799. doi:10.1073/pnas.1415301111

Bestor, T.H., Tycko, B., 1996. Creation of genomic methylation patterns. Nat. Genet. 12, 363-367. doi:10.1038/ng0496-363

Bickler, P.E., Buck, L.T., 1998. Adaptations of vertebrate neurons to hypoxia and anoxia: maintaining critical Ca2+ concentrations. J. Exp. Biol. 201, 1141-52.

Biggar, K., Groom, A., Storey, K., 2011. Hypometabolism and turtles: Physiological and molecular strategies of anoxic survival, in: Nowakowska, A., Caputa, M. (Eds.), Hypometabolism: Strategies of Survival in Vertebrates and Invertebrates. Research 
Signpost, Kerala, pp. 57-94.

Biggar, K., Storey, K., 2011. The emerging roles of microRNAs in the molecular responses of metabolic rate depression. J. Mol. Cell Biol. 3, 167-175. doi:10.1093/jmcb/mjq045

Biggar, K.K., Kornfeld, S.F., Storey, K.B., 2011. Amplification and sequencing of mature microRNAs in uncharacterized animal models using stem-loop reverse transcription-polymerase chain reaction, Analytical Biochemistry. doi:10.1016/j.ab.2011.05.015

Biggar, K.K., Storey, K.B., 2015. Insight into post-transcriptional gene regulation: stressresponsive microRNAs and their role in the environmental stress survival of tolerant animals. J. Exp. Biol. 218, 1281-1289. doi:10.1242/jeb.104828.

Biggar, K.K., Storey, K.B., 2012. Evidence for cell cycle suppression and microRNA regulation of cyclin D1 during anoxia exposure in turtles. Cell Cycle 11, 1705-1713. doi:10.4161/cc. 19790

Biggar, Y., Storey, K.B., 2014. Global DNA modifications suppress transcription in brown adipose tissue during hibernation. Cryobiology 69, 333-338. doi:10.1016/j.cryobiol.2014.08.008

Bird, A., 2002. DNA methylation patterns and epigenetic memory. Genes Dev. 16, 6-21. doi:10.1101/gad.947102

Bird, A.P., Taggart, M.H., 1980. Variable patterns of total DNA and rDNA methylation in animals. Nucleic Acids Res. 8, 1485-97.

Blokhina, O., Virolainen, E., Fagerstedt, K. V, 2003. Antioxidants, oxidative damage and oxygen deprivation stress: A review. Ann. Bot. 91 Spec No, 179-94. 
Bogdanović, O., Veenstra, G.J.C., 2009. DNA methylation and methyl-CpG binding proteins: Developmental requirements and function. Chromosoma 118, 549-565. doi:10.1007/s00412-009-0221-9

Brand, M., 2003. Approximate yield of ATP from glucose, designed by donald nicholson: Commentary. Biochem. Mol. Biol. Educ. 31, 2-4.

doi:10.1002/bmb.2003.494031010178

Brierley, J., 1977. Experimental hypoxic brain damage. J. Clin. Pathol. R. Coll. Pathol. $30,181-187$.

Brooks, S., Storey, K., 1993. De novo protein synthesis and protein phosphorylation during anoxia and recovery in the red-eared turtle. Am. J. Physiol. 265, R1380-6.

Brooks, S., Storey, K., 1989. Regulation of glycolytic enzymes during anoxia in the turtle Pseudemys scripta. Am. J. Physiol. 257, R278-R283.

Buck, L., Land, S., Hochachka, P., 1993. Anoxia-tolerant hepatocytes: Model system for study of reversible metabolic suppression. Am. J. Physiol. 265, 49-56.

Calvanese, V., Lara, E., Kahn, A., Fraga, M.F., 2009. The role of epigenetics in aging and age-related diseases. Ageing Res. Rev. 8, 268-276. doi:10.1016/j.arr.2009.03.004

Chen, T., Li, E., 2006. Establishment and maintenance of DNA methylation patterns in mammals. Curr. Top. Microbiol. Immunol. 301, 179-201.

Cheng, X., Roberts, R.J., 2001. AdoMet-dependent methylation, DNA methyltransferases and base flipping. Nucleic Acids Res. 29, 3784-95.

Cheung, P., Allis, C.D., Sassone-Corsi, P., 2000. Signaling to chromatin through histone modifications. Cell 103, 263-271. doi:10.1016/S0092-8674(00)00118-5

Chiacchiera, F., Piunti, A., Pasini, D., 2013. Epigenetic methylations and their 
connections with metabolism. Cell. Mol. Life Sci. 70, 1495-1508. doi:10.1007/s00018-013-1293-5

Cowan, K.J., Storey, K.B., 2003. Mitogen-activated protein kinases: New signaling pathways functioning in cellular responses to environmental stress. J. Exp. Biol. 206, $1107-15$.

Cramer, F., Englisch, U., Freist, W., Sternbach, H., 1991. Aminoacylation of tRNAs as critical step of protein biosynthesis. Biochimie 73, 1027-35.

Davis, E., Jackson, D., 2007. Lactate uptake by skeletal bone in anoxic turtles, Trachemys scripta. Comp. Biochem. Physiol. Part A Mol. Integr. Physiol. 146, 299-304. doi:10.1016/j.cbpa.2006.10.034

Dawson, N., Bell, R., Storey, K., 2013. Purification and properties of white muscle lactate dehydrogenase from the anoxia-tolerant turtle, the red-eared slider, Trachemys scripta elegans. Enzyme Res. 2013, 1-8. doi:10.1155/2013/784973

Dawson, N.J., Bell, R.A. V, Storey, K.B., 2013. Purification and properties of white muscle lactate dehydrogenase from the anoxia-tolerant turtle, the red-eared slider, Trachemys scripta elegans. Enzyme Res. 2013, 784973. doi:10.1155/2013/784973

Embley, T.M., Martin, W., 2006. Eukaryotic evolution, changes and challenges. Nature 440, 623-630. doi:10.1038/nature04546

Fraser, K., Houlihan, D., Lutz, P., Leone-Kabler, S., Manuel, L., Brechin, J., 2001. Complete supression of protein synthesis during anoxia with no post-anoxia protein synthesis debt in the red-eared slider turtle, Trachemys scripta elegans. J. Exp. Biol. $204,4353-4360$.

Georgel, P.T., Horowitz-Scherer, R.A., Adkins, N., Woodcock, C.L., Wade, P.A., 
Hansen, J.C., 2003. Chromatin Compaction by Human MeCP2: Assembly of novel secondary chromatin structures in the absences of DNA methylation. J. Biol. Chem. 278, 32181-32188. doi:10.1074/jbc.M305308200

Gibney, E.R., Nolan, C.M., 2010. Epigenetics and gene expression. Heredity (Edinb). 105, 4-13. doi:10.1038/hdy.2010.54

Greenway, S.C., Storey, K.B., 2000. Mitogen- activated protein kinases and anoxia tolerance in turtles. J. Exp. Zool. Part A Ecol. Genet. Physiol. 287, 477-484. doi:10.1002/1097-010X(20001201)287:7<477::AID-JEZ3>3.0.CO;2-4

Hahn, M., Szabó, P., Pfeifer, G., 2014. 5-Hydroxymethylcytosine: A stable or transient DNA modification? Genomics 104, 314-323. doi:10.1016/j.ygeno.2014.08.015

Hermes-Lima, M., Zenteno-Savín, T., 2002. Animal response to drastic changes in oxygen availability and physiological oxidative stress. Comp. Biochem. Physiol. Toxicol. Pharmacol. 133, 537-56.

Hicks, J.W., Wang, T., 1998. Cardiovascular regulation during anoxia in the turtle: An in vivo study. Physiol. Zool. 71, 1-14.

Hill, P.W.S., Amouroux, R., Hajkova, P., 2014. DNA demethylation, Tet proteins and 5hydroxymethylcytosine in epigenetic reprogramming: An emerging complex story. Genomics 104, 324-333. doi:10.1016/j.ygeno.2014.08.012

Hochachka, P., 1986. Defense strategies against hypoxia and hypothermia. Science (80-. ). $231,234-41$.

Hochachka, P.W., 1988. Metabolic suppression and oxygen availability. Can. J. Zool. 66, $152-158$.

Hochachka, P.W., Buck, L.T., Doll, C.J., Land, S.C., 1996. Unifying theory of hypoxia 
tolerance: molecular/metabolic defense and rescue mechanisms for surviving oxygen lack. Proc. Natl. Acad. Sci. U. S. A. 93, 9493-8.

Hochachka, P.W., Lutz, P.L., 2001a. Mechanism, origin, and evolution of anoxia tolerance in animals. Comp. Biochem. Physiol. B. Biochem. Mol. Biol. 130, 435-59. Hochachka, P.W., Lutz, P.L., 2001b. Mechanism, origin, and evolution of anoxia tolerance in animals. Comp. Biochem. Physiol. B. Biochem. Mol. Biol. 130, 435-59. Hochachka, P.W., Rupert, J.L., Monge, C., 1999. Adaptation and conservation of physiological systems in the evolution of human hypoxia tolerance. Comp. Biochem. Physiol. A. Mol. Integr. Physiol. 124, 1-17.

Ito, S., D’Alessio, A.C., Taranova, O. V., Hong, K., Sowers, L.C., Zhang, Y., 2010. Role of Tet proteins in $5 \mathrm{mC}$ to $5 \mathrm{hmC}$ conversion, ES-cell self-renewal and inner cell mass specification. Nature 466, 1129-1133. doi:10.1038/nature09303

Jackson, D., 1997. Lactate accumulation in the shell of the turtle, Chrysemys picta bellii, during anoxia at 3 and $10^{\circ}$ C. J. Exp. Biol. 200, 2295-2300.

Jackson, D., 1968. Metabolic depression and oxygen depletion in the diving turtle. J. Appl. Physiol. 24, 503-9.

Jackson, D., Crocker, C., Ultsch, G., 2000. Bone and shell contribution to lactic acid buffering of submerged turtles Chrysemys picta bellii at $3^{\circ} \mathrm{C}$. Am. J. Physiol. Regul. Integr. Comp. Physiol. 278, R1564-1571.

Jackson, D., Heisler, N., 1983. Intracellular and extracellular acid-base and electrolyte status of submerged anoxic turtles at $3^{\circ} \mathrm{C}$. Respir. Physiol. 53, 187-201.

Jackson, D., Ramsey, A., Paulson, J., Crocker, C., Ultsch, G., 2000. Lactic acid buffering by bone and shell in anoxic softshell and painted turtles. Physiol. Biochem. Zool. 73, 
290-297. doi:10.1086/316754

Jackson, D., Toney, V., Okamoto, S., 1999. Lactate distribution and metabolism during and after anoxia in the turtle, Chrysemys picta bellii. Am. J. Physiol. 271, R409R416.

Jackson, D., Ultsch, G., 1982. Long-term submergence at $3^{\circ} \mathrm{C}$ of the turtle, Chrysemys picta bellii, in normoxic and severely hypoxic water: II. Extracellular ionic responses to extreme lactic acidosis. J. Exp. Biol. 29-43.

Jackson, D., Wang, T., Koldkjaer, P., Taylor, E.W., 2001. Lactate sequestration in the carapace of the crayfish Austropotamobius pallipes during exposure in air. J. Exp. Biol. 204, 941-946.

Jackson, D.C., 2000. Living without oxygen: Lessons from the freshwater turtle. Comp. Biochem. Physiol. Part A Mol. Integr. Physiol. 125, 299-315. doi:10.1016/S10956433(00)00160-4

Jackson, D.C., Taylor, S.E., Asare, V.S., Villarnovo, D., Gall, J.M., Reese, S.A., 2006. Comparative shell buffering properties correlate with anoxia tolerance in freshwater turtles. AJP Regul. Integr. Comp. Physiol. 292, R1008-R1015. doi:10.1152/ajpregu.00519.2006

Jaenisch, R., Bird, A., 2003. Epigenetic regulation of gene expression: how the genome integrates intrinsic and environmental signals. Nat. Genet. 33, 245-254.

doi:10.1038/ng1089

Jørgensen, H.F., Ben-Porath, I., Bird, A.P., 2004. Mbd1 is recruited to both methylated and nonmethylated CpGs via distinct DNA binding domains. Mol. Cell. Biol. 24, 3387-95. 
Kaplan, N., Moore, I.K., Fondufe-Mittendorf, Y., Gossett, A.J., Tillo, D., Field, Y., LeProust, E.M., Hughes, T.R., Lieb, J.D., Widom, J., Segal, E., 2009. The DNAencoded nucleosome organization of a eukaryotic genome. Nature 458, 362-366. doi:10.1038/nature07667

Khorasanizadeh, S., Gerchman, S.E., Ramakrishnan, V., Travers, A., Muyldermans, S., Selker, E.U., Cheng, X., Burlingame, A.L., Wong, J., Tempst, P., Zhang, Y., 2004. The nucleosome: From genomic organization to genomic regulation. Cell 116, 259_ 72. doi:10.1016/S0092-8674(04)00044-3

Kohli, R., Zhang, Y., 2013. TET enzymes, TDG and the dynamics of DNA demethylation. Nature 502, 472-479. doi:10.1038/nature12750

Krivoruchko, A., Storey, K., 2013a. Activation of the unfolded protein response during anoxia exposure in the turtle Trachemys scripta elegans. Mol. Cell. Biochem. 374, 91-103. doi:10.1007/s11010-012-1508-3

Krivoruchko, A., Storey, K., 2013b. Anoxia-responsive regulation of the FoxO transcription factors in freshwater turtles, Trachemys scripta elegans. Biochim. Biophys. Acta - Gen. Subj. 1830, 4990-4998. doi:10.1016/j.bbagen.2013.06.034

Krivoruchko, A., Storey, K., 2010a. Regulation of the heat shock response under anoxia in the turtle, Trachemys scripta elegans. J. Comp. Physiol. B 180, 403-414. doi:10.1007/s00360-009-0414-9

Krivoruchko, A., Storey, K., 2010b. Activation of antioxidant defenses in response to freezing in freeze-tolerant painted turtle hatchlings. Biochim. Biophys. Acta - Gen. Subj. 1800, 662-668. doi:10.1016/j.bbagen.2010.03.015

Krivoruchko, A., Storey, K., 2010c. Molecular mechanisms of turtle anoxia tolerance: A 
role for NF-kB. Gene 450, 63-69. doi:10.1016/j.gene.2009.10.005

Krivoruchko, A., Storey, K., 2010d. Epigenetics in anoxia tolerance: A role for histone deacetylases. Mol. Cell. Biochem. 342, 151-161. doi:10.1007/s11010-010-0479-5

Kunert, N., Marhold, J., Stanke, J., Stach, D., Lyko, F., 2003. A Dnmt2-like protein mediates DNA methylation in Drosophila. Development 130, 5083-5090. doi:10.1242/dev.00716

Kuo, M.H., Zhou, J., Jambeck, P., Churchill, M.E., Allis, C.D., 1998. Histone acetyltransferase activity of yeast Gcn5p is required for the activation of target genes in vivo. Genes Dev. 12, 627-39.

Kurdistani, S.K., Tavazoie, S., Grunstein, M., 2004. Mapping global histone acetylation patterns to gene expression. Cell 117, 721-733. doi:10.1016/j.cell.2004.05.023

Lachner, M., O'Sullivan, R.J., Jenuwein, T., 2003. An epigenetic road map for histone lysine methylation. J. Cell Sci. 116, 2117-2124. doi:10.1242/jcs.00493

Land, S.C., Buck, L.T., Hochachka, P.W., 1993. Response of protein synthesis to anoxia and recovery in anoxia-tolerant hepatocytes. Am. J. Physiol. 265, R41-8.

Lutz, P.L., Milton, S.L., 2004. Negotiating brain anoxia survival in the turtle. J. Exp. Biol. 207, 3141-3147. doi:10.1242/jeb.01056

Macaluso, M., Montanari, M., Cinti, C., Giordano, A., 2005. Modulation of cell cycle components by epigenetic and genetic events. Semin. Oncol. 32, 452-457. doi:10.1053/j.seminoncol.2005.07.009

Martin, C., Zhang, Y., 2005. The diverse functions of histone lysine methylation. Nat. Rev. Mol. Cell Biol. 6, 838-849. doi:10.1038/nrm1761

Mehrani, H., Storey, K., 1995a. Enzymatic control of glycogenolysis during anoxic 
submergence in the freshwater turtle Trachemys scripta. Int. J. Biochem. Cell Biol. 821-830, 821-830. doi:10.1016/1357-2725(95)00042-N

Mehrani, H., Storey, K., 1995b. Effects of anoxia on protein phosphatase in turtle organs: purification and properties of protein phosphatase type-1 from turtle liver. Arch. Biochem. Biophys. 316, 836-843. doi:10.1006/abbi.1995.1112

Mehrani, H., Storey, K., 1995c. cAMP-Dependent protein kinase and anoxia survival in turtles: purification and properties of liver PKA. Molular Cell. Biochem. 145, 81-88.

Milton, S.L., Prentice, H.M., 2007. Beyond anoxia: The physiology of metabolic downregulation and recovery in the anoxia-tolerant turtle. Comp. Biochem. Physiol. Part A Mol. Integr. Physiol. 147, 277-290. doi:10.1016/j.cbpa.2006.08.041

Morin, P., Storey, K.B., 2005. Cloning and expression of hypoxia-inducible factor $1 \alpha$ from the hibernating ground squirrel, Spermophilus tridecemlineatus. Biochim. Biophys. Acta - Gene Struct. Expr. 1729, 32-40. doi:10.1016/j.bbaexp.2005.02.009

Nikitina, T., Shi, X., Ghosh, R.P., Horowitz-Scherer, R.A., Hansen, J.C., Woodcock, C.L., 2007. Multiple modes of interaction between the methylated DNA binding protein MeCP2 and chromatin. Mol. Cell. Biol. 27, 864-877. doi:10.1128/MCB.01593-06

Nilsson, G.E., Lutz, P.L., 1991. Release of inhibitory neurotransmitters in response to anoxia in turtle brain. Am. J. Physiol. 261, R32-7.

Rouble, A., Storey, K., 2015. Characterization of the SIRT family of NAD+-dependent protein deacetylases in the context of a mammalian model of hibernation, the thirteen-lined ground squirrel. Cryobiology 71, 334-43. doi:10.1016/j.cryobiol.2015.08.009 
Selbach, M., Schwanhäusser, B., Thierfelder, N., Fang, Z., Khanin, R., Rajewsky, N., 2008. Widespread changes in protein synthesis induced by microRNAs. Nature 455 , 58-63. doi:10.1038/nature07228

Shi, Y., Whetstine, J.R., 2007. Dynamic regulation of histone lysine methylation by demethylases. Mol. Cell 25, 1-14. doi:10.1016/j.molcel.2006.12.010

Sims, R.J., Nishioka, K., Reinberg, D., 2003. Histone lysine methylation: a signature for chromatin function. Trends Genet. 19, 629-639. doi:10.1016/j.tig.2003.09.007

Smith, H., 1929. The inorganic composition of the body fluids of the Chelonia. J. Biol. Chem 82, 651-661.

Stecyk, J.A.W., Galli, G.L., Shiels, H.A., Farrell, A.P., 2008. Cardiac survival in anoxiatolerant vertebrates: An electrophysiological perspective. Comp. Biochem. Physiol. Part C Toxicol. Pharmacol. 148, 339-354. doi:10.1016/j.cbpc.2008.05.016

Storey, K., 2007. Anoxia tolerance in turtles: Metabolic regulation and gene expression. Comp. Biochem. Physiol. Part A Mol. Integr. Physiol. 147, 263-276. doi:10.1016/j.cbpa.2006.03.019

Storey, K., 1996. Metabolic adaptations supporting anoxia tolerance in reptiles: recent advances. Comp. Biochem. Physiol. Part B Comp. Biochem. 113, 23-35. doi:10.1016/0305-0491(95)02043-8

Storey, K., Storey, J., 2007. Tribute to P. L. Lutz: putting life on 'pause' - molecular regulation of hypometabolism. J. Exp. Biol. 210, 1700-1714. doi:10.1242/jeb.02716

Storey, K., Storey, J., 2004. Oxygen limitation and metabolic rate depression, in: Storey, K.B. (Ed.), Functional Metabolism. John Wiley \& Sons, Inc., Hoboken, NJ, USA, pp. 415-442. doi:10.1002/047167558X.ch15 
Storey, K., Storey, J., 1992. Natural freeze tolerance in ectothermic vertebrates. Annu. Rev. Physiol. 54, 619-637. doi:10.1146/annurev.ph.54.030192.003155

Storey, K., Storey, J., 1990a. Metabolic rate depression and biochemical adaptation in anaerobiosis, hibernation and estivation. Q. Rev. Biol. 65, 145-74.

Storey, K., Storey, J., 1990b. Metabolic rate depression and biochemical adaptation in anaerobiosis, hibernation and estivation. Q. Rev. Biol. 65, 145-74. doi:10.4172/2157-7625.1000224

Storey, K.B., Storey, J.M., 2004. Metabolic rate depression in animals: transcriptional and translational controls. Biol. Rev. Camb. Philos. Soc. 79, 207-33.

Strahl, B.D., Allis, C.D., 2000. The language of covalent histone modifications. Nature 403, 41-45. doi:10.1038/47412

Tahiliani, M., Koh, K., Shen, Y., Pastor, W., Bandukwala, H., Brudno, Y., Agarwal, S., Iyer, L., Liu, D., Aravind, L., Rao, A., 2009. Conversion of 5-methylcytosine to 5hydroxymethylcytosine in mammalian DNA by MLL partner TET1. Science (80-. ). 324, 930-5. doi:10.1126/science.1170116

Tost, J., Wu, J., Lemieux, M., Faber, J., Vempati, S., Sinha, A., Xia, X., Jesneck, J., Bracken, A., Silverman, L., 2009. DNA methylation: An introduction to the biology and the disease-associated changes of a promising biomarker, in: Reproductive Biology and Endocrinology. BioMed Central, pp. 3-20. doi:10.1007/978-1-59745$522-0+1$

Tribble, D.L., Aw, T.Y., Jones, D.P., 1987. The pathophysiological significance of lipid peroxidation in oxidative cell injury. Hepatology 7, 377-86.

Ultsch, G., Jackson, D., 1996. pH and temperature in ectothermic vertebrates. Bull. 
Alabama Museum Nat. Hist. 18, 1-41.

Ultsch, G., Jackson, D., 1982. Long-Term submergence at $3^{\circ} \mathrm{C}$ of the turtle, Chrysemys Picta Bellii, in normoxic and severely hypoxic water: Survival, gas exchange, and acid-base status. J. Exp. Biol. 96, 11-28.

Vakoc, C.R., Sachdeva, M.M., Wang, H., Blobel, G.A., 2006. Profile of histone lysine methylation across transcribed mammalian chromatin. Mol. Cell. Biol. 26, 9185-95. doi:10.1128/MCB.01529-06

van der Maarel, S.M., 2008. Epigenetic mechanisms in health and disease. Ann. Rheum. Dis. 67, 97-100. doi:10.1136/ard.2008.098392

Venkatesh, S., Workman, J.L., 2015. Histone exchange, chromatin structure and the regulation of transcription. Nat. Rev. Mol. Cell Biol. 16, 178-189. doi: $10.1038 / \mathrm{nrm} 3941$

Waddington, C.H., 2012. The epigenotype. Int. J. Epidemiol. 41, 10-13. doi:10.1093/ije/dyr184

Waddington, C.H., 1956. Genetic assimilation of the bithorax phenotype. Evolution (N. Y). 10, 1. doi:10.2307/2406091

Wijenayake, S., Storey, K.B., 2016. The role of DNA methylation during anoxia tolerance in a freshwater turtle (Trachemys scripta elegans). J. Comp. Physiol. B 186, 333-342. doi:10.1007/s00360-016-0960-x

Willmore, W., Storey, K.B., 1997. Antioxidant systems and anoxia tolerance in a freshwater turtle Trachemys scripta elegans. Mol. Cell. Biochem. 170, 177-85. doi:10.1023/A:1006817806010

Wu, H., Zhang, Y., 2014. Reversing DNA methylation: Mechanisms, genomics, and 
biological functions. Cell 156, 45-68. doi:10.1016/j.cell.2013.12.019

Xiong, Z.J., Storey, K.B., 2012. Regulation of liver lactate dehydrogenase by reversible phosphorylation in response to anoxia in a freshwater turtle. Comp. Biochem.

Physiol. Part B Biochem. Mol. Biol. 163, 221-228. doi:10.1016/j.cbpb.2012.06.001

Zhang, J., Biggar, K.K., Storey, K.B., 2013. Regulation of p53 by reversible posttranscriptional and post-translational mechanisms in liver and skeletal muscle of an anoxia tolerant turtle, Trachemys scripta elegans. Gene 513, 147-155. doi:10.1016/j.gene.2012.10.049

Ziello, J.E., Jovin, I.S., Huang, Y., 2007. Hypoxia-Inducible Factor (HIF)-1 regulatory pathway and its potential for therapeutic intervention in malignancy and ischemia. Yale J. Biol. Med. 80, 51-60. 


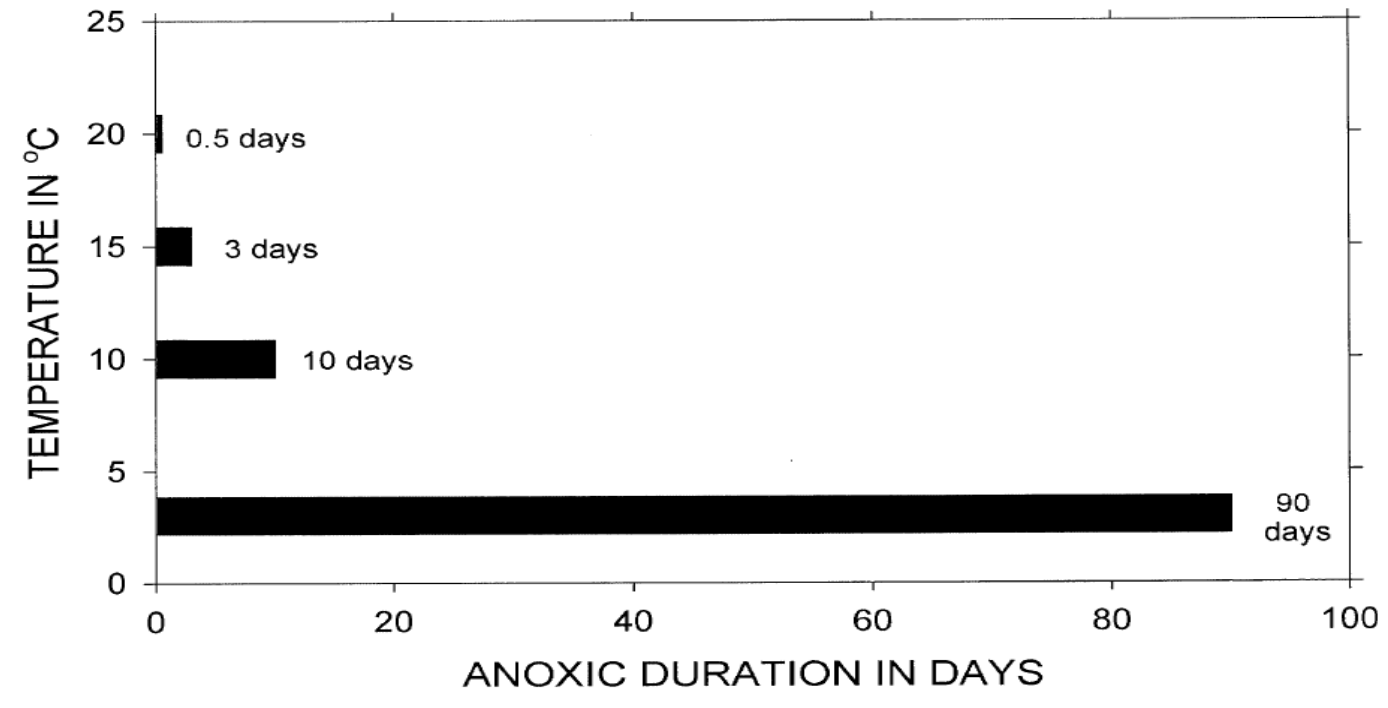

Figure 1. The duration of anoxia tolerance at different temperatures for which the anoxia tolerant painted turtle (Chrysemys picta bellii) have been observed to recover. The figure was adapted from (Jackson, 2000). 


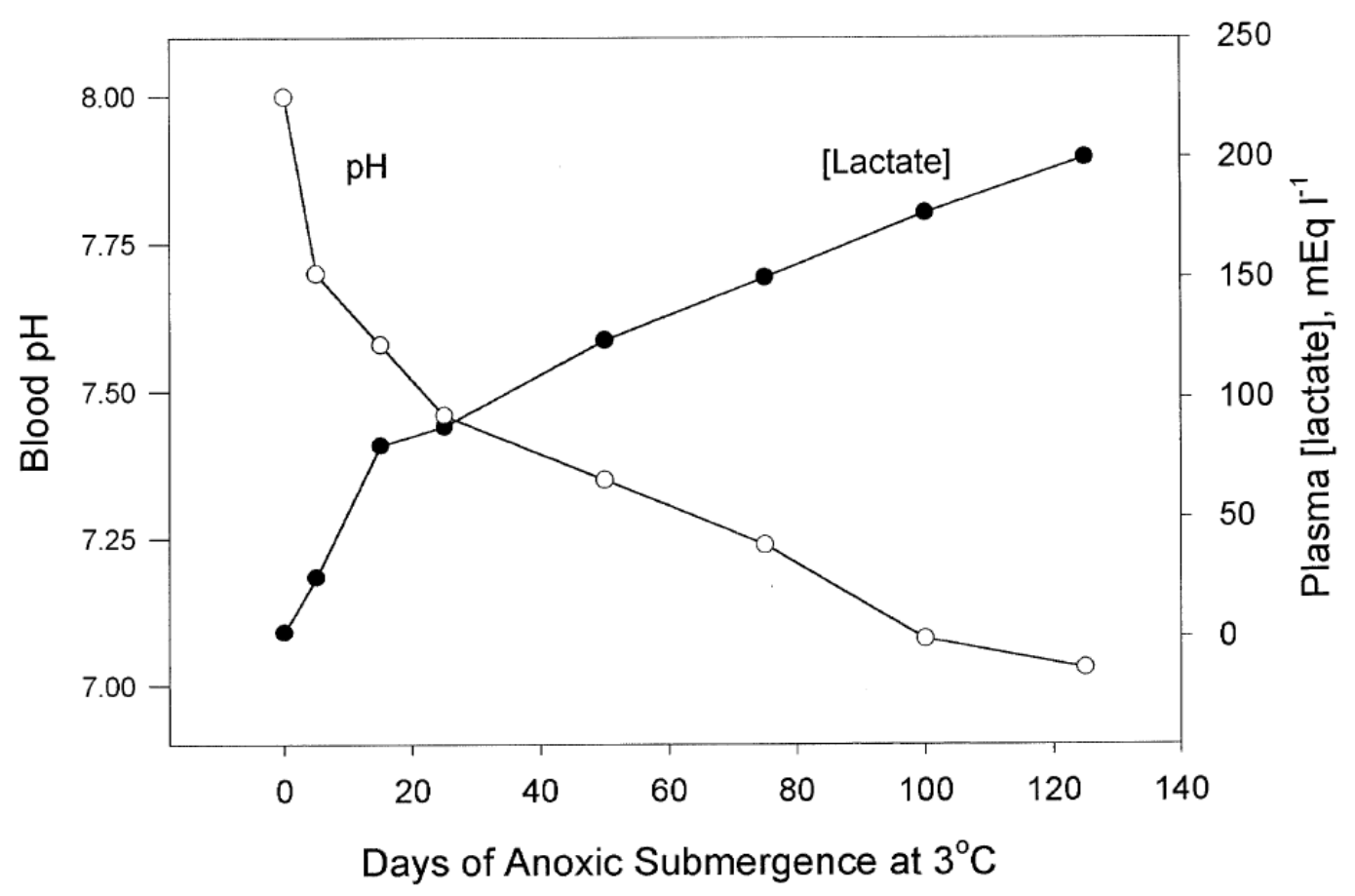

Figure 2. The relationship between blood $\mathrm{pH}$ and plasma lactate concentration during 125 days of anoxic submergence in the Eastern painted turtle (Chrysemys picta picta). Figure adapted from (Jackson, 2000). 
Mechanism 1

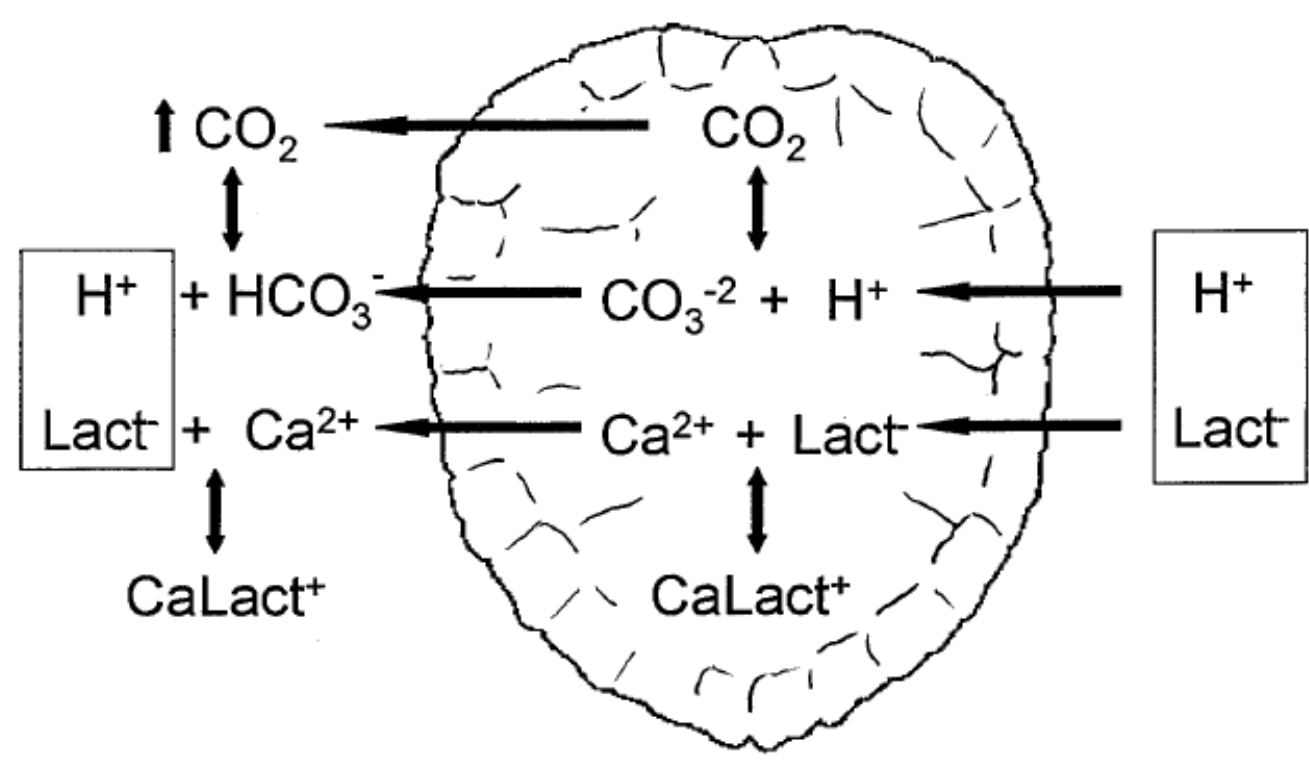

Figure 3. Schematic model portraying shell buffering of plasma ions during prolonged exposure to anoxia in the painted turtle (Chrysemys picta bellii). In mechanism 1, calcium, magnesium, and sodium carbonates move from the shell to the blood in response to the accumulation of lactic acid and provide extracellular buffering. In mechanism 2 , lactic acid enters the shell, is buffered and stored. The figure was adapted from (Jackson, 2000). 


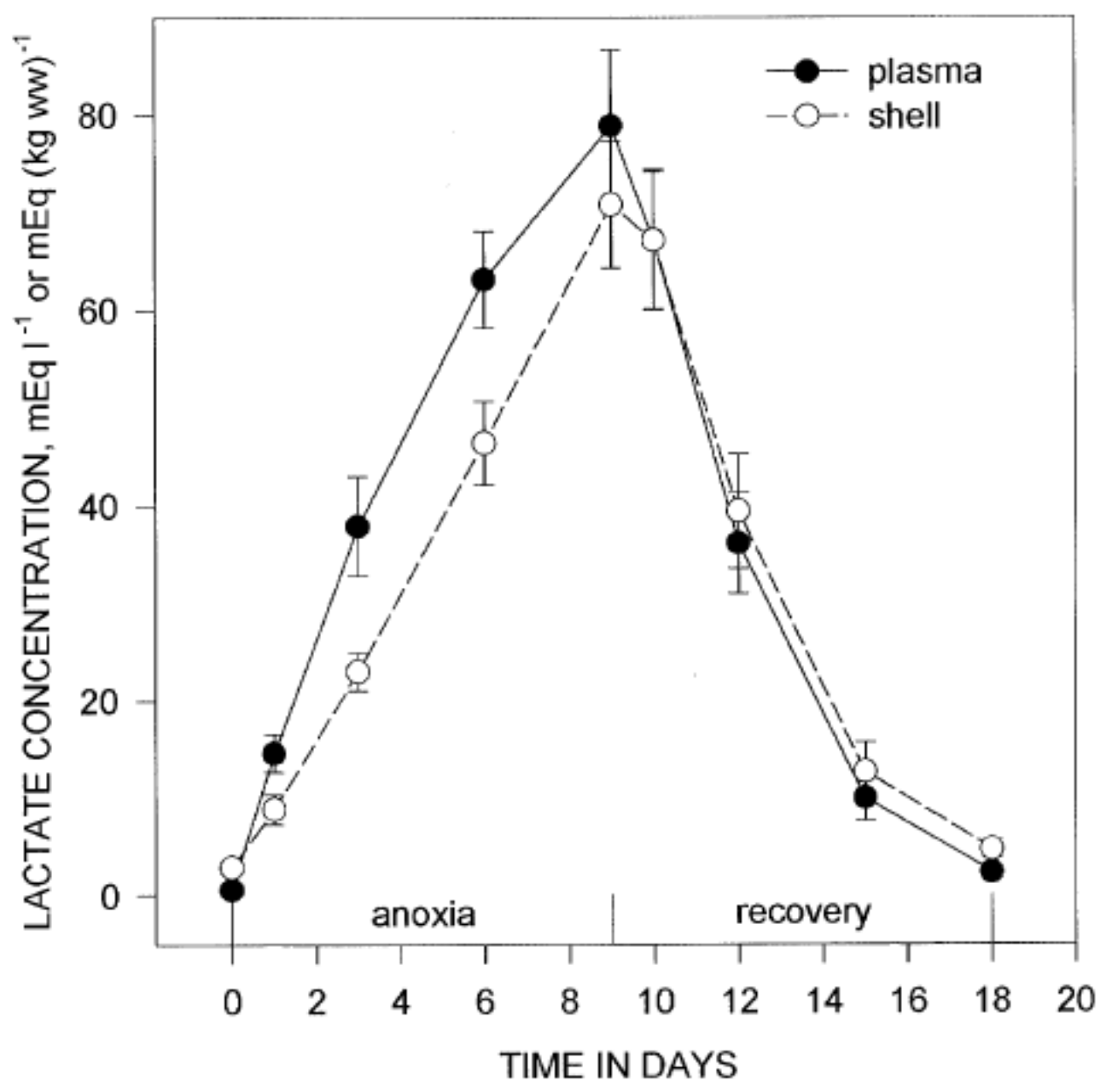

Figure 4. The accumulation of lactate concentration in the shell and plasma of the anoxia tolerant painted turtle (Chrysemys picta bellii) sampled at intervals during 9 days of anoxia and 9 days of recovery. This figure was adapted from (Jackson, 2000). 


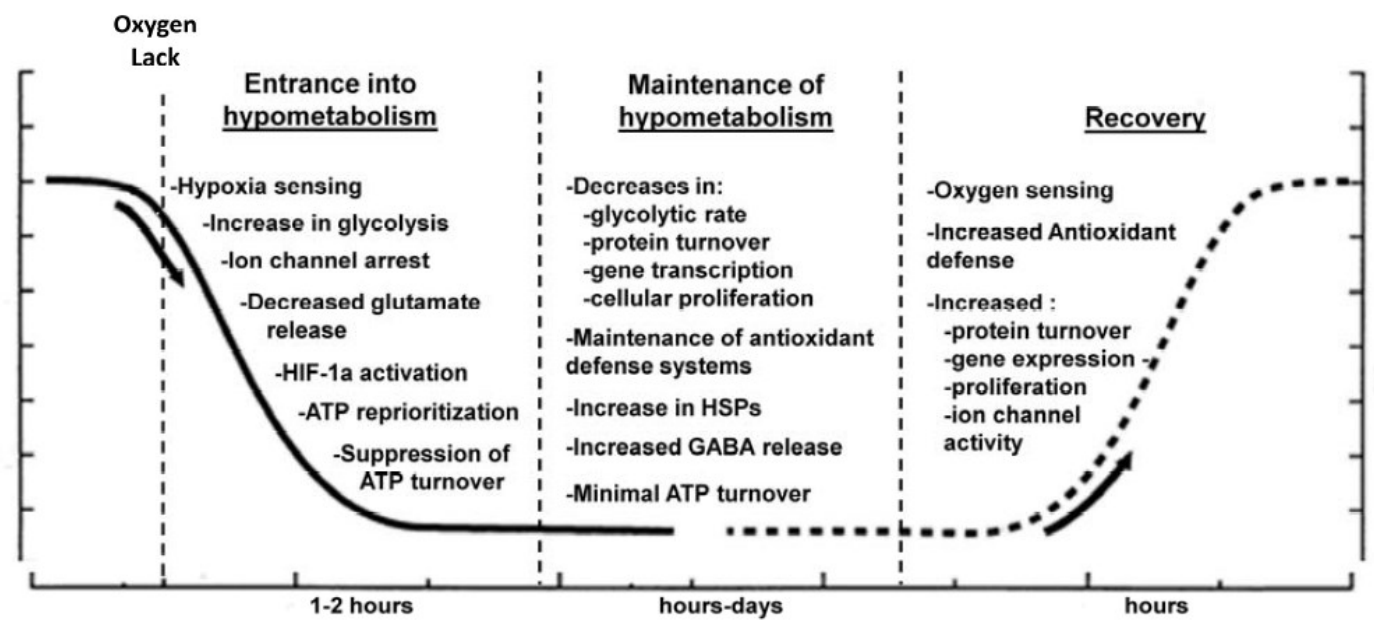

Figure 5. Three main stages of hypometabolic response during anoxia exposure in red-eared sliders (K. Biggar et al., 2011). Upon exposure to low oxygen, a variety of cellular adjustments take place to reprioritize ATP usage and survive long-term anoxia. 


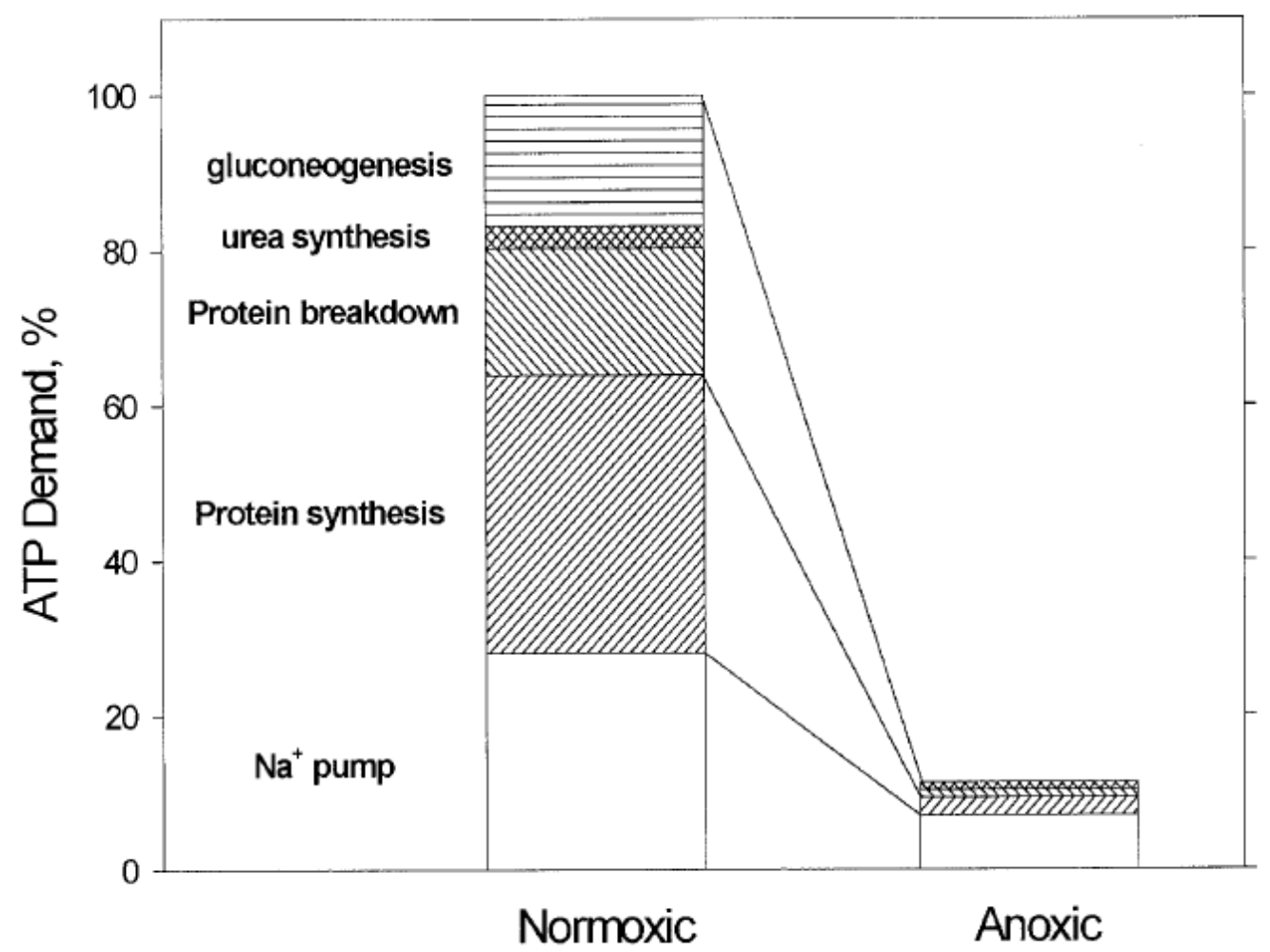

Figure 6. The percent decrease of ATP usage by cellular processes of isolated turtle hepatocytes in response to anoxia. The overall cumulative decrease $(\sim 90 \%)$ is similar to the decrease in ATP usage observed for the whole animal and to the total metabolic rate of hepatocytes. The figure was adapted from (Jackson, 2000). 


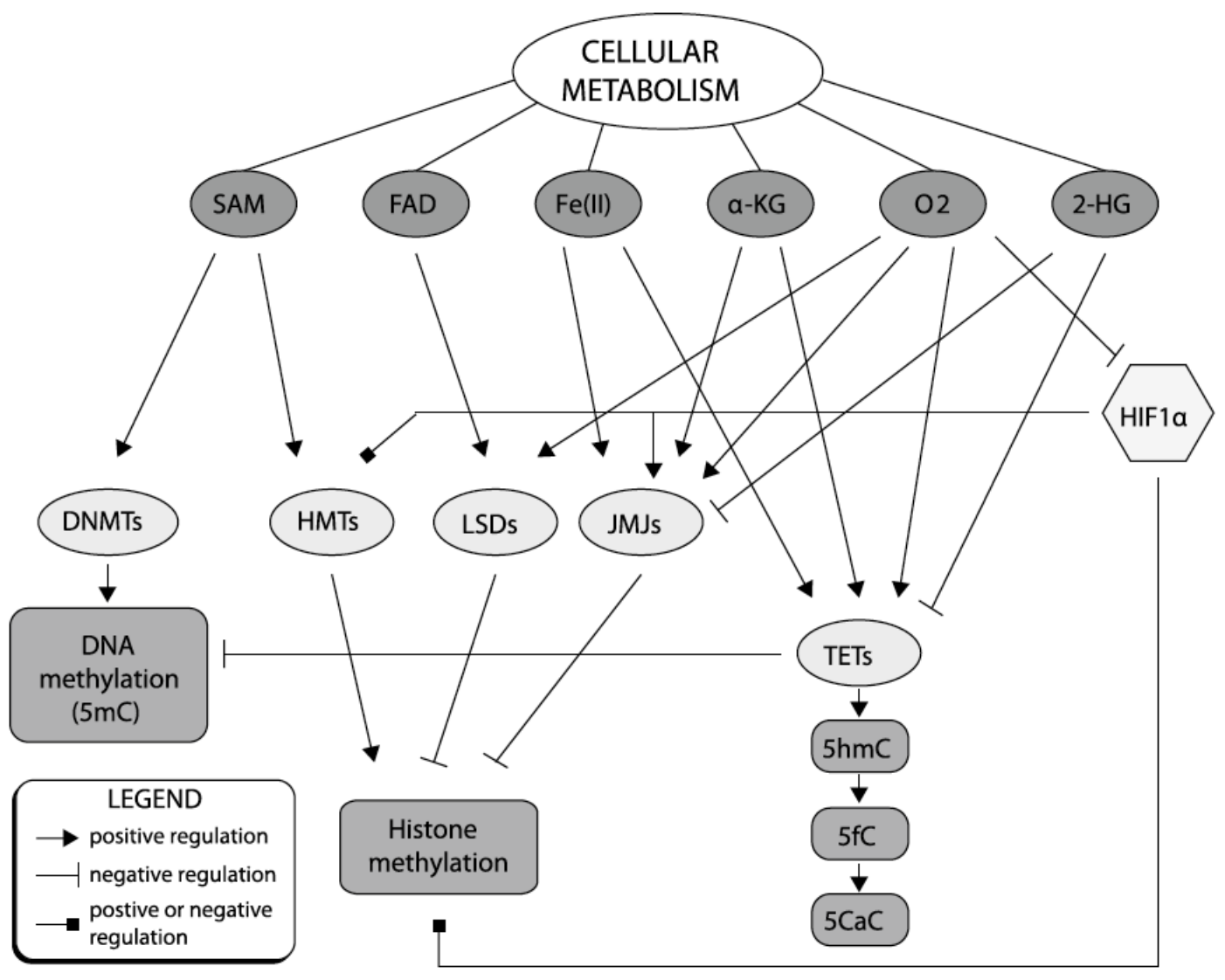

Figure 7. Epigenetics and connection to metabolism. The figure represents the connection between different epigenetic regulators such as DNA methyltransferases (DNMTs), histone methyltransferases (HMTs), lysine specific demethylases (LSD), jumonji domain family (JMJs), methylcytosine deoxygenases (TETs), etc and products of cellular metabolism such as SAM, FAD, O2, 2-HG, Fe(III), and alpha-ketoglutarate. This figure was adapted from (Kohli and Zhang, 2013). 
CHAPTER 2 
The Role of DNA Methylation during Anoxia Tolerance in a Freshwater Turtle (Trachemys scripta elegans)

\author{
Sanoji Wijenayake ${ }^{\mathrm{a}}$ and Kenneth B Storey ${ }^{\mathrm{a}^{*}}$
}

a - Institute of Biochemistry, Department of Biology, Carleton University, 1125 Colonel By Drive, Ottawa, ON, K1S 5B6, Canada.

This study has been published in the Journal of Comparative Physiology B.

Citation: Wijenayake S, Storey KB (2016) The role of DNA methylation during anoxia

tolerance in a freshwater turtle (Trachemys scripta elegans). J Comp Physiol B. 186: 33342 . 


\begin{abstract}
Oxygen deprivation is a lethal stress that only a few animals can tolerate for extended periods. This study focuses on analyzing the role of DNA methylation in aiding natural anoxia tolerance in a champion vertebrate facultative anaerobe, the red-eared slider turtle (Trachemys scripta elegans). We examined the relative expression and total enzymatic activity of four DNA methyltransferases (DNMT1, DNMT2, DNMT3a and DNMT3b), two methyl-binding domain proteins (MBD1 and MBD2), and relative genomic levels of 5-methylcytosine under control, $5 \mathrm{~h}$ anoxic, and $20 \mathrm{~h}$ anoxic conditions in liver, heart, and white skeletal muscle $(n=4, p<0.05)$. In liver, protein expression of DNMT1, DNMT2, MBD1, and MBD2 rose significantly by 2-4 fold after $5 \mathrm{~h}$ anoxic submergence compared to normoxic-control conditions. In heart, $5 \mathrm{~h}$ anoxia submergence resulted in a 1.4-fold increase in DNMT3a levels and a significant decrease in MBD1 and MBD2 levels to $\sim 30 \%$ of control values. In white muscle, DNMT3a and DNMT3b increased 3-fold and MBD1 levels increased by 50\% in response to $5 \mathrm{~h}$ anoxia. Total DNMT activity rose by 0.6-2.0 fold in liver and white muscle and likewise global $5 \mathrm{mC}$ levels significantly increased in liver and white muscle under $5 \mathrm{~h}$ and $20 \mathrm{~h}$ anoxia. The results demonstrate an overall increase in DNA methylation, DNMT protein expression and enzymatic activity in response to $5 \mathrm{~h}$ and $20 \mathrm{~h}$ anoxia in liver and white muscle indicating a potential downregulation of gene expression via this epigenetic mechanism during oxygen deprivation.
\end{abstract}

\title{
Keywords:
}

Metabolic rate depression. Anoxia. Trachemys scripta elegans. Epigenetics. DNA methyltransferases. Methyl binding proteins. 


\section{Introduction}

The term epigenetics was first coined to refer to heritable changes in gene expression and phenotype that arise independent of changes in the primary DNA sequence (Waddington 1942; Wolffe and Matzke 1999; Bird 2002). Such epigenetic changes are coordinated via permanent (such as during tissue differentiation) or reversible (such as stress-responsive) modifications to DNA and histone proteins. Many previous studies have shown that epigenetic mechanisms play a vital role in most, if not all, cellular and physiological processes, such as gene expression (Grewal and Moazed 2003), cell cycle control (Macaluso et al. 2005), growth and development (Bestor and Tycko 1996), disease and cancer (van der Maarel, 2008), aging (Calvanese et al. 2009), and genomic immunity (Barlow 1993). However, the involvement of epigenetic controls in the reversible regulation of animal adaptation to environmental stress has been understudied and is only beginning to be explored. For example, do epigenetic mechanisms such as DNA methylation play a role in metabolic rate depression, the nearly universal survival response to abiotic stresses (e.g. lack of oxygen, dehydration, temperature extremes, and food restriction)?

Hypoxia stress (low levels of oxygen) and anoxia (no oxygen) occur when the metabolic demand for oxygen exceeds the supply, and most vertebrates, particularly mammals, are highly sensitive to hypoxia/anoxia exposure. Oxygen deprivation is a particularly challenging stress to manage for intolerant species due to its dire consequences for ATP production via oxidative phosphorylation (Fraser et al. 2001). However, an obligate attachment to oxygen is not universal to all animals and many 
species experience natural situations where their access to oxygen can be cut off for long periods of time and yet they survive.

Among terrestrial vertebrates long-term survival without oxygen (anoxia) is most highly developed in some freshwater turtles. Turtles in the Chrysemys and Trachemys genera are champion facultative anaerobes, capable of surviving submerged underwater for $>24 \mathrm{~h}$ at $25^{\circ} \mathrm{C}$ and up to three to five months at $3^{\circ} \mathrm{C}$ (Ultsch and Jackson 1982; Ultsch 1985). The anoxia tolerance of these species supports extended hours of breath-hold diving, and is crucial to underwater hibernation in ice-locked ponds and lakes in northern latitudes. Turtles can be blocked from surfacing to breathe by ice locked ponds while at the same time oxygen is depleted in the water as winter progresses, thereby compromising the limited non-pulmonary oxygen uptake capacities of these species (Boutilier et al. 1997; Ultsch 2006). Red-eared sliders utilize a variety of physiological and biochemical adaptations to confer anoxia tolerance. These include maintaining high glycogen stores in liver and white muscle, use of the calciferous shell to store and buffer lactic acid, and up-regulation of cytoprotective mechanisms including antioxidant defenses and chaperone proteins (Ultsch and Jackson 1982; Hochachka et al. 1996; Lutz and Milton 2004; Storey and Storey 2007; Biggar et al. 2011). However, long-term anoxia survival is primarily achieved by suppressing, rebalancing and reprioritizing ATP use through metabolic rate depression (Storey and Storey 1990; Hochachka et al. 1996). Indeed, calorimetry has shown that the metabolic rate of submerged red-eared sliders is only about $10-20 \%$ of the normoxic value at the same temperature (Herbert and Jackson 1985; Jackson and Heisler 1982). 
Many physiological and genetic adaptations that support hypoxia/anoxia survival are interconnected with underlying epigenetic mechanisms in the form of DNA methylation and histone modifications (Krivoruchko and Storey 2010a). Epigenetic modifications are one of the essential transcriptional regulatory mechanisms in cells, and since gene transcription is a major ATP-consuming processes, typically utilizing 1-10\% of a cell's total energy budget (Rolfe and Brown 1997), it could be expected that epigenetic mechanisms would contribute to the suppression of transcription and the induction/maintenance of a hypometabolic state. In particular, previous evidence points towards a tight link between short and long-term exposure to stresses, caloric intake, diet, and epigenetic control of certain metabolic pathways (Chiacchiera et al. 2013; Krivoruchko and Storey 2010b).

DNA methylation is a chemically stable, reversible, and post-replicative modification of the $5^{\text {th }}$ position on cytosine $(5 \mathrm{mC})$. Approximately $60-70 \%$ of all $\mathrm{CpG}$ sites (regions of DNA in which cytosine nucleotides are located next to guanine nucleotides and separated by a single phosphate group) are methylated with the exception of relatively short regions characterized by high $\mathrm{CpG}$ density (called $\mathrm{CpG}$ islands). $\mathrm{CpG}$ islands are located upstream of the promoters of most genes. These $\mathrm{CpG}$ islands are differentially methylated in different tissues at different times, suggesting a highly dynamic transcriptional regulatory mechanism (Bird 2002). Hypermethylation of CpG islands correlates with transcriptional silencing due to (1) direct interference of transcription factor binding at the promoter, and/or (2) through recruitment of repressive methyl-binding proteins such as MBD1 and MBD2 (Bogdanovic and Veenstra 2009). MBD1 and MBD2 bind to methylated $\mathrm{CpG}$ islands and recruit repressive chromatin 
modifiers (such as histone deacetylases) and remodeling complexes that indirectly prevent the transcriptional machinery from binding to the promoter regions to initiate transcription. MBD1 has also been shown to bind DNA and induce chromatin compaction independent of DNA methylation (Boyes and Bird 1991).

DNMTs regulate the transfer of methyl groups from S-adenosylmethionine (SAM) to cytosine residues on genomic DNA and are essential for the maintenance and de novo creation of genomic methylation patterns (Goll and Bestor 2005). DNMT1 is attributed with preferring hemimethylated DNA, is known to maintain existing methylation patterns (Goll and Bestor 2005), and is considered a replication factor. Complete inhibition of DNMT1 has been shown to kill all dividing cells and partial inhibition may cause genome instability. Therefore, DNMT1 is considered to be a vital regulator of DNA methylation patterns in the genome (Goll and Bestor 2005). DNMT3a and $3 \mathrm{~b}$ (de novo methyltransferases) do not require hemi-methylated DNA to function and transfer methyl groups to mainly non-methylated cytosine residues (Okano et al. 1998; Ramsahoye et al. 2000). DNMT3a and b are both essential for early development and regulation of gene expression and the loss of either enzyme is fatal (Okano et al. 1999). On the other hand, DNMT2 is quite different with little to no DNA methylation activity, but instead methylate cytosines at position 38 of the anticodon loop of several tRNAs (Goll et al. 2006; Jeltsch et al.2006) and regulates folding and stability of their structures (Alexandrov et al. 2006). Schaefer et al. (2010) suggested a link between tRNA methylation by DNMT2 and the cellular stress response in which the tRNA methyltransferase activity of DNMT2 may interfere directly with the stress-induced fragmentation of various tRNAs and thereby play a role in regulating protein translation. 
The present study provides the first examination of the potential role of DNA methylation in the global suppression of gene expression in response to oxygen deprivation in a vertebrate model of anoxia tolerance, the red-eared slider turtle. We investigated the expression of four DNMTs and two MBDs, measured global 5-mC levels in genomic DNA, and assayed total DNMT activity in turtle liver, heart, and white muscle in response to $5 \mathrm{~h}$ and $20 \mathrm{~h}$ anoxic submergence. The results show adjustments to tissue-specific expression patterns of DNMTs and MBDs in the three organs in response to anoxia as well as significant increases in both 5-mC levels and total DNMT enzymatic activity under anoxia in liver and white muscle.

\section{Materials and Methods:}

\section{Animal Care and Treatment}

Adult female red-eared sliders (Trachemys scripta elegans), weighing 700-1500 g, were acquired from local suppliers. The animals were held at $5 \pm 1{ }^{\circ} \mathrm{C}$ in large tubs filled with dechlorinated tap water for at least a week before experiments began. Control normoxic turtles were sampled from this condition. For $5 \mathrm{~h}$ and $20 \mathrm{~h}$ anoxia exposures, turtles were transferred to large tubs at $5 \pm 1{ }^{\circ} \mathrm{C}$ that had been previously bubbled with nitrogen gas for $1 \mathrm{~h}$; 2-3 turtles were added per tub in 30 min intervals. Bubbling was continued for $1 \mathrm{~h}$ after the last turtle was added to a tub, then halted and restarted during sampling of the animals. A wire mesh was fitted into the top of the tubs, situated $\sim 5 \mathrm{~cm}$ below the water to prevent the turtles from surfacing. All animals were killed by decapitation and tissues were immediately excised, frozen in liquid nitrogen, and stored at $-80^{\circ} \mathrm{C}$. 
All animals were cared for in accordance with the guidelines of the Canadian Council on Animal Care and all experimental procedures had the prior approval of the Carleton University Animal Care Committee.

\section{Total Protein Extraction}

For isolation of total soluble protein, samples of frozen tissues $(\sim 0.5 \mathrm{~g})$ were crushed under liquid nitrogen and then homogenized 1:2.5 w:v in homogenizing buffer (20 mM Hepes pH 7.5, 200 mM NaCl, 0.1 mM EDTA, $10 \mathrm{mM} \mathrm{NaF,} 1 \mathrm{mM} \mathrm{Na} \mathrm{VO}_{4}, 10$ $\mathrm{mM} \beta$-glycerophosphate) with $10 \mu \mathrm{L} / \mathrm{mL}$ Sigma protease inhibitor cocktail (104 mM AEBSF, $80 \mu \mathrm{M}$ aprotinin, $4 \mathrm{mM}$ bestatin, $1.4 \mathrm{mM}$ E-64, $2 \mathrm{mM}$ leupeptin, $1.5 \mathrm{mM}$ pepstatin A) added, and a few crystals of phenylmethylsulfonyl fluoride [PMSF] added immediately before use. Samples were homogenized using a Polytron homogenizer on high for $15 \mathrm{sec}$ and then centrifuged at $4^{\circ} \mathrm{C}$ for $15 \mathrm{~min}$ at $10,000 \mathrm{x} g$; the supernatant was saved and the pellet was discarded. Soluble protein concentrations were quantified using the BioRad protein assay (Cat\# 500-0006) with bovine serum albumin as the standard. All samples were then adjusted to a constant protein concentration by adding a calculated small volume of homogenizing buffer. Aliquots of samples were then mixed 1:1 v:v with 2X SDS loading buffer (100 mM Tris-base, 4\% w:v SDS, 20\% v:v glycerol, $0.2 \% \mathrm{w}: \mathrm{v}$ bromophenol blue, 10\% v:v 2-mercaptoethanol). Final sample concentrations were 3 or 5 $\mu \mathrm{g} / \mu \mathrm{L}$, depending on tissue. Proteins were denatured by placing the tubes in boiling water for $10 \mathrm{~min}$ and then samples were stored at $-40^{\circ} \mathrm{C}$ until use.

\section{Western Immunoblotting}

Samples of protein extracts containing 20-30 $\mu \mathrm{g}$ of protein were loaded onto 6- 
$10 \%$ SDS-polyacrylamide gels and resolved by electrophoresis for $45-90 \mathrm{~min}$ at $180 \mathrm{~V}$ in 1x Tris-glycine running buffer ( $75.5 \mathrm{~g}$ of Tris-base, $460 \mathrm{~g}$ glycine, $25 \mathrm{~g}$ SDS, $\mathrm{ddH}_{2} 0$ up to $2.5 \mathrm{~L}$ ) using a BioRad Mini-Protean 3 System. Four $\mu 1$ aliquots of pre-stained protein molecular weight ladders (Froggabio; Cat. \# PM005-0500 and PM007-0500K) were run alongside the protein samples. Proteins were subsequently electroblotted onto 0.45 micron PVDF membranes (Millipore, Cat. \#: IPVH00010) in transfer buffer (60.6 g Trisbase, $288 \mathrm{~g}$ glycine, $4 \mathrm{~L}$ methanol, $16 \mathrm{~L} \mathrm{ddH}_{2} \mathrm{O}$ ) at $160 \mathrm{~mA}$ for $90-120$ min using a BioRad Mini-Protean Transfer cell. Subsequently, PVDF membranes were washed $3 \times 5$ $\min$ in $0.5 \mathrm{x}$ TBST $(10 \mathrm{mM}$ Tris, $150 \mathrm{mM} \mathrm{NaCl}, 0.05 \% \mathrm{v} / \mathrm{v}$ Tween-20, $\mathrm{pH} 7.5)$ and blocked with $2.5-5 \%$ milk for $30 \mathrm{~min}$ or $1 \mathrm{mg} / \mathrm{ml}$ polyvinyl alcohol $(70-100 \mathrm{kDa})$ for one $\min$. The membranes were subsequently washed $3 \times 5 \mathrm{~min}$ in $0.5 \mathrm{x}$ TBST and incubated with primary antibody (diluted 1:500 for DNMT 1 and 1:1000 v:v for all remaining targets) for $24 \mathrm{~h}$ at $4^{\circ} \mathrm{C}$. All six antibodies used in this analysis were purchased from Genetex (DNMT1-GTX116011; DNMT2-GTX13892; DNMT3a-GTX128157; DNMT3b-GTX129127; MBD1-GTX110612; MBD2-GTX105622).

Membranes were then washed $3 \times 5 \mathrm{~min}$ in $0.5 \mathrm{x}$ TBST and incubated with HRPconjugated anti-rabbit IgG secondary antibody (Bioshop; Cat. \# APA007P), diluted 1:8000 v:v in TBST, for 30-40 min at room temperature (RT) on a rocker. Proteins on the membranes were visualized using enhanced chemiluminescence and a ChemiGenius BioImaging System (Syngene, Frederick, MD). Protein band densities were quantified using Gene Tools software. After immunoblotting was complete, membranes were stained with Coomassie blue $(0.25 \% \mathrm{w}$ : v Coomassie brilliant blue stain, $7.5 \%$ v:v acetic acid, $50 \%$ v:v methanol) and band densities were similarly quantified using the ChemiGenius. 


\section{Preparation of Nuclear Extracts}

Tissue samples $(\sim 0.5 \mathrm{~g})$ were homogenized using a Dounce homogenizer in $1 \mathrm{~mL}$ of homogenization buffer (10 mM Hepes pH 7.9, $10 \mathrm{mM} \mathrm{KCl,} 10 \mathrm{mM}$ EDTA, $1 \mathrm{mM}$ dithiothreitol [DTT]). A few crystals of PMSF and $1 \mu \mathrm{L}$ of Sigma protease inhibitor cocktail were added just prior to homogenization. Samples were centrifuged at $10,000 \times g$ for $10 \mathrm{~min}$ at $4^{\circ} \mathrm{C}$ and the supernatant (cytoplasmic extract) was removed. The pellet was resuspended in $150 \mu \mathrm{L}$ of extraction buffer $(20 \mathrm{mM}$ HEPES, $400 \mathrm{mM} \mathrm{NaCl}, 1 \mathrm{mM}$ EDTA, 10\% v/v glycerol, $1 \mathrm{mM}$ DTT). Again, DTT and $1 \mu \mathrm{L}$ of Sigma protease inhibitor cocktail, were added just prior to addition of the buffer to the pellet. Tubes containing the samples were put on ice horizontally on a rocking platform for $1 \mathrm{~h}$. Samples were then centrifuged at $10,000 \times \mathrm{g}$ for $10 \mathrm{~min}$ at $4^{\circ} \mathrm{C}$. The supernatant (nuclear extract) was collected. Protein concentrations in the extracts were quantified and then extracts were treated as described above to create samples for western blotting. Final sample concentrations were $5 \mu \mathrm{g} / \mu \mathrm{L}$. To confirm the separation of cytoplasmic and nuclear fractions samples of both fractions were immunoblotted and then probed with histone $\mathrm{H} 3$ antibody (diluted 1:1000 v:v; Genetex-GTX129546) to show that this nuclear protein remained in the nuclear fraction.

\section{DNMT Activity Assay}

Relative levels of total DNMT activity were assessed using the EpiQuick DNMT Activity/Inhibition Colorimetric Assay Ultra Kit from Epigentek (Catalog \# P-3009) according to manufacturer's instructions. In summary, $10 \mu \mathrm{g}$ of nuclear protein extract from liver and heart, or $20 \mu \mathrm{g}$ of nuclear protein extracts from white muscle of control, 5 $\mathrm{h}$ anoxic, and $20 \mathrm{~h}$ anoxic red-eared sliders were incubated in a 96-well microplate for 
120 min at $37^{\circ} \mathrm{C}$. A blank well (containing $50 \mu \mathrm{L}$ of assay buffer) was run per tissue type alongside a purified DNMT enzyme positive control ( $50 \mu \mathrm{g} / \mathrm{ml}$; provided by Epigentek). After incubation, the plate was washed 3-5 times with $150 \mu 1$ of $1 \mathrm{x}$ wash buffer. Subsequently, $50 \mu 1$ of capture antibody $(1000 \mu \mathrm{g} / \mu \mathrm{l})$ was added to each well and incubated at RT for $60 \mathrm{~min}$. The capture antibody was then removed, and after washing the wells, $50 \mu \mathrm{l}$ of detection antibody $(400 \mu \mathrm{g} / \mathrm{ml})$ was added and incubated at RT for 30 min, followed by adding $50 \mu 1$ of enhancer solution and further incubating for another 30 min at RT. Lastly, $100 \mu 1$ of developer solution was added to each well and incubated at RT for10 min away from direct light. Once the color of the positive control well had turned blue (indicating presence of sufficient methylated DNA), $100 \mu 1$ of stop solution was added to stop the enzyme reaction and the plate was read using a microplate reader (Multiscan Spectrum, Thermo Labsystems) at $450 \mathrm{~nm}$.

The DNMT activity was calculated by the following formula:

DNMT Activity $\left(\frac{\frac{\mathrm{OD}}{\mathrm{h}}}{\mathrm{mg}}\right)=\frac{(\text { Sample OD }- \text { Blank } O D)}{[\text { Protein amount }(\mu g) \times \text { Incubation time }(h)]} \times 1000$

\section{Genomic DNA Extraction}

Total Genomic DNA was extracted using Zymo Research, Quick-gDNA MiniPrep kit (Catalog \#: D3050) as per manufacturer's instructions. In summary, $25 \mathrm{mg}$ samples of frozen tissue were suspended in $95 \mu 1$ of $\mathrm{ddH}_{2} \mathrm{O}, 95 \mu 1$ of $2 \mathrm{x}$ Digestion Buffer, and $10 \mu \mathrm{l}$

of Proteinase K. The samples were incubated in a $55^{\circ} \mathrm{C}$ bath for $3 \mathrm{~h}$. Subsequently, $700 \mu 1$ of genomic lysis buffer were added to each tube, thoroughly mixed and centrifuged at $10,000 \mathrm{x} \mathrm{g}$ for $1 \mathrm{~min}$. The supernatant was transferred to a Zymo-Spin IIC Column in a 
collection tube, and centrifuged for $10,000 \mathrm{x}$ g for $1 \mathrm{~min}$. Then $200 \mu 1$ of DNA pre-wash buffer was added to the same spin column but in a new collection tube, and centrifuged at $10,000 \mathrm{x} g$ for $1 \mathrm{~min}$. Subsequently, $400 \mu \mathrm{l}$ of g-DNA wash buffer was added to each spin column and centrifuged at $10,000 \mathrm{x} g$ for $1 \mathrm{~min}$. Finally the spin column was transferred to a clean $1.5 \mathrm{ml}$ microcentrifuge tube and $200 \mu 1$ of DNA elution buffer was added and centrifuged at $15,000 \mathrm{x}$ g for $30 \mathrm{sec}$ to elute the extracted and purified genomic DNA. The concentrated gDNA product was diluted 25 -fold with $\mathrm{ddH}_{2} \mathrm{O}$ and quantified using a GeneQuant Pro spectrophotometer (Pharmacia). The quality and integrity of the extracted genomic DNA was assessed by running each of the samples in a $0.6 \%$ agarose gel at 130 $\mathrm{V}$ for $40-60 \mathrm{~min}$.

\section{Global DNA methylation}

Relative levels of global DNA methylation (\%) was assessed using the MethylFlash Methylated DNA Quantification Kit, Colorimetric (Source: Epigentek, Cat \# P-1034), according to manufacturer's instructions. This kit quantifies global DNA methylation levels colorimetrically by measuring levels of 5-methylcytosine (5-mC) in an ELISA format using genomic DNA. In summary, aliquots of $150 \mathrm{ng}$ of extracted genomic DNA from liver, white muscle, and heart tissues of normoxic control, $5 \mathrm{~h}$ anoxic, and 20 $\mathrm{h}$ anoxic red-eared sliders were incubated with $80 \mu \mathrm{l}$ of binding solution in a 96-well microplate for $90 \mathrm{~min}$ at $37^{\circ} \mathrm{C}$. Aliquots of $1 \mu \mathrm{l}$ of negative control $(20 \mu \mathrm{g} / \mathrm{ml})$ representing unmethylated polynucleotide containing $50 \%$ of cytosine, and $1 \mu 1$ of positive control ( $5 \mathrm{ng} / \mu \mathrm{l})$ representing methylated polynucleotide containing $50 \% 5$ methylcytosine were loaded into independent wells of the microplate. The wells were then incubated for $60 \mathrm{~min}$ at room temperature with a capture antibody $(1 \mathrm{ng} / \mathrm{ml})$. 
Subsequently, a $50 \mu \mathrm{l}$ aliquot of detection antibody $(0.2 \mu \mathrm{g} / \mathrm{ml})$ was added and incubated at room temperature for $30 \mathrm{~min}$ and upon completion $50 \mu \mathrm{l}$ of enhancer solution was added to each well and further incubated for $30 \mathrm{~min}$ at room temperature. Lastly, $100 \mu \mathrm{l}$ of developer solution was added to initiate the colorimetric chemical reaction and incubated at room temperature for 10 min away from direct light. Subsequently, $100 \mu 1$ stop solution was added to each well to halt the reaction and then absorbance values were read using a microplate reader (Multiscan Spectrum by Thermo Labsystems) at $450 \mathrm{~nm}$.

The relative 5-mC levels were determined using the following formula:

$$
\text { Relative } 5 m C \%=\frac{\frac{(\text { Sample OD }- \text { Negative Control OD })}{S}}{\frac{[(\text { Positive Conrtol OD }- \text { Negative Control OD }) \times 2]}{P}} \times 100 \%
$$

Where;

$\mathrm{S}$ is the input sample DNA in ng.

$\mathrm{P}$ is the input positive control in ng.

2 is a factor that is used to normalize $5-\mathrm{mC}$ in the positive control to $100 \%$, since the positive control contains only $50 \%$ of $5-\mathrm{mC}$.

\section{Data Analysis}

In order to adjust for minor protein loading irregularities and ensure equivalent protein loading, immunoblot band intensities were normalized against the summed intensity of a group of Coomassie-stained protein bands in the same lane that showed constant expression between control, $5 \mathrm{~h}$ anoxic, $20 \mathrm{~h}$ anoxic experimental conditions. In other words total protein analysis was used for normalization as an alternative technique to using a single housekeeping protein loading control. Target protein bands were identified by running FroggaBio standard protein molecular weight ladder and $4 \mu \mathrm{L}$ of mammalian positive control samples (ground squirrel, Ictidomys tridecemlineatus) of 
liver, white muscle, and heart tissues were run alongside.

Statistical analysis used a one-way ANOVA with a Tukey post-hoc test $(\mathrm{p}<0.05)$ to compare three experimental conditions. Sigmaplot 11 software (Systat Softwaree Inc., San Jose, CA) was used for this analysis as well as construction of figures.

\section{Results}

DNMT and MBD protein expression in in response to $5 \mathrm{~h}$ or $20 \mathrm{~h}$ anoxia exposure

Relative protein expression levels of DNMT1, 2, 3a and 3b as well as MBD1 and 2 were assessed in liver of $T$. s. elegans comparing aerobic control turtles with animals given 5 or $20 \mathrm{~h}$ of anoxic submergence in nitrogen-gassed water (Figure 1). DNMT1, DNMT2, MBD1, and MBD2 showed robust 2-4 fold upregulation in response to $5 \mathrm{~h}$ anoxic exposure as compared to normoxic control conditions $(\mathrm{P}<0.05)$. However, levels of all four proteins, as well as DNMT3a had decreased significantly after $20 \mathrm{~h}$ anoxia. DNMT1 and DNMT2 levels returned to near control values, DNMT3a fell to about 50\% of control, and MBD1 and MBD2 levels were reduced but still remained significantly higher $(\sim 2$-fold) than control values $(\mathrm{P}<0.05)$. DNMT3b did not show any significant change in response to anoxia stress. 

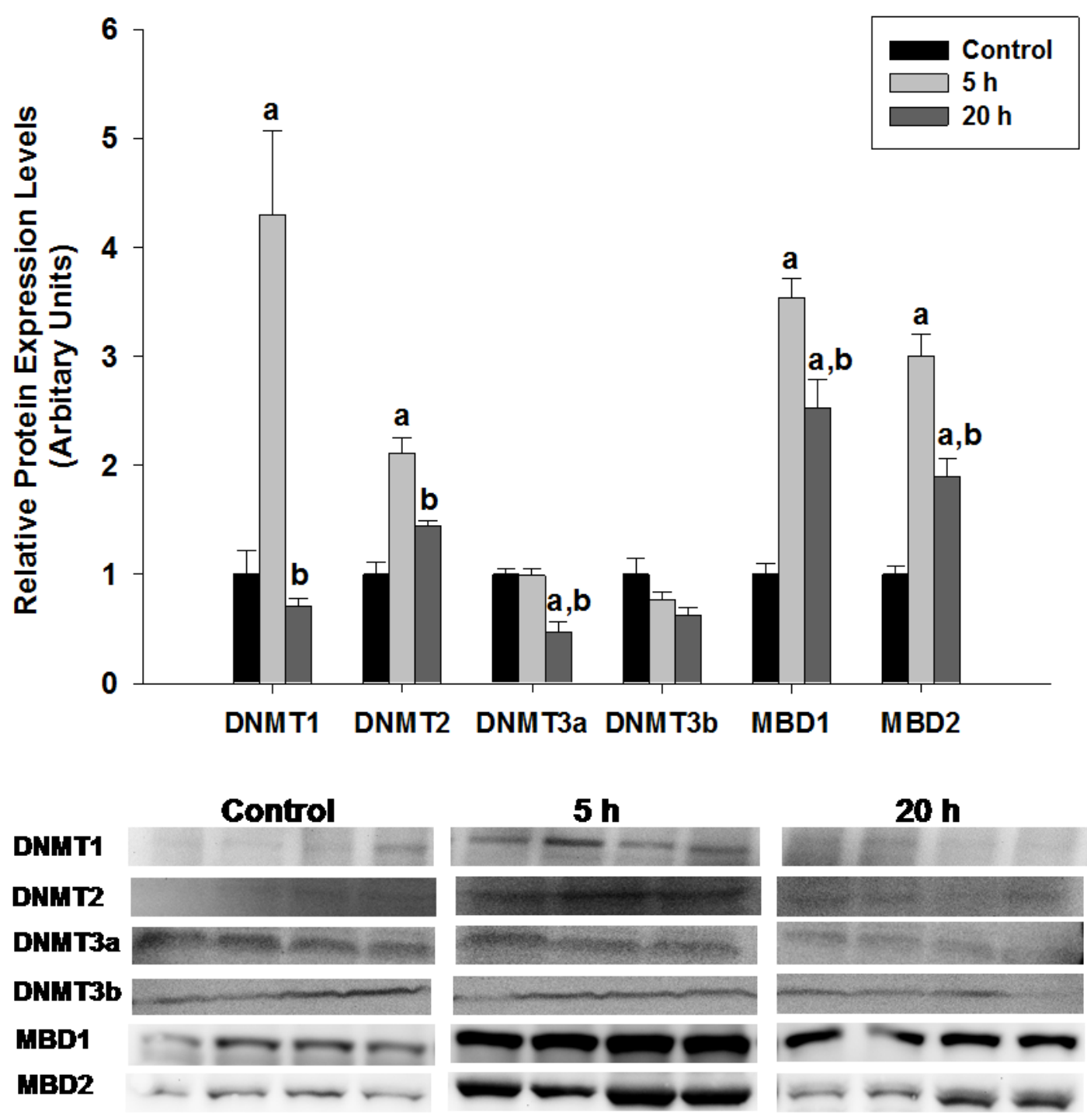

Figure. 1 Effect of $5 \mathrm{~h}$ and $20 \mathrm{~h}$ anoxic submergence on total protein levels of DNMT1, DNMT2, DNMT3a, DNMT3b, MBD1, and MBD2 in liver of T.s. elegans as determined by Western immunoblotting. Data are mean $\pm S E M$, and $n=3-4$ independent trials on tissue samples from different animals. a - significantly different from the corresponding control $(\mathrm{P}<0.05)$. b -significantly different values from the $5 \mathrm{~h}$ anoxic value. Reprinted with permission from Springer.

In heart, short-term anoxic submergence $(5 \mathrm{~h})$ resulted in an approximately 1.4fold increase in DNMT3a levels and significant decreases in MBD1 and MBD2 to about $30 \%$ of control values $(\mathrm{P}<0.05)$ (Figure 2$)$. With longer anoxia exposure $(20 \mathrm{~h})$, these 
changes were reversed for DNMT3a and MBD2. However, two proteins showed strong increases after $20 \mathrm{~h}$ anoxia: DNMT 3b levels increased by 2.5 fold over control values and MBD1 levels increased to about 1.6 fold over control (or about 4-fold higher than $5 \mathrm{~h}$ values).

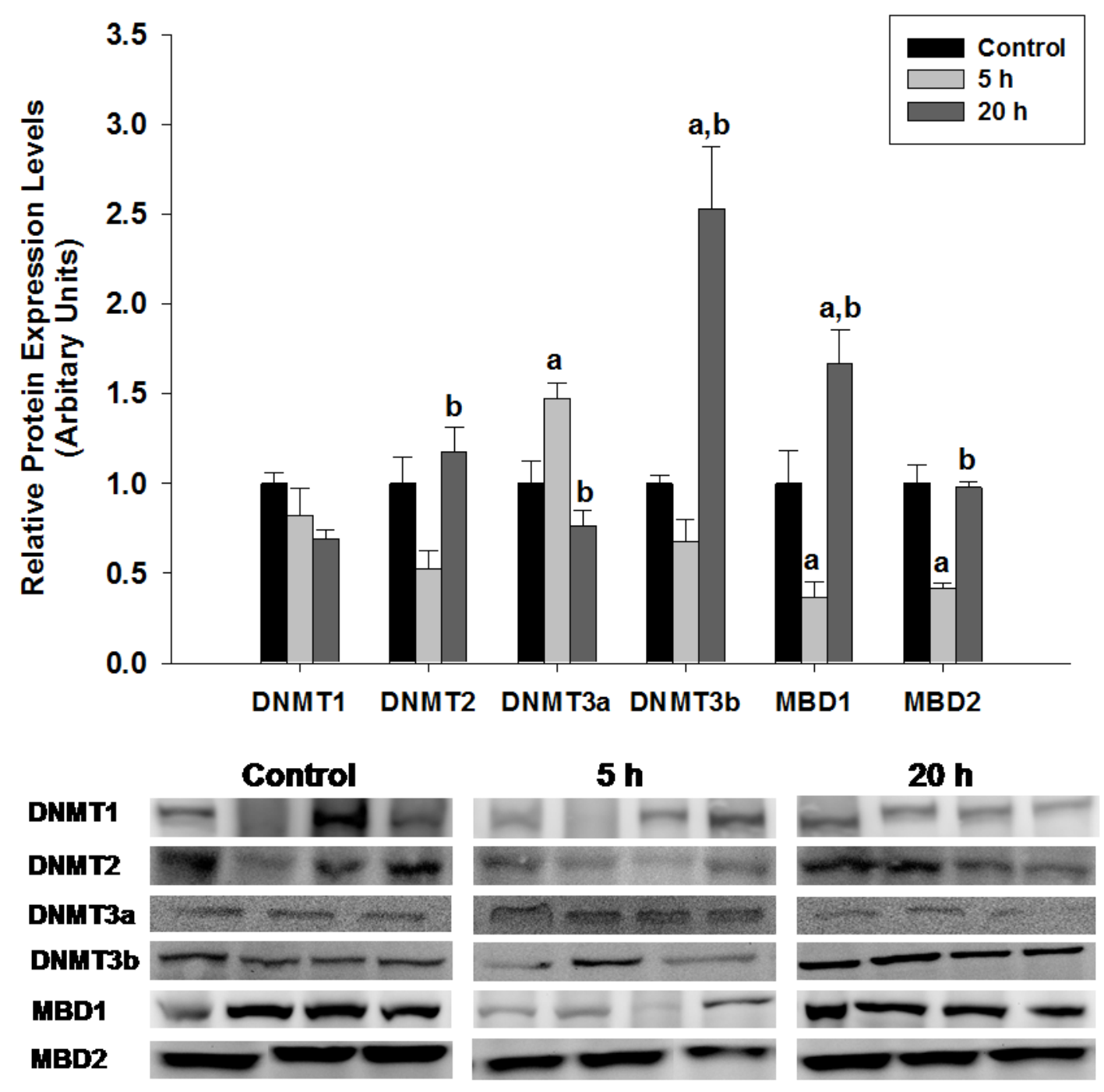

Figure. 2. Effect of $5 \mathrm{~h}$ and $20 \mathrm{~h}$ anoxic submergence on total protein levels of DNMT1, DNMT2, DNMT3a, and DNMT3b, MBD1, and MBD2 in heart of T. s. elegans as determined by Western immunoblotting. Other information as in Figure 1. Reprinted with permission from Springer. 
The pattern in white skeletal muscle (neck retractor) included approximately 3fold increases in DNMT3a and DNMT3b in response to $5 \mathrm{~h}$ anoxic submergence as well as a $50 \%$ increase in MBD1 levels $(\mathrm{P}<0.05)$ (Figure 3). With prolonged anoxia $(20 \mathrm{~h})$ DNMT3a levels fell strongly to only about $30 \%$ of controls. By contrast, DNMT3b levels continued to increase to about 3.8-fold higher than controls and MBD1 levels also remained elevated. DNMT1, DNMT2, and MBD2 in skeletal muscle were largely unaffected by anoxia exposure.
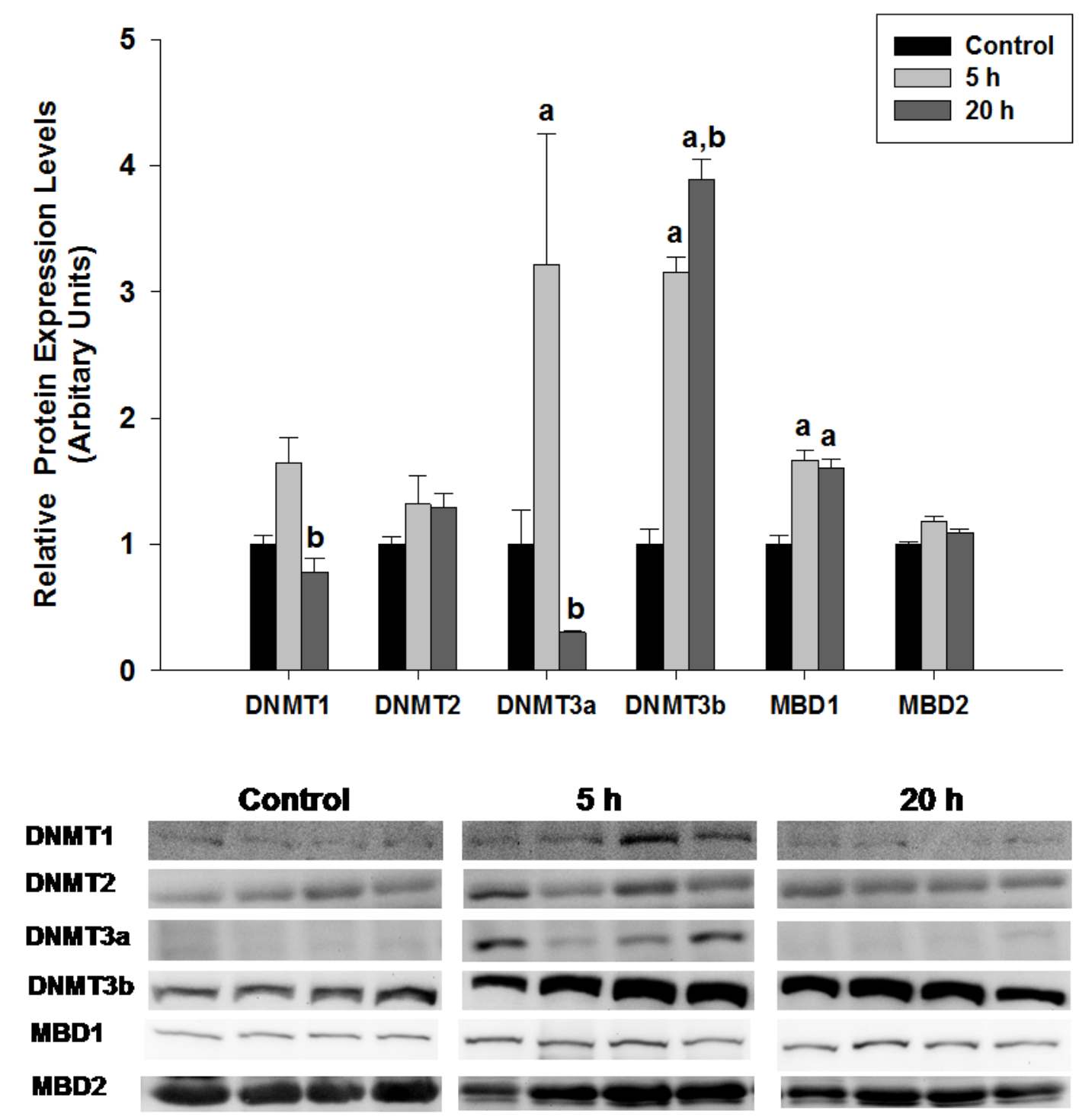
Figure. 3. Effect of $5 \mathrm{~h}$ and $20 \mathrm{~h}$ anoxic submergence on total protein levels of DNMT1, DNMT2, DNMT3a, DNMT3b, MBD1, and MBD2 in white muscle of T. s. elegans as determined by Western immunoblotting. Other information as in Figure 1. Reprinted with permission from Springer.

DNMT activity in liver, heart, and white skeletal muscle in response to anoxia

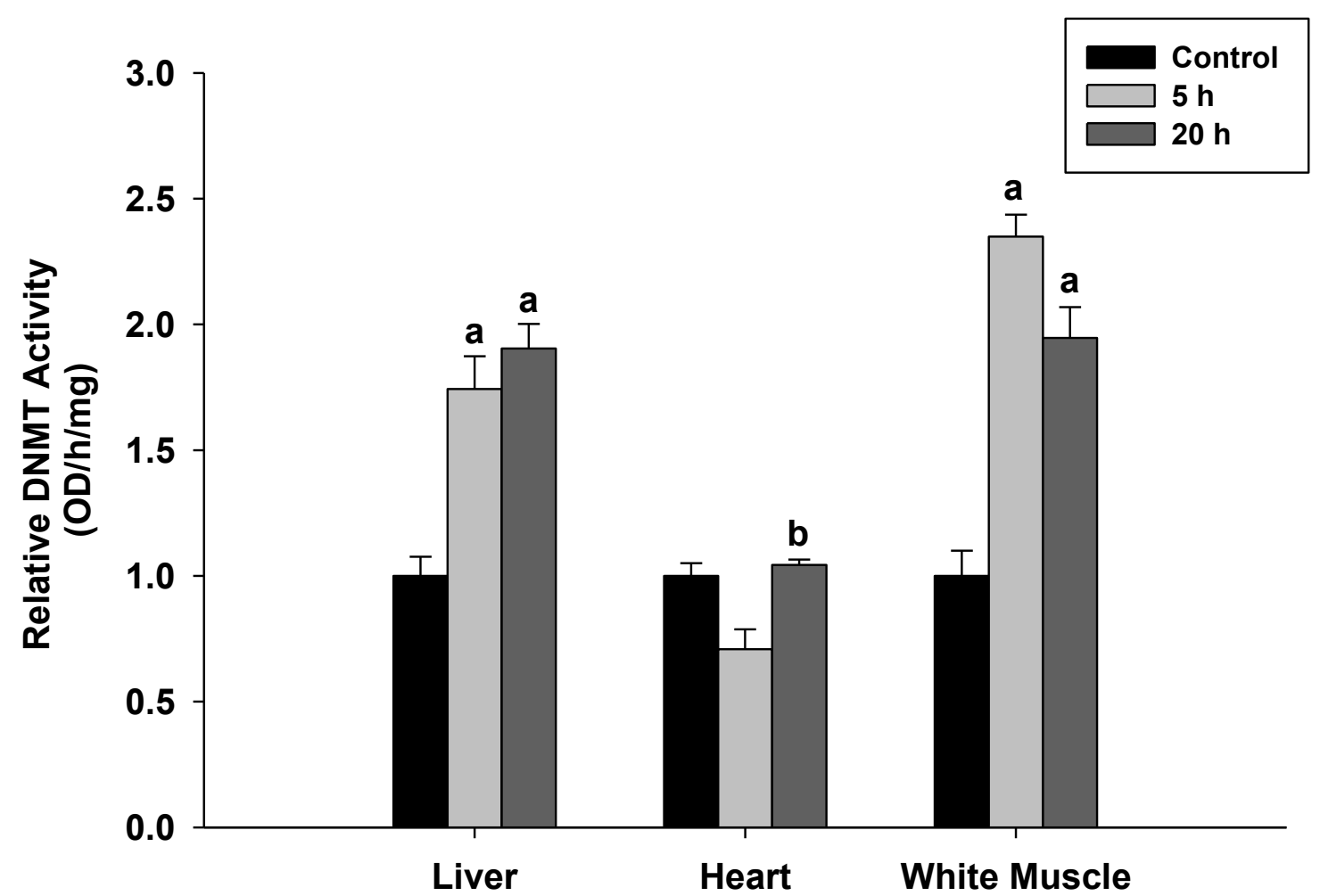

Figure. 4. Total DNMT enzyme activity (activity was measured as OD/h/mg nuclear protein) in liver, heart, and white muscle of T. s. elegans as determined by EpiQuick DNMT Activity/Inhibition Colorimetric Assay Ultra Kit from Epigentek. Other information as in Figure 1. Reprinted with permission from Springer.

Total DNMT activities were measured as the change in optical density per h per mg nuclear protein in liver, heart, and white skeletal muscle. Activity was highest in liver with mean values of $57.3 \pm 4.4,99.8 \pm 7.4$ and $109.0 \pm 5.6 \mathrm{OD} / \mathrm{h} / \mathrm{mg}$ nuclear protein for aerobic controls, $5 \mathrm{~h}$ anoxia, and $20 \mathrm{~h}$ anoxia, respectively. Heart showed intermediate 
activity levels of $41.8 \pm 2.1,29.6 \pm 3.2$ and $43.6 \pm 0.9 \mathrm{OD} / \mathrm{h} / \mathrm{mg}$, respectively, whereas white skeletal muscle had the lowest overall DNMT activities of $5.96 \pm 0.6,14.0 \pm 0.5$ and 11.6 $\pm 0.7 \mathrm{OD} / \mathrm{h} / \mathrm{mg}$, respectively, for controls, $5 \mathrm{~h}$ anoxia and $20 \mathrm{~h}$ anoxia. Relative changes in DMNT activities are shown in Figure 4. In liver, activity increased significantly by 1.7 and 1.9 fold over control values after 5 and $20 \mathrm{~h}$ of anoxia exposure $(\mathrm{P}<0.05)$. Activity also increased significantly in white muscle by 2.4 and 2.0 , fold, respectively $(\mathrm{P}<0.05)$. In heart, however, there was little effect of anoxia on total DNMT activity.

5-mC levels in genomic DNA of red-eared slider liver, heart, and white skeletal muscle in response to anoxia.

Relative changes in global DNA methylation levels (in terms of total 5methylcytosine content) in response to anoxic submergence are shown in Figure 5. Compared with a relative mean level of $0.77 \pm 0.03$ for liver control, $5 \mathrm{mC}$ levels significantly increased to $1.07 \pm 0.02$ during $5 \mathrm{~h}$ anoxia and to $0.98 \pm 0.04$ during $20 \mathrm{~h}$ anoxia. White muscle showed similar increase in relative $5 \mathrm{mC}$ levels with $0.86 \pm 0.03$ for normoxic control, $1.30 \pm 0.02$ for $5 \mathrm{~h}$ anoxia, and $1.11 \pm 0.02$ for $20 \mathrm{~h}$ anoxia. Heart showed no change in relative $5 \mathrm{mC}$ content. 


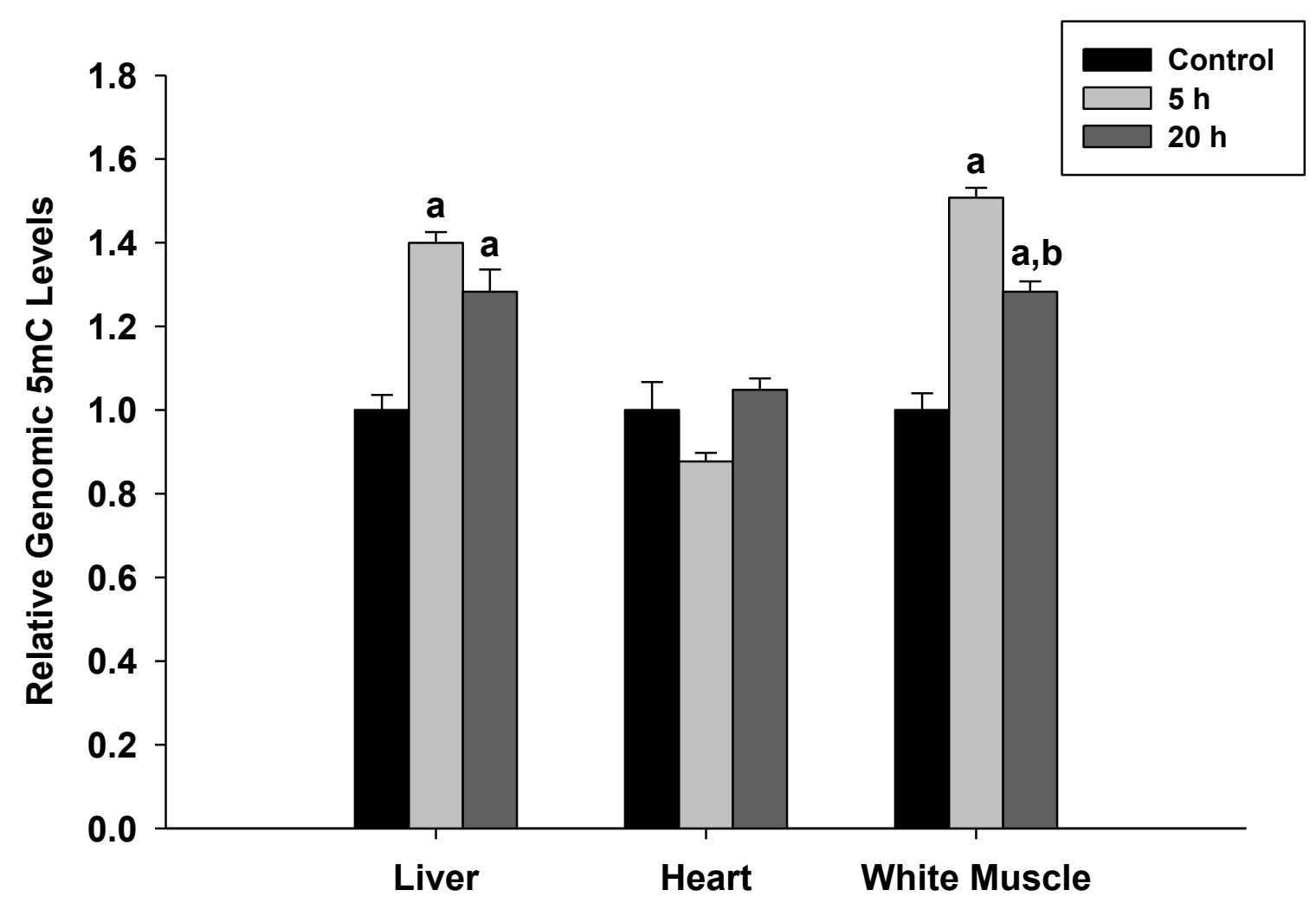

Figure. 5 Relative levels of global DNA methylation (5-mC content) in liver, heart, and white muscle of $T$. s. elegans as determined by MethylFlash Methylated DNA colorimetric quantification kit from Epigentek. Other information as in Figure 1. Reprinted with permission from Springer.

\section{Discussion}

Most organisms can withstand unfavorable environmental conditions such as high or low temperature, dehydration, or lack of food for short periods of time. However, due to the importance of oxygen-based metabolism for generating ATP, oxygen deprivation is a lethal stress that only a handful of vertebrates can endure for extended periods of time. Freshwater turtles belonging to the genera Trachemys (sliders) and Chrysemys (painted turtles) represent the extreme of anoxia tolerance among terrestrial vertebrates and can withstand as much as three months of anoxic submergence at $3^{\circ} \mathrm{C}$ and recover with little 
or no metabolic damage (Ultsch and Jackson 1982; Ultsch 1985, 2006; Hermes-Lima and Zenteno-Savin 2002; Jackson 2002).

Red-eared sliders (T. s. elegans), the experimental model of this paper, use an array of physiological responses at the onset of hypoxia in an attempt to compensate for the drop in oxygen availability, such as increasing lung ventilation, releasing more red blood cells from the spleen, alterations to hemoglobin affinity for oxygen, an overall increase in cardiac output, and resorting to alternative modes of oxygen uptake across the epithelia of cloacal and/or buccopharrygeal cavities (Lutz and Storey 1997; Jackson 2002). However, if blood oxygen levels continue to decline and are not quickly remediated, these physiological responses fall short in meeting tissue ATP demands and then biochemical mechanisms are implemented to deal with long-term anoxia. These include: (1) a significant reduction in metabolic rate (ie. ATP demand) to as low as 10$20 \%$ of the corresponding aerobic rate at the same temperature by suppressing the activities of many metabolic processes (e.g. ion-motive ATPases, cell cycle, protein translation, gene expression) (Storey 2007), and (2) a switch to dependence on glycolytic ATP production supported by high glycogen reserves in liver, and (3) acid buffering by release of biocarbonate from the shell and lactate storage into the calciferous shell (Jackson and Heisler 1982; Jackson et al. 2000) that allows turtles to tolerate lactate buildup as high as $150-200 \mathrm{mM}$ in plasma.

Various studies have examined transcriptional regulation during anoxia-induced hypometabolism in turtles from the point of view of altered expression of transcription factors (e.g. NF-кB, ChREBP, FoxO, HIF-1) and genes under their control (Biggar et al., 2011; Krivoruchko and Storey, 2010b, 2013, 2014). Global controls on transcriptional 
activity via changes in histone acetylation and HDAC expression have also been reported (Krivoruchko and Storey, 2010a). However, the use of DNA methylation as a means of anoxia-induced transcriptional suppression in turtles has not previously been investigated. The present study examined genomic 5-methyl cytosine levels, DNMT enzymatic activity, and the protein expression levels of DNMTs and MBDs to show that changes in DNA methylation patterns are a previously unrecognized response to anoxia in turtle organs and represent a new regulatory mechanism to be considered in stress-induced metabolic rate depression.

In multicellular eukaryotes, DNA methylation is restricted to cytosine residues on genomic DNA and is often associated with a rigid chromatin state (heterochromatin) and inhibition of gene expression (Bird and Wolffe 1999; Klose and Bird 2006). There are two main mechanisms by which DNA methylation represses gene expression; (1) covalent modifications to the fifth position of cytosine directly prevent the association and binding of the transcriptional unit to promoter sequences through steric hindrance (Watt and Malloy 1998), and (2) 5-mC attracts methyl-CpG-binding proteins (MBD1-4) to the methylated promoter sequences and thereby indirectly represses gene expression (Boyes and Bird 1991). Furthermore, MBDs recruit and target chromatin remodeling corepressors to methylated regions on the DNA and silence gene expression (Jones et al. 1998; $\mathrm{Ng}$ et al. 1999).

Relative genomic 5-methyl cytosine levels increased by 1.3-1.5 fold in liver and white muscle of red-eared sliders in response to $5 \mathrm{~h}$ and $20 \mathrm{~h}$ anoxic submergence (Figure 5). Correlated with this, protein expression levels of MBD1 and MBD2 were observed to increase 2-3 fold in liver and MBD1 increased by 1.5 fold in white skeletal muscle 
(Figure 1 and 3). These results are consistent with the creation of an overall repressive chromatin state and probable down regulation of the expression of many genes under anoxic conditions in liver and white muscle.

DNA methylation is mediated by DNA methyltransferases (DNMTs) with four isozymes known in vertebrates: DNMT 1, 2, 3a and 3b. Changes in DNMT protein expression and activity added further support for an overall suppression of transcriptional activity during turtle anoxia. Total DNMT activity increased by 1.7-2.4 fold in liver and white muscle, correlated with the increase in 5-mC levels in these two tissues. The changes in total DNMT activity were well supported by the up-regulation of DNMT protein expression in all three organs although organ-specific expression patterns of the DNMT isozymes were evident. Liver showed a robust increase in DNMT1 and DNMT2 expression levels in response to short term anoxia exposure but no increase in DNMT3a or 3b (Figure 1), whereas white muscle showed 3-4 fold increase in DNMT3a and 3b expression with no increase in DNMT1 or 2 (Figure 3). The lack of change in DNMT1 expression in white muscle may be a reflection of the post-mitotic, non-proliferative state of muscle (Biggar and Storey 2012). The neck retractor muscle is a fast-twitch, mainly glycolytic muscle with low numbers of mitochondria and used mainly for rapid movements of the neck. Since DNMT1 has been shown to localize to DNA replication foci during the $\mathrm{S}$ phase of the cell cycle and is known to selectively methylate hemimethylated $\mathrm{CpG}$ dinucleotides to copy pre-existing methylation patterns onto newly synthesized DNA (Sharif et al. 2007; Avvakumov et al. 2008), it is perhaps not surprising that there was no significant response to anoxia by this enzyme in white muscle where little, if any, cell cycle activity would be expected, especially under anoxia. Overall, white 
muscle seems to exclusively utilize the de novo methyltransferases DNMT3a and DNMT3b to methylate genomic DNA in response to anoxic exposure.

On the other hand, liver is a proliferative tissue, the largest organ in the turtle body, vital to the biosynthetic needs of the animal, and contains the majority of the glycogen reserves needed to sustain energy metabolism under anoxia. Turtle liver hepatocytes (from C. picta bellii) have been shown to respond robustly to anoxia with a 90\% reduction in metabolic rate compared to normoxic hepatocytes (Buck et al. 1993). Limiting energy expenditure is important for long-term anoxia survival and the present data indicate that liver is utilizing the actions of DNMT1, MBD1, and MBD2 and possibly DNMT2 to implement methylation. DNMT1 and genomic 5-mC marks are known to interact with and recruit chromatin modifiers such as histone deacetylase 1 (HDAC1) to increase chromosome condensation and suppress gene expression (Jones et al. 1998). Interestingly, Krivoruchko and Storey (2010a) showed a significant increase in $\mathrm{HDAC} 1$ transcripts and protein levels in the liver of red-eared sliders after $5 \mathrm{~h}$ anoxia along with a 25\% decrease in histone $\mathrm{H} 3$ acetylation at Lys 9 and 23 (indicative of increased chromatin compaction under anoxia).

By contrast, heart showed less evidence of genome silencing via DNA methylation during anoxia with no significant change in 5-mC levels and a significant increase for only MBD1 at $20 \mathrm{~h}$. In addition, cardiac muscle showed no significant increase in total DNMT enzymatic activity and restricted changes in DNMT protein levels (Figure 2 and 4). Heart has an important role to play under anoxia in order to continue circulation of remaining oxygen to key tissues (e.g. brain) for as long as possible, as well as to distribute anaerobic fuel (glucose) and remove anaerobic end 
product (lactate) from organs over the duration of the anoxic period. The heart of diving turtles exhibits 10-fold higher cardiac glycogen levels than in other terrestrial vertebrates and approximately five-fold higher than in diving mammals such as the seal and cardiac glycogen can be used as a source of hexose units during long-term anoxia (Beall and Privitera 1973; Storey 1975). In addition, a study on lactate dehydrogenase (LDH) kinetics have shown that anoxic-tolerant turtle heart LDH can function more efficiently by increasing the affinity of LDH for pyruvate during anaerobic conditions (Beall and Privitera 1973). Hence, heart may not experience a strong repression of gene expression compared to liver and white skeletal muscle during anaerobic conditions in the turtle and may continue to function.

Overall, the present study provides the first evidence that DNA methylation and its regulators, DNA methyltransferases and methyl-binding proteins, are differentially regulated during $5 \mathrm{~h}$ and $20 \mathrm{~h}$ of anoxic exposure in a tissue-specific manner. An overall stringency in chromatin compaction and a significant down-regulation in gene expression in liver and white muscles correlates with a global state of metabolic arrest that supports long term anoxia survival in turtles. DNA methylation could potentially be used as a gene regulatory mechanism not only during the early entrance phase in the hypometabolic response to anoxia but it could also be used in the maintenance phase in which global suppression of transcription and translation is stringently enforced. One of the most important feats at a time of low/no oxygen availability is to conserve ATP as much as possible, and red-eared sliders are potentially using DNA methylation and its regulator proteins to facilitate the strong suppression of gene expression when oxygen is limiting. 


\section{References}

Alexandrov A, Chernyakov I, Gu W, Hiley SL, Hughes TR, Grayhack EJ, Phizicky EM (2006) Rapid tRNA decay can result from lack of nonessential modifications. Mol Cell 21: 87-96.

Avvakumov GV, Walker JR, Xue S, Li Y, Duan S, Bronner C, Arrowsmith CH, DhePaganon S (2008) Structural basis for recognition of hemi-methylated DNA by the SRA domain of human UHRF1. Nature 455: 822-825.

Barlow DP (1993) Methylation and imprinting: from host defense to gene regulation? Science 260: 309-310.

Beall R, Privitera C (1973) Effects of cold exposure on cardiac metabolism of the turtle Chrysemys picta. Am J Physiol 224: 435-441.

Bestor TH, Tycko B (1996) Creation of genomic methylation patterns. Nat Genet 12: 363-367.

Biggar KK, Groom, AG, Storey KB (2011) Hypometabolism and turtles: physiological and molecular strategies of anoxic survival. In: Nowakowska A, Caputa M (ed.), Hypometabolism: Strategies of Survival in Vertebrates and Invertebrates, Research Signpost, Kerala, India, pp 57-94.

Biggar KK, Storey KB (2012) Evidence of cell cycle suppression and microRNA regulation of cyclin D1 during anoxia exposure in turtles. Cell Cycle 9:1705-1713.

Bird A (2002) DNA methylation patterns and epigenetic memory. Genes Dev 16: 621.

Bird AP, Wolffe AP (1999) Methylation-induced repression belts, braces, and chromatin. Cell 99: 451-454.

Bogdanovic O, Veenstra JC (2009) DNA methylation and methyl-CpG binding proteins: developmental requirements and function. Chromosoma 118: 549-565.

Boyes J, Bird A (1991) DNA methylation inhibits transcription indirectly via a methylCpG binding protein. Cell 64: 1123-1134.

Boutilier R, Donohoe P, Tattersall G, West T (1997) Hypometabolic homeostasis in overwintering aquatic amphibians. J Exp Biol 200: 387-400.

Buck LT, Land SC, Hochachka PW (1993) Anoxia-tolerant hepatocytes: model system for study of reversible metabolic suppression. Am J Physiol 265: 49-56. 
Calvanese V, Lara E, Kahn A, Fraga MF (2009) The role of epigenetics in aging and agerelated diseases. Ageing Res Rev 8: 268-276.

Chiacchiera F, Piunti A, Pasini D (2013) Epigenetic methylations and their connections with metabolism. Cell Mol Life Sci 70: 1495-1508.

Fraser K, Houlihan D, Lutz DP, Leone-Kabler S, Manuel L, Brechin J (2001) Complete suppression of protein synthesis during anoxia with no post-anoxia protein synthesis debt in the red-eared slider turtle Trachemys scripta elegans. J Exp Biol 204: 4353-4360.

Grewal SIS, Moazed D (2003) Heterochromatin and epigenetic control of gene expression. Science 301: 798-802.

Goll MG, Bestor TG (2005) Eukaryotic cytosine methyltransferases. Annu Rev Biochem 74: 481-514.

Goll, MG, Kirpekar F, Maggert KA, Yoder JA, Hsieh CL, Zhang X, Golic KG, Jacobsen SE, Bestor TH (2006) Methylation of tRNAAsp by the DNA methyltransferase homolog Dnmt2. Science 311: 395-398.

Herbert CV, Jackson DC (1985) Temperature effects on the responses to prolonged submergence in the turtle Chrysemys picta bellii. II. Metabolic rate, blood acid-base and ionic changes, and cardiovascular function in aerated and anoxic water. Physiol Zool 58: 670-681.

Hermes-Lima M, Zenteno-Savin T (2002) Animal response to drastic changes in oxygen availability and physiological oxidative stress. Comp Biochem Physiol C Toxicol Pharmacol 133: 537-556.

Hochachka PW, Buck LT, Doll CJ, Land SC (1996) Unifying theory of hypoxia tolerance: molecular/metabolic defense and rescue mechanisms for surviving oxygen lack. Proc Natl Acad Sci USA 93: 9493-9498.

Jackson DC (2002) Hibernating without oxygen: physiological adaptations of the painted turtle. J Physiol 543: 731-737.

Jackson DC, Heisler N (1982) Plasma ion balance of submerged anoxic turtles at $3^{\circ} \mathrm{C}$ : the role of calcium lactate formation. Respir Physiol 49: 159-174.

Jackson DC, Crocker CE, Ultsch GR (2000) Bone and shell contribution to lactic acid buffering of submerged turtles Chrysemys picta bellii at $3^{\circ} \mathrm{C}$. Am J Physiol Regul Integr Comp Physiol 278: 1564-1571.

Jeltsch A, Nellen W, Lyko F (2006) Two substrates are better than one: dual specificities for DNMT2 methyltransferases. Trends Biochem Sci 31: 306-308. 
Jones PL, Veenstra GJ, Wade PA, Vermaak D, Kass SU, Landsberger N, Strouboulis J, Wolffe Klose RJ, Bird AP (2006) Genomic DNA methylation: the mark and its mediators. Trends Biochem Sci 31: 89-97.

Krivoruchko A, Storey KB (2010a) Epigenetics in anoxia tolerance: a role for histone deacetylases. Mol Cell Biochem 342: 151-161.

Krivoruchko A, Storey KB (2010b) Molecular mechanisms of turtle anoxia tolerance: a role for NF-kappaB. Gene 450: 63-69.

Krivoruchko A, Storey KB (2013) Anoxia-responsive regulation of the FoxO transcription factors in freshwater turtles, Trachemys scripta elegans. Biochim Biophys Acta 1830: 4990-4998.

Krivoruchko A, Storey KB (2014) Activation of the carbohydrate response element binding protein (ChREBP) in response to anoxia in the turtle (Trachemys scripta elegans). Biochim Biophys Acta 1840: 3000-3005.

Lutz PL, Storey KB (1997) Adaptations to variations in oxygen tension by vertebrates and invertebrates. In: Dantzler WH (ed), Handbook of Physiology, section 13, Comparative Physiology, Vol. 2, Oxford University Press, Oxford, 1479-1522.

Lutz PL, Milton SL (2004) Negotiating brain anoxia survival in the turtle. J Exp Biol 207: 3141-3147.

Macaluso M, Montanari M, Cinti C, Giordano A (2005) Modulation of cell cycle components by epigenetic and genetic events. Semin Oncol 32: 452-457.

Ng HH, Zhang Y, Hendrich B, Johnson CA, Turner BM, Erdjument-Bromage H, Tempest P, Reignberg D, Bird A (1999) MBD2 is a transcriptional repressor belonging to the MeCP1 histone deacetylase complex. Nat Genet 1: 58-61.

Okano, M., Xie, S., and Li, E (1998) Cloning and characterization of a family of novel mammalian DNA (cytosine-5) methyltransferases. Nat Genet. 19: 219-220.

Okano, M, Bell DW, Haber DA, Li E (1999) DNA methyltransferases Dnmt3a and Dnmt $3 b$ are essential for de novo methylation and mammalian development. Cell 99: 247-257.

Ramsahoye BH, Biniszkiewics D, Lyko F, Clark V, Bird AP, Jaenisch R (2000) NonCpG methylation is prevalent in embryonic stem cells and may be mediated by DNA methyltransferase 3a. Proc Natl Acad Sci USA 97: 5237-5242.

Rolfe, DF, Brown GC (1997) Cellular energy utilization and molecular origin of standard metabolic rate in mammals. Physiol Rev 77:731-758. 
Schaefer M, Pollex T, Hanna K, Tuorto F, Meusburger M, Helm M, Lyko F (2010) RNA methylation by Dnmt2 protects transfer RNAs against stress-induced cleavage. Genes Dev 24: $1590-1595$.

Sharif J, Muto M, Takebayashi S, Suetake I, A. Iwamatsu, T.A. Endo, J. Shinga, Y. Mizutani-Koseki, T. Toyoda, K. Okamura, S. Tajima, K. Mitsuya, M. Okano, H. Koseki. The SRA protein Np95 mediates epigenetic inheritance by recruiting DNMT1 to methylated DNA. Nature 7171: 908-912.

Storey KB (1975) Purification and properties of turtle heart creatine kinase: role for the enzyme in glycolytic control. Int J Biochem 6: 53-59.

Storey KB (2007) Anoxia tolerance in turtles: Metabolic regulation and gene expression. Comp. Biochem Physiol A 147: 263-276.

Storey KB, Storey JM (2007) Tribute to P.L. Lutz: putting life on 'pause'- molecular regulation of hypometabolism. J Exp Biol 210: 1700-1714.

Storey KB, Storey JM (1990) Metabolic rate depression and biochemical adaptation in anaerobiosis, hibernation and estivation. Q Rev Biol 65: 145-174.

Ultsch GR (1985) The viability of Nearctic freshwater turtles submerged in anoxia and normoxia at 3 and $10^{\circ} \mathrm{C}$. Comp Biochem Physiol A 3: 607-611.

Ultsch GR (2006) The ecology of overwintering among turtles: where turtles overwinter and its consequences. Biol Rev 81: 339-367.

Ultsch GR, Jackson DC (1982) Long-term submergence at $3^{\circ} \mathrm{C}$ of the turtle, Chrysemys picta bellii, in normoxic and severely hypoxic water: survival, gas exchange and acidbase status. J. Exp Biol 96: 11-28.

Van der Maarel SM (2008) Epigenetic mechanisms in health and disease. Ann Rheum Dis 67: $97-100$.

Waddington CH (1942) Canalization of development and the inheritance of acquired characters. Nature 150: 563-565.

Watt F, Molloy PL (1998) Cytosine methylation prevents binding to DNA of HeLa cell transcription factor required for optimal expression of the adenovirus major late promoter. Genes Dev 2: 1136-1143.

Wolffe AP, Matzke MA (1999) Epigenetics: regulation through repression. Science 286: 481-486. 
CHAPTER 3 


\title{
Demethylate that DNA! \\ Dynamic regulation of TET-mediated DNA demethylation in response to anoxia tolerance in a freshwater turtle, Trachemys scripta elegans
}

\author{
Sanoji Wijenayake ${ }^{\mathrm{a}}$ and Kenneth B Storey ${ }^{\mathrm{a}^{*}}$
}

a - Institute of Biochemistry, Department of Biology, Carleton University, 1125 Colonel By Drive, Ottawa, ON, K1S 5B6, Canada.

\section{*Corresponding author:}

Kenneth B. Storey

Professor of Biochemistry

Canada Research Chair in Molecular Physiology

Institute of Biochemistry, Department of Biology, and Department of Chemistry

1125 Colonel By Drive, Ottawa, ON. Canada. K1S 5B.

E-mail address: Kenneth storey@carleton.ca

Tel: 1-613-520-3678; Fax: 1-613-520-3749

This manuscript will be submitted for publication in 2019 to the journal Epigenetics. 


\begin{abstract}
Similar to DNA methylation, DNA demethylation via ten-eleven translocation (TET) family of proteins is an important facet of transcriptional regulation that is involved in cancer, neurological and metabolic disorders, aging, genomic immunity, and cell identity. However, the potential role of DNA demethylation in facilitating anoxia tolerance and survival in a terrestrial vertebrate, such as the red-eared slider (Trachemys scripta elegans), is yet to be explored. Red-eared sliders are champion anaerobes that can withstand three continuous months of anoxic exposure at $3{ }^{\circ} \mathrm{C}$ by utilizing a variety of physiological and biochemical strategies, with metabolic rate depression being the most important contributor. Red-eared sliders can decrease their metabolic rate by $90 \%$ in response to anoxia by primarily employing a state of global transcriptional repression along with transcriptional activation of a few genes. As such, the main aim of this study was to determine whether DNA demethylation is a potential contributor of the coordinated transcriptional activation and repression that is associated with metabolic rate depression in the liver, white muscle, and heart of red-eared sliders over control, $5 \mathrm{~h}$, and $20 \mathrm{~h}$ anoxic exposures $(\mathrm{n}=4)$. Western immunoblotting, DNA dot blotting, and commercially available enzymatic activity assays were used for the analysis. Overall, DNA demethylation, a genomic mark of active transcription, decreased in the liver and white muscle, potentially as part of the global suppression of gene expression, whereas heart illustrated limited TET-mediated DNA demethylation.
\end{abstract}

\title{
Keywords
}

Anoxia, DNA demethylation, TETs, transcriptional repression, metabolic rate depression, T.s. elegans 


\section{Introduction}

DNA cytosine methylation was long considered to be a very stable epigenetic mark with well-established roles in early development, cellular identity, disease and cancer regulation, genomic immunity, gene expression, as well as aging (Bestor et al., 2015; Bestor and Coxon, 1993; Bird, 2002; Jaenisch and Bird, 2003; Smith and Meissner, 2013; Suzuki and Bird, 2008). Although the main enzymes that are responsible for catalyzing 5-methylcytosine $(5 \mathrm{mC})$ modification such as DNA methyltransferases (DNMTs) as well as methyl-binding proteins (MBDs) have been thoroughly investigated, the mechanistic understanding behind target-specific DNA demethylation remained elusive until very recently. In the past, demethylation of $5 \mathrm{mC}$ was believed to occur passively through DNA replication, however target-specific as well as global DNA demethylation that occur during two waves of global epigenetic reprogramming as well as in response to external stimuli and environmental stress could not be explained by a passive demethylation process (Wu and Zhang, 2011). In 2009, a novel methyl cytosine variant, 5-hydroxymethylcytosine $(5 \mathrm{hmC})$, was recognized as an enzymatically derived modification of 5mC in mammalian DNA (Kriaucionis and Heintz, 2009; Tahiliani et al., 2009) and the Ten-Eleven-Translocation 1 (TET1) protein was identified to catalyze the oxidation of $5 \mathrm{mC}$ to $5 \mathrm{hmC}$ depending on the availability of cofactors, such as $\mathrm{Fe}(\mathrm{II})$ and 2-ketogluterate (Tahiliani et al., 2009). Soon thereafter, TET2 and TET3 was identified to have similar DNA hydroxylating properties as TET1 (Ito et al., 2010b). TET1 and 3 contain a conserved $\mathrm{CXXC}$ domain that has high affinity for clustered unmethylated $\mathrm{CpG}$ dinucleotides and a catalytic domain that has high affinity for Fe(II) and 2-oxogluterate (2OG) (Shinsuke Ito et al., 2011; Wu and Zhang, 2011). TET1-3 has the ability to oxidize 
$5 \mathrm{mC}$ into $5 \mathrm{hmC}$ and continue the reaction to form 5-formylcytosine (5fC) and 5carboxylcytosine $(5 \mathrm{caC})$ in a step-wise manner (Shinsuke Ito et al., 2011). Finally, thymine-DNA glycosylase (TDG) has been shown to catalyze the final step of the demethylation pathway by recognizing and excising either $5 \mathrm{fC}$ or $5 \mathrm{caC}$ from the DNA (Shen et al., 2013) followed by base-excision repair (BER) that substitutes the missing site with an unmodified cytosine residue. Together, TET1-3 driven oxidation of $5 \mathrm{mC}$ may provide an effective mechanistic route to regulate DNA replication-independent, targetspecific DNA demethylation in the cell, in response to external stimuli and environmental stress such as high and low temperatures, lack of food, dehydration, as well as oxygen deprivation.

Most terrestrial vertebrates are hypersensitive to oxygen deprivation due to oxygen's fundamental role as the final acceptor of electrons in the electron transport chain (ETC). As such, oxygen is considered to be the main driver of oxidative phosphorylation, the main metabolic hub that can generate ATP from catabolizing macromolecules such as fatty acids, proteins, and complex carbohydrates (Hochachka and Lutz, 2001a; K. Storey and Storey, 2004a). Although oxygen deprivation can be detrimental to most animals, some have evolved effective defense strategies against anoxia (absolute lack of oxygen) (P. W. Hochachka, 1986). Amongst terrestrial vertebrates, anoxia tolerance is well established in freshwater turtles belonging to Chrysemys and Trachemys genera (Storey, 2007, 1996; Storey and Storey, 2007). In particular, the red-eared slider (Trachemys scripta elegans) is a unique facultative anaerobe that can tolerate short-term anoxia that is typically associated with apnoic dives in search of food, and very-long term anoxia that is typically associated with months of 
winter hibernation at the bottom of ice-locked ponds (Hochachka, 1988; Hochachka and Lutz, 2001a; Storey, 2007). Red-eared sliders employ various physiological and biochemical adaptations to survive anoxia including increase glycogen storage in the liver, muscle, and heart (P. W. Hochachka, 1986; Hochachka and Lutz, 2001a), prevent lactate acidosis by using the shell to release calcium and magnesium ions into the extracellular fluid, storing lactate in the shell (DC. Jackson et al., 2000; Jackson, 1997; Jackson et al., 1999, 2006b; Jackson and Heisler, 1983), enhance cytoprotective mechanisms to limit reactive oxygen species (ROS)-induced cellular damage (HermesLima et al., 2001; Krivoruchko and Storey, 2010a, 2010b, 2010c; Willmore and Storey, 1997), and most importantly strongly reduce the overall metabolic rate to $<10 \%$ compared to normoxic, control conditions in order to balance the discrepancy between ATP usage and ATP production (Hochachka, 1988; Jackson, 1968, 2000, Storey, 2007, 1996; K. Storey and Storey, 2004a; Storey and Storey, 1990b).

The molecular basis of metabolic rate depression (MRD) is a controlled and coordinated suppression of most ATP-utilizing cellular processes and reprioritization of ATP to drive cellular processes that are necessary for anoxia survival (Storey, 1996; K. Storey and Storey, 2004a; Storey and Storey, 1990b). Red-eared sliders have been shown to employ various molecular mechanisms to maintain and regulate MRD during extended periods of oxygen deprivation including transcriptional regulation through transcription factors (Krivoruchko and Storey, 2013b, 2010c; Zhang et al., 2013a), post-transcriptional regulation through miRNA (Biggar and Storey, 2011, 2015, 2012b, 2014), and posttranslational regulation of key transcription factors and metabolic enzymes (Brooks and Storey, 1989; SPJ Brooks and Storey, 1993; Duncan and Storey, 1992; Greenway and 
Storey, 2000; Mehrani and Storey, 1995a, 1995b; Xiong and Storey, 2012). However, recent studies by (Krivoruchko and Storey, 2010d; Sanoji Wijenayake and Storey, 2016) have reported DNA methylation and histone deacetylation through HDAC (histone deacetylase) proteins as alternate yet fundamental modes of transcriptional regulation in red-eared sliders in response to short and long-term anoxia. However, the role of DNA demethylation, catalyzed by TET family of DNA demethylases in regulating global as well as target-specific gene expression during anaerobiosis warrants further study.

The current paper explores the expression of TET family of DNA demethylases along with TDG DNA repair enzyme, genomic expression levels of three methyl-cytosine variants $(5 \mathrm{hmC}, 5 \mathrm{fC}$, and $5 \mathrm{caC}$ ) that are part of the DNA demethylation pathway, as well as total enzymatic activity of TETs in T.s. elgans liver, white skeletal muscle, and heart tissues in response to control, $5 \mathrm{~h}$, and $20 \mathrm{~h}$ anoxic exposure. To our knowledge, this is the first study to provide insights into the potential role of DNA demethylation in regulating MRD and anoxia tolerance in a terrestrial facultative anaerobe. Overall, the data indicates a significant repression of TET-mediated DNA demethylation in the liver and white skeletal muscle in response to anoxia, while the turtle heart showed limited TET regulation.

\section{Materials and Methods}

\section{Animal care and treatment}

Adult female red-eared sliders (Trachemys scripta elegans), weighing 700-1500 g, were acquired from local suppliers. Upon arrival at the laboratory, the animals were kept at $5 \pm 1{ }^{\circ} \mathrm{C}$ in large tubs filled with dechlorinated tap water for a minimum of seven days before starting the experiments. Four-five control, normoxic, turtles were randomly 
chosen and sampled from this condition. The remaining turtles were transferred to large tubs $\left(5 \pm 1{ }^{\circ} \mathrm{C}\right)$ containing water that had been previously bubbled with nitrogen gas for 1 h. Two-three turtles were added to each tub at 30 min intervals. The tubs were bubbled with nitrogen gas for $1 \mathrm{~h}$ after the last turtle was added. A wire mesh was fitted about 5 $\mathrm{cm}$ below the water surface to prevent turtles from breaching. Four-five turtles were randomly sampled at $5 \mathrm{~h}$ anoxia time point and the remaining 4-5 turtles were sampled at $20 \mathrm{~h}$ anoxia time point. Note: All turtles survived the $5 \mathrm{~h}$ and $20 \mathrm{~h}$ anoxia treatments. All animals were killed by decapitation, the shell was opened, and liver, skeletal muscle, and heart were quickly dissected, immediately frozen in liquid nitrogen and stored in $-80{ }^{\circ} \mathrm{C}$ freezers for later use.

All animals were cared for in accordance to the guidelines of the Canadian Council on Animal Care based on the prior approval of Carleton University Animal Care Committee.

\section{Total protein extraction}

Total soluble protein was extracted from approximately $500 \mathrm{mg}$ of frozen liver, skeletal muscle, and heart by homogenizing in 1:2.5 (w:v) in $1 \mathrm{X}$ homogenization buffer (20 mM Hepes pH 7.5, $200 \mathrm{mM} \mathrm{NaCl}, 0.1 \mathrm{mM}$ EDTA, $10 \mathrm{mM} \mathrm{NaF}, 1 \mathrm{mM} \mathrm{Na}_{3} \mathrm{VO}_{4}, 10$ $\mathrm{mM} \beta$-glycerophosphate) with $10 \mu \mathrm{L}$ of protease inhibitor cocktail (Bioshop; Catalog \#. PIC001) and a few crystals of phenylmethylsulfonyl fluoride (PMSF) using a Polytron homogenizer for $15 \mathrm{sec}$. Following homogenization, the samples were immediately placed on ice for $5 \mathrm{~min}$ and centrifuged for $15 \mathrm{~min}$ at $10,000 \mathrm{rpms}$ at $4{ }^{\circ} \mathrm{C}$. The supernatant was collected in new microcentrifuge tubes and soluble protein concentrations were measured using a BioRad protein assay (Catalog \#. 500-0006) with 
bovine serum albumin as a standard. All samples were normalized to a final concentration of $10 \mu \mathrm{g} / \mu \mathrm{L}$ and $6 \mu \mathrm{g} / \mu \mathrm{L}$ depending on the tissue and mixed 1:1 (v:v) with 2X-SDS loading buffer (100 mM Tris-base, 4 \% (w:v) SDS, $20 \%$ (v:v) glycerol, $0.2 \%$ (w:v) bromophenol blue, $10 \%$ (v:v) 2-mercaptoethanol). The final concentration of the liver samples was $5 \mu \mathrm{g} / \mu \mathrm{L}$ and $3 \mu \mathrm{g} / \mu \mathrm{L}$ for white skeletal muscle and heart. Finally, the sample tubes were placed in boiling water for $10 \mathrm{~min}$ to further denatured the proteins and stored for later use at $-40{ }^{\circ} \mathrm{C}$.

\section{Western immunoblotting}

Protein extracts of liver, skeletal muscle, and heart containing 20-35 $\mu \mathrm{g}$ of protein were loaded on to $8 \%$ SDS-polyacrylamide gels and resolved for $100 \mathrm{~min}$ at $180 \mathrm{~V}$ in $1 \mathrm{X}$ running buffer (75.5 $\mathrm{g}$ Tris-base, $460 \mathrm{~g}$ glycine, $25 \mathrm{~g}$ SDS, and $\mathrm{ddH}_{2} \mathrm{O}$ up to a final volume of 2.5 L) using a Mini-Protean System 3 electrophoresis system (Biorad; Catalog \#. 1658004). Five $\mu \mathrm{L}$ of BLUeye prestained high molecular weight protein ladder (Froggabio, Catalog \#. PM007-0500G) and $25 \mu \mathrm{g}$ of mammalian positive control (13lined ground squirrel liver, skeletal muscle, and heart) was run alongside the samples. Subsequently, the samples were electroblotted on to $0.45 \mu \mathrm{m}$ PVDF membranes (Millipore; Catalog \#. IPVH00010) in 1X transfer buffer (60.6 g Tris-base, $288 \mathrm{~g}$ glycine, $4 \mathrm{~L}$ methanol, $16 \mathrm{~L} \mathrm{ddH}_{2} \mathrm{O}$ ) at $160 \mathrm{~mA}$ for $960 \mathrm{~min}$ at $4{ }^{\circ} \mathrm{C}$ using Mini-Protean transfer cell (Biorad; Catalog \#. 1658004). The PVDF membranes were then washed 3 x 5 min in 1X TBST (10 mM Tri-base, $15 \mathrm{mM} \mathrm{NaCl,} \mathrm{0.05 \%} \mathrm{(v:v)} \mathrm{Tween-20,} \mathrm{pH} \mathrm{7.5)} \mathrm{and} \mathrm{blocked}$ with 5-10\% milk for $30 \mathrm{~min}$ or $1 \mathrm{mg} / \mathrm{mL}$ of high molecular weight polyvinyl alcohol (70$100 \mathrm{kDa}$ ) for $2 \mathrm{~min}$. Upon blocking, membranes were washed 3 x 5 min with $1 \mathrm{X}$ TBST 
and incubated with primary antibody (diluted $1: 1,000$ in $1 \mathrm{X}$ TBST) overnight at $4{ }^{\circ} \mathrm{C}$.

The three antibodies used in this analysis are as followed: TET1 (Genetex; Catalog \#. GTX124207), TET2 (Genetex; Catalog \#. GTX124205), and TDG1 (Genetex; Catalog \#. GTX110473). On the next day, the membranes were washed 3 x 5 min in 1X TBST and incubated with HRP-conjugated anti-rabbit IgG secondary antibody (Bioshop; Catalog \#. APA007P) diluted 1: $8000(\mathrm{v}: \mathrm{v})$ in 1X TBST for $40 \mathrm{~min}$ at room temperature. Target proteins were visualized using enhanced chemiluminescence (ECL) with hydrogen peroxide and a ChemiGenius Bio-imaging system (Syngene, Frederick, MD). In order to control for potential discrepancies in protein loading, the membranes were stained with Coommassie blue stain solution $(0.25 \%$ (w:v) Coomassie blue stain, $7.5 \%$ acetic acid, $50 \%$ (v:v) methanol) for 15 min and destained with destain solution (25\% (v:v) methanol and $\mathrm{ddH}_{2} \mathrm{O}$ ) for $5 \mathrm{~min}$ at room temperature. The Coomassie stained protein bands were similarly visualized using a ChemiGenius Bio-imaging system (Syngene, Frederick, MD) and were quantified using GeneTools software (Syngene, Frederick, $\mathrm{MD})$.

\section{Cytoplasmic and Nuclear Fractionation}

40-50 mg of frozen liver, white muscle, and heart were homogenized 1:5 (w:v) in pre-chilled 1X cytoplasmic extraction buffer (100 mM HEPES, $100 \mathrm{mM} \mathrm{KCl,} 100 \mathrm{mM}$ EDTA, $200 \mathrm{mM} \beta$-glycerolphosphate, pH 7.9 with $10 \mu \mathrm{L} / \mathrm{mL}$ of $100 \mathrm{mM}$ DTT and 10 $\mu \mathrm{L} / \mathrm{mL}$ of protease inhibitor cocktail (Bioshop; Catalog \# PIC001)) using a glass homogenizer with 3-4 gentle piston strokes. The samples were held on ice during homogenization and subsequently incubated on ice for $25 \mathrm{~min}$. The samples were then centrifuged at $12,000 \mathrm{rpms}$ for $15 \mathrm{~min}$ at $4^{\circ} \mathrm{C}$ and the supernatants were kept as the 
cytoplasmic fraction. The pellet containing intact nuclei were lysed with 1:5 (w:v) 5X nuclear extraction buffer (100 mM HEPES, $2 \mathrm{M} \mathrm{NaCl}, 5$ mM EDTA, 50 \% (v:v) glycerol, $100 \mathrm{mM} \beta$-glycerol phosphate, pH 7.9 with $10 \mu \mathrm{L} / \mathrm{mL}$ of $100 \mathrm{mM}$ DTT and $10 \mu \mathrm{L} / \mathrm{mL}$ of protease inhibitor cocktail (Bioshop; Catalog \# PIC001)). The nuclear samples were subsequently sonicated on high for $10 \mathrm{sec}$ and incubated on ice for $10 \mathrm{~min}$ to further increase nuclear protein extraction. The samples were centrifuged at $14,000 \mathrm{rpms}$ for 10 min at $4{ }^{\circ} \mathrm{C}$ and the supernatant was removed and kept as the nuclear fraction. Total soluble protein concentration of cytoplasmic and nuclear fractions was measured using BioRad protein assay (Catalog \#. 500-0006) with bovine serum albumin as the standard. The cytoplasmic and nuclear fractions were normalized to a final concentration of 5 $\mu \mathrm{g} / \mu \mathrm{L}$. Fifty $\mu \mathrm{L}$ aliquots of nuclear and cytoplasmic fractions were combined 1:1 (v:v) with 2X SDS loading buffer (100 mM Tris-base, $4 \%$ (w:v) SDS, $20 \%$ (v:v) glycerol, 0.2 $\%(\mathrm{w}: \mathrm{v})$ bromophenol blue, $10 \%(\mathrm{v}: \mathrm{v})$ 2-mercaptoethanol) to a final concentration of 2.5 $\mu \mathrm{g} / \mu \mathrm{L})$. Western immunoblotting was used to test the integrity of the cytoplasmic and nuclear fractions by probing for a protein that exclusively reside in the nucleus, histone H3 (Genetex; Catalog \#. GTX129546) diluted 1:1000 (v:v) in 1X TBST. Please refer to Appendix I for more information on old and new cytoplasmic and nuclear extraction protocols and testing.

\section{TET enzymatic activity assay}

Total enzymatic activity of TETs was measured using the Epigenase $5 \mathrm{mC}$ hydroxylase TET activity/inhibition assay kit (Epigentek; Catalog \#. P-3086) according to manufacturer's instructions. Liver, white skeletal muscle, and heart nuclear fractions were used for the assay. In brief, a standard curve was prepared by diluting TET assay 
standard, $20 \mu \mathrm{g} / \mathrm{mL}$ (provided with the kit) with TET assay buffer (provided with the kit) to an initial concentration of $2 \mathrm{ng} / \mathrm{mL}$ and further diluted to $0.05 \mathrm{ng} / \mathrm{mL}, 0.2 \mathrm{ng} / \mathrm{mL}, 0.5$ $\mathrm{ng} / \mathrm{mL}, 1.0 \mathrm{ng} / \mathrm{mL}$, and $2.0 \mathrm{ng} / \mathrm{mL}$. In order to determine the linear range of nuclear proteins needed for this assay, a dilution curve ranging from $2 \mu \mathrm{g}$ to $20 \mu \mathrm{g}$ of nuclear proteins from a pooled sample was run for each tissue. Based on the absorbance values generated for the dilution curves, $5 \mu \mathrm{g}, 10 \mu \mathrm{g}$, and $10 \mu \mathrm{g}$ of total nuclear proteins were used for liver, white muscle, and heart quantification runs respectively. The standard wells contained $50 \mu \mathrm{L}$ of diluted TET assay standard concentrations, blank wells contained $50 \mu \mathrm{L}$ of TET assay buffer, and test sample wells contained $1 \mu \mathrm{L}$ of liver nuclear extract, $2 \mu \mathrm{L}$ of white muscle, and $2 \mu \mathrm{L}$ of heart nuclear extracts and $48-49 \mu \mathrm{L}$ of TET assay buffer. The strip wells were covered with aluminum foil and incubated at 37 ${ }^{\circ} \mathrm{C}$ for 90 min on a plate shaker (50-100 rpm). Post incubation, the well contents were removed and the wells were washed three times with $150 \mu \mathrm{L}$ of $1 \mathrm{X}$ wash buffer $(10 \mathrm{X}$ stock was provided with the kit). The capture antibody, $1000 \mu \mathrm{g} / \mathrm{mL}$ (provided with the kit) was diluted at a ratio of 1:1000 with $1 \mathrm{X}$ wash buffer and $50 \mu \mathrm{L}$ was added to all wells. The strips were then covered with aluminum foil, and incubated at room temperature for $60 \mathrm{~min}$. The content was removed and the wells were washed three times with $150 \mu \mathrm{L}$ of $1 \mathrm{X}$ wash buffer. Detection antibody, $400 \mu \mathrm{g} / \mathrm{mL}$ (provided with the kit) was diluted at a ratio of 1:2000 with $1 \mathrm{X}$ wash buffer and $50 \mu \mathrm{L}$ was added to each well, covered with aluminum foil, and incubated at room temperature for $30 \mathrm{~min}$ on a plate shaker (50-100 rpm). The detection antibody was removed from each well and the wells were washed five times with $150 \mu \mathrm{L}$ of $1 \mathrm{X}$ wash buffer. Next, $100 \mu \mathrm{L}$ of developing solution (provided with the kit) was added to each well and the wells were incubated at 
room temperature for $10 \mathrm{~min}$ away from light. Finally, $50 \mu \mathrm{L}$ of stop solution (provided with the kit) was added to each well to stop the enzymatic reaction. The absorbance readings were measured within 5 mins using a microplate reader (Multiscan Spectrum, Thermo Labsystems) at $450 \mathrm{~nm}$.

The total TET activity was calculated using the following formulas;

$$
\text { Hydroxymethylated product }(n g)=\frac{(\text { Sample OD }- \text { Blank OD })}{\text { Slope } *}
$$

Where;

* Slope of the standard curve

$$
\text { TET Activity }\left(\frac{n g}{\frac{m i n}{m g}}\right)=\frac{\text { Hydroxymethylated Product }(n g)}{(\text { Protein Amount } *(u g) \times \min * *)} \times 1000
$$

Where;

*Amount of nuclear proteins in sample wells

**Incubation time

\section{Genomic extraction}

Total genomic DNA was extracted according to the manufacturer's instructions using Zymo Research, Quick gDNA Mini Prep kit (Catalog \#. D3050). In brief, 25-50 mg of frozen liver, white skeletal muscle, and heart incubated with $95 \mu \mathrm{l}$ of $\mathrm{H}_{2} \mathrm{O}, 95 \mu \mathrm{l}$ of $2 \mathrm{X}$ digestion buffer, and $10 \mu \mathrm{l}$ of proteinase $\mathrm{K}$ (provided with the kit) for $3 \mathrm{hr}$ in a $55^{\circ} \mathrm{C}$ water bath. Post incubation, $700 \mu 1$ of genomic lysis buffer (provided with the kit) was added to all sample tubes, vortexed for $30 \mathrm{sec}$ and centrifuged at 10,000 x g for $1 \mathrm{~min}$. The supernatant was then transferred to a Zymo-Spin ${ }^{\mathrm{TM}}$ IIC Column with a collection tube and centrifuged at 10,000 x g for $1 \mathrm{~min} .200 \mu \mathrm{l}$ of DNA pre-wash buffer (provided with the kit) was added to the spin column in a new collection tube and centrifuged again 
for $10,000 \mathrm{x}$ g for $1 \mathrm{~min} .400 \mu \mathrm{l}$ of gDNA wash buffer (provided with the kit) was added to the spin column and centrifuged at 10,000 $\mathrm{x} g$ for $1 \mathrm{~min}$. Lastly, the spin column was transferred to a new $1.5 \mathrm{~mL}$ microcentrifuge collection tube and $200 \mu \mathrm{l}$ of DNA elution buffer (provided with the kit) was added to the spin column. Samples were incubated at room temperature for $5 \mathrm{~min}$, centrifuged at $15,000 \mathrm{x}$ g for $30 \mathrm{sec}$ to elute the extracted and purified gDNA and stored at $-20{ }^{\circ} \mathrm{C}$ for further use. The DNA was quantified using a Gene-Quant Pro Spectrophotometer (Pharmacia) and the integrity and purity of the DNA was tested by running the samples on a $0.6 \%$ agarose gel at $130 \mathrm{~V}$ for $40 \mathrm{~min}$.

\section{DNA dot blots}

DNA dot blots were used to measure the genomic expression of $5 \mathrm{mC}$ variants. The extracted gDNA samples were normalized to a final concentration of $2 \mathrm{ng} / \mu \mathrm{L}$ and treated with an alkaline solution containing $0.4 \mathrm{M} \mathrm{NaOH} / 10 \mathrm{mM}$ EDTA (pH 8.2) solution and heated for $10 \mathrm{~min}$ in a water bath at $100{ }^{\circ} \mathrm{C}$. All samples were spun down after the alkaline/heat treatment. Positively charged $0.2 \mu \mathrm{M}$ nylon membranes (Biorad; Catalog \#. 9004-700) were hydrated with $10 \mathrm{~mL}$ of $\mathrm{ddH}_{2} \mathrm{O}$ for $10 \mathrm{~min}$ prior to use. Bio-Dot microfiltration manifold (Biorad; Catalog \#. 1706545) was used for the analysis according to manufacturer's instructions. In brief, hydrated nylon membranes were placed on the Bio-Dot gasket and prewashed with $500 \mu \mathrm{L}$ of $\mathrm{ddH}_{2} \mathrm{O}$ using vacuum filtration. A dilution range of $0 \mathrm{ng}$ to $400 \mathrm{ng}$ from pooled samples was tested per methyl-target and per tissue prior to running the quantification runs. A total of $100-150 \mu \mathrm{L}$ of DNA samples were carefully applied to the wells and allowed to filter through by gravity at room temperature for $6 \mathrm{hr}$. After the samples filtered through, the wells were washed with 500 $\mu \mathrm{L}$ of $0.4 \mathrm{M} \mathrm{NaOH}$ using vacuum filtration. The membranes were taken out of the Bio- 
Dot manifold and left to air dry for $5 \mathrm{~min}$ at room temperature and the DNA samples were cross-linked to the nylon membranes in an oven at $80{ }^{\circ} \mathrm{C}$ for $2 \mathrm{hr}$. Following the DNA crosslinking, the membranes were washed $3 \times 5 \mathrm{~min}$ in $2 \mathrm{X}$ SSCT $(3 \mathrm{M} \mathrm{NaCl}, 0.3 \mathrm{M}$ sodium-citrate, $0.05 \%$ Tween-20). The membranes were blocked with 5-10 \% milk diluted in 2X SSCT for $60 \mathrm{~min}$ at room temperature and subsequently washed $3 \times 5 \mathrm{~min}$ in 2X SSCT and incubated with primary antibody (diluted 1:7.500 (v/v) in 2X SSCT for $5 \mathrm{hmC}, 1: 2,500(\mathrm{v} / \mathrm{v})$ in $2 \mathrm{X} \mathrm{SSCT}$ for $5 \mathrm{fC}$, and 1:2,500 (v/v) in 2X SSCT for $5 \mathrm{caC})$ for 24 hr at $4{ }^{\circ} \mathrm{C}$. The three antibodies used in this analysis were purchased from Active Motif (5hmC $-39770 ; 5 f C-61224 ; 5 \mathrm{caC}-61226)$. Post primary antibody incubation, the membranes were washed $3 \times 5$ min with 2X SSCT and incubated with HRP-conjugated anti-rabbit IgG secondary antibody (Bioshop; Catalog \#. APA007P), diluted in 1:15,000 $(\mathrm{v} / \mathrm{v})$ in $2 \mathrm{X}$ SSCT for $40 \mathrm{~min}$ at room temperature. The membranes were visualized using enhanced chemiluminescence and detected using a Chemi-Genius Bio-Imaging System (Syngene, Frederick, MD). DNA methyl dot densities were quantified using Gene Tools

software. The membranes were stained with $1 \mathrm{X}$ methylene blue $(0.02 \%$ methylene blue in $1 \mathrm{X} \mathrm{TAE}$ ) for $10 \mathrm{~min}$ at room temperature in order to standardize the amount of DNA loaded to each test well. Finally, the membranes were destained with $20 \%$ ethanol solution $\left(20 \%\right.$ ethanol and $\left.80 \% \mathrm{ddH}_{2} \mathrm{O}\right)$ for $3 \mathrm{hr}$ and the dot intensities were similarly measured using the Gene Tools software.

\section{Quantification and Statistics}

Minor variations in protein loading for western immunoblotting was corrected for by normalizing the immunoblot band densities against the summed intensity of a group of Coomassie-stained protein bands that showed constant expression between control, $5 \mathrm{~h}$, 
and $20 \mathrm{~h}$ anoxia in the same lane without including the target band of interest. This method has been shown to be far superior in accounting for irregular protein loading when compared to using a single reference or house-keeping gene. Regarding DNA dot blots, methylene blue stain was used as the normalization method for discrepancies in DNA loading. All statistical analysis was performed using a one-way ANOVA with a Tukey post-hoc test $(\mathrm{p}<0.05)$ to compare three experimental conditions. Sigmaplot 11 software (Systat Softwaree Inc., San Jose, CA) was used for this analysis as well as construction of figures.

\section{Results}

The relative protein expression levels of TETs as well as the methylation levels of three DNA methyl-variants illustrated tissue-specific responses in T.s. elegans in response to control, $5 \mathrm{~h}$, and $20 \mathrm{~h}$ anoxic exposures. In the liver, TET2 protein expression significantly decreased by $0.57 \pm 0.03$ - fold in response to $5 \mathrm{~h}$ and decreased by $0.48 \pm$ 0.07-fold in response to $20 \mathrm{~h}$ anoxia, compared to the control (Figure 1). Whereas, TDG, a prominent regulator of DNA damage repair, significantly increased in expression by $2.05 \pm 0.26$-fold in response to $20 \mathrm{~h}$ anoxia compared to the control and remained unchanged in response to $5 \mathrm{~h}$ anoxia. Furthermore, TET1 protein expression remained unchanged in response to $5 \mathrm{~h}$ and $20 \mathrm{~h}$ anoxia (Figure 1). 


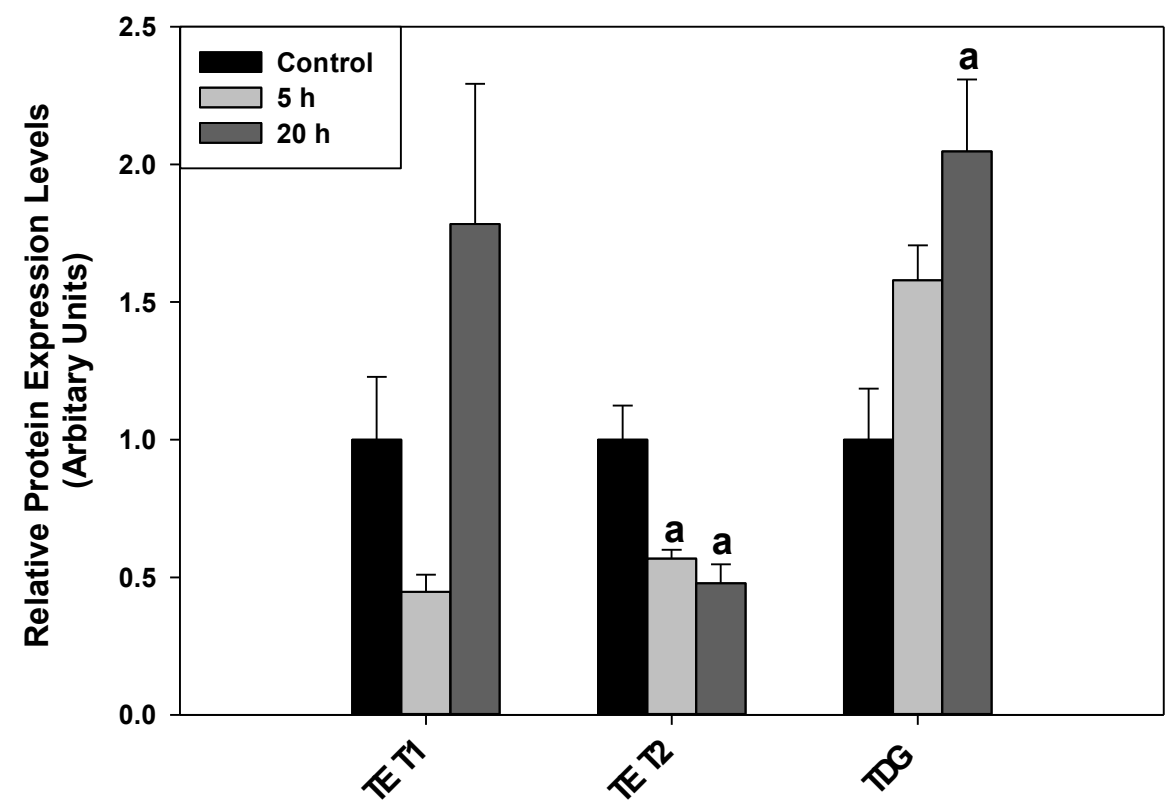

Control

$5 \mathrm{~h}$

$20 \mathrm{~h}$

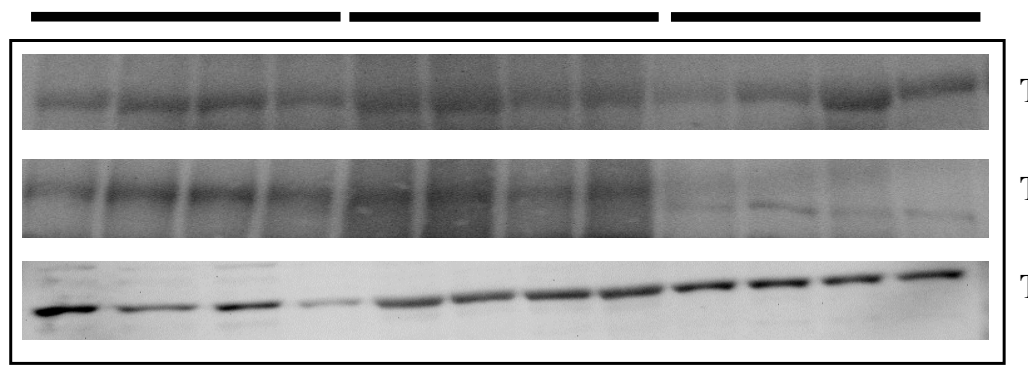

TET1

TET2

TDG

Figure 1. The relative protein expression levels of TET DNA demethylases and TDG in response to control $5 \mathrm{~h}$ anoxic, and $20 \mathrm{~h}$ anoxic submergence in the liver of T.s. elegans as determined by western immunoblotting. Data are mean \pm SEM and $n=3-4$ biological replicates. One-way ANOVA analysis of variance with a post-hoc Tukey test $(p<0.05)$ was used for data analysis. a significantly different from the control $(p<0.05)$; b significantly different from $5 \mathrm{~h}$ anoxia $(\mathrm{p}<0.05)$.

Genomic levels of $5 \mathrm{hmC}$ significantly decreased by $0.52 \pm 0.05$-fold during $5 \mathrm{~h}$ anoxia and continued to be decreased during $20 \mathrm{~h}$ anoxia by $0.48 \pm 0.02$-fold compared to the control in the liver (Figure 2). Additionally, genomic levels of $5 \mathrm{fC}$ significantly decreased by $0.47 \pm 0.05$ and $0.15 \pm 0.03$-fold during $5 \mathrm{~h}$ and $20 \mathrm{~h}$ anoxic exposure, 
respectively when compared to the control. The genomic levels of $5 \mathrm{caC}$ remained unchanged during $5 \mathrm{~h}$ and $20 \mathrm{~h}$ anoxia compared to the control, normoxic condition (Figure 2).

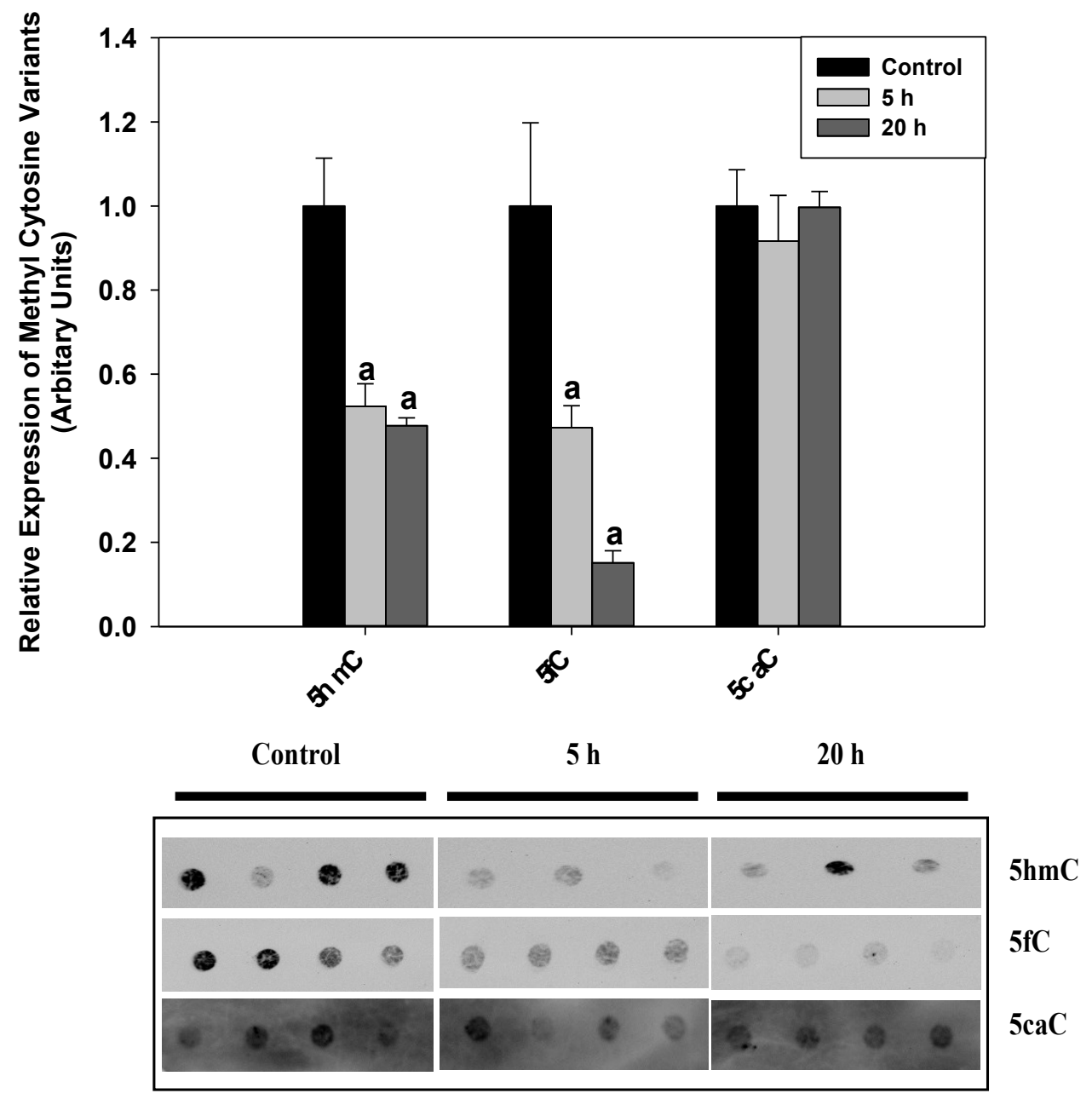

Figure 2. Relative expression levels of three methyl-variants of DNA demethylation in response to $5 \mathrm{~h}$ and $20 \mathrm{~h}$ anoxic exposure in the liver of T.s. elegans as determined by DNA dot blotting. Other information as in Figure 1.

In the white skeletal muscle, all three DNA demethylases examined significantly increased during $5 \mathrm{~h}$ anoxia when compared to control, normoxic conditions. TET1 increased in expression by $1.78 \pm 0.21$-fold, TET2 increased in expression by $2.99 \pm$ 
0.52-fold, and TDG increased in expression by $1.52 \pm 0.14$-fold compared to the control. Moreover, the expression levels of all three DNA demethylases returned to control levels during $20 \mathrm{~h}$ anoxia (TET1: $0.755 \pm 0.06$; TET2: $0.38 \pm 0.09$; TDG: $0.92 \pm 0.04$ ) (Figure $3)$.
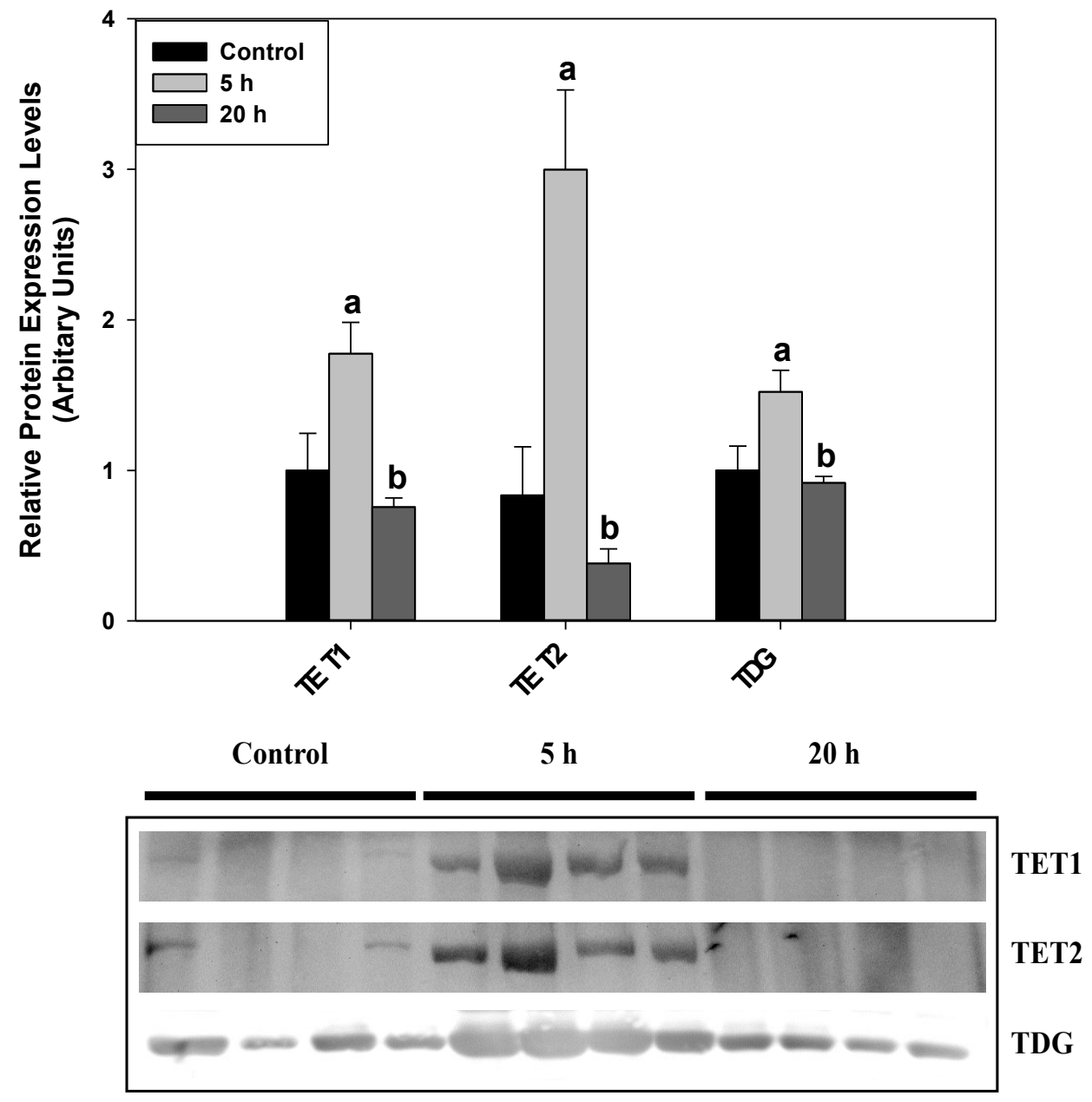

Figure 3. The relative protein expression levels of TET DNA demethylases and TDG in response to control $5 \mathrm{~h}$ anoxic, and $20 \mathrm{~h}$ anoxic submergence in the white skeletal muscle of T.s. elegans as determined by western immunoblotting. Other information as in Figure 1. 
However, the corresponding genomic modification levels of $5 \mathrm{hmC}$ significantly decreased by $0.71 \pm 0.01$ during $5 \mathrm{~h}$ anoxia and $0.544 \pm 0.15$ during $20 \mathrm{~h}$ anoxia compared to the control (Figure 4). A similar trend was seen with the genomic levels of $5 \mathrm{fC}$ in white muscle, in which $5 \mathrm{fC}$ levels decreased by $0.68 \pm 0.07$-fold and $0.74 \pm 0.02$ fold during $5 \mathrm{~h}$ and $20 \mathrm{~h}$ anoxia compared to the control. Levels of $5 \mathrm{caC}$ significantly decreased by $0.58 \pm 0.07$-fold during $20 \mathrm{~h}$ anoxia compared to the control but illustrated no change during $5 \mathrm{~h}$ anoxia.

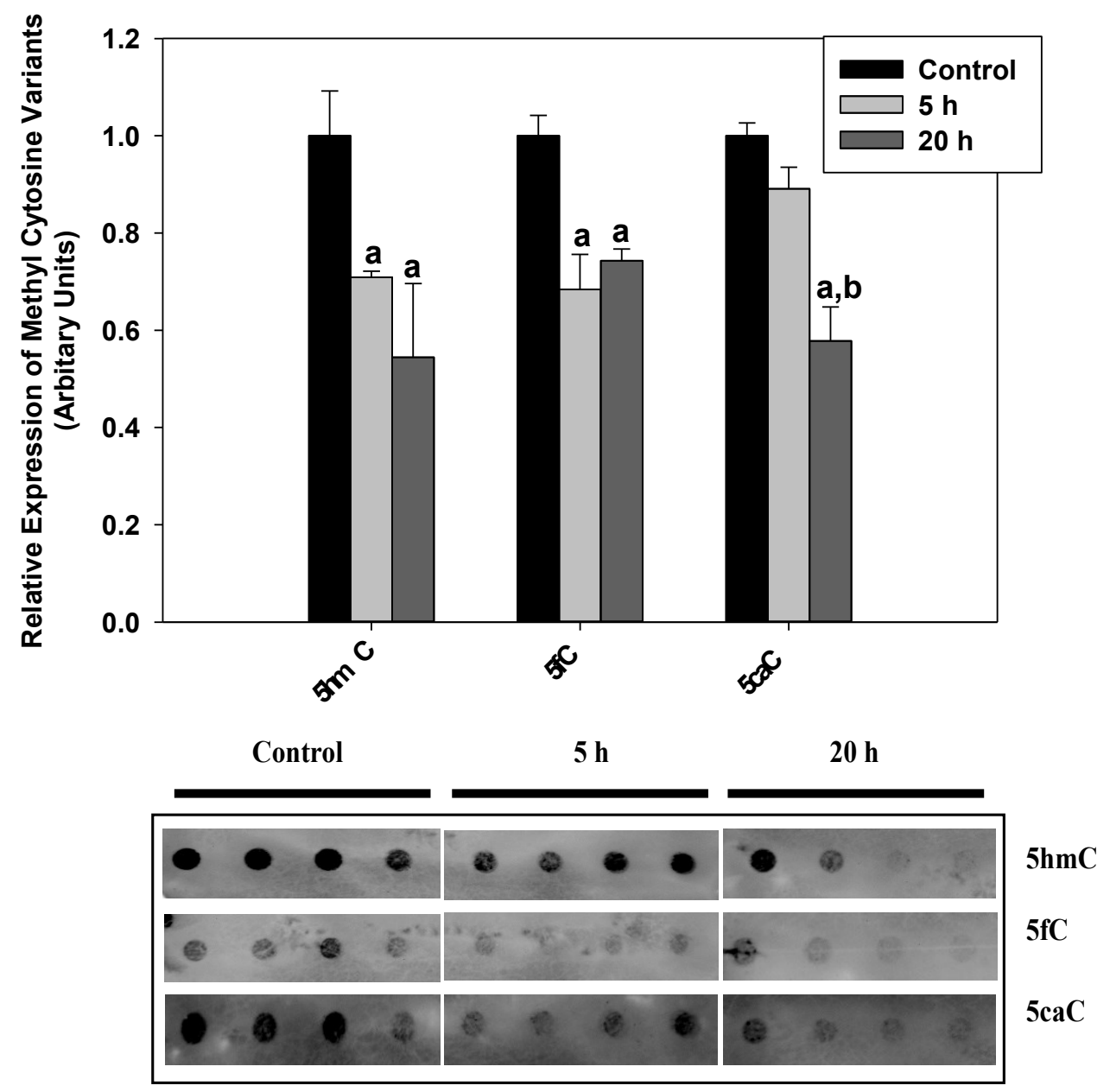


Figure 4. Relative expression levels of three methyl-variants of DNA demethylation in response to $5 \mathrm{~h}$ and $20 \mathrm{~h}$ anoxic exposure in the white skeletal muscle of T.s. elegans as determined by DNA dot blotting. Other information as in Figure 1.

In the heart, TET1 protein expression levels increased by $1.91 \pm 0.27$-fold during $5 \mathrm{~h}$ anoxic exposure and $1.65 \pm 0.11$-fold during $20 \mathrm{~h}$ anoxic exposure compare to the control, while TET2 protein expression remained unchanged during $5 \mathrm{~h}$ anoxic exposure, but significantly increased by $1.31 \pm 0.08$-fold during $20 \mathrm{~h}$ anoxic exposure compared to the control (Figure 5). In addition, TDG protein expression significantly decreased by $0.62 \pm 0.12$-fold and $0.29 \pm 0.04$-fold, in response to $5 \mathrm{~h}$ and $20 \mathrm{~h}$ anoxia (Figure 5) compared to the control. There was limited variability in the genomic methyl-variants with $5 \mathrm{hmC}$ and $5 \mathrm{caC}$ remained unchanged in response to anoxia, while $5 \mathrm{fC}$ levels significantly decreased in response to $5 \mathrm{~h}$ anoxia and returned back to control conditions (Figure 6). 

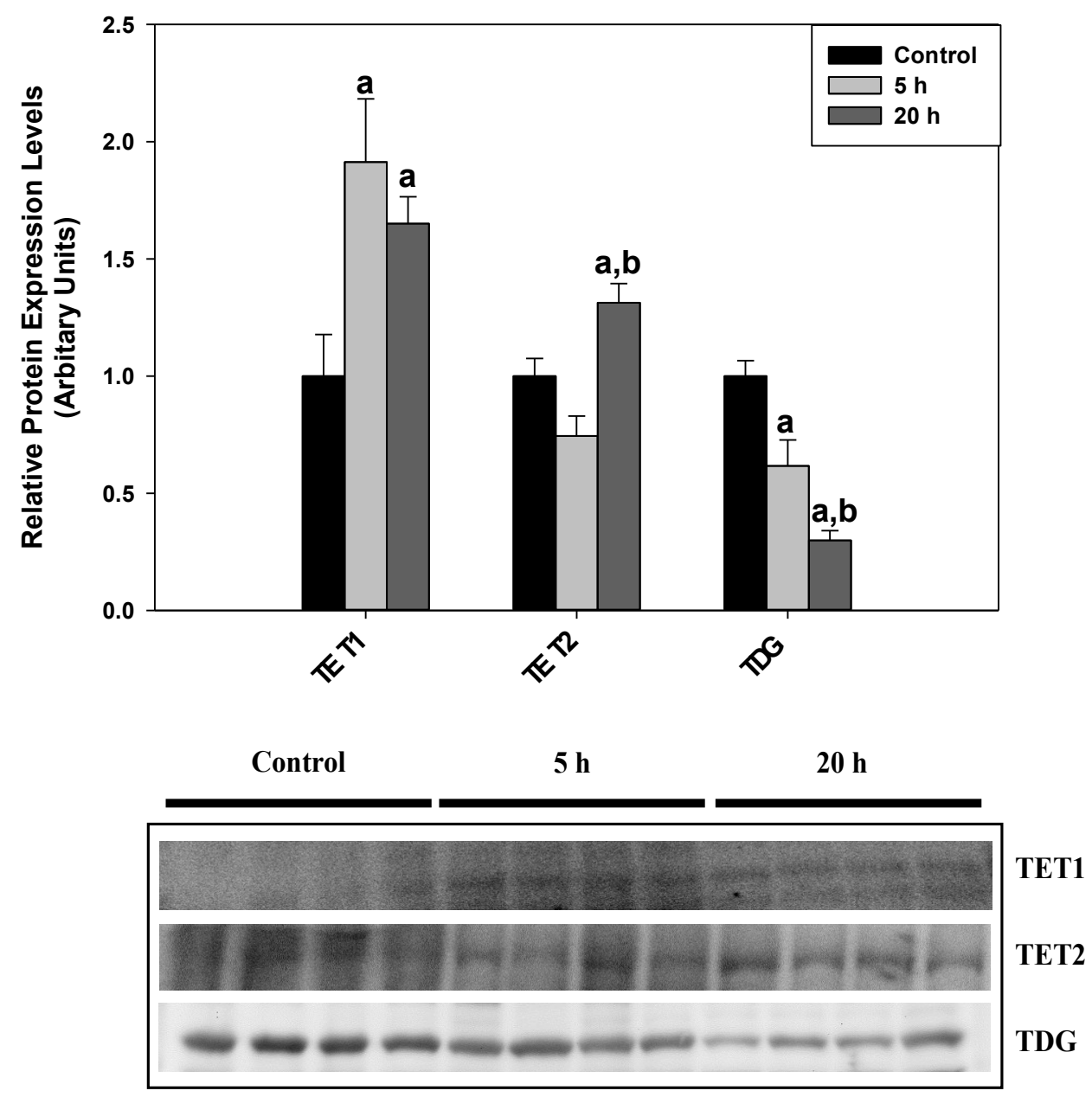

Figure 5. The relative protein expression levels of TET DNA demethylases and TDG in response to control $5 \mathrm{~h}$ anoxic, and $20 \mathrm{~h}$ anoxic submergence in the heart of T.s. elegans as determined by western immunoblotting. Other information as in Figure 1. 


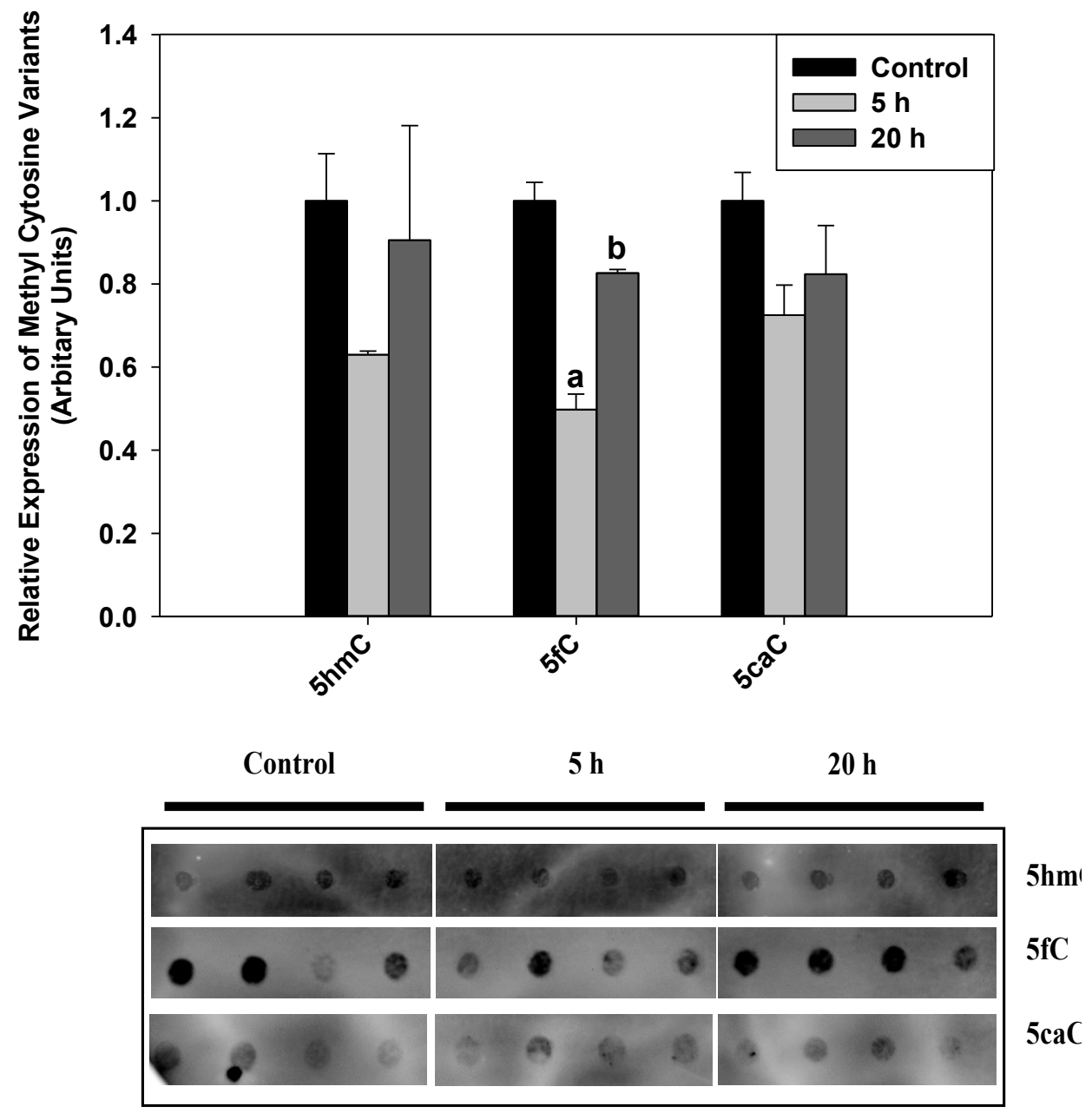

Figure 6. Relative expression levels of three methyl-variants of DNA demethylation in response to $5 \mathrm{~h}$ and $20 \mathrm{~h}$ anoxic exposure in the heart of T.s. elegans as determined by DNA dot blotting. Other information as in Figure 1.

The total enzymatic activity of TETs was measured using a commercially available enzymatic assay from Epigentek. The total TET enzyme activity (ng/h/mg of nuclear protein) remained unchanged during $5 \mathrm{~h}$ anoxia but decreased by $0.47 \pm 0.06$-fold during $20 \mathrm{~h}$ anoxia compared to the control and 5H anoxia in the liver (Figure 7). Similarly, total TET enzymatic activity decreased by $0.63 \pm 0.04$-fold during $5 \mathrm{~h}$ anoxia 
compared to the control and continued to decrease by $0.39 \pm 0.02$-fold during $20 \mathrm{~h}$ anoxia in the white skeletal muscle, compared to both the control. TET enzymatic activity of the anoxic heart remained unchanged (Figure 7).

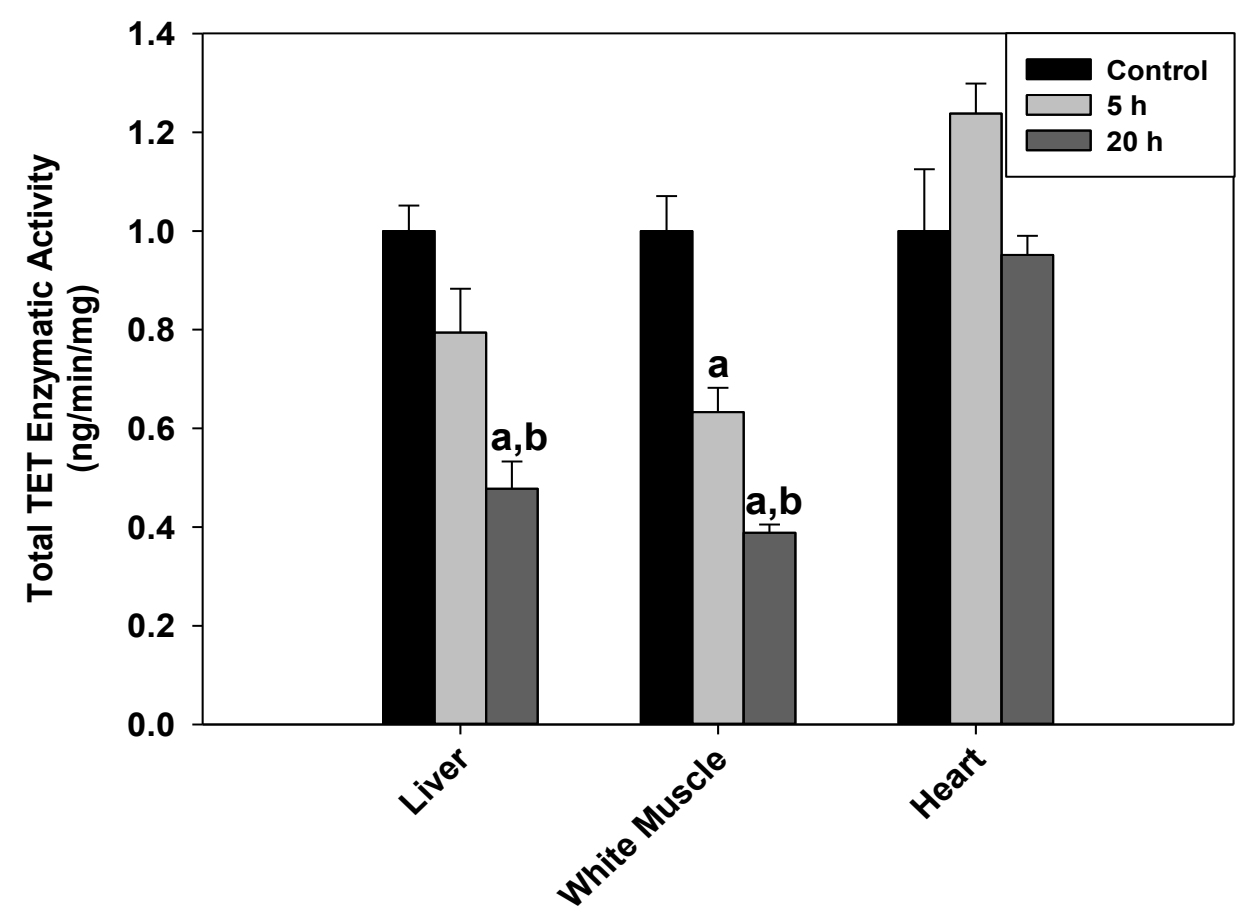

Figure 7. Total TET enzyme activity ( $\mathrm{ng} / \mathrm{h} / \mathrm{mg}$ of nuclear protein) on $5 \mathrm{mC}$ in the liver, white muscle, and heart of T.s. elegans as determined by Epigenase $5 \mathrm{mC}$ hydroxylase TET activity/inhibition assay kit from Epigentek. Other information as in Figure 1.

\section{Discussion}

Previous research on anoxia tolerant red-eared sliders have identified DNA methylation as a prominent regulator of global transcriptional repression, a hallmark of MRD (Sanoji Wijenayake and Storey, 2016). However, the mechanistic basis of MRD is the coordinated suppression of most ATP-utilizing processes and reprioritization of ATP to drive cellular processes that are vital for anoxia survival such as HSPs, antioxidants, UPR, miRNA regulatory machinery, as well as epigenetic regulators (Biggar and Storey, 2011, 2015, Krivoruchko and Storey, 2010a, 2010b, 2010c; Storey, 2007; Storey and 
Storey, 1990b; Willmore and Storey, 1997). As such, a global increase in $5 \mathrm{mC}$ levels in response to anoxia does not necessarily correlate to a global shut down of all transcription but rather a coordinated balance between enhanced gene expression and repression of selected gene targets (Storey, 2007, 1996; Storey and Storey, 1990b). Therefore, a safe balance between global DNA methylation and promoter-specific DNA demethylation must be maintained as part of the global reduction in gene expression that is typical of MRD in anoxia tolerant red-eared sliders. This study explored the dynamic regulation of TET-mediated DNA demethylation responses in anoxic red-eared sliders in order to better understand the mechanistic route of passive and active DNA demethylation. In particular, the expression levels of TET1, TET2, and TDG as well as genomic expression of the three cytosine variants $(5 \mathrm{hmC}, 5 \mathrm{fC}$, and $5 \mathrm{caC})$, along with total TET enzymatic activity was measured in liver, white skeletal muscle, and heart during control, $5 \mathrm{~h}$, and $20 \mathrm{~h}$ anoxic exposures.

TET1-3 family of deoxygenases catalyze the step-wise oxidation of $5 \mathrm{mC}$ into $5 \mathrm{hmC}, 5 \mathrm{fC}$, and $5 \mathrm{caC}$, with TDG recognizing and excising either $5 \mathrm{fC}$ or $5 \mathrm{caC}$ methyl variant from the DNA (He et al., 2011; S. Ito et al., 2011). The DNA demethyaltion process is completed with DNA damage repair mechanism, BER, replacing the missing nucleotide base with an unmodified cytosine residue (Hahn et al., 2014; He et al., 2011; Ito et al., 2010b; Shinsuke Ito et al., 2011; Wu and Zhang, 2011). The catalytic function of TETs are regulated by the presence of two main co-factors, $\mathrm{Fe}(\mathrm{II})$ and $\alpha$-ketoglutarate (He et al., 2011). $\alpha$-ketoglutarate is an important TCA (tricarboxylic acid) cycle intermediate that is produced along with NADH from the conversion of D-isocitrate by isocitrate dehydrogenase and is one of the rate-limiting steps of the TCA cycle. Thus, 
TET-mediated DNA demethylation may be directly controlled by the overall metabolic output of red-eared sliders especially during anoxia-induced MRD in which the metabolic rate is reduced by approximately $90 \%$ when compared to control conditions.

Tissue-specific responses were observed in TET-mediated DNA demethylation during anoxia in the turtle. Liver exhibited a strong reduction in DNA demethylation in response to $5 \mathrm{~h}$ and $20 \mathrm{~h}$ anoxia with a significant reduction in TET2 protein expression (Figure 1) and corresponding reductions in genomic $5 \mathrm{hmC}$ and $5 \mathrm{fC}$ methyl-variants (Figure 2) along with a significant reduction in total TET enzymatic activity during $20 \mathrm{~h}$ anoxia (Figure 7). TET1 protein expression remained unchanged in response to anoxia. These results correlate with previous findings (Sanoji Wijenayake and Storey, 2016) in which DNA methylation levels robustly increased in response to anoxic exposure in the liver of red-eared sliders, suggesting a state of global transcriptional suppression. A combinatorial increase in DNA methylation paired with a global decrease in DNA demethylation in the anoxic liver could be an important characteristic of a hypometabolic state. According to previous studies, the overall metabolic rate is reduced by $90 \%$ in anoxic hepatocytes when compared to control, normoxic conditions (Buck et al., 1993), and lactate production has also shown to decrease by 16 -fold in the very first hour of anoxic exposure in turtles, suggesting a rapid glycolytic inhibition in the liver as part of the overall MRD (Duncan and Storey, 1992). Given that liver is considered to be the main metabolic hub and the principal site of glycogen storage (Jackson, 2000; Storey, 2007; K. Storey and Storey, 2004a; Storey and Storey, 2007), red-eared sliders may be limiting TET-mediated DNA demethylation to maintain a state of global transcriptional shutdown, and to reduce ATP usage and conserve glycogen. According to (Jackson, 2000), by 
slowing the rate of liver glycogen utilization by 10 -fold, freshwater turtles can extend the anoxic survival period by an equal magnitude. On the contrary to TET2 expression in the liver, TDG protein expression significantly increased in response to $20 \mathrm{~h}$ anoxia. Although, TDG recognizes and excise either $5 \mathrm{fC}$ or $5 \mathrm{caC}$ methyl variant from the DNA and is a vital component of TET-mediated DNA demethylation pathway, TDG by definition is a base excision repair enzyme that actively remove ethenoC, a product of lipid peroxidation, as well as correct the deamination-induced DNA mismatches such as uracil and thymine at G:U and G:T sites (Nakamura et al., 2017; Wood et al., 2001). Therefore, the significant increase in TDG could be attributed to an enhanced BER response in the liver to combat reactive oxygen damage.

TET-mediated DNA demethylation patterns differed in white muscle during $5 \mathrm{~h}$ and $20 \mathrm{~h}$ anoxia. In particular, TET1, TET2, and TDG protein expression levels increased in response to $5 \mathrm{~h}$ anoxia and returned to control, normoxic levels during $20 \mathrm{~h}$ anoxia (Figure 3), whereas oxidized forms of 5mC, $5 \mathrm{fC}$ and $5 \mathrm{fC}$ methyl-variants, decreased in expression during $5 \mathrm{~h}$ and $20 \mathrm{~h}$ anoxia (Figure 4). Furthermore, the total enzymatic activity of TETs also decreased in response to $5 \mathrm{~h}$ and $20 \mathrm{~h}$ anoxia (Figure 7). The increase in TET expression during $5 \mathrm{~h}$ anoxia may not necessarily indicate an increase in TET-mediated DNA demethylation and enhanced gene expression during a low energy anoxic state. According to (Wood et al., 2001), methyl-binding proteins, including MBD1, MBD2, and MeCP2 protect existing 5-mC moieties from TET-mediated oxidation from directly restricting TET1 access to DNA. Correspondingly, MBD1 protein level as well as global $5 \mathrm{mC}$ level significantly increased in white skeletal muscle in response to $5 \mathrm{~h}$ and $20 \mathrm{~h}$ anoxic exposures in T.s. elegans (Sanoji Wijenayake and Storey, 
2016). Hence, it is possible that even though TET expression increases, MBDs are inhibiting DNA binding capability of TETs. Consequently, the significant decrease in the oxidized methyl-variants as well as total TET enzymatic activity may indicate an increased compaction of chromatin and a global reduction in gene expression in white skeletal muscle during anoxia. These results correlate to what is already known about the metabolic and epigenetic regulation of white skeletal muscle in red-eared sliders. White skeletal muscle is highly glycolytic, a minor storage site of glycogen, and is considered metabolically inactive during anoxia-induced MRD (Storey, 2007; K. Storey and Storey, 2004a; Storey and Storey, 1990b). Epigenetic players including, DNA methytransferases (DNMTs) and type I and II HDACs, have also been reported to play vital roles in chromatin condensation and transcriptional repression in white skeletal muscle in response to anoxic exposure in red-eared sliders (Krivoruchko and Storey, 2010d; Sanoji Wijenayake and Storey, 2016).

TET-mediated demethylation in the anoxic heart of red-eared sliders was limited in comparison to the dramatic changes in liver and white skeletal muscle and did not illustrate a strong repression or activation of TET-mediated DNA demethylation. In particular, TET1 increased in expression in response to $5 \mathrm{~h}$ and $20 \mathrm{~h}$ anoxia, and TET2 expression increased during $20 \mathrm{~h}$ anoxia (Figure 5). Moreover, the total TET enzymatic activity remained unchanged during anoxia, when compared to the control (Figure 7). A similar trend was reported by (Sanoji Wijenayake and Storey, 2016) in DNA methylation of T.s. elegans hearts, in which $5 \mathrm{mC}$ levels and total DNMTs enzymatic activity showed limited regulation during anoxia. Cardiac anoxia survival of freshwater turtles belonging to Cherysemys and Trachemys genus is an interesting phenomenon because, the anoxic 
heart, even though bradycardic and with significantly reduced stroke volume, continues to function during prolonged periods of anoxia (Farrell and Stecyk, 2007; Stecyk et al., 2008b). Furthermore, anoxia- tolerant freshwater-turtle hearts have high glycogen storage compared to other terrestrial vertebrates where cardiac glycogen is used as a source of hexose during low ATP conditions (Beall and Privitera, 1973). However, the cardiac ATP demand of anoxic freshwater turtles at $5{ }^{\circ} \mathrm{C}$ is still over 300 -times lower than that of control freshwater turtles at $22{ }^{\circ} \mathrm{C}$ (Hicks and Farrell, 2000). As such, although the heart is functional during anoxia and is breaking down glycogen through anaerobic glycolysis to produce ATP, a strong MRD is evident. Therefore, it is possible that cardiac muscle is utilizing alternate transcriptional regulatory mechanisms, including histone modifications and miRNA, to achieve a hypometabolic state during anoxia. In correlation, several diseases, including cardiac hypertrophy $(\mathrm{CH})$, has been linked to the deregulation of histone acetyltransfereases (HATs), HDACs, histone methylation (H3K4 and H3K9) as well as the overexpression of miRNAs (miR-23a, miR-23b, miR-24) (Abi Khalil, 2014; Nührenberg et al., 2014). As such, TET-mediated DNA demethylation may not be a prominent regulator of chromatin accessibility and transcriptional regulation in the anoxic heart.

In summary, this study is the first to suggest a regulatory role for TET-mediated DNA demethylation in anoxia tolerance in red-eared sliders, showing that TET family of DNA demethylases as well as TDG protein are expressed in a tissue-specific manner. Liver and white skeletal muscle illustrated the most robust repression of TET-mediated DNA demethylation during anoxia, suggesting a hypometabolic state with global 
transcriptional repression. TET-mediated DNA demethylation could potentially be an integral component of anoxia survival strategy in T.s. elegans.

\section{Acknowledgements}

I would like to thank Jan Storey for the editorial review of this manuscript.

\section{References}

Abi Khalil, C., 2014. The emerging role of epigenetics in cardiovascular disease. Ther. Adv. Chronic Dis. 5, 178-187. doi:10.1177/2040622314529325

Beall, R.J., Privitera, C.A., 1973. Effects of cold exposure on cardiac metabolism of the turtle Pseudemys (Chrysemys) picta. Am. J. Physiol. 224, 435-41.

Bestor, T.H., Coxon, A., 1993. Cytosine methylation; The pros and cons of DNA methylation. Curr. Biol. 3, 384-386. doi:10.1016/0960-9822(93)90209-7

Bestor, T.H., Edwards, J.R., Boulard, M., 2015. Notes on the role of dynamic DNA methylation in mammalian development. PNAS 112, 6796-6799. doi:10.1073/pnas.1415301111

Biggar, K., Storey, K., 2011. The emerging roles of microRNAs in the molecular responses of metabolic rate depression. J. Mol. Cell Biol. 3, 167-175. doi:10.1093/jmcb/mjq045

Biggar, K.K., Storey, K.B., 2015. Insight into post-transcriptional gene regulation: stressresponsive microRNAs and their role in the environmental stress survival of tolerant animals. J. Exp. Biol. 218, 1281-1289. doi:10.1242/jeb.104828.

Biggar, K.K., Storey, K.B., 2012. Evidence for cell cycle suppression and microRNA regulation of cyclin D1 during anoxia exposure in turtles. Cell Cycle 11, 1705-1713. 
doi:10.4161/cc.19790

Biggar, Y., Storey, K.B., 2014. Global DNA modifications suppress transcription in brown adipose tissue during hibernation. Cryobiology 69, 333-338. doi:10.1016/j.cryobiol.2014.08.008

Bird, A., 2002. DNA methylation patterns and epigenetic memory. Genes Dev. 16, 6-21. doi:10.1101/gad.947102

Brooks, S., Storey, K., 1993. Protein kinase C in turtle brain: changes in enzyme activity during anoxia. J. Comp. Physiol. B 163, 84-88. doi:10.1007/BF00309670

Brooks, S., Storey, K., 1989. Regulation of glycolytic enzymes during anoxia in the turtle Pseudemys scripta. Am. J. Physiol. 257, R278-R283.

Buck, L., Land, S., Hochachka, P., 1993. Anoxia-tolerant hepatocytes: Model system for study of reversible metabolic suppression. Am. J. Physiol. 265, 49-56.

Duncan, J., Storey, K., 1992. Subcellular enzyme binding and the regulation of glycolysis in anoxic turtle brain. Am J Physiol 262, R517-R523.

Farrell, A.P. (Tony), Stecyk, J.A.W., 2007. The heart as a working model to explore themes and strategies for anoxic survival in ectothermic vertebrates. Comp. Biochem. Physiol. Part A Mol. Integr. Physiol. 147, 300-312. doi:10.1016/j.cbpa.2007.01.021

Greenway, S.C., Storey, K.B., 2000. Mitogen- activated protein kinases and anoxia tolerance in turtles. J. Exp. Zool. Part A Ecol. Genet. Physiol. 287, 477-484. doi:10.1002/1097-010X(20001201)287:7<477::AID-JEZ3>3.0.CO;2-4

Hahn, M., Szabó, P., Pfeifer, G., 2014. 5-Hydroxymethylcytosine: A stable or transient DNA modification? Genomics 104, 314-323. doi:10.1016/j.ygeno.2014.08.015 
He, Y.-F., Li, B.-Z., Li, Z., Liu, P., Wang, Y., Tang, Q., Ding, J., Jia, Y., Chen, Z., Li, L., Sun, Y., Li, X., Dai, Q., Song, C.-X., Zhang, K., He, C., Xu, G.-L., 2011. Tetmediated formation of 5-carboxylcytosine and its excision by TDG in mammalian DNA. Science (80-. ). 333, 1303-1307.

Hermes-Lima, M., Storey, J.M., Storey, K.B., 2001. Antioxidant defenses and animal adaptation to oxygen availability during environmental stress, in: Storey, K., Storey, J. (Eds.), Cell and Molecular Responses to Stress, Volume 2. Elsevier Press, Amesterdam, pp. 263-287. doi:10.1016/S1568-1254(01)80022-X

Hicks, J.M., Farrell, A.P., 2000. The cardiovascular responses of the red-eared slider (Trachemys scripta) acclimated to either 22 or 5 degrees C. I. Effects of anoxic exposure on in vivo cardiac performance. J. Exp. Biol. 203, 3765-74.

Hochachka, P.W., 1988. Metabolic suppression and oxygen availability. Can. J. Zool. 66, $152-158$.

Hochachka, P.W., 1986. Defense strategies against hypoxia and hypothermia. Science (80-. ). 231, 234-41.

Hochachka, P.W., Lutz, P.L., 2001. Mechanism, origin, and evolution of anoxia tolerance in animals. Comp. Biochem. Physiol. B. Biochem. Mol. Biol. 130, 435-59.

Ito, S., D’Alessio, A.C., Taranova, O. V., Hong, K., Sowers, L.C., Zhang, Y., 2010. Role of Tet proteins in $5 \mathrm{mC}$ to $5 \mathrm{hmC}$ conversion, ES-cell self-renewal and inner cell mass specification. Nature 466, 1129-1133. doi:10.1038/nature09303

Ito, S., Shen, L., Dai, Q., Wu, S.C., Collins, L.B., Swenberg, J.A., He, C., Zhang, Y., 2011. Tet Proteins can convert 5-methylcytosine to 5-formylcytosine and 5carboxylcytosine. Science (80-. ). 333. 
Ito, S., Shen, L., Dai, Q., Wu, S.C., Collins, L.B., Swenberg, J.A., He, C., Zhang, Y., 2011. Tet proteins can convert 5-methylcytosine to 5-formylcytosine and 5carboxylcytosine. doi.org 333, 1300-1303. doi:10.1126/science.1210597

Jackson, D., 1997. Lactate accumulation in the shell of the turtle, Chrysemys picta bellii, during anoxia at 3 and $10^{\circ}$ C. J. Exp. Biol. 200, 2295-2300.

Jackson, D., 1968. Metabolic depression and oxygen depletion in the diving turtle. J. Appl. Physiol. 24, 503-9.

Jackson, D., Crocker, C., Ultsch, G., 2000. Bone and shell contribution to lactic acid buffering of submerged turtles Chrysemys picta bellii at $3^{\circ} \mathrm{C}$. Am. J. Physiol. Regul. Integr. Comp. Physiol. 278, R1564-1571.

Jackson, D., Heisler, N., 1983. Intracellular and extracellular acid-base and electrolyte status of submerged anoxic turtles at $3^{\circ} \mathrm{C}$. Respir. Physiol. 53, 187-201.

Jackson, D., Toney, V., Okamoto, S., 1999. Lactate distribution and metabolism during and after anoxia in the turtle, Chrysemys picta bellii. Am. J. Physiol. 271, R409R416.

Jackson, D.C., 2000. Living without oxygen: Lessons from the freshwater turtle. Comp. Biochem. Physiol. Part A Mol. Integr. Physiol. 125, 299-315. doi:10.1016/S10956433(00)00160-4

Jackson, D.C., Taylor, S.E., Asare, V.S., Villarnovo, D., Gall, J.M., Reese, S.A., 2006. Comparative shell buffering properties correlate with anoxia tolerance in freshwater turtles. AJP Regul. Integr. Comp. Physiol. 292, R1008-R1015. doi:10.1152/ajpregu.00519.2006

Jaenisch, R., Bird, A., 2003. Epigenetic regulation of gene expression: how the genome 
integrates intrinsic and environmental signals. Nat. Genet. 33, 245-254. doi:10.1038/ng1089

Kriaucionis, S., Heintz, N., 2009. The nuclear DNA base 5-hydroxymethylcytosine Is present in purkinje neurons and the brain. Science (80-. ). 324, 929-930.

Krivoruchko, A., Storey, K., 2013. Anoxia-responsive regulation of the FoxO transcription factors in freshwater turtles, Trachemys scripta elegans. Biochim. Biophys. Acta - Gen. Subj. 1830, 4990-4998. doi:10.1016/j.bbagen.2013.06.034 Krivoruchko, A., Storey, K., 2010a. Regulation of the heat shock response under anoxia in the turtle, Trachemys scripta elegans. J. Comp. Physiol. B 180, 403-414. doi:10.1007/s00360-009-0414-9

Krivoruchko, A., Storey, K., 2010b. Activation of antioxidant defenses in response to freezing in freeze-tolerant painted turtle hatchlings. Biochim. Biophys. Acta - Gen. Subj. 1800, 662-668. doi:10.1016/j.bbagen.2010.03.015

Krivoruchko, A., Storey, K., 2010c. Molecular mechanisms of turtle anoxia tolerance: A role for NF-кB. Gene 450, 63-69. doi:10.1016/j.gene.2009.10.005

Krivoruchko, A., Storey, K., 2010d. Epigenetics in anoxia tolerance: A role for histone deacetylases. Mol. Cell. Biochem. 342, 151-161. doi:10.1007/s11010-010-0479-5

Mehrani, H., Storey, K., 1995a. Enzymatic control of glycogenolysis during anoxic submergence in the freshwater turtle Trachemys scripta. Int. J. Biochem. Cell Biol. 821-830, 821-830. doi:10.1016/1357-2725(95)00042-N

Mehrani, H., Storey, K., 1995b. Effects of anoxia on protein phosphatase in turtle organs: purification and properties of protein phosphatase type-1 from turtle liver. Arch. Biochem. Biophys. 316, 836-843. doi:10.1006/abbi.1995.1112 
Nakamura, T., Murakami, K., Tada, H., Uehara, Y., Nogami, J., Maehara, K., Ohkawa, Y., Saitoh, H., Nishitani, H., Ono, T., Nishi, R., Yokoi, M., Sakai, W., Sugasawa, K., 2017. Thymine DNA glycosylase modulates DNA damage response and gene expression by base excision repair-dependent and independent mechanisms. Genes to Cells 22, 392-405. doi:10.1111/gtc.12481

Nührenberg, T., Gilsbach, R., Preiss1, S., Schnick, T., Hein, L., 2014. Epigenetics in cardiac development, function, and disease. Cell Tissue Res. 356, 585-600. doi:10.1007/s00441-014-1887-8

Shen, L., Wu, H., Diep, D., Yamaguchi, S., D’Alessio, A.C., Fung, H.-L., Zhang, K., Zhang, Y., 2013. Genome-wide analysis reveals TET- and TDG-dependent 5methylcytosine oxidation dynamics. Cell 153, 692-706. doi:10.1016/j.cell.2013.04.002

Smith, Z.D., Meissner, A., 2013. DNA methylation: Roles in mammalian development. Nat. Rev. Genet. 14, 204-220. doi:10.1038/nrg3354

Stecyk, J.A.W., Galli, G.L., Shiels, H.A., Farrell, A.P., 2008. Cardiac survival in anoxiatolerant vertebrates: An electrophysiological perspective. Comp. Biochem. Physiol. Part C Toxicol. Pharmacol. 148, 339-354. doi:10.1016/j.cbpc.2008.05.016

Storey, K., 2007. Anoxia tolerance in turtles: Metabolic regulation and gene expression. Comp. Biochem. Physiol. Part A Mol. Integr. Physiol. 147, 263-276. doi:10.1016/j.cbpa.2006.03.019

Storey, K., 1996. Metabolic adaptations supporting anoxia tolerance in reptiles: recent advances. Comp. Biochem. Physiol. Part B Comp. Biochem. 113, 23-35. doi:10.1016/0305-0491(95)02043-8 
Storey, K., Storey, J., 2007. Tribute to P. L. Lutz: putting life on 'pause' - molecular regulation of hypometabolism. J. Exp. Biol. 210, 1700-1714. doi:10.1242/jeb.02716

Storey, K., Storey, J., 2004. Oxygen limitation and metabolic rate depression, in: Storey, K.B. (Ed.), Functional Metabolism. John Wiley \& Sons, Inc., Hoboken, NJ, USA, pp. 415-442. doi:10.1002/047167558X.ch15

Storey, K., Storey, J., 1990. Metabolic rate depression and biochemical adaptation in anaerobiosis, hibernation and estivation. Q. Rev. Biol. 65, 145-74. doi:10.4172/2157-7625.1000224

Suzuki, M.M., Bird, A., 2008. DNA methylation landscapes: Provocative insights from epigenomics. Nat. Rev. Genet. 9, 465-476. doi:10.1038/nrg2341

Tahiliani, M., Koh, K., Shen, Y., Pastor, W., Bandukwala, H., Brudno, Y., Agarwal, S., Iyer, L., Liu, D., Aravind, L., Rao, A., 2009. Conversion of 5-methylcytosine to 5hydroxymethylcytosine in mammalian DNA by MLL partner TET1. Science (80-. ). 324, 930-5. doi:10.1126/science.1170116

Wijenayake, S., Storey, K.B., 2016. The role of DNA methylation during anoxia tolerance in a freshwater turtle (Trachemys scripta elegans). J. Comp. Physiol. B 186, 333-342. doi:10.1007/s00360-016-0960-x

Willmore, W., Storey, K.B., 1997. Antioxidant systems and anoxia tolerance in a freshwater turtle Trachemys scripta elegans. Mol. Cell. Biochem. 170, 177-85. doi:10.1023/A:1006817806010

Wood, R.D., Mitchell, M., Sgouros, J., Lindahl, T., 2001. Human DNA repair genes. Science (80-. ). 291, 1284-1289. doi:10.1126/science.1056154

Wu, H., Zhang, Y., 2011. Mechanisms and functions of Tet protein-mediated 5- 
methylcytosine oxidation. Genes Dev. 25, 2436-2452. doi:10.1101/gad.179184.111

Xiong, Z.J., Storey, K.B., 2012. Regulation of liver lactate dehydrogenase by reversible phosphorylation in response to anoxia in a freshwater turtle. Comp. Biochem.

Physiol. Part B Biochem. Mol. Biol. 163, 221-228. doi:10.1016/j.cbpb.2012.06.001

Zhang, J., Biggar, K.K., Storey, K.B., 2013. Regulation of p53 by reversible posttranscriptional and post-translational mechanisms in liver and skeletal muscle of an anoxia tolerant turtle, Trachemys scripta elegans. Gene 513, 147-155.

doi:10.1016/j.gene.2012.10.049 
CHAPTER 4 
The dynamic regulation of histone $\mathrm{H3}$ acetylation and deacetylation in response to prolonged oxygen deprivation in the champion anaerobe, Trachemys scripa elegans

\author{
Sanoji Wijenayake $^{\mathrm{a}}$ and Kenneth B Storey ${ }^{\mathrm{a}^{*}}$
}

a - Institute of Biochemistry, Department of Biology, Carleton University, 1125 Colonel By Drive, Ottawa, ON, K1S 5B6, Canada.

\title{
*Corresponding author:
}

Kenneth B. Storey

Professor of Biochemistry

Canada Research Chair in Molecular Physiology

Institute of Biochemistry, Department of Biology, and Department of Chemistry 1125 Colonel By Drive, Ottawa, ON. Canada. K1S 5B.

E-mail address: Kenneth_storey@carleton.ca

Tel: 1-613-520-3678; Fax: 1-613-520-3749

This manuscript will be submitted in 2019 to the Journal of Experimental Biology. 


\begin{abstract}
Anoxia-tolerant red-eared sliders, Trachemys scripta elegans, can survive up to three months of absolute anoxia at $3{ }^{\circ} \mathrm{C}$ and recover with minimal cellular damage. Red-eared sliders employ various physiological and biochemical adaptations to survive anoxia with metabolic rate depression being the most prominent adaptation. Global metabolic suppression is mediated by epigenetic, transcriptional, post-transcriptional, and post-translational regulatory mechanism aimed at shutting down cellular processes that are not needed for anoxia survival, while reprioritizing the ATP towards cell processes that are vital for anaerobiosis. Histone acetylation/deacetylation are epigenetic modifications that maintain a proper balance between permissive chromatin and restricted chromatin, yet very little is known about the dynamic regulation of acetylation/deacetylation during natural anoxia tolerance in red-eared sliders. This study explored the expression of transcriptional activators, histone acetyltransferases, and transcriptional repressors, class III histone deacetylases (SIRTs), along with three prominent acetyl-lysine moieties of histone H3 in the liver of red-eared sliders. Overall, a strong suppression of histone H3 acetylation was evident in the liver. However, surprisingly SIRT-mediated histone deacetylation also decreased in the liver during shortterm and long-term anoxia. Histone $\mathrm{H} 3$ acetylation and deacetylation may be key to transcriptional regulation during anoxia tolerance.
\end{abstract}

\title{
Keywords
}

Anoxia, T.s. elegans, HATs, SIRTs, epigenetics, transcriptional regulation 


\section{Introduction}

Freshwater turtles belonging to the Chrysemys and Trachemys genre are champion anaerobes that can survive approximately 90 days of continual anoxia at $3{ }^{\circ} \mathrm{C}$ and recover with minimal cellular injury (Jackson, 1968; Jackson and Ultsch, 1982; Storey, 2007; Storey and Storey, 1990b). The red-eared sliders (Trachemys scripta elegans) in particular, employ numerous well-adapted designed strategies to combat cellular consequences that are associated with anaerobiosis including 1) increasing liver, white skeletal muscle, and heart glycogen storage, 2) exclusively use glycolysis to generate ATP by catabolizing the glycogen reserves (Hochachka, 1988; P. W. Hochachka, 1986; Jackson, 2000; Storey, 2007; Storey and Storey, 1992), 3) buffering and storing the excess lactic acid produced by anaerobic glycolysis in the shell (HermesLima and Zenteno-Savín, 2002; DC. Jackson et al., 2000; Jackson, 1997; Jackson et al., 1999, 2006a; Jackson and Heisler, 1983), 4) increase cytoprotection in all organs to combat cellular damage that can be caused by reactive oxygen species (ROS) (HermesLima and Zenteno-Savín, 2002; Krivoruchko and Storey, 2013a, 2010a, 2010b, 2010c; Willmore and Storey, 1997), and most importantly, 5) reduce the overall metabolic rate by $90 \%$ when compared to normoxic conditions (Hochachka, 1988; Hochachka et al., 1996; Jackson, 1968; Storey, 2007, 1996; Storey and Storey, 1990b), by a strong coordinated suppression of all energy expensive cellular processes such as global gene expression, protein translation, proteolysis, cell cycle, apoptosis, gluconeogenesis, urea synthesis and reprioritizing the available ATP toward cellular processes that are needed for survival (K. Biggar et al., 2011; Krivoruchko and Storey, 2013a, 2010a, 2010b, Storey, 2007, 1996; K. Storey and Storey, 2004a; Storey and Storey, 1990b). Although 
extensive work has already been done on glycolytic controls (Bell and Storey, 2012; Brooks and Storey, 1989; N. Dawson et al., 2013; Neal J. Dawson et al., 2013; Mehrani and Storey, 1995a), transcriptional regulation (Bansal et al., 2016; Biggar and Storey, 2012b; Krivoruchko and Storey, 2013b; Zhang et al., 2013b), post-transcriptional regulation via miRNAs (Biggar and Storey, 2011, 2015, 2012b; K. K. Biggar et al., 2011), as well as post-translational regulation (K. Biggar et al., 2011; SP Brooks and Storey, 1993; Storey, 1996; Storey and Storey, 2007) of anoxia tolerance in red-eared sliders, epigenetic regulation of anoxia tolerance, in particular, regulation of global gene expression through histone modification remains to be explored.

The genomic DNA of every living cell exists in the form of DNA within the nucleus. Chromatin DNA is wrapped around nucleosomes, structures consisting of an octamer of four core histone proteins, H2A, H2B, H3, and H4 with $\mathrm{H} 1$ linkers. These core histone proteins are subjected to numerous covalent modifications such as acetylation, phosphorylation, methylation, ubiquitination, ADP-ribosylation, and SUMOlation to name a few (E Bártová et al., 2008; S. Berger, 2002). When combined all these modifications make up the "Histone Code". The Histone Code hypothesis predicts that the various modifications on the amino $(\mathrm{N})$-terminal tails of the histone proteins can interdependently as well as independently induce euchromatin or heterochromatin formation at selected regions of the genome and thereby regulate gene expression (P Cheung et al., 2000; Jenuwein and Allis, 2001; Margueron et al., 2005; Zhou et al., 2011). Thus, histone proteins and the corresponding covalent modifications reprogram chromatin accessibility in a target-specific manner, thereby leading to heritable changes in transcriptional on/off states (Allis and Jenuwein, 2016). As such, the diverse array of 
covalent modifications of histone proteins represents a vital epigenetic mechanism that may regulate and organize chromatin structure and the overall transcriptional outcome in response anoxia, an adverse environmental stress, in red-eared sliders.

Reversible protein acetylation (RPA) of lysine residues has been one of the most well studied epigenetic signatures mainly due to the discovery of more than 200 acetylated non-histone proteins including metabolically relevant enzymes as well as transcription factors in mammals (Choudhary and Mann, 2010), along with the discovery of histone acetyltransferases (HATs) and type I-IV histone deacetylases (HDACs) that work towards establishing a steady-state balance between transcriptional activation and repression of target promoters (B. Strahl and Allis, 2000). Histone acetylation in particular, is associated with transcriptional activation regardless of the level of acetylation and the location of the targeted lysine sites that are modified (S. Berger, 2002; Shahbazian and Grunstein, 2007; B. Strahl and Allis, 2000), because acetylation of histone $\mathrm{H} 3$ and $\mathrm{H} 4 \mathrm{~N}$-terminal tails alter the overall positive charge of the nucleosome assembly and thereby disrupt electrostatic interactions to the negatively charge DNA (Jenuwein and Allis, 2001; Margueron et al., 2005; Shahbazian and Grunstein, 2007), and promote an open chromatin state. Whereas, histone deacetylation involves the removal of acetyl-moieties $\left(\mathrm{COCH}_{3}\right)$ that are covalently bound to lysine residues and reinstate the strong covalent interaction between the histones and the DNA, and is associated with transcriptional repression (Clayton et al., 2006; Struhl, 1998; Wade et al., 1997). Additionally, a more complex transcriptional regulatory mechanism for histone deacetylation has been reported, in which histone deacetylation was found to be a key regulator of proper transcriptional output (Shahbazian and Grunstein, 2007). Both HATs 
and HDACs are capable of maintaining global as well as targeted acetylation, and may function as a regulatory switch between repressive heterochromatin and permissive euchromatin (Eberharter and Becker, 2002). In an environment where oxygen is limited or absent, this type of transcriptional regulation may be critical for silencing numerous genes that are not required for anoxia survival, while enhancing the expression of genes that are necessary in the red-eared sliders.

HATs are grouped into six major families each with distinct acetyltransferases functions. These include the GNAT (Gcn5-related N-acetyltransferases) superfamily (Dyda et al., 2000; Neuwald and Landsman, 1997), the MYST family (Avvakumov and Cote, 2007; Sterner and Berger, 2000), CBP/p300 (Bannister and Kouzarides, 1996; Liu et al., 2008), the TBP-associated factor TAF 250 and TFIID (Mizzen et al., 1996), members of the steroid receptor co-activators (O’Malley et al., 1997), and some gene specific transcription factors such as ATF-2 and CIITA (Kawasaki et al., 2000). HDACs also can be divided in to distinct families including HDAC2, HDAC3, HDAC8 that are part of class I HDACs, HDAC4, HDAC5, HDAC6, HDAC7, and HDAC9 belonging to class II HDACs, along with HDAC11 that is part of class IV HDACs. Class I HDACs are typically localized and functional in the nucleus where as class II HDACs can be both cytoplasmic and/or nuclear. Class I, II, and IV HDACs share a conserved catalytic functions in that HDACs belonging to all three classes are metalloenzymes that requires zinc transition metal ion to function (Lombardi et al., 2011). In particular, these HDACs use zinc ions to catalyze the hydrolysis of the lysine-amino bonds of targeted histone and non-histone proteins (de Ruijter et al., 2003; Lombardi et al., 2011) and thus are related to acetylpolyamine amidohydrolases and acetoin utilization proteins (Leipe and 
Landsman, 1997). Class III HDACs however consist of seven SIRTs that require NAD ${ }^{+}$ as a cofactor to induce deacetylation (Delcuve et al., 2012). As such, HATs and HDACs are bifunctional proteins that are not limited to acetylating only histone proteins, but rather can also acetylate non-histone proteins that are part of DNA recombination, DNA replication, and DNA repair (Glozak et al., 2005; Polevoda and Sherman, 2000). Furthermore, addition of an acetyl group to lysine residues prevents positive charges from forming on the amino group and significantly impact the electrostatic properties of the targeted protein (Glozak et al., 2005). Transcription factors such as p53 (Gu and Roeder, 1997), HMG family of proteins (Munshi et al., 1998), STAT3 (Wang et al., 2005), c-Myc (Patel et al., 2004), Hif-1, and NFkB (Chen et al., 2001) are directed regulated by acetylation. Furthermore, metabolic enzymes such as acetyl-CoA synthetase (Xiong and Guan, 2012) and glycelaldehyde-3-phosphate dehydrogenase (GAPDH), an important glycolytic enzyme (Ventura et al., 2010), are also acetylated. However, this study focuses on characterizing the dynamic transcriptional regulation of histone H3 acetylation in response to normoxic control, $5 \mathrm{~h}$ anoxia, and $20 \mathrm{~h}$ anoxic exposure in the liver of T.s. elegans. In particular, protein expression levels of HAT1 (acetyltransferases 1), GCN5L2 (general control of amino acid synthesis yeast homolog-like protein 2), and PCAF (p300/CBP-associated factor) that are part of the GCN-family of HATs, along with Tip60, a member of the MYST family, and CBP (CREB-binding proteins), that is part of the CPB-p300 HATs were measured. In addition, to better understand the interplay between acetylation and deacetylation, three type-III HDACs, the nuclear SIRTs, as well as total histone $\mathrm{H} 3$, and the acetylation levels of three downstream lysine (K) residues on histone $\mathrm{H} 3(\mathrm{H} 3 \mathrm{~K} 14, \mathrm{H} 3 \mathrm{~K} 18$, and H3K56) were measured. Global and 
nuclear-specific enzymatic activity of HATs along with enzymatic activity of all nuclear SIRTs, including SIRT1 (sirtuin1), SIRT6 (sirtuin6), and SIRT7 (sirtuin7) were also measured. The HATs, HDACs, and the respective histone H3-acetylation sites were chosen based on their roles in regulating transcription in the liver. The results suggest a unique regulatory role for histone $\mathrm{H} 3$ acetylation in the global suppression of gene expression during anaerobiosis in the freshwater turtle.

\section{Materials and Methods}

\section{Animal care and treatment}

Adult red-eared sliders (Trachemys scripta elegans) were purchased from local distributors and held in large tubs filled with decholorinated tap water at $5 \pm 1{ }^{\circ} \mathrm{C}$ for a full week before experiments began. 4-5 normoxic, control turtles were randomly sampled from this condition. The remaining turtles were transferred to large tubs filled with water that had previously been bubbled with nitrogen gas for $1 \mathrm{~h}$ at $5 \pm 1{ }^{\circ} \mathrm{C}$. Approximately 2-3 turtles were added per tub and the water was bubbled with nitrogen gas for $1 \mathrm{~h}$ after the last turtle was added. A wire mesh was placed about $5 \mathrm{~cm}$ from the water surface to prevent turtles from coming up to the surface to breath. Post $5 \mathrm{~h}$ anoxic submergence, $4-5$ turtles were randomly sampled. The remaining turtles were kept in the tubs for $20 \mathrm{~h}$ and sacrificed. These turtles were used as the $20 \mathrm{~h}$ anoxia experimental condition. All turtles used in this experiment survived the $5 \mathrm{~h}$ and $20 \mathrm{~h}$ anoxia treatments. The red-eared sliders were euthanized and the tissues were excised and immediately placed in liquid nitrogen to stop all cellular processes. The samples were subsequently stored in $-80^{\circ} \mathrm{C}$ freezers for later use. 
All animals were cared for in accordance to the guidelines of the Canadian Council on Animal Care based on the prior approval of Carleton University Animal Care Committee.

\section{Total soluble protein extraction}

$500 \mathrm{mg}$ of frozen liver from control, $5 \mathrm{~h}$ anoxic, and $20 \mathrm{~h}$ anoxic T.s. elegans were crushed into powder in liquid nitrogen using a mortar and pestle and homogenized in 1:2.5 (w:v) 1X homogenization buffer (20 mM Hepes pH 7.5, $200 \mathrm{mM} \mathrm{NaCl}, 0.1 \mathrm{mM}$ EDTA, $10 \mathrm{mM} \mathrm{NaF}, 1 \mathrm{mM} \mathrm{Na} \mathrm{VO}_{4}, 10 \mathrm{mM} \beta$-glycerophosphate) with $10 \mu \mathrm{L} / \mathrm{mL}$ of protease inhibitor cocktail (Bioshop; Catalog \#. PIC001) and a few crystals of phenylmethylsulfonyl fluoride (PMSF) using a Polytron homogenizer on high for $15 \mathrm{~s}$. The samples were immediately placed on ice for 5-10 min, vortexed, and centrifuged at $10,000 \mathrm{rpm}$ at $4{ }^{\circ} \mathrm{C}$. The supernatant containing the total soluble protein was collected and the total soluble protein concentration was determined using the Bio-Rad Protein assay (Catalog \#. 500-0006). The liver control, $5 \mathrm{~h}$, and $20 \mathrm{~h}$ samples were normalized to $10 \mu \mathrm{g} / \mu \mathrm{L}$ and $50 \mu \mathrm{L}$ aliquots were reserved for HAT total enzymatic assay. The remaining sample volume was mixed 1:1 (v:v) with 2X-SDS loading buffer (100 mM Tris-base, $4 \%$ (w:v) SDS, $20 \%$ (v:v) glycerol, $0.2 \%$ (w:v) bromophenol blue, $10 \%$ (v:v) 2-mercaptoethanol) to a final concentration of $5 \mu \mathrm{g} / \mu \mathrm{L}$. Finally the samples were boiled for $10 \mathrm{~min}$ in a water bath and stored at $-40{ }^{\circ} \mathrm{C}$ for later use.

\section{Western immunoblotting}

25-35 $\mu \mathrm{g}$ of total soluble protein were loaded on to 8-10\% SDS-polyacrylamide gels and resolved by electrophoresis for $45-120 \mathrm{~min}$ at $180 \mathrm{~V}$ in $1 \mathrm{X}$ Tris-glycine running buffer (75.5 g of Tris-base, $460 \mathrm{~g}$ glycine, $25 \mathrm{~g}$ SDS, $\mathrm{ddH}_{2} \mathrm{O}$ up to $2.5 \mathrm{~L}$ ) using a Mini- 
Protean 3 System (Bio-Rad). Histone H3 total and acetyl-modifications were loaded on to $15 \%$ tris-tricine gels ( $30 \%$ acrylamide, glycerol, TEMED, $10 \%$ APS, and $\mathrm{ddH}_{2} 0$ ) and resolved for $180 \mathrm{~min}$ at $4{ }^{\circ} \mathrm{C}$ using an inner chamber $1 \mathrm{X}$ Tris/Tricine/SDS running buffer (121.1 $\mathrm{g}$ of Tris base, $179.2 \mathrm{~g}$ of Tricine, $10 \mathrm{~g}$ of SDS in $800 \mathrm{~mL}$ of $\mathrm{ddH}_{2} \mathrm{O}, \mathrm{pH} 8.3$ ) and an outer chapter $1 \mathrm{X}$ anode buffer (242 $\mathrm{g}$ of Tris base in $700 \mathrm{~mL}$ of $\mathrm{ddH}_{2} \mathrm{O}, \mathrm{pH} 8.8$ ), due to the small molecular weight of histone proteins. $5 \mu \mathrm{L}$ of Pink Plus Prestained Protein Ladder (Froggabio; Catalog \#. PM005-0500K) and $25 \mu \mathrm{g}$ of a mammalian positive control (13-lined ground squirrel liver) was run alongside each gel as molecular weight references. The samples were then electroblotted on to $0.25 \mu \mathrm{m}$ (All histone H3 modifications) or $0.45 \mu \mathrm{m}$ (HATs and SIRT proteins) PVDF membranes (Millipore; Catalog \#. ISEQ00010 and IPVH00010) in 1X transfer buffer (60.6 g Tris-base, $288 \mathrm{~g}$ glycine, $4 \mathrm{~L}$ methanol, $16 \mathrm{~L} \mathrm{ddH}_{2} \mathrm{O}$ ) at $160 \mathrm{mV}$ for $120 \mathrm{~min}$ for HATs and SIRTs and 45 min for histone H3-modifications at room temperature using Mini-Protean transfer cell (Bio-Rad; Catalog \#. 1658004). The PVDF membranes were washed three times, $5 \mathrm{~min}$ in $1 X$ TBST (10 mM Tri-base, $15 \mathrm{mM} \mathrm{NaCl}, 0.05 \%$ (v:v) Tween-20, pH 7.5) and blocked with $2.5-5 \%$ milk for $30 \mathrm{~min}$ or $1 \mathrm{mg} / \mathrm{mL}$ of high molecular weight polyvinyl alcohol (70-100 kDa) for $2 \mathrm{~min}$. Post blocking, the membranes were washed three times, 5 min each and incubated with primary antibody (diluted 1:1000 (v:v) in 1X TBST) on a rocker overnight at $4{ }^{\circ} \mathrm{C}$. The antibodies used in this analysis include, Histone $\mathrm{H} 3$-total (Cell Signaling; Catalog \#. 4499), H3K14ac (Cell Signaling; Catalog \#. 7627), H3K18ac (Cell Signaling; Catalog \#. 13998), H3K56ac (Cell Signaling; Catalog \#. 4243), HAT1 (Genetex; Catalog \#. GTX110643), GCN5L2 (Cell Signaling; Catalog \#. 3305), PCAF (Cell Signaling; Catalog \#. 3378), Tip60 (Cell Signaling; Catalog \#. 12058), CBP (Cell 
Signaling; Catalog \#. 3379), SIRT1 (Active Motif; Catalog \#. 39354), SIRT6 (Active Motif; Catalog \#. 39912), and SIRT7 (Genetex; Catalog \#. GTX105732). The membranes were washed three times, 5 min each in $1 \mathrm{X}$ TBST and incubated with HRP-conjugated anti-rabbit IgG secondary antibody (Bioshop; Catalog \#. APA007P) diluted 1: 8000 (v:v) in $1 \mathrm{X}$ TBST for $40 \mathrm{~min}$ on a rocker at room temperature. Target protein bands were visualized using enhanced chemiluminescence (ECL) and hydrogen peroxide and a ChemiGenius Bio-Imaging system (Syngene, Frederick, MD). Potential discrepancies in protein loading was corrected for by staining the membranes with Coomassie blue protein stain $(0.25 \%$ (w:v) Coomassie blue stain, $7.5 \%$ acetic acid, $50 \%$ (v:v) methanol) for 15 min and destained with destain solution $\left(25 \%(\mathrm{v}: \mathrm{v})\right.$ methanol and $\left.\mathrm{ddH}_{2} \mathrm{O}\right)$ for 5 min at room temperature. Both ECL and Coomassie membranes were quantified using GeneTools software (Syngene, Frederick, MD).

\section{Cytoplasmic and Nuclear Protein Extraction}

Approximately $50 \mathrm{mg}$ of frozen liver was homogenized 1:5 (w:v) in pre-chilled 1X cytoplasmic extraction buffer (100 mM HEPES, 100 mM KCl, 100 mM EDTA, 200 $\mathrm{mM} \beta$-glycerolphosphate, $\mathrm{pH} 7.9$ with $10 \mu \mathrm{L} / \mathrm{mL}$ of $100 \mathrm{mM} \mathrm{DTT}$ and $10 \mu \mathrm{L} / \mathrm{mL}$ of protease inhibitor cocktail (Bioshop; Catalog \# PIC001)) using a mortar and pestle with 3-4 gentle piston strokes. Post homogenization, the samples were incubated on ice for 30 min with intermittent vortexing. The samples were subsequently centrifuged at 12,000 $\mathrm{rpm}$ for $15 \mathrm{~min}$ at $4^{\circ} \mathrm{C}$. The supernatant was removed and labeled as the cytoplasmic fraction and the pellet containing the intact nuclei was lysed with 5X nuclear extraction buffer (100 mM HEPES, 2 M NaCl, 5 mM EDTA, 50 \% (v:v) glycerol, $100 \mathrm{mM} \beta$ glycerol phosphate, pH 7.9 with $10 \mu \mathrm{L} / \mathrm{mL}$ of $100 \mathrm{mM}$ DTT and $10 \mu \mathrm{L} / \mathrm{mL}$ of protease 
inhibitor cocktail (Bioshop; Catalog \# PIC001)) 1:5 (w:v). Post homogenization, the samples were sonicated on high for $10 \mathrm{~s}$ and incubated on ice for $10 \mathrm{~min}$ to mediate nuclear lysis. The samples were then centrifuged at $14,000 \mathrm{rpms}$ for $10 \mathrm{~min}$ at $4{ }^{\circ} \mathrm{C}$ and the supernatant was removed and kept as the nuclear fraction. The soluble protein content of the cytoplasmic and nuclear fractions was measured using the Bio-Rad protein assay with bovine serum albumin as the standard. Both cytoplasmic and nuclear fractions were normalized to a final concentration of $5 \mu \mathrm{g} / \mu \mathrm{L}$. To test for the integrity of cytoplasmic and nuclear isolations, $30 \mu \mathrm{L}$ aliquots of each sample was combined with $2 \mathrm{X}$ SDS loading buffer to a final concentration of $2.5 \mu \mathrm{g} / \mu \mathrm{L}$ and run on a $15 \%$ tris-tricine gel and probed with histone H3 (Genetex; Catalog \#. GTX129546) diluted 1:1000 (v:v) in 1X TBST. Histone H3 is a nuclear protein and as such would provide insight into the quality of the cytoplasmic and nuclear extraction. Please refer to Appendix I for more information on old and new cytoplasmic and nuclear extraction protocols and testing.

\section{HAT Enzymatic Activity Assays}

The total enzymatic activity and nuclear enzymatic activity of HATs was measured using the EpiQuik HAT Activity/Inhibition Assay kit from Epigentek (Catalog \#. P-4003-96) according to manufactures instructions. Briefly, the assays were conducted using total liver soluble protein extracts and liver nuclear protein extracts in independent wells because HATs are known to acetylate both histones as well as non-histone proteins. We were interested to see whether the overall HAT enzymatic assay profile may differ between total soluble proteins and nuclear protein fractions. A standard curve was prepared by adding $0.1,0.2,0.5,1.0,2.0,5.0$, and $10 \mathrm{ng}$ of HAT assay standard (supplied with the kit with an initial concentration of $20 \mu \mathrm{g} / \mathrm{mL}$ ) into the wells along with $50 \mu \mathrm{L}$ of 
diluted 1X wash buffer (10X wash buffer was supplied with the kit). To determine the linear range of protein that is needed for the assay, a dilution curve ranging from $5 \mu \mathrm{g}$ to $30 \mu \mathrm{g}$ of total soluble protein as well as a dilution curve ranging from $5 \mu \mathrm{g}$ to $30 \mu \mathrm{g}$ of nuclear protein was tested. Based on the values obtained from the dilution test curves and the standard curve, $10 \mu \mathrm{g}$ of total soluble liver protein and $10 \mu \mathrm{g}$ of nuclear liver protein was used for the quantification runs. To start, $50 \mu \mathrm{L}$ HAT substrate $(20 \mu \mathrm{g} / \mathrm{mL}$ was supplied with the kit) diluted 1:50 ratio with $1 \mathrm{X}$ wash buffer was hybridized into all wells, except for the standard wells, and the wells were covered in parafilm and incubated at room temperature for $45 \mathrm{~min}$. Subsequently, the wells were washed three times with $150 \mu \mathrm{L}$ of $1 \mathrm{X}$ wash buffer. In reaction wells now hybridized with the HAT substrate, 1 $\mu \mathrm{L}$ of each $10 \mu \mathrm{g} / \mathrm{uL}$ samples of total and nuclear extracts were added to $26 \mu \mathrm{L}$ of HAT assay buffer and $2 \mu \mathrm{L}$ of acetyl-CoA (30 mM was supplied with the kit) diluted 1:20 in HAT assay buffer. For the standard wells, $28 \mu \mathrm{L}$ of assay buffer was added along with 2 $\mu \mathrm{L}$ of diluted acetyl-CoA. Negative control wells contained everything as the sample wells except for the protein lysate. The microplate was incubated at $37^{\circ} \mathrm{C}$ on a plate shaker (50-100 rpm) for $60 \mathrm{~min}$. Post incubation, the wells were washed with $150 \mu \mathrm{L}$ of diluted wash buffer and incubated with $50 \mu \mathrm{L}$ of $1 \mu \mathrm{g} / \mathrm{mL}$ capture antibody $(100 \mu \mathrm{g} / \mathrm{mL}$ was supplied with the kit) at room temperature on a plate shaker (50-100 rpm) for 60 min. Post incubation, the wells were washed four times with $150 \mu \mathrm{L}$ of diluted wash buffer. Then the wells were incubated with $50 \mu \mathrm{L}$ of $0.2 \mu \mathrm{g} / \mathrm{mL}$ detection antibody (200 $\mu \mathrm{g} / \mathrm{mL}$ was provided with the kit) and incubated at room temperature for $30 \mathrm{~min}$. The wells were washed five times with $150 \mu \mathrm{L}$ of wash buffer and $100 \mu \mathrm{L}$ of developing 
solution (supplied with the kit) was added to each well and incubated at room temperature for $10 \mathrm{~min}$. Post $10 \mathrm{~min}, 50 \mu \mathrm{L}$ of stop solution (supplied with the kit) was added to each well and the absorbance at $450 \mathrm{~nm}$ was measured using a Powerwave HT spectrophotometer (BioTek). The total HAT activity was calculated using the following formula;

$$
\text { Activity }\left(\frac{n g}{\frac{h}{m g}}\right)=\left[\frac{\text { OD }(\text { untreated sample }- \text { blank })}{(\text { protein amount }(\mathrm{u} g) \times h \times \text { slope })}\right] \times 1000
$$

Where;

Protein amount is the soluble and nuclear extract $(\mu \mathrm{g})$ added to the test sample wells. $\mathrm{h}$ is the incubation time at $37^{\circ} \mathrm{C}$.

Slope is the slope of the line of the standard curve created from standard amounts ranging from $0.1,0.2,0.5,1.0,2.0,5.0$, and $10 \mathrm{ng}$.

\section{SIRT Enzymatic Activity Assays}

Enzymatic activity of the nuclear SIRTs was assayed using Epigenase Universal SIRT Activity/Inhibition Fluorometric Assay (Epigentek; Catalog \#. P-4037-96). Only the nuclear samples from the liver of control, $5 \mathrm{~h}$ and, $20 \mathrm{~h}$ anoxic red-eared sliders were used for this analysis. The assay was conduced according to manufactures instructions. In brief, a standard curve was prepared by using SIRT assay standard ( $50 \mu \mathrm{g} / \mathrm{mL}$ supplied with the kit) at concentrations ranging from $0.2,0.5,1.0,2.0$, and $5.0 \mathrm{ng} / \mu \mathrm{L}$ along with a dilution curve ranging from $5,10,15,20$, and $25 \mu \mathrm{g}$ of pooled nuclear liver test samples. Blank wells and No NAD control (NNC) wells were run alongside the standard and dilution curves. The well contents are as follows; Standard wells contained $49 \mu \mathrm{L}$ of SIRT assay buffer and $1 \mu \mathrm{L}$ of SIRT assay standard at different concentrations. The 
sample test wells contained $10 \mu \mathrm{g}$ of liver nuclear protein, $46 \mu \mathrm{L}$ of SIRT assay buffer, 1 $\mu \mathrm{L}$ of SIRT substrate, $1 \mu \mathrm{L}$ of HDAC I, II, and IV inhibitor TSA (50 $\mu \mathrm{M}$ supplied with the kit), and $1 \mu \mathrm{L}$ SIRT co-factor NAD (50 X supplied with the kit). Blank wells contained $48 \mu \mathrm{L}$ of SIRT assay buffer, $1 \mu \mathrm{L}$ of SIRT substrate, and $1 \mu \mathrm{L}$ NAD. No NAD Control (NNC) wells contained $10 \mu \mathrm{g}$ of pooled liver nuclear protein, and $47 \mu \mathrm{L}$ of SIRT assay buffer, $1 \mu \mathrm{L}$ of SIRT substrate, and $1 \mu \mathrm{L}$ of TSA. The microplate was sealed with parafilm and incubated at $37^{\circ} \mathrm{C}$ for $90 \mathrm{~min}$. Well contents were removed and the wells were washed three times with $150 \mu \mathrm{L}$ of $1 \mathrm{X}$ wash buffer (10X supplied with the kit). 50 $\mu \mathrm{L}$ of capture antibody (1000X supplied with the kit) was diluted at a ratio of 1:1,000 with $1 \mathrm{X}$ wash buffer, was added to each well and incubated at room temperature for 60 $\min$. The wells were subsequently washed and incubated with $50 \mu \mathrm{L}$ of detection antibody (2000X supplied with the kit), diluted at a 1:2,000 ratio with $1 \mathrm{X}$ wash buffer, for $30 \mathrm{~min}$ at room temperature. The wells were washed for the last time with $150 \mu \mathrm{L}$ of $1 \mathrm{X}$ wash buffer and $50 \mu \mathrm{L}$ of fluorescence developing solution (supplied with the kit) was added to all wells and incubated at room temperature for $5 \mathrm{~min}$. Finally, the wells were read using a fluorescence microplate reader at $530 \mathrm{ex} / 590 \mathrm{em} \mathrm{nm}$.

Nuclear SIRT activity was calculated using the following formula;

$$
\operatorname{Activity}\left(\frac{R F U}{\frac{m i n}{m g}}\right)=\left[\frac{(\text { sample } R F U-N N C R F U)}{(\text { protein amount }(\mathrm{u} g) * \times \min * *)}\right] \times 1000
$$

Where;

* is the liver nuclear protein amount used in the analysis. 
** is the incubation time at $37^{\circ} \mathrm{C}$.

\section{Quantification Statistics}

To correct for minor irregularities in protein loading, chemiluminescent data for each immunoblot target was divided by the absorption density of the corresponding Coomassie-stained protein bands that showed constant expression across control, $5 \mathrm{~h}$ anoxic, and $20 \mathrm{~h}$ anoxic exposures. This method has been shown to be far superior to using one housekeeping or reference gene as a loading control (Krivoruchko and Storey, 2010d; S Wijenayake and Storey, 2016). Target protein bands were identified by running a standard protein molecular weight ladder and a mammalian positive control sample from Ictidomys tridecemlineatus. The total soluble protein and nuclear samples used in the HAT and SIRT enzymatic activity assays were subjected to multiple rounds of BioRad protein quantification method prior to usage and experienced a maximum of one freeze-thaw cycle. Statistical analysis used a one-way ANOVA with a Tukey post hoc test $(\mathrm{p}<0.05)$ to compare three experimental conditions. Sigmaplot 11 software (Systat Softwaree Inc., San Jose, CA) was used for this analysis as well as construction of figures.

\section{Results}

The focus of the study was to explore dynamic changes in histone H3 acetylation along with HATs and HDACs that may contribute to liver transcriptional regulation in response to oxygen deprivation in an anoxia-tolerant terrestrial vertebrate, the red-eared

sliders. Overall, histone $\mathrm{H} 3$ acetylation is significantly decreased in response to anoxia in the liver (Figure 1). In particular, histone H3-K14 acetylation significantly decreased by 
$0.46 \pm 0.14$-fold in response to $5 \mathrm{~h}$ anoxia and $0.49 \pm 0.08$-fold in response to $20 \mathrm{~h}$ anoxia compared to the control, normoxia. H3-K18 acetylation levels were seen to increase during $5 \mathrm{~h}$ anoxia by $3.8 \pm 0.59$-fold and returned back to control levels during $20 \mathrm{~h}$ anoxia. Furthermore, H3-total and H3-K56 acetylation levels remained unchanged in response to $5 \mathrm{~h}$ and $20 \mathrm{~h}$ anoxic exposure.
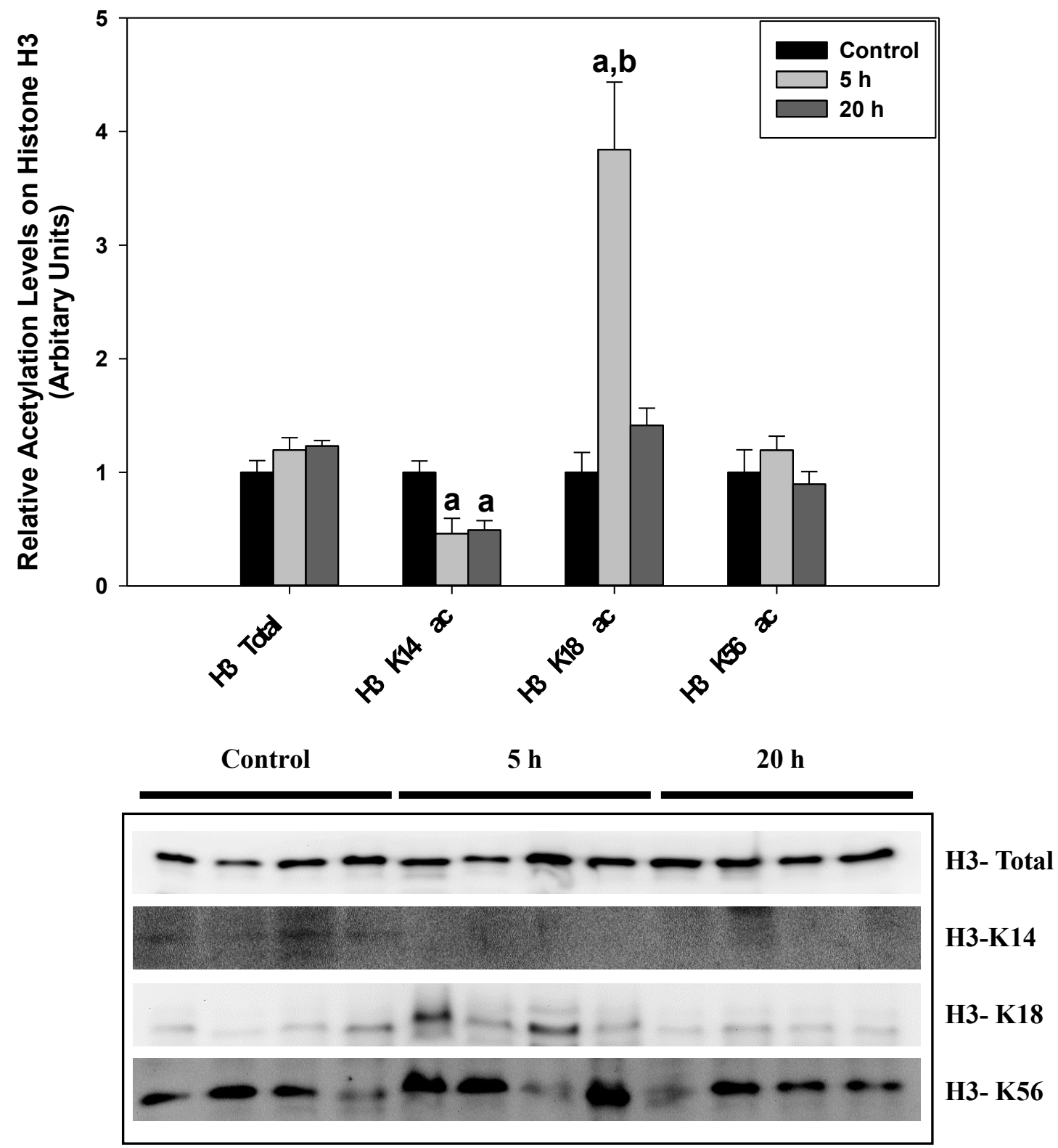
Figure 1. The protein expression level of histone $\mathrm{H} 3$ along with the acetylation levels of four lysine residues on histone $\mathrm{H} 3$ in the liver of T.s. elegans in response to control, $5 \mathrm{~h}$ anoxia, and $20 \mathrm{~h}$ anoxia as determined by western immunoblotting. Data are mean \pm SEM, and $n=3-4$ independent trials on tissue samples from different animals. a Significantly different from the corresponding control $(\mathrm{p}<0.05)$. $\mathrm{b}$ Significantly different values from the $5 \mathrm{~h}$ anoxic value.

The protein expression levels of the corresponding acetyltransferases were also measured. HAT1, a GCN-family of acetyltransferases, decreased in expression by $0.67 \pm$ 0.09 -fold in response to $5 \mathrm{~h}$ anoxia and continued to decrease by $0.24 \pm 0.11$-fold in response to $20 \mathrm{~h}$ anoxia compared to the control. The expression levels of two other prominent GCN-family of acetyltransferases, GCN5L2 and PCAF remained unchanged (Figure 2). 

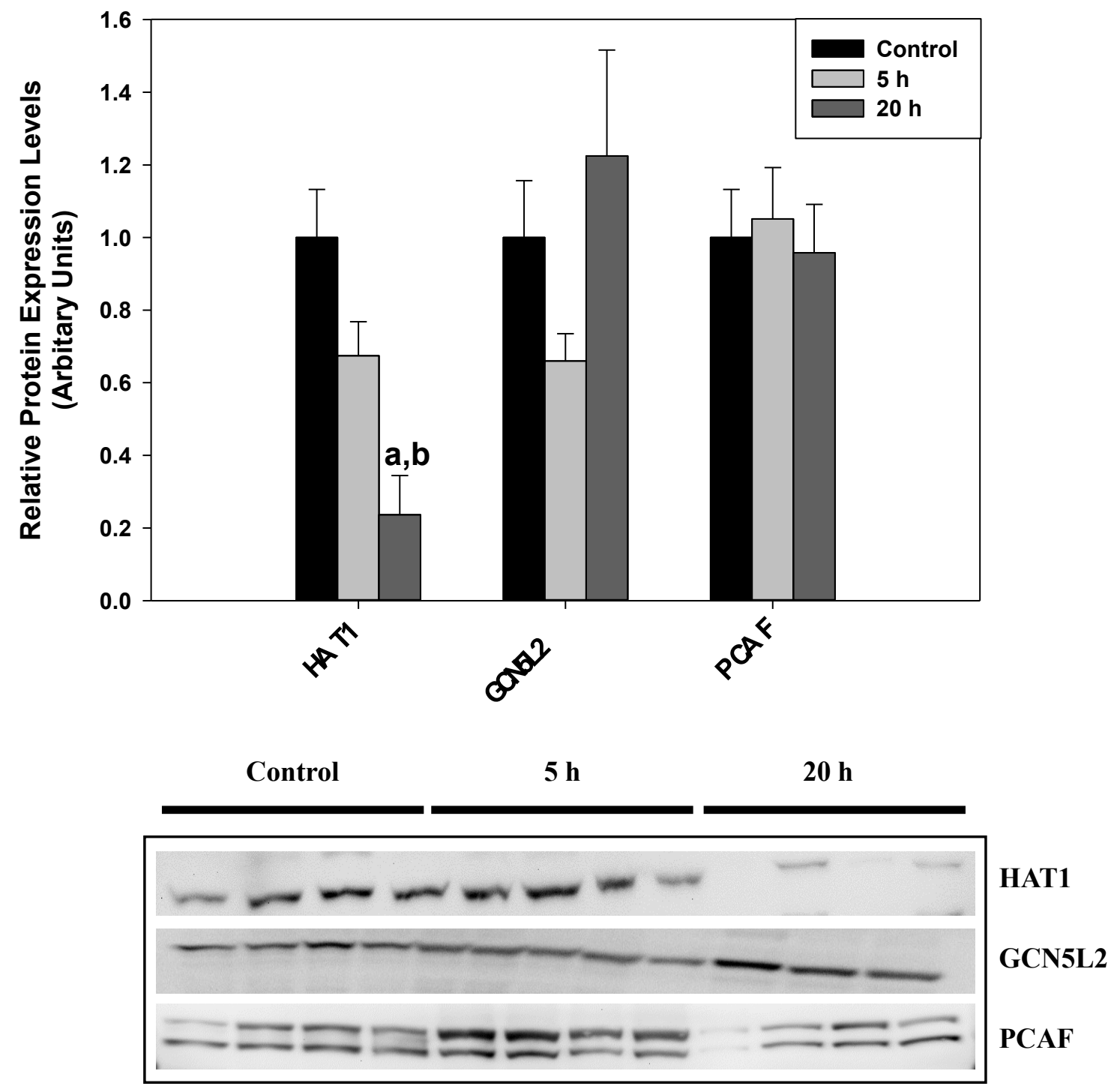

Figure 2. The relative protein expression levels of GCN-family of acetyltransferases, HAT1, GCN5L2, and PCAF in response to control, $5 \mathrm{~h}$, and $20 \mathrm{~h}$ anoxia in the liver of T.s. elegans. Other information as in Figure 1.

Tip60, a prominent member of the MYST family of acetyltransferases, significantly decreased in expression by $0.47 \pm 0.01$-fold during $5 \mathrm{~h}$ anoxia and returned back to control levels during $20 \mathrm{~h}$ anoxia (Figure 3 ). 

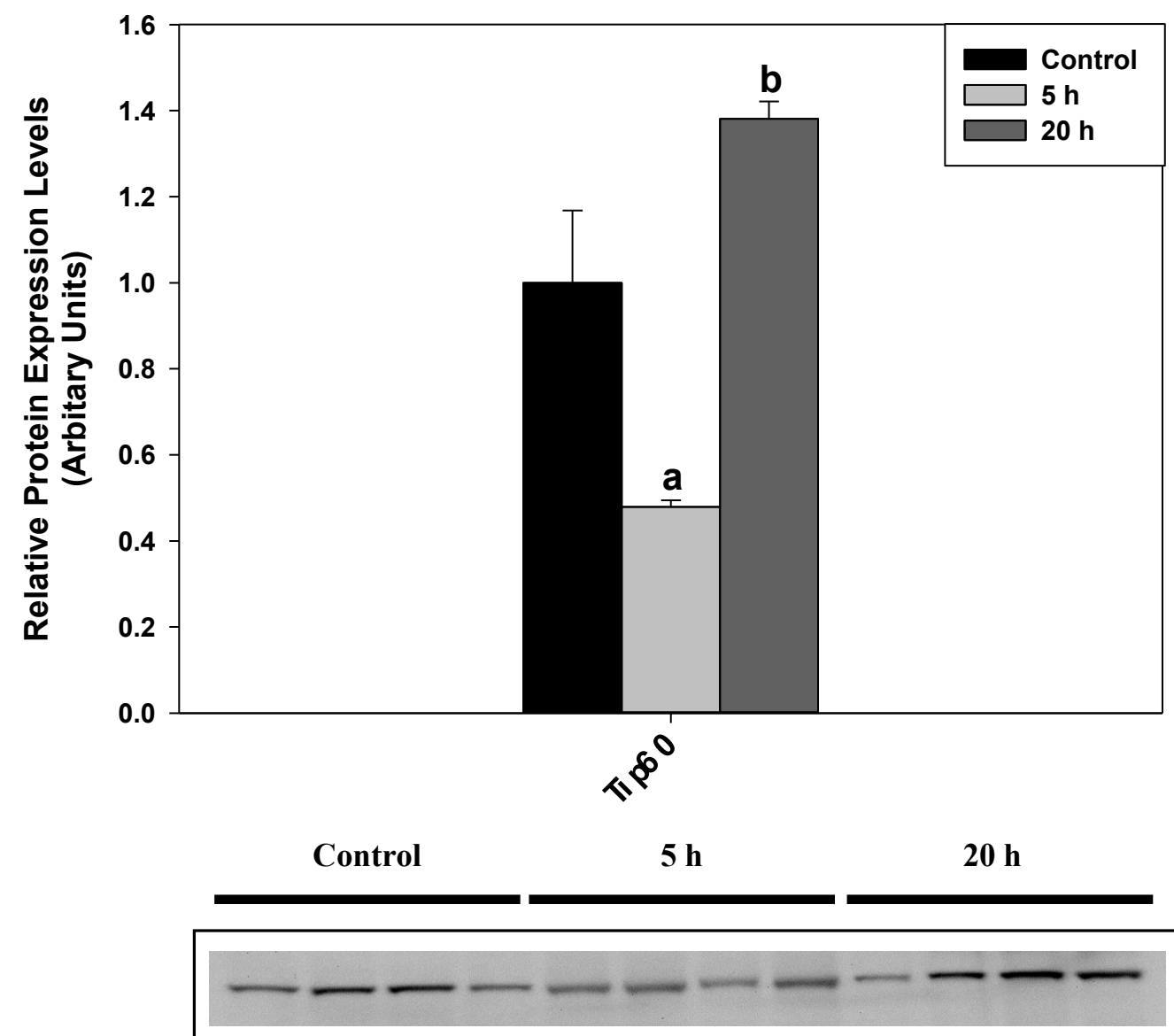

Tip60

Figure 3. The relative protein expression levels of MYST family of acetyltransferases, Tip60, in response to control, $5 \mathrm{~h}$, and $20 \mathrm{~h}$ anoxia in the liver of T.s. elegans. Other information as in Figure 1.

The protein expression level of CBP, a vital component of CBP-p300 HATs, also decreased in expression by $0.42 \pm 0.06$-fold during $5 \mathrm{~h}$ anoxia and continued to decrease by $0.29 \pm 0.06$-fold during $20 \mathrm{~h}$ anoxia compared to the control (Figure 4). 


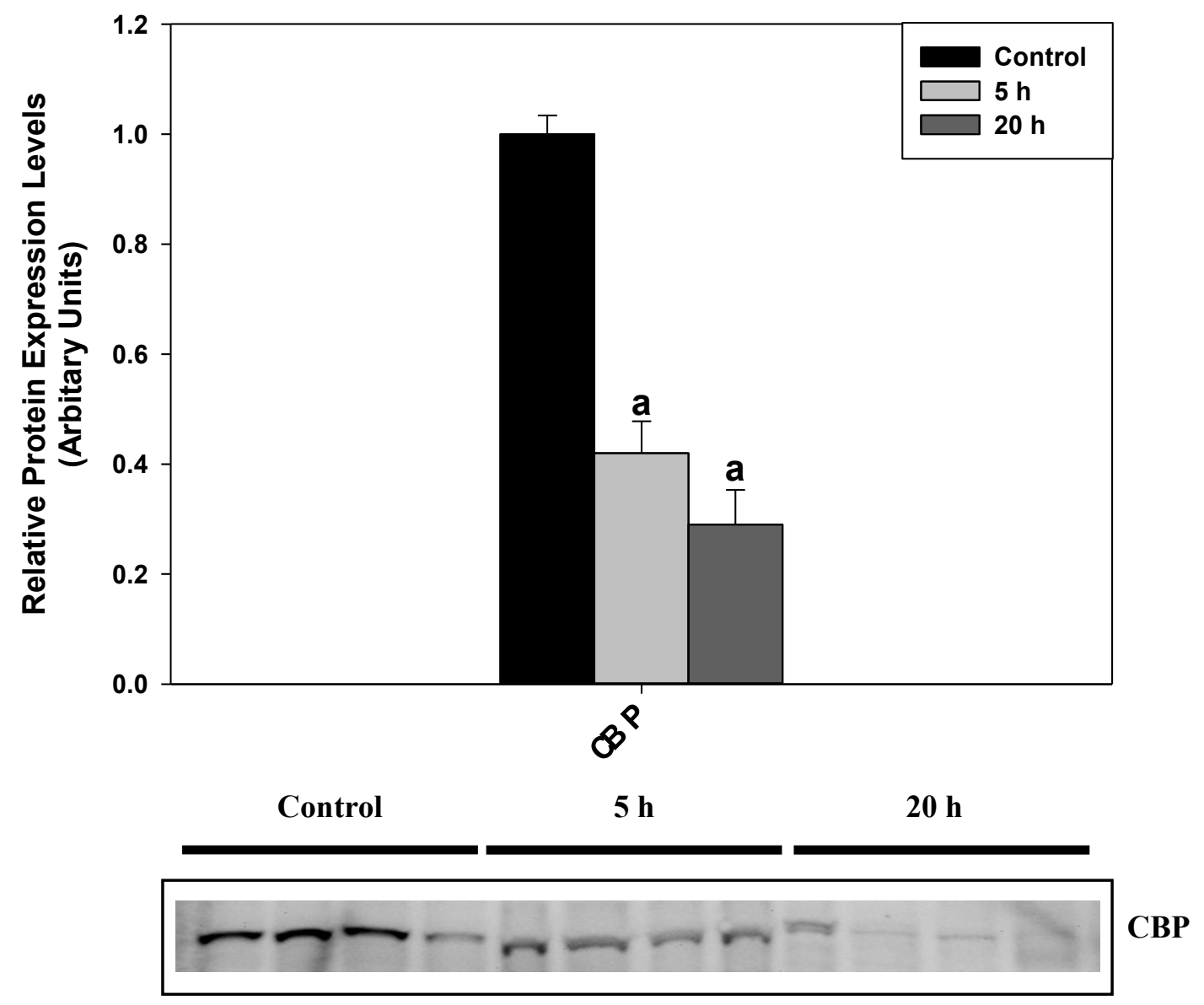

Figure 4. The relative protein expression levels of CBP acetyltransferases in response to control, $5 \mathrm{~h}$, and $20 \mathrm{~h}$ anoxia in the liver of T.s. elegans. Other information as in Figure 1.

Correspondingly, the total enzymatic activity of all nuclear HATs that can acetylate histone $\mathrm{H} 3$ significantly decreased in expression by $0.24 \pm 0.05$ during $5 \mathrm{~h}$ anoxia and remained decreased by $0.3 \pm 0.02$-fold during $20 \mathrm{~h}$ anoxia. The total enzymatic level of HATs however remained unchanged (Figure 5). 


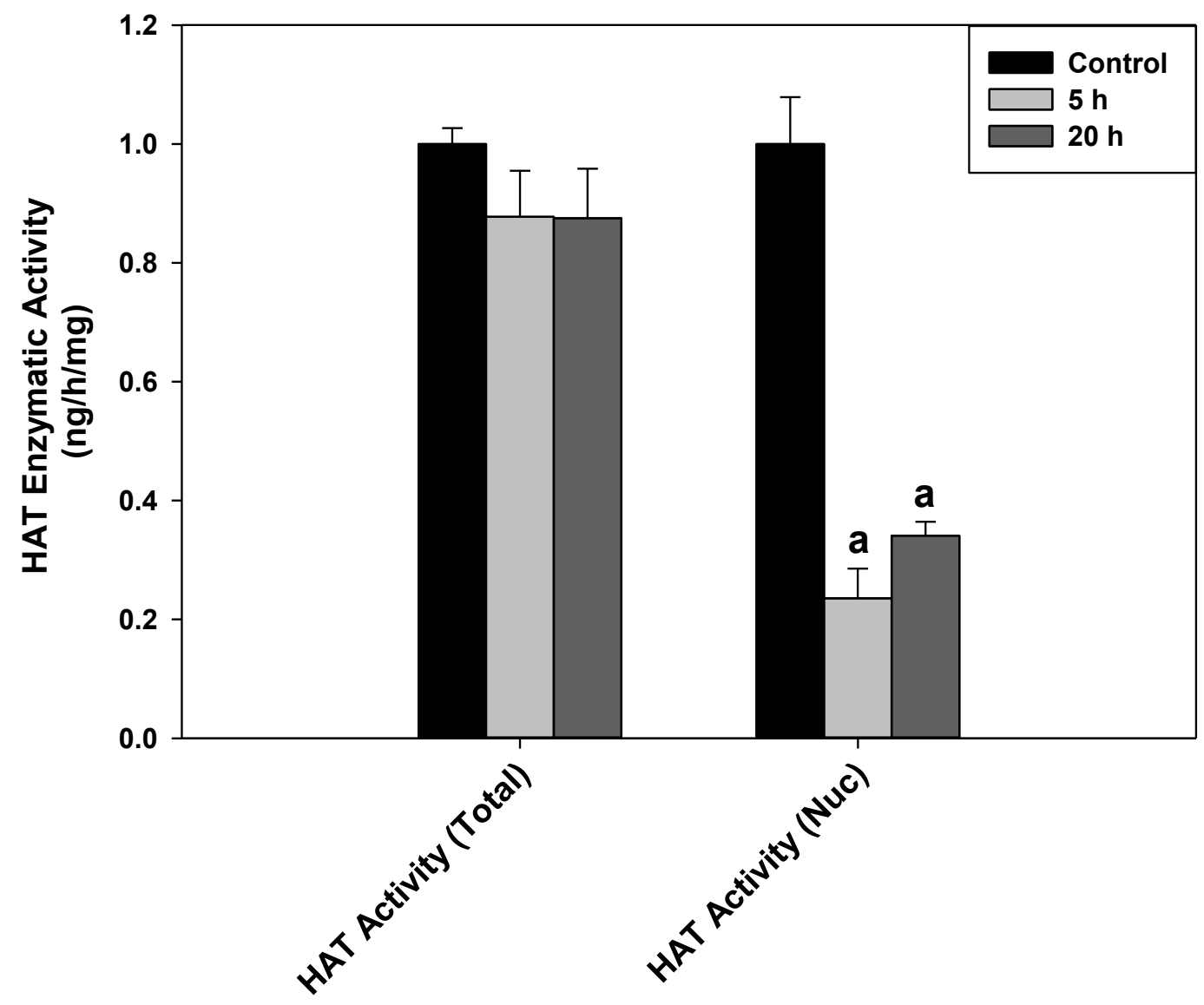

Figure 5. Total HAT enzymatic activity and nuclear HAT enzymatic activity (ng/h/mg) were measured in the liver of T.s. elegans in response to control, $5 \mathrm{~h}$ anoxia, and $20 \mathrm{~h}$ anoxia as determined by EpiQuik HAT Activity/Inhibition Assay kit from Epigentek. Other information as in Figure 1.

The protein expression levels of the type III nuclear histone deacetylases, SIRT1 and SIRT6, significantly decreased during anoxic exposure with SIRT 1 expression levels remained unchanged during $5 \mathrm{~h}$ anoxia but decreased by $0.37 \pm 0.02$-fold during $20 \mathrm{~h}$ anoxia. SIRT 6 protein expression levels decreased during $5 \mathrm{~h}$ anoxia by $0.65 \pm 0.11$-fold and $20 \mathrm{~h}$ anoxia by $0.48 \pm 0.06$-fold, compared to the control. The protein expression levels of SIRT 7 remained unchanged (Figure 6). 

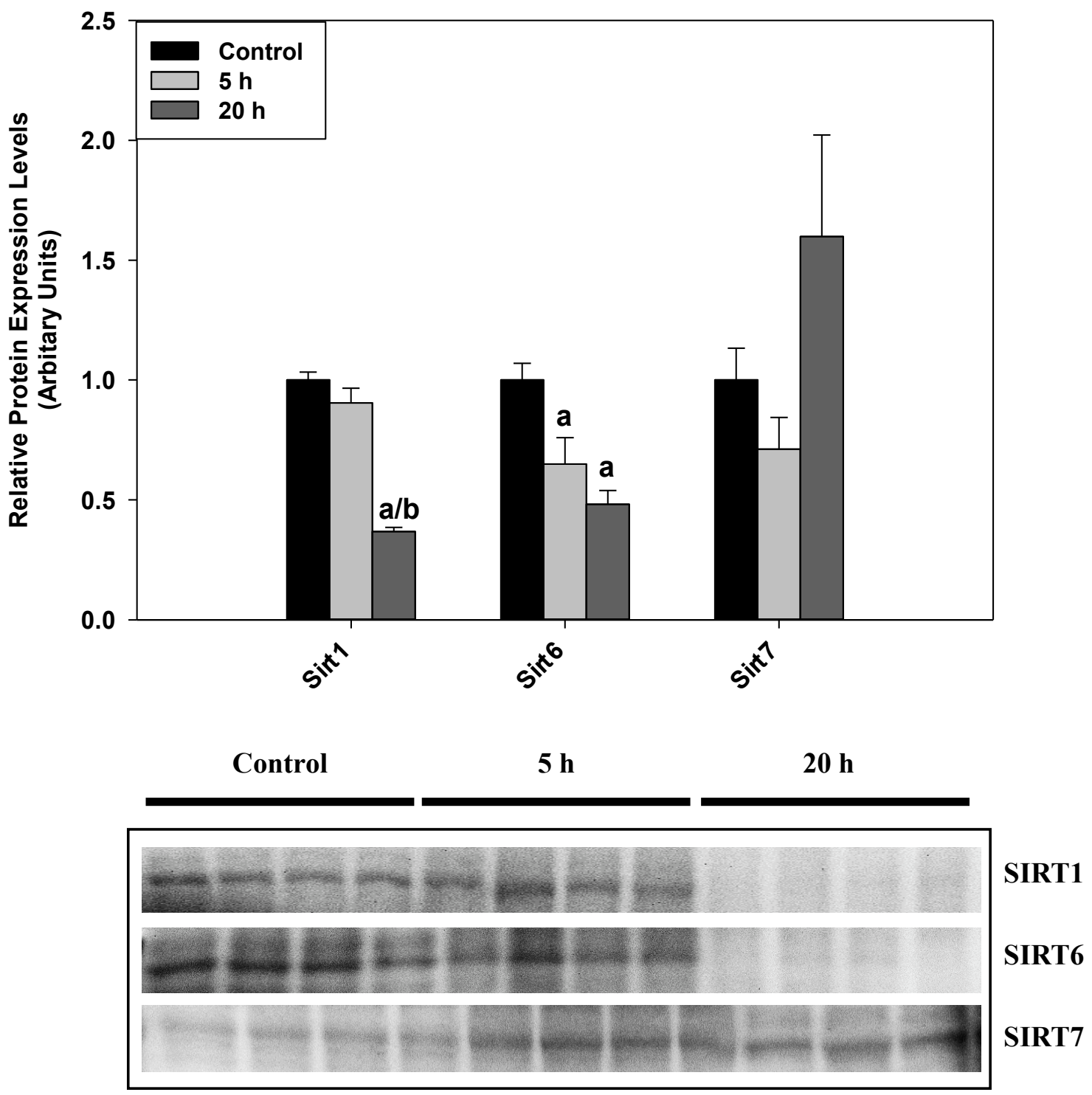

Figure 6. The relative protein expression levels of the nuclear SIRTs, SIRT1, SIRT6, and SIRT7 in response to control, $5 \mathrm{~h}$ anoxia, and $20 \mathrm{~h}$ anoxia, in the liver of T.s.elegans. Other information as in Figure 1.

Similarly, the nuclear enzymatic activity of SIRTs significantly decreased by 0.22 \pm 0.04 -fold during $5 \mathrm{~h}$ anoxia and remained decreased by $0.18 \pm 0.07$-fold during $20 \mathrm{~h}$ anoxia (Figure 7). 


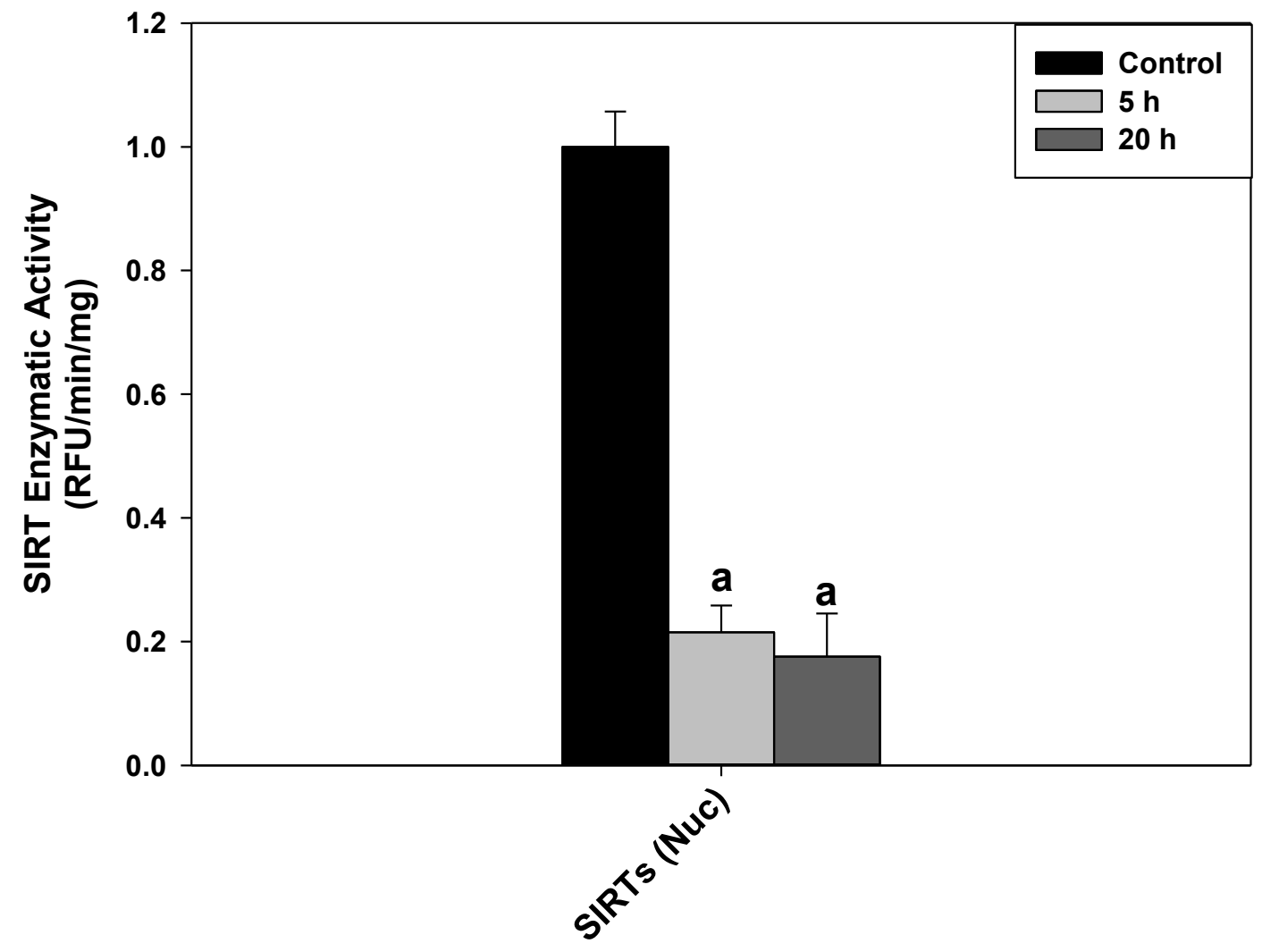

Figure 7. SIRT enzymatic activity (RFU/min/mg) was measured in the liver of T.s. elegans in response to control, $5 \mathrm{~h}$ anoxia, and $20 \mathrm{~h}$ anoxia as determined by Epigenase Universal SIRT Activity/Inhibition Fluorometric Assay. Other information as in Figure 1.

\section{Discussion}

Histone acetylation was first discovered more than 50 years ago and was identified to regulate the overall transcriptional output of eukaryotic genomes (Allfrey et al., 1964). Since then, histone acetylation in particular, was reported to be located in actively transcribed, euchromatic regions of the genome (Hebbes et al., 1988; Sealy and Chalkley, 1978; Vidali et al., 1978). Acetylation is a stable epigenetic mark that occurs only on the amino-tails (N-tails) of the core histone protein (the building blocks of nucleosomes). Histone acetylation alters the positive charge of the histone proteins and 
thereby disrupts the overall ionic interaction between positively charged histone tails and the negatively charged DNA (Hebbes et al., 1988; Hong et al., 1993; Sterner and Berger, 2000; Struhl, 1998). Consequently, acetylation of core histones reduce internucleosomal interactions and increases the accessibility of RNA polymerase and the transcriptional machinery to targeted promoter regions of chromatin templates and enhance gene transcription (Nightingale et al., 1998; Ura et al., 1997). Histone acetylation is catalyzed by HATs, that are also referred to as KATs (lysine acetyltransferases), and can be reversed swiftly by HDACs (Khochbin et al., 2001; Spange et al., 2009). Thus, the interplay between HAT-mediated histone acetylation and HDAC-mediated histone deacetylation allows the genome to switch between permissive and restricted chromatin states not only at a global level but also at a single promoter-level. This type of swift and energy-wise transcriptional regulation may be vital for the global reduction in gene expression seen in hypometabolic, anoxia-tolerant red-eared sliders.

Red-eared sliders are capable of surviving three months of continuous oxygen deprivation mainly by reducing the overall metabolic rate to $10 \%$ of control, normoxic values. MRD is achieved by a complete reorganization of all metabolic pathways and a coordinated suppression and redirection of all cellular processes including protein translation, degradation, cell cycle, apoptosis, ion motive regulation, and gene expression (Hochachka, 1988; Hochachka and Lutz, 2001a; Jackson, 1968, 2000, Storey, 2007, 1996; K. Storey and Storey, 2004a; Storey and Storey, 1990b). To date, multiple epigenetic regulatory mechanisms have been elucidated as prominent players of global transcriptional regulation in red-eared sliders (K. Biggar et al., 2011; Biggar and Storey, 2011, 2015; Krivoruchko and Storey, 2010d; S Wijenayake and Storey, 2016). However, 
the dynamic balance between HAT-mediated histone H3 acetylation and SIRT-mediated deacetylation warrants further investigation.

The present study explored the regulation of gene expression, a unique characteristic of MRD, in the context of histone acetylation in the liver of control normoxic, $5 \mathrm{~h}$ anoxic, and $20 \mathrm{~h}$ anoxic red-eared sliders. The liver was chosen for the study because liver plays a critical role in anoxia-tolerance in freshwater turtles as the primary site of glycogen storage as well as glycogenolysis. Glycolysis is the sole metabolic fuel that can be broken down to produce ATP during anaerobiosis. Furthermore, although anoxic hepatocytes have shown to decrease the metabolic rate by 90\% (Buck et al., 1993), liver remains proliferative and active during MRD. As such, liver would be an optimal tissue that can be used to investigate the balance between transcriptionally permissive histone $\mathrm{H} 3$ acetylation and transcriptionally repressive histone $\mathrm{H} 3$ deacetylation.

Target-specific responses were seen for histone H3-acetylation in the liver in response to $5 \mathrm{~h}$ and $20 \mathrm{~h}$ anoxia. In particular, histone $\mathrm{H} 3$ (total) remained unchanged in response to anoxia (Figure 1). A stable maintenance of histone $\mathrm{H} 3$ is expected, as posttranslational modifications (PTMs) are more swift and energy-wise methods of controlling protein function, activity, cellular distribution, and protein-protein interactions, instead of modifying the overall amount of enzymes in response in a low energy state (Storey, 2007). Furthermore, histone H3 was measured as a protein expression control to demonstrate that the changes in acetylation levels seen in response to anoxia are not due to changes in histone $\mathrm{H} 3$ protein levels. These results correspond to the findings of (Krivoruchko and Storey, 2010d), in which histone H3 protein expression 
levels also remained unchanged in response to anoxia in red-earlier sliders. H3K14ac, typically associated with active promoters, significantly decreased in response to both short-term (5 h) and long-term (20 h) anoxia. According to previous studies, genomewide distribution of $\mathrm{H} 3 \mathrm{~K} 14 \mathrm{ac}$ and $\mathrm{H} 3 \mathrm{~K} 9 \mathrm{ac}$ highly correlate to one another and can be found in euchromatic promoter regions, gene regulatory elements, as well as bivalent promoters (Karmodiya et al., 2012). Similarly, the genome-wide expression of H3K9ac significantly decreased in response to anoxia in red-eared sliders (Krivoruchko and Storey, 2010d). As such, a significant decrease in H3K14ac and H3K9ac may indicate a potential increase in chromatin condensation and a state of transcriptional repression in the liver in response to anoxia. On the contrary, H3K18ac levels significantly increased in expression during $5 \mathrm{~h}$ anoxia and returned back to control conditions during $20 \mathrm{~h}$ anoxia. However, the increase in H3K18ac may not indicate a global increase in transcription in a low energy state, such as anoxia, in which the overall transcriptional output is significantly decreased, but rather an increase in H3K18ac could correlate to an increase $\mathrm{NF} \kappa \mathrm{B}$ expression. $\mathrm{NF \kappa B}$ is a master transcription factor that is central to the anoxic stress response. Correspondingly, a plausible correlation between NFKB expression and the expression of H3K18ac marks in the promoter regions have previously been reported (Huang et al., 2015). Furthermore, NFkB pathway is activated in the turtle liver during anoxia and was reported to play a role in anoxia tolerance and survival in T.s. elgans (Krivoruchko and Storey, 2010c). The final acetylation marks of the study, H3K56ac remained unchanged in response to anoxia. H3K56ac could be maintained in the red-eared sliders during anoxia because histones with H3K56ac modifications were found to be enriched at the sites of DNA repair (Wurtele et al., 2012). 
As such, H3K56ac could play a prominent role in the DNA damage response in T.s. elegans.

HATs are a diverse group of enzymes that are categorized into groups based on the catalytic domains and the specificity of the lysine residues they acetylate (Lee and Workman, 2007). GNATs including HAT1, GCN5L2, and PCAF along with Hpa2 and Nutla catalyze the transfer of acetyl groups from acetyl-CoA to a primary amine (Dyda et al., 2000; Huang et al., 2015; Kimura et al., 2005a; Neuwald and Landsman, 1997). GNATs are well-established epigenetic players that are involved in many different cellular processes, including acetylation of histone proteins at specific lysine residues, a process that is associated with active transcription and euchromatic regions of the genome (Allfrey et al., 1964; Dyda et al., 2000; Hebbes et al., 1988; Sterner and Berger, 2000; Ura et al., 1997). HAT1 expression significantly decreased in expression during 20 $\mathrm{h}$ anoxia and remained unchanged during $5 \mathrm{~h}$ anoxia (Figure 2). Decreased HAT1 protein expression could indicate an overall decrease in histone acetylation in the red-eared sliders as a way of reducing the overall transcriptional output during anoxia. On the contrary two other established GNATs, GCN5L2 and PCAF, remained unchanged during $5 \mathrm{~h}$ and $20 \mathrm{~h}$ anoxia. GCN5L2 is an activator of transcriptional initiation and is recruited to gene promoters (Dyda et al., 2000; Neuwald and Landsman, 1997). GCN5L2 also acetylate lysine14 and lysine23 residues of histone H3 (Johnsson et al., 2009; XueFranzen et al., 2013). However, H3K14 (figure 1) and H3K23 (Krivoruchko and Storey, 2010d) decreased in response to anoxia in red-eared sliders. Therefore, although the protein expression levels of GCN5L2 remained unchanged in response to anoxia, the GCN5L2 HAT enzymatic activity may have been affected by PTMs. GCN5L2 activity is 
regulated by reversible protein phosphorylation (RPP) by DNA-dependent protein kinase (DNA-PK) (Barlev et al., 1998). Similar to GCN5L2 levels, PCAF protein expression levels remained unchanged in response to anoxia in red-reared sliders. PCAF has been reported to acetylate and reduce the overall enzymatic activity of pyruvate kinase (PK), one of the major glycolytic enzyme that control the metabolic flux through glycolysis ( $\mathrm{Lv}$ et al., 2011). Correspondingly, turtles use covalent modifications to regulate the enzymatic actives of PK, as part of the anoxia tolerant metabolic strategy (Brooks and Storey, 1989). Therefore, PCAF protein expression may remain stagnant during anoxia in the liver as a means of regulating the glycolytic flux.

The MYST family of acetyltransferases include Morf, Ybf2, Sas2, and Tip60. Possible functions of the Tip60 complex include transcriptional activation as well as DNA repair (Kimura et al., 2005b). MYST family of HATs acetylate six lysine residues of histone proteins including H2AK5ac, H3K14ac, H4K5/8/12/16ac (Kimura and Horikoshi, 1998). Tip60 protein expression levels decreased in response to $5 \mathrm{~h}$ anoxia and returned back to control levels during $20 \mathrm{~h}$ anoxia (Figure 3) and in correlation H3K14ac levels decreased in response to anoxia (Figure 1). As such, the decrease in Tip60 levels during $5 \mathrm{~h}$ anoxia could be part of the global decrease in gene expression, a prominent characteristic of MRD in red-eared sliders.

CBP is not only a well-established HAT that targets H3K56 but it is also a wellestablished co-transcriptional regulator of several transcription factors including CREB and p53 (Kimura and Horikoshi, 1998). Therefore, a decrease in CBP expression that is seen during to $5 \mathrm{~h}$ and $20 \mathrm{~h}$ anoxia (Figure 5) could contribute to the widespread transcriptional suppression that is characteristic of the low-energy anoxic state. 
The total as well as nuclear HAT enzymatic activity yielded very interesting results. Although, the total enzymatic activity of all HATs that can acetylate lysine residues of both histone and non-histone proteins remained unchanged in response to $5 \mathrm{~h}$ and $20 \mathrm{~h}$ anoxia, the nuclear HATs that acetylate only the histone proteins decreased in expression during anoxia (Figure 6). These results correspond to the overall decrease in histone $\mathrm{H} 3$ acetylation as well as the overall decrease in HAT expression seen in the study. Suppression of histone H3 acetylation during anoxia in red-eared sliders could be a prominent characteristic of anaerobiosis and MRD.

SIRTs are $\mathrm{NAD}^{+}$- dependent class III HDACs, that regulate a variety of cellular processes ranging from transcriptional regulation through histone deacetylation, to DNA repair, metabolic regulation, regulation of glucose homeostasis, as well as aging (Finkel et al., 2009a; Milne and Denu, 2008; Sauve et al., 2006). In the context of turtle anaerobiosis, Class I and II HDACs were shown to increase in mRNA and protein expression during $5 \mathrm{~h}$ and $20 \mathrm{~h}$ anoxia and was postulated to be a major characteristic of anoxia-survival (Krivoruchko and Storey, 2010d). However, the potential involvement of nuclear SIRTs (SIRT1, SIRT6, and SIRT7) in anaerobiosis requires further exploration. Overall, the results suggest a limited SIRT regulation in the liver during $5 \mathrm{~h}$ and $20 \mathrm{~h}$ anoxia in red-eared sliders. In particular, the protein expression levels of SIRT1 and SIRT6 decreased significantly in response to anoxia, where as SIRT7 protein levels remained unchanged (Figure 6). Correspondingly, the nuclear enzymatic activity of SIRTs significantly decreased during $5 \mathrm{~h}$ and $20 \mathrm{~h}$ anoxia (Figure 7). A decrease in nuclear SIRTs expression and enzymatic activity could be part of the global suppression of gene expression during MRD that has been reported in red-eared sliders. MRD is the 
combinatorial suppression of all energy consuming processes and reprioritization of ATP towards cell processes that are necessary for anoxia survival (Storey, 2007, 1996; Storey and Storey, 1990b). Therefore, during MRD, hepatocytes could be monopolizing type I and II HDACs to deacetylate transcriptionally relevant lysine residues of histone $\mathrm{H} 3$ and enforce a state of chromatin condensation in T.s. elegans. As such, it is possible that transcriptional silencing in the liver by SIRT1, 6, and 7 is not as prominent.

In summary, this study suggests a role for histone $\mathrm{H} 3$ acetylation and deacetylation in the liver during anoxia. Maintaining a proper balance between permissive chromatin and repressive chromatin is of utmost importance in a low energy, anoxic state, in which anaerobic glycolysis is the sole source of ATP production. Therefore, red-eared sliders could be suppressing permissive histone marks such as acetylation while promoting repressive histone marks to promote a transcriptionally silent state in the liver during anoxia.

\section{Acknowledgements}

We thank Jan Storey for editing this paper. 


\section{Reference}

Allfrey, V., Faulkner, R., Mirsky, A., 1964. Acetylation and methyaltion of histones and their possible roles in the regulation of RNA synthesis. Proc. Natl. Acad. Sci. U. S. A. 51, 786-94.

Allis, C.D., Jenuwein, T., 2016. The molecular hallmarks of epigenetic control. Nat. Rev. Genet. 17, 487-500. doi:10.1038/nrg.2016.59

Avvakumov, N., Cote, J., 2007. The MYST family of histone acetyltransferases and their intimate links to cancer. Oncogene 26, 5395-5407. doi:10.1038/sj.onc.1210608

Bannister, A., Kouzarides, T., 1996. The CBP co-activator is a histone acetyltransferase. Nature 384, 641-643. doi:10.1038/384641a0

Bansal, S., Biggar, K.K., Krivoruchko, A., Storey, K.B., 2016. Response of the JAKSTAT signaling pathway to oxygen deprivation in the red eared slider turtle, Trachemys scripta elegans. Gene 593, 34-40. doi:10.1016/j.gene.2016.08.010

Barlev, N., Poltoratsky, V., Owen-Hughes, T., Ying, C., Liu, L., Workman, J., Berger, S., 1998. Repression of GCN5 histone acetyltransferase activity via bromodomainmediated binding and phosphorylation by the $\mathrm{Ku}-\mathrm{DNA}-$ dependent protein kinase complex. Mol. Cell. Biol. 18, 1349-58.

Bártová, E., Krejčí, J., Harničarová, A., Galiová, G., Kozubek, S., 2008. Histone modifications and nuclear architecture: A review. J. Histochem. Cytochem. 56, 711721. doi:10.1369/jhc.2008.951251

Bell, R., Storey, K., 2012. Regulation of liver glutamate dehydrogenase from an anoxiatolerant freshwater turtle. HOAJ Biol. 1, 1-3. doi:org/10.7243/2050-0874-1-3

Berger, S., 2002. Histone modifications in transcriptional regulation. Curr. Opin. Genet. 
Dev. 12, 142-148. doi:10.1016/S0959-437X(02)00279-4

Biggar, K., Groom, A., Storey, K., 2011. Hypometabolism and turtles: Physiological and molecular strategies of anoxic survival, in: Nowakowska, A., Caputa, M. (Eds.), Hypometabolism: Strategies of Survival in Vertebrates and Invertebrates. Research Signpost, Kerala, pp. 57-94.

Biggar, K., Storey, K., 2011. The emerging roles of microRNAs in the molecular responses of metabolic rate depression. J. Mol. Cell Biol. 3, 167-175. doi:10.1093/jmcb/mjq045

Biggar, K.K., Kornfeld, S.F., Storey, K.B., 2011. Amplification and sequencing of mature microRNAs in uncharacterized animal models using stem-loop reverse transcription-polymerase chain reaction, Analytical Biochemistry. doi:10.1016/j.ab.2011.05.015

Biggar, K.K., Storey, K.B., 2015. Insight into post-transcriptional gene regulation: stressresponsive microRNAs and their role in the environmental stress survival of tolerant animals. J. Exp. Biol. 218, 1281-1289. doi:10.1242/jeb.104828.

Biggar, K.K., Storey, K.B., 2012. Evidence for cell cycle suppression and microRNA regulation of cyclin D1 during anoxia exposure in turtles. Cell Cycle 11, 1705-1713. doi:10.4161/cc. 19790

Brooks, S., Storey, K., 1993. De novo protein synthesis and protein phosphorylation during anoxia and recovery in the red-eared turtle. Am. J. Physiol. 265, R1380-6.

Brooks, S., Storey, K., 1989. Regulation of glycolytic enzymes during anoxia in the turtle Pseudemys scripta. Am. J. Physiol. 257, R278-R283.

Buck, L., Land, S., Hochachka, P., 1993. Anoxia-tolerant hepatocytes: Model system for 
study of reversible metabolic suppression. Am. J. Physiol. 265, 49-56.

Chen, L.-F., Fischle, W., Verdin, E., Greene, W., 2001. Duration of Nuclear NF-kappa B action regulated by reversible acetylation. Science (80-. ). 293, 1653-1657. doi:10.1126/science. 1062374

Cheung, P., Allis, C., Sassone-Corsi, P., 2000. Signaling to chromatin through histone modifications. Cell 103, 263-271. doi:10.1016/S0092-8674(00)00118-5

Choudhary, C., Mann, M., 2010. Decoding signalling networks by mass spectrometrybased proteomics. Nat. Rev. Mol. Cell Biol. 11, 427-439. doi:10.1038/nrm2900 Clayton, A., Hazzalin, C., Mahadevan, L., 2006. Enhanced histone acetylation and transcription: A dynamic perspective. Mol. Cell 23, 289-296. doi:10.1016/j.molcel.2006.06.017

Dawson, N., Bell, R., Storey, K., 2013. Purification and properties of white muscle lactate dehydrogenase from the anoxia-tolerant turtle, the red-eared slider, Trachemys scripta elegans. Enzyme Res. 2013, 1-8. doi:10.1155/2013/784973

Dawson, N.J., Biggar, K.K., Storey, K.B., 2013. Characterization of fructose-1,6bisphosphate aldolase during anoxia in the tolerant turtle, Trachemys scripta elegans: An assessment of enzyme activity, expression and structure. PLoS One 8, e68830. doi:10.1371/journal.pone.0068830

de Ruijter, A., van Gennip, A., Caron, H., Kemp, S., van Kuilenburg, A., 2003. Histone deacetylases (HDACs): characterization of the classical HDAC family. Biochem. J. 370, 737-49. doi:10.1042/BJ20021321

Delcuve, G., Khan, D., Davie, J., Rogers, M., Lichter, P., Pscherer, A., Schnölzer, M., Martinez, E., Wong, J., Rasko, J., Rokhsar, D., Degnan, B., Mattick, J., Hughes, T., 
Strahl, B., Grunstein, M., Greenblatt, J., Buratowski, S., Krogan, N., Hiebert, S., Kruse, U., Neubauer, G., Ramsden, N., Drewes, G., 2012. Roles of histone deacetylases in epigenetic regulation: Emerging paradigms from studies with inhibitors. Clin. Epigenetics 4, 5. doi:10.1186/1868-7083-4-5

Dyda, F., Klein, D., Hickman, A., 2000. GCN5-related N-acetyltransferases: A structural overview. Annu. Rev. Biophys. Biomol. Struct. 29, 81-103.

doi:10.1146/annurev.biophys.29.1.81

Eberharter, A., Becker, P., 2002. Histone acetylation: A switch between repressive and permissive chromatin: Second in review series on chromatin dynamics. EMBO Rep. 3, 224-229. doi:10.1093/embo-reports/kvf053

Finkel, T., Deng, C.-X., Mostoslavsky, R., 2009. Recent progress in the biology and physiology of sirtuins. Nature 460, 587-591. doi:10.1038/nature08197

Glozak, M., Sengupta, N., Zhang, X., Seto, E., 2005. Acetylation and deacetylation of non-histone proteins. Gene 363, 15-23. doi:10.1016/j.gene.2005.09.010

Gu, W., Roeder, R., 1997. Activation of p53 sequence-specific DNA binding by acetylation of the p53 C-terminal domain. Cell 90, 595-606.

Hebbes, T., Thorne, A., Crane-Robinson, C., 1988. A direct link between core histone acetylation and transcriptionally active chromatin. EMBO J. 7, 1395-402.

Hermes-Lima, M., Zenteno-Savín, T., 2002. Animal response to drastic changes in oxygen availability and physiological oxidative stress. Comp. Biochem. Physiol. Toxicol. Pharmacol. 133, 537-56.

Hochachka, P.W., 1988. Metabolic suppression and oxygen availability. Can. J. Zool. 66, $152-158$. 
Hochachka, P.W., 1986. Defense strategies against hypoxia and hypothermia. Science (80-. ). 231, 234-41.

Hochachka, P.W., Buck, L.T., Doll, C.J., Land, S.C., 1996. Unifying theory of hypoxia tolerance: molecular/metabolic defense and rescue mechanisms for surviving oxygen lack. Proc. Natl. Acad. Sci. U. S. A. 93, 9493-8.

Hochachka, P.W., Lutz, P.L., 2001. Mechanism, origin, and evolution of anoxia tolerance in animals. Comp. Biochem. Physiol. B. Biochem. Mol. Biol. 130, 435-59.

Hong, L., Schroth, G., Matthews, H., Yau, P., Bradbury, E., 1993. Studies of the DNA binding properties of histone $\mathrm{H} 4$ amino terminus. Thermal denaturation studies reveal that acetylation markedly reduces the binding constant of the $\mathrm{H} 4$ \&quot;tail\&quot; to DNA. J. Biol. Chem. 268, 305-14.

Huang, J., Wan, D., Li, J., Chen, H., Huang, K., Zheng, L., 2015. Histone acetyltransferase PCAF regulates inflammatory molecules in the development of renal injury. Epigenetics 10, 62-72. doi:10.4161/15592294.2014.990780

Jackson, D., 1997. Lactate accumulation in the shell of the turtle, Chrysemys picta bellii, during anoxia at 3 and $10^{\circ}$ C. J. Exp. Biol. 200, 2295-2300.

Jackson, D., 1968. Metabolic depression and oxygen depletion in the diving turtle. J. Appl. Physiol. 24, 503-9.

Jackson, D., Crocker, C., Ultsch, G., 2000. Bone and shell contribution to lactic acid buffering of submerged turtles Chrysemys picta bellii at $3^{\circ} \mathrm{C}$. Am. J. Physiol. Regul. Integr. Comp. Physiol. 278, R1564-1571.

Jackson, D., Heisler, N., 1983. Intracellular and extracellular acid-base and electrolyte status of submerged anoxic turtles at $3^{\circ} \mathrm{C}$. Respir. Physiol. 53, 187-201. 
Jackson, D., Toney, V., Okamoto, S., 1999. Lactate distribution and metabolism during and after anoxia in the turtle, Chrysemys picta bellii. Am. J. Physiol. 271, R409R416.

Jackson, D., Ultsch, G., 1982. Long-term submergence at $3^{\circ} \mathrm{C}$ of the turtle, Chrysemys picta bellii, in normoxic and severely hypoxic water: II. Extracellular ionic responses to extreme lactic acidosis. J. Exp. Biol. 29-43.

Jackson, D.C., 2000. Living without oxygen: Lessons from the freshwater turtle. Comp. Biochem. Physiol. Part A Mol. Integr. Physiol. 125, 299-315. doi:10.1016/S10956433(00)00160-4

Jackson, D.C., Taylor, S.E., Asare, V.S., Villarnovo, D., Gall, J.M., Reese, S.A., 2006. Comparative shell buffering properties correlate with anoxia tolerance in freshwater turtles. AJP Regul. Integr. Comp. Physiol. 292, R1008-R1015.

doi:10.1152/ajpregu.00519.2006

Jenuwein, T., Allis, C., 2001. Translating the histone code. Science (80-. ). 293, $1074-$ 1080.

Johnsson, A., Durand-Dubief, M., Xue-Franzen, Y., R?nnerblad, M., Ekwall, K., Wright, A., 2009. HAT-HDAC interplay modulates global histone H3K14 acetylation in gene-coding regions during stress. EMBO Rep. 10, 1009-1014.

doi:10.1038/embor.2009.127

Karmodiya, K., Krebs, A., Oulad-Abdelghani, M., Kimura, H., Tora, L., 2012. H3K9 and H3K14 acetylation co-occur at many gene regulatory elements, while H3K14ac marks a subset of inactive inducible promoters in mouse embryonic stem cells. BMC Genomics 13, 424. doi:10.1186/1471-2164-13-424 
Kawasaki, H., Schiltz, L., Chiu, R., Itakura, K., Taira, K., Nakatani, Y., Yokoyama, K., 2000. ATF-2 has intrinsic histone acetyltransferase activity which is modulated by phosphorylation. Nature 405, 195-200. doi:10.1038/35012097

Khochbin, S., Verdel, A., Lemercier, C., Seigneurin-Berny, D., 2001. Functional significance of histone deacetylase diversity. Curr. Opin. Genet. Dev. 11, 162-6.

Kimura, A., Horikoshi, M., 1998. Tip60 acetylates six lysines of a specific class in core histones in vitro. Genes Cells 3, 789-800.

Kimura, A., Matsubara, K., Horikoshi, M., 2005a. A Decade of Histone Acetylation: Marking Eukaryotic Chromosomes with Specific Codes. J. Biochem. 138, 647-662. doi:10.1093/jb/mvi184

Kimura, A., Matsubara, K., Horikoshi, M., 2005b. A Decade of histone acetylation: Marking eukaryotic chromosomes with specific codes. J. Biochem. 138, 647-662. doi:10.1093/jb/mvi184

Krivoruchko, A., Storey, K., 2013a. Activation of the unfolded protein response during anoxia exposure in the turtle Trachemys scripta elegans. Mol. Cell. Biochem. 374, 91-103. doi:10.1007/s11010-012-1508-3

Krivoruchko, A., Storey, K., 2013b. Anoxia-responsive regulation of the FoxO transcription factors in freshwater turtles, Trachemys scripta elegans. Biochim. Biophys. Acta - Gen. Subj. 1830, 4990-4998. doi:10.1016/j.bbagen.2013.06.034 Krivoruchko, A., Storey, K., 2010a. Activation of antioxidant defenses in response to freezing in freeze-tolerant painted turtle hatchlings. Biochim. Biophys. Acta - Gen. Subj. 1800, 662-668. doi:10.1016/j.bbagen.2010.03.015

Krivoruchko, A., Storey, K., 2010b. Regulation of the heat shock response under anoxia 
in the turtle, Trachemys scripta elegans. J. Comp. Physiol. B 180, 403-414. doi:10.1007/s00360-009-0414-9

Krivoruchko, A., Storey, K., 2010c. Molecular mechanisms of turtle anoxia tolerance: A role for NF-kB. Gene 450, 63-69. doi:10.1016/j.gene.2009.10.005

Krivoruchko, A., Storey, K., 2010d. Epigenetics in anoxia tolerance: A role for histone deacetylases. Mol. Cell. Biochem. 342, 151-161. doi:10.1007/s11010-010-0479-5

Lee, K., Workman, J., 2007. Histone acetyltransferase complexes: One size doesn't fit all. Nat. Rev. Mol. Cell Biol. 8, 284-295. doi:10.1038/nrm2145

Leipe, D., Landsman, D., 1997. Histone deacetylases, acetoin utilization proteins and acetylpolyamine amidohydrolases are members of an ancient protein superfamily. Nucleic Acids Res. 25, 3693-7.

Liu, X., Wang, L., Zhao, K., Thompson, P., Hwang, Y., Marmorstein, R., Cole, P., 2008. The structural basis of protein acetylation by the p300/CBP transcriptional coactivator. Nature 451, 846-850. doi:10.1038/nature06546

Lombardi, P., Cole, K., Dowling, D., Christianson, D., 2011. Structure, mechanism, and inhibition of histone deacetylases and related metalloenzymes. Curr. Opin. Struct. Biol. 21, 735-43. doi:10.1016/j.sbi.2011.08.004

Lv, L., Li, D., Zhao, D., Lin, R., Chu, Y., Zhang, H., Zha, Z., Liu, Y., Li, Z., Xu, Y., Wang, G., Huang, Y., Xiong, Y., Guan, K.-L., Lei, Q.-Y., 2011. Acetylation targets the M2 isoform of pyruvate kinase for degradation through chaperone-mediated autophagy and promotes tumor growth. Mol. Cell 42, 719-730. doi:10.1016/j.molcel.2011.04.025

Margueron, R., Trojer, P., Reinberg, D., 2005. The key to development: Interpreting the 
histone code? Curr. Opin. Genet. Dev. 15, 163-176. doi:10.1016/j.gde.2005.01.005

Mehrani, H., Storey, K., 1995. Enzymatic control of glycogenolysis during anoxic submergence in the freshwater turtle Trachemys scripta. Int. J. Biochem. Cell Biol. 821-830, 821-830. doi:10.1016/1357-2725(95)00042-N

Milne, J., Denu, J., 2008. The sirtuin family: Therapeutic targets to treat diseases of aging. Curr. Opin. Chem. Biol. 12, 11-17. doi:10.1016/j.cbpa.2008.01.019

Mizzen, C., Yang, X., Kokubo, T., Brownell, J., Bannister, A., Owen-Hughes, T., Workman, J., Wang, L., Berger, S., Kouzarides, T., Nakatani, Y., Allis, C., 1996. The TAF(II)250 subunit of TFIID has histone acetyltransferase activity. Cell 87, $1261-70$.

Munshi, N., Merika, M., Yie, J., Senger, K., Chen, G., Thanos, D., 1998. Acetylation of HMG I(Y) by CBP turns off IFN? Expression by disrupting the enhanceosome. Mol. Cell 2, 457-467. doi:10.1016/S1097-2765(00)80145-8

Neuwald, A., Landsman, D., 1997. GCN5-related histone N-acetyltransferases belong to a diverse superfamily that includes the yeast SPT10 protein. Trends Biochem. Sci. $22,154-5$.

Nightingale, K., Wellinger, R., Sogo, J., Becker, P., 1998. Histone acetylation facilitates RNA polymerase II transcription of the Drosophila hsp26 gene in chromatin. EMBO J. 17, 2865-76. doi:10.1093/emboj/17.10.2865

O’Malley, B., Spencer, T., Jenster, G., Burcin, M., Allis, C., Zhou, J., Mizzen, C., McKenna, N., Onate, S., Tsai, S., Tsai, M.-J., 1997. Steroid receptor coactivator-1 is a histone acetyltransferase. Nature 389, 194-198. doi:10.1038/38304

Patel, J., Du, Y., Ard, P., Phillips, C., Carella, B., Chen, C.-J., Rakowski, C., Chatterjee, 
C., Lieberman, P., Lane, W., Blobel, G., McMahon, S., 2004. The c-MYC oncoprotein is a substrate of the acetyltransferases hGCN5/PCAF and TIP60. Mol. Cell. Biol. 24, 10826-10834. doi:10.1128/MCB.24.24.10826-10834.2004

Polevoda, B., Sherman, F., 2000. Nalpha -terminal acetylation of eukaryotic proteins. J. Biol. Chem. 275, 36479-82. doi:10.1074/jbc.R000023200

Sauve, A., Wolberger, C., Schramm, V., Boeke, J., 2006. The biochemistry of sirtuins. Annu. Rev. Biochem. 75, 435-465. doi:10.1146/annurev.biochem.74.082803.133500

Sealy, L., Chalkley, R., 1978. DNA associated with hyperacetylated histone is preferentially digested by DNase I. Nucleic Acids Res. 5, 1863-76.

Shahbazian, M., Grunstein, M., 2007. Functions of site-specific histone acetylation and deacetylation. Annu. Rev. Biochem. 76, 75-100. doi:10.1146/annurev.biochem.76.052705.162114

Spange, S., Wagner, T., Heinzel, T., Krämer, O., 2009. Acetylation of non-histone proteins modulates cellular signalling at multiple levels. Int. J. Biochem. Cell Biol. 41, 185-198. doi:10.1016/j.biocel.2008.08.027

Sterner, D., Berger, S., 2000. Acetylation of histones and transcription-related factors. Microbiol. Mol. Biol. Rev. 64, 435-59.

Storey, K., 2007. Anoxia tolerance in turtles: Metabolic regulation and gene expression. Comp. Biochem. Physiol. Part A Mol. Integr. Physiol. 147, 263-276. doi:10.1016/j.cbpa.2006.03.019

Storey, K., 1996. Metabolic adaptations supporting anoxia tolerance in reptiles: recent advances. Comp. Biochem. Physiol. Part B Comp. Biochem. 113, 23-35. 
doi:10.1016/0305-0491(95)02043-8

Storey, K., Storey, J., 2007. Tribute to P. L. Lutz: putting life on 'pause' - molecular regulation of hypometabolism. J. Exp. Biol. 210, 1700-1714. doi:10.1242/jeb.02716

Storey, K., Storey, J., 2004. Oxygen limitation and metabolic rate depression, in: Storey, K.B. (Ed.), Functional Metabolism. John Wiley \& Sons, Inc., Hoboken, NJ, USA, pp. 415-442. doi:10.1002/047167558X.ch15

Storey, K., Storey, J., 1992. Natural freeze tolerance in ectothermic vertebrates. Annu. Rev. Physiol. 54, 619-637. doi:10.1146/annurev.ph.54.030192.003155

Storey, K., Storey, J., 1990. Metabolic rate depression and biochemical adaptation in anaerobiosis, hibernation and estivation. Q. Rev. Biol. 65, 145-74. doi:10.4172/2157-7625.1000224

Strahl, B., Allis, C., 2000. The language of covalent histone modifications. Nature 403, 41-45. doi:10.1038/47412

Struhl, K., 1998. Histone acetylation and transcriptional regulatory mechanisms. Genes Dev. 12, 599-606.

Ura, K., Kurumizaka, H., Dimitrov, S., Almouzni, G., Wolffe, A., 1997. Histone acetylation: Influence on transcription, nucleosome mobility and positioning, and linker histone-dependent transcriptional repression. EMBO J. 16, 2096-107. doi:10.1093/emboj/16.8.2096

Ventura, M., Mateo, F., Serratosa, J., Salaet, I., Carujo, S., Bachs, O., Pujol, M., 2010. Nuclear translocation of glyceraldehyde-3-phosphate dehydrogenase is regulated by acetylation. Int. J. Biochem. Cell Biol. 42, 1672-1680.

doi:10.1016/j.biocel.2010.06.014 
Vidali, G., Boffa, L., Bradbury, E., Allfrey, V., 1978. Butyrate suppression of histone deacetylation leads to accumulation of multiacetylated forms of histones H3 and H4 and increased DNase I sensitivity of the associated DNA sequences. Proc. Natl. Acad. Sci. U. S. A. 75, 2239-43.

Wade, P., Pruss, D., Wolffe, A., 1997. Histone acetylation: Chromatin in action. Trends Biochem. Sci. 22, 128-132. doi:10.1016/S0968-0004(97)01016-5

Wang, R., Cherukuri, P., Luo, J., 2005. Activation of Stat3 sequence-specific DNA binding and transcription by $\mathrm{p} 300 / \mathrm{CREB}-$ binding protein-mediated acetylation. J. Biol. Chem. 280, 11528-11534. doi:10.1074/jbc.M413930200

Wijenayake, S., Storey, K., 2016. The role of DNA methylation during anoxia tolerance in a freshwater turtle (Trachemys scripta elegans). J. Comp. Physiol. B 186, $333-$ 342. doi:10.1007/s00360-016-0960-X

Willmore, W., Storey, K.B., 1997. Antioxidant systems and anoxia tolerance in a freshwater turtle Trachemys scripta elegans. Mol. Cell. Biochem. 170, 177-85. doi:10.1023/A:1006817806010

Wurtele, H., Kaiser, G., Bacal, J., St-Hilaire, E., Lee, E.-H., Tsao, S., Dorn, J., Maddox, P., Lisby, M., Pasero, P., Verreault, A., 2012. Histone H3 lysine 56 acetylation and the response to DNA replication fork damage. Mol. Cell. Biol. 32, 154-72. doi:10.1128/MCB.05415-11

Xiong, Y., Guan, K.-L., 2012. Mechanistic insights into the regulation of metabolic enzymes by acetylation. J. Cell Biol. 198, 155-164. doi:10.1083/jcb.201202056

Xue-Franzen, Y., Henriksson, J., Burglin, T., Wright, A., 2013. Distinct roles of the Gcn5 histone acetyltransferase revealed during transient stress-induced reprogramming of 
the genome. BMC Genomics 14, 479. doi:10.1186/1471-2164-14-479

Zhang, J., Biggar, K.K., Storey, K.B., 2013. Regulation of p53 by reversible posttranscriptional and post-translational mechanisms in liver and skeletal muscle of an anoxia tolerant turtle, Trachemys scripta elegans. Gene 513, 147-155.

doi:10.1016/j.gene.2012.10.049

Zhou, V., Goren, A., Bernstein, B., 2011. Charting histone modifications and the functional organization of mammalian genomes. Nat. Rev. Genet. 12, 7-18. doi:10.1038/nrg2905 
CHAPTER 5 
Regulation of histone lysine methylation in response to prolonged anoxia exposure. Sanoji Wijenayake ${ }^{\mathrm{a}}$, Liam J. Hawkins ${ }^{\mathrm{a}}$, and Kenneth B Storey ${ }^{\mathrm{a}^{*}}$

a - Institute of Biochemistry, Department of Biology, Carleton University, 1125 Colonel By Drive, Ottawa, ON, K1S 5B6, Canada.

\section{*Corresponding author:}

Kenneth B. Storey

Professor of Biochemistry

Canada Research Chair in Molecular Physiology

Institute of Biochemistry, Department of Biology, and Department of Chemistry 1125 Colonel By Drive, Ottawa, ON. Canada. K1S 5B.

E-mail address: Kenneth_storey@carleton.ca

Tel: 1-613-520-3678; Fax: 1-613-520-3749

This manuscript is currently under peer-review at Gene.

Submission ID: GENE-D-17-01733. 


\begin{abstract}
The importance of epigenetic mechanisms, in particular histone lysine methylation, is well established in health, disease, early development, aging, and cancer related-research. However, the potential role of epigenetics in regulating global as well as target-specific gene expression in response to extended periods of oxygen deprivation (anoxia) in a natural anoxia-tolerant model system is underexplored. Red-eared sliders (Trachemys scripta elegans) can tolerate and survive three months of absolute anoxia and recover without incurring detrimental cellular damage mainly by reducing the overall metabolic rate by $90 \%$ when compared to control normoxic, conditions. Stringent regulation of gene expression is a vital aspect of metabolic rate depression in red-eared sliders, and as such we examined the anoxia-responsive regulation of histone lysine methylation in the liver during $5 \mathrm{~h}$ and $20 \mathrm{~h}$ anoxic exposure. H3K4me1, a histone mark associated with active transcription, and two corresponding histone lysine methyltransferases that modify $\mathrm{H} 3 \mathrm{~K} 4$ site, significantly increased in response to anoxia. On the contrary, H3K27me1, another transcriptionally active histone mark, significantly decreased in expression during $20 \mathrm{~h}$ anoxia, and two transcriptionally repressive histone marks, and $\mathrm{H} 3 \mathrm{~K} 9 \mathrm{me} 3$ and $\mathrm{H} 3 \mathrm{~K} 9$ mepan as well as the corresponding methyltransferases, similarly increased in expression during $20 \mathrm{~h}$ anoxia. Overall, the results suggest a dynamic, yet promoter-specific regulation of histone lysine methylation in the liver of red-eared sliders that could potentially aid in the selective upregulation of genes that are necessary for anoxia survival, while globally suppressing others to conserve energy.
\end{abstract}

\title{
Keywords:
}

Histone lysine methylation, epigenetics, anoxia, liver, Trachemys scripta elegans 


\section{Introduction}

Anoxia (defined as complete lack of oxygen) is an environmental stress most mammals, including humans, cannot tolerate for long periods of time without incurring harmful cellular damage. In a nutshell, oxygen is the final acceptor of electrons in the electron transport chain (ETC) and essentially drives all oxygen-dependent catabolic pathways with the exception of anaerobic glycolysis (Hochachka, 1988; Storey, 2007). Thus, during times of low oxygen availability (hypoxia) and anoxia, the ETC shuts down, the tricarboxylic acid cycle (TCA) backlogs, and anaerobic glycolysis becomes the sole source of ATP production in the cell (Storey, 1996; Storey and Storey, 1990b). However, a sole reliance on glycolysis to generate enough ATP to support all cellular processes is not without limitations (Jackson, 1968). Increased rate of glycolysis increase the overall ATP output, however also quickly deplete glycogen fuel stores in the liver and skeletal muscle, and leads to increased accumulation of acidic end products, such as lactate (Hochachka et al., 1996; Jackson, 1997; Jackson et al., 1999, 2006b; Storey and Storey, 1990b). Therefore, a sole reliance on glycolysis to generate ATP is not a sufficient longterm adaptation to anoxia survival, and more organized strategies of regulating the overall metabolic output and end product buffering is needed.

Among vertebrates, short and long-term anoxia tolerance is well established in freshwater turtles. Chrysemys picta bellii (painted turtles) and Trachemys picta elegans (red-eared sliders) are two of the most well studied models of anoxia tolerance (Jackson, 2000). Apart from using this animal model to explore and uncover novel biochemical and molecular mechanisms of anaerobiosis, they are also widely used as medical models in the search for solutions against ischemia/reperfusion injuries that are associated with 
myocardial infarctions (heart attacks), strokes, and neonatal umbilical cord injuries (Bickler, 2004; Buck, 2004; Jackson, 1968; Lutz, 1992; Storey, 2007). Furthermore, anoxia-tolerant freshwater turtles are a great model system for anti-aging and enhanced longevity studies due to enhanced neuroprotective mechanisms present in the turtle brain (Lutz and Milton, 2004).

Red-eared sliders employ several physiological and biochemical adaptation to survive daily, short-term anoxia that is associated with aponoic dives in search of food and long-term seasonal anoxia that is associated with winter hibernation in ice-locked ponds and lakes (K. Storey and Storey, 2004a). Several main components of anoxia tolerance in red-eared sliders have been recognized and explored to date; 1) accumulation of large glycogen fuel reserves to support anaerobic glycolysis for 3-5 months at $3{ }^{\circ} \mathrm{C}$ (Hochachka et al., 1999; Jackson, 2000; Storey, 1996), 2) combat acidosis by releasing calcium and magnesium carbonate from the shell into the extracellular fluid and store a high percentage of lactate in the shell (Jackson, 1997, 2000, Jackson et al., 1999, 2006b; Jackson and Heisler, 1983), 3) greatly enhance cytoprotective mechanisms such as antioxidant defense, heat shock protein response, and unfolded protein response (HermesLima et al., 2001; P. W. Hochachka, 1986; Krivoruchko and Storey, 2013a, 2010a, 2010b; Storey, 2007; Willmore and Storey, 1997), and most importantly, 4) establishing a hypometabolic state in which the metabolic rate is reduced to $10 \%$ of normorxic values by suppressing all energy expensive cellular processes and reprioritizing ATP towards enhancing the expression of genes selected with the use of transcriptional, posttranscriptional, post-translational, and epigenetic regulators (K. Biggar et al., 2011; 
Jackson, 2000; Storey, 2007, 1996; K. Storey and Storey, 2004a; Storey and Storey, 2007, 1990b).

Histone $\mathrm{H} 3$ methylation is a dynamic epigenetic modification that is fundamental for the formation of euchromatin (open chromatin that is transcriptionally active) and facultative/constitutive heterochromatin (closed chromatin that is transcriptionally inactive). Furthermore, histone $\mathrm{H} 3$ methylation can also induce a region of chromatin to undergo nuclear compartmentalization in response to environmental stimuli or stress (Eva Bártová et al., 2008). Histone methylation occurs on the side chains of lysine (K) and arginine (R) residues of terminal tails of histone H1B, H2B, H3 and histone $\mathrm{H} 4$ (Vakoc et al., 2006; Venkatesh and Workman, 2015). For the purpose of this paper, we have only explored the dynamic nature of histone $\mathrm{H} 3 \mathrm{~K}$ methylation in response to anoxia. Unlike other histone modifications, such as acetylation and phosphorylation, histone lysine methylation does not alter the charge on the histone proteins and thus do not change the interaction with surrounding DNA. Rather, the uncharged methyl-groups present on lysine residues, attract methyl-binding proteins to targeted promoter sites and can either facilitate or repress transcription depending on the type of proteins that are recruited (Bannister and Kouzarides, 2011; S. L. Berger, 2002). As such, histone methylation does not generate a clear transcriptional activation or repression based on the presence or absence of methyl residues, rather mono, di, or tri methylation of different lysine residues within histone $\mathrm{H} 3$ tails and the type of methyl-binding proteins present at the sites determine the transcriptional outcome of target gene promoters (Martin and Zhang, 2005; Shi and Whetstine, 2007; Sims et al., 2003). For example, actively transcribed gene promoters are typically associated with histone $\mathrm{H} 3$ monomethyl lysine 4 (H3K4me1) and 
histone H3 monomethyl lysine 27 (H3K27me1) (Barski et al., 2007; Martin and Zhang, 2005; Schneider et al., 2004), whereas histone H3 tri and pan methylation of lysine 9 (H3K9me3 and H3K9mepan) promote gene silencing and heterochromatin formation by recruiting and binding to heterochromatin protein 1 (HP1) (Lachner et al., 2003; Lehnertz et al., 2003; Peters et al., 2002). HP1 can also recruit and bind to DNA methyltransferase $3 b$, further repressing transcription at target gene loci (Lehnertz et al., 2003). As such, histone lysine methylation has a higher level of complexity as well as plasticity in regulating target-specific gene expression in response to environmental changes and/or stimuli.

Histone lysine methyltransferases (HKMTs) that methylate the N-terminal lysine residues of histones universally use S-adenosyl-L-methionine (SAM) as a co-factor to methylate the $\varepsilon$-amino group of target lysine residues on histones and other regulatory protiens (Herz et al., 2013), and leave a methylated lysine residue and a modified version of SAM, S-adenosyl-L-homocysteine (AdoHcy) (Dillon et al., 2005). HKMTs such as SET7/9, RBBP5, ASH2L, and SMYD2 have been shown to methylate H3K4 residues. Unlike that of other HKMTs, RBBP5 and ASH2L cannot directly methylate lysine residues but rather form the MLL/SET1 complex with WDR5 protein and a catalytic subunit containing a SET domain (Dou et al., 2005; Hughes et al., 2004; Nakamura et al., 2002). These proteins are required to work together to have efficient H3K4 methylation. However, recent findings by (Cao et al., 2010) identified RBBP5 and ASH2L heterodimerization as the most critical regulatory point in MLL1-mediated H3K4 methylation. EHMT2 and SUV39H1 modify H3K9 residue with mono, di, and tri methylation, while EHMT2 can monomethylate H3K27 residue (Herz et al., 2013; Peters 
et al., 2002; Schneider et al., 2004; Sims et al., 2003; Vakoc et al., 2006, 2005; Venkatesh and Workman, 2015) (Figure 1).
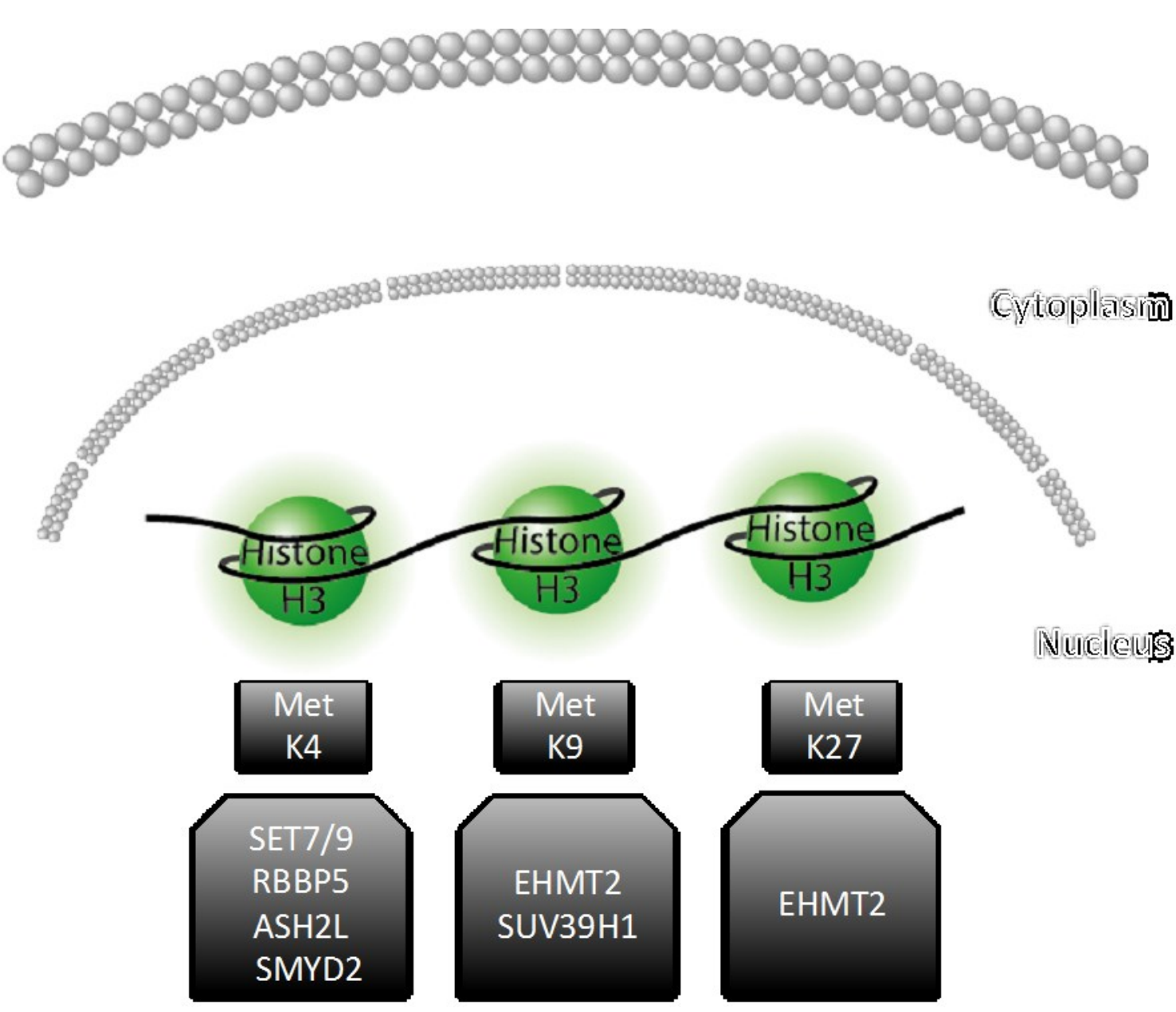

Figure 1. Histone $\mathrm{H} 3$ lysine 4, 9, and 27 residues that are mono, di, or tri methylated by respective histone methyltransferases such as SET7/9, RBBP5, ASH2L, SMYD2, EHMT2, and SUV39H1.

Although extensive work has already been done on the physiological and biochemical strategies of anoxia tolerance in red-eared sliders, the role of epigenetics, in particular the role of histone lysine methylation in regulating global as well as targetspecific gene expression during MRD remains elusive. As such, this paper focuses on investigating the dynamic expression and regulation of histone $\mathrm{H} 3$ methylation at three main lysine residues, $\mathrm{H} 3 \mathrm{~K} 4, \mathrm{H} 3 \mathrm{~K}$, and $\mathrm{H} 3 \mathrm{~K} 27$ that are transcriptionally relevant, as well 
as the protein expression levels and total enzymatic activity of HKMTs that methylate $\mathrm{H} 3 \mathrm{~K} 4, \mathrm{H} 3 \mathrm{~K} 9$, and $\mathrm{H} 3 \mathrm{~K} 27$ residues in response to normoxic control, $5 \mathrm{~h}$, and $20 \mathrm{~h}$ anoxia in the liver of T.s. elegans.

\section{Materials and Methods}

\section{Animal care and treatment}

Adult female red-eared sliders, weighing 700-1500 g, were purchased from local suppliers in Ottawa. Upon arrival at the laboratory, the animals were housed in large tubs filled with dechlorinated tap water at $5 \pm 1{ }^{\circ} \mathrm{C}$ for a week before starting the animal experiments. Control, normoxic turtles were sampled from this condition after a week and the tissues were excised. The remaining turtles were transferred to separate tubs filled with water that had been previously bubbled with nitrogen gas for $1 \mathrm{~h}$. The bubbling continued for $1 \mathrm{~h}$ after the last turtle was added to the tub, then immediately halted and restarted during sampling of the animals. A wire mesh was fitted $5 \mathrm{~cm}$ below the surface of the water to prevent turtles from breaching. $4-5$ turtles were sampled after $5 \mathrm{~h}$ in the tub and the tissues were excised. These tissues were used as the $5 \mathrm{~h}$ anoxia experimental condition. The remaining turtles were kept in the tubs for $20 \mathrm{~h}$ and sampled. These tissues were used as the $20 \mathrm{~h}$ anoxic experimental condition. All animals were killed by decapitation and all tissues were immediately put in liquid nitrogen upon excision and then stored at $-80^{\circ} \mathrm{C}$.

All animals were cared for in accordance with the guidelines of the Canadian Council on Animal Care and all experimental procedures had the prior approval of the Carleton University Animal Care Committee. 


\section{Total protein extraction}

$0.5-1 \mathrm{~g}$ of frozen turtle liver was homogenized in homogenization buffer (20 mM HEPES pH 7.5, $200 \mathrm{mM} \mathrm{NaCl}, 0.1 \mathrm{mM}$ EDTA, $10 \mathrm{mM} \mathrm{NaF}, 1 \mathrm{mM} \mathrm{Na}_{3} \mathrm{VO}_{4}, 10$ $\mathrm{mM} \beta$-glycerophosphate with $10 \mu \mathrm{L} / \mathrm{mL}$ protease inhibitor cocktail with EDTA (Bioshop; Catalog \#. PIC001) and a few crystals of phenylmethylsulfonyl fluoride (PMSF)) at 1: $2.5(\mathrm{w}: \mathrm{v})$ using a polytron homogenizer on high for $15 \mathrm{~s}$. The samples were immediately placed on ice for $5 \mathrm{~min}$ and then centrifuged for $15 \mathrm{~min}$ at $10,000 \mathrm{xg}$ at $4{ }^{\circ} \mathrm{C}$. The supernatant was collected and the pellet was discarded. Total soluble protein concentrations were measured using the BioRad protein assay (Cat\# 500-0006) with bovine serum albumin as the standard using a PowerWave HT microplate spectrophotometer (Biotek). The samples were normalized to an initial concentration of $10 \mu \mathrm{g} / \mu \mathrm{L}$ using the homogenization buffer and $50 \mu \mathrm{L}$ aliquots were kept aside for the enzymatic assays. The remaining samples were mixed with 1:1 (v:v) with 2x SDS loading buffer (100 mM Tris-base, $4 \%$ (w:v) SDS, $20 \%$ (v:v) glycerol, $0.2 \%$ (w:v) bromophenol blue, $10 \%$ (v:v) 2-mercaptoethanol) to a final concentration of $5 \mu \mathrm{g} / \mu \mathrm{L}$. Subsequently, the protein samples were boiled at $100{ }^{\circ} \mathrm{C}$ for $10 \mathrm{~min}$ and stored at $-40^{\circ} \mathrm{C}$ for further use.

\section{Western Immunoblotting}

Liver tissue homogenates containing $25-30 \mu \mathrm{g}$ of total soluble protein were loaded on to 6-15 \% SDS-polyacrylamide gels and resolved by electrophoresis for 45-120 min at $180 \mathrm{~V}$ in $1 \mathrm{x}$ Tris-glycine running buffer ( $75.5 \mathrm{~g}$ of Tris-base, $460 \mathrm{~g}$ glycine, $25 \mathrm{~g}$ SDS, $\mathrm{ddH}_{2} \mathrm{O}$ up to $2.5 \mathrm{~L}$ ) using a Mini-Protean 3 System (Biorad). The amount of total 
protein loaded varied for each target; a dilution curve ranging from 10-40 $\mu \mathrm{g}$ of protein was run per target to determine the linear portion of the chemiluminescent signal prior to running the quantification runs. $4-5 \mu 1$ of pre-stained protein molecular weight ladder (Froggabio; Cat. \#. PM005- 0500 and PM007-0500 K) were run alongside the protein samples for reference. Subsequently, the proteins were electroblotted onto $0.45 \mu \mathrm{m}$ PVDF membranes (Millipore; Cat. \#. IPVH00010) in 1x transfer buffer (60.6 g Tris-base, $288 \mathrm{~g}$ glycine, $4 \mathrm{~L}$ methanol, $16 \mathrm{~L} \mathrm{ddH2O}$ ) at $160 \mathrm{~mA}$ for $90-180 \mathrm{~min}$ using a MiniProtean Transfer cell (Biorad). The PVDF membranes were then washed 3 x 5 min in 1x TBST (10 mM Tris, $150 \mathrm{mM} \mathrm{NaCl}, 0.05 \% \mathrm{v}: \mathrm{v}$ Tween-20, $\mathrm{pH}$ 7.5) and blocked with 2.5$5 \%$ milk in $1 \mathrm{x}$ TBST for 30 min to reduce unspecific binding. The membranes were washed again $3 \times 5$ min in $1 \times$ TBST and probed with primary antibody diluted at 1:1,000 (v:v) in $1 \mathrm{x}$ TBST for $24 \mathrm{~h}$ at $4{ }^{\circ} \mathrm{C}$. The antibodies used in this analysis were purchased from the following sources; ASH2L (Cell Signalling; Cat. \#. 5019), SET7/9 (Cell Signalling; Cat. \#. 2813), RBBP5 (Cell Signalling; Cat. \#. 13171), SMYD2 (Cell Signalling; Cat. \#. 9734), EHMT2 (Cell Signalling; Cat. \#. 3306), and SUV39H1 (Cell Signalling; Cat. \#. 8729). Upon primary antibody incubation, the membranes were washed $3 \times 5$ min in $1 \times$ TBST and incubated with HRP-conjugated anti-rabbit IgG secondary antibody (Bioshop; Catalog \#. APA007P), diluted 1:8000 (v:v) in 1x TBST for 40 min on a rocker at RT, and subsequently washed $3 \times 5$ min in $1 \times$ TBST prior to visualization. The membranes were visualized using enhanced chemiluminescence and a ChemiGenius Bio-Imaging System (Syngene, Frederick, MD). Protein band densities were quantified using Gene Tools software. After immunoblotting was complete, membranes were stained with Coomassie blue (0.25 \% (w:v) Coomassie 336 brilliant 
blue stain, $7.5 \%(\mathrm{v}: \mathrm{v})$ acetic acid, $50 \%(\mathrm{v}: \mathrm{v})$ methanol) and band densities were similarly quantified using the ChemiGenius Bio-Imaging system.

\section{Enzymatic Activity Assays}

Three histone methyltransferase enzymatic activity/inhibition kits from Epigentek were used to measure the relative levels of total histone methylation activity on three main histone H3 moieties; Histone H3-Lys4 (Epigentek; Catalog \#. P-3002-96), histone H3-Lys9 (Epigentek; Catalog \#. P-3003-96), and histone H3-Lys27 (Epigentek; Catalog \#. P-3005-96). The assays were performed according to manufactures instructions using total soluble protein extracts. A standard curve was prepared for each of the three assays using the HKMT standard (supplied with the kits) at concentrations ranging from 0.1 , $0.2,0.5,1,2$, and $5 \mathrm{ng} / \mu \mathrm{L}$ along with negative and positive controls. The standard wells contained HKMT standard at different concentration and histone assay buffer (supplied with the kits) instead of the protein extract. The negative control wells contained identical well contents as the sample test wells except for the protein extract. A positive control well was set up by adding $1 \mu \mathrm{L}$ of control enzyme (supplied with the kit) along with histone assay buffer instead of the protein extract. To determine the linear range of protein needed for each of the three assays, a dilution curve ranging from 5-30 $\mu \mathrm{g}$ of total soluble protein from a pooled test sample was assayed for each kit. Based on the values obtained from the dilution test curves and the standard curves, $25 \mu \mathrm{g}$ of protein was used for $\mathrm{H} 3 \mathrm{~K} 4$ and $\mathrm{H} 3 \mathrm{~K} 9$ methyltransferase assays, while $5 \mu \mathrm{g}$ of protein was used for the more sensitive H3K27 methyltransferase assay. The test samples were set up by adding the protein extracts, histone assay buffer, adomet substrate (supplied with the kit), and biotinylated substrate at $25 \mu \mathrm{g} / \mathrm{mL}$ (supplied with the kit). The strip wells were covered 
with aluminum foil and incubated on a plate shaker $(50-100 \mathrm{rpm})$ at $37^{\circ} \mathrm{C}$ for $90 \mathrm{~min}$. Upon incubation, the strip wells were aspirated and washed with $150 \mu \mathrm{L}$ of $1 \mathrm{x}$ wash buffer (stock of 10x was provided with the kit) three times. Each strip well was then incubated with $50 \mu \mathrm{L}$ of $1 \mu \mathrm{g} / \mathrm{mL}$ of capture antibody $(100 \mu \mathrm{g} / \mathrm{mL}$ were supplied with the kit) at room temperature for $60 \mathrm{~min}$ on plate shaker (50-100 rpm). Next, the strip wells were aspirated and washed with $150 \mu \mathrm{L}$ of $1 \mathrm{x}$ wash buffer five times. Subsequently, 50 $\mu \mathrm{L}$ of $0.2 \mu \mathrm{g} / \mathrm{mL}$ detection antibody ( $200 \mu \mathrm{g} / \mathrm{mL}$ were supplied with the kit) was added to each strip well and incubated at room temperature for $30 \mathrm{~min}$ on a plate shaker (50-100 $\mathrm{rpm})$. The strip wells were then aspirated and washed with $150 \mu \mathrm{L}$ of $1 \mathrm{x}$ wash buffer five times. $100 \mu \mathrm{L}$ of the developing solution (supplied by the kit) was added to each strip well and incubated at room temperature for $10 \mathrm{~min}$ away from the light. Lastly, $50 \mu \mathrm{L}$ of stop solution (supplied by the kit) was added to each strip well to stop the enzyme reactions and the absorbance was measured within 5 min using a microplate reader (Multiscan Spectrum, Thermo Labsystems) at $450 \mathrm{~nm}$. The total HKMT activity was calculated using the following formula;

$$
\operatorname{Activity}\left(\frac{n g}{\frac{h}{m g}}\right)=\left[\frac{\text { OD }(\text { sample }- \text { blank })}{(\text { protein amount }(\mathrm{ug}) \times h \times \text { slope })}\right] \times 1000
$$

Where;

Protein amount is the total soluble protein $(\mu \mathrm{g})$ added to the test sample wells. $\mathrm{h}$ is the incubation time at $37^{\circ} \mathrm{C}$. 
Slope is the slope of the line of the standard curve created from concentrations ranging from $0.1,0.2,0.5,1,2$, and $5 \mathrm{ng} / \mu \mathrm{L}$.

\section{Quantification Statistics}

Minor irregularities in protein loading during western immunoblotting were adjusted by normalizing the immunoblot band intensities against the summed intensity of a group of Commassie-stained protein bands in the same lane that showed constant expression between the experimental conditions. This normalization method was done per each immunoblot. This method has been shown to be far superior to using one housekeeping or reference gene as a loading control. Target protein bands were identified by running a standard protein molecular weight ladder and a mammalian positive control sample from Ictidomys tridecemlineatus. Statistical analysis used a one-way ANOVA with a Tukey post hoc test $(\mathrm{p}<0.05)$ to compare three experimental conditions. Sigmaplot 11 software (Systat Softwaree Inc., San Jose, CA) was used for this analysis as well as construction of figures.

\section{Results}

The relative methylation levels of histone $\mathrm{H} 3 \mathrm{~K} 4 \mathrm{me} 1, \mathrm{H} 3 \mathrm{~K} 9 \mathrm{me}$, and H3K27me1 in the liver of anoxic red-eared sliders were measured using western immunoblotting. Although there are numerous other histone $\mathrm{H} 3$ methyl modifications, $\mathrm{H} 3 \mathrm{~K} 4, \mathrm{H} 3 \mathrm{~K} 9$, and $\mathrm{H} 3 \mathrm{~K} 27$ are three of the most well studied and transcriptionally relevant regulatory sites that are prone to environmental stimuli and perturbations. As such, this study explores dynamic changes in $\mathrm{H} 3 \mathrm{~K} 4, \mathrm{H} 3 \mathrm{~K} 9$, and $\mathrm{H} 3 \mathrm{~K} 27$ that may occur during short and long-term oxygen-deprivation an anoxia-tolerant red-eared slider (Figure 2). H3K4me1 levels significantly increased by $17.0 \pm 5.1$ fold in response to $20 \mathrm{~h}$ anoxia, but remained 
unchanged in response to $5 \mathrm{~h}$ anoxia. $\mathrm{H} 3 \mathrm{~K} 9 \mathrm{me} 3$ significantly increased by $2.8 \pm 0.9$ fold during $5 \mathrm{~h}$ anoxia and $4.7 \pm 1.9$ fold during $20 \mathrm{~h}$ anoxia when compared to the control condition. H3K9mepan levels significantly decreased by $0.3 \pm 0.08$ fold during $5 \mathrm{~h}$ anoxia, but robustly increased by $2.62 \pm 0.23$ fold during $20 \mathrm{~h}$ anoxia when compared to the control. Lastly, H3K27me1 expression levels decreased by $0.14 \pm 0.03$ and $0.39 \pm$ 0.08 fold during $5 \mathrm{~h}$ and $20 \mathrm{~h}$ anoxia, respectively.

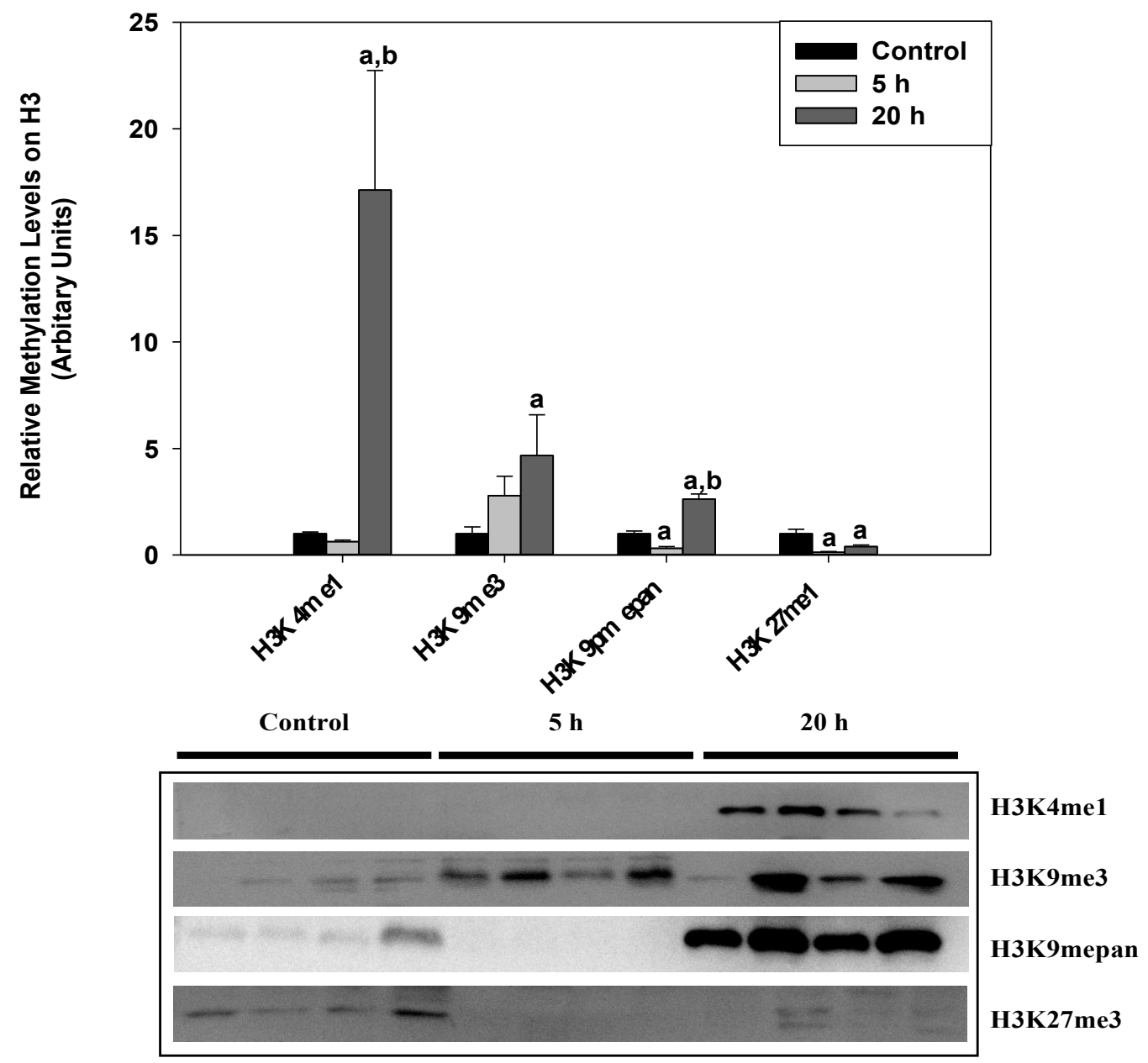

Figure 2. The relative expression of methyl moieties on histone $\mathrm{H} 3$ in response to control, $5 \mathrm{~h}$, and $20 \mathrm{~h}$ anoxia exposure in the liver of T.s. elegans as determined by western immunoblotting. Data are mean \pm SEM, $n=4$ independent trials on samples from different animals. Data were analyzed using analysis of variance with a post hoc 
Tukey test $(\mathrm{p}<0.05)$; a Statistically significant from the control, normoxia $(\mathrm{p}<0.05)$. b Statistically significant from $5 \mathrm{~h}$ anoxia $(\mathrm{p}<0.05)$.

Relative protein expression levels of five HKMTs were measured by western immunoblotting in the liver of control, $5 \mathrm{~h}$ anoxia, and $20 \mathrm{~h}$ anoxia red-eared sliders. The HKMTs that are known to modify the H3K4me1 residue, ASH2L, SET7/9, RBBP5, and SMYD2 showed varying results (Figure 3) in response to anoxia. ASH2L protein expression levels increased by $3.9 \pm 0.28$ fold during $5 \mathrm{~h}$ anoxia and $2.5 \pm 0.43$ fold during $20 \mathrm{~h}$ anoxia when compared to the control, normoxic condition. Whereas, the protein expression levels of SET7/9 significantly decreased by $0.6 \pm 0.04$ and $0.6 \pm 0.06$ fold in response to $5 \mathrm{~h}$ and $20 \mathrm{~h}$ anoxia respectively. RBBP5 protein levels remained unchanged at $5 \mathrm{~h}$ anoxia, but significantly increased by $2.0 \pm 0.24$ fold during $20 \mathrm{~h}$ anoxia and the protein expression levels of SMYD2 decreased in $0.7 \pm 0.07$ during $5 \mathrm{~h}$ anoxia and returned back to control levels during $20 \mathrm{~h}$ anoxia. The HKMTs that are known to modify H3K9me3/pan, EHMT2 and SUV39H, also showed variable expression patterns (Figure 2). EHMT2 protein expression levels remained unchanged during $5 \mathrm{~h}$ anoxia, however robustly increased in response to $20 \mathrm{~h}$ anoxia by $5.3 \pm 0.86$ fold. However, SUV39H1 protein expression levels remained unchanged during $5 \mathrm{~h}$ and $20 \mathrm{~h}$ anoxia when compared to the control. Note; EHMT2 also actively methylate H3K27me3 methyl moiety. 

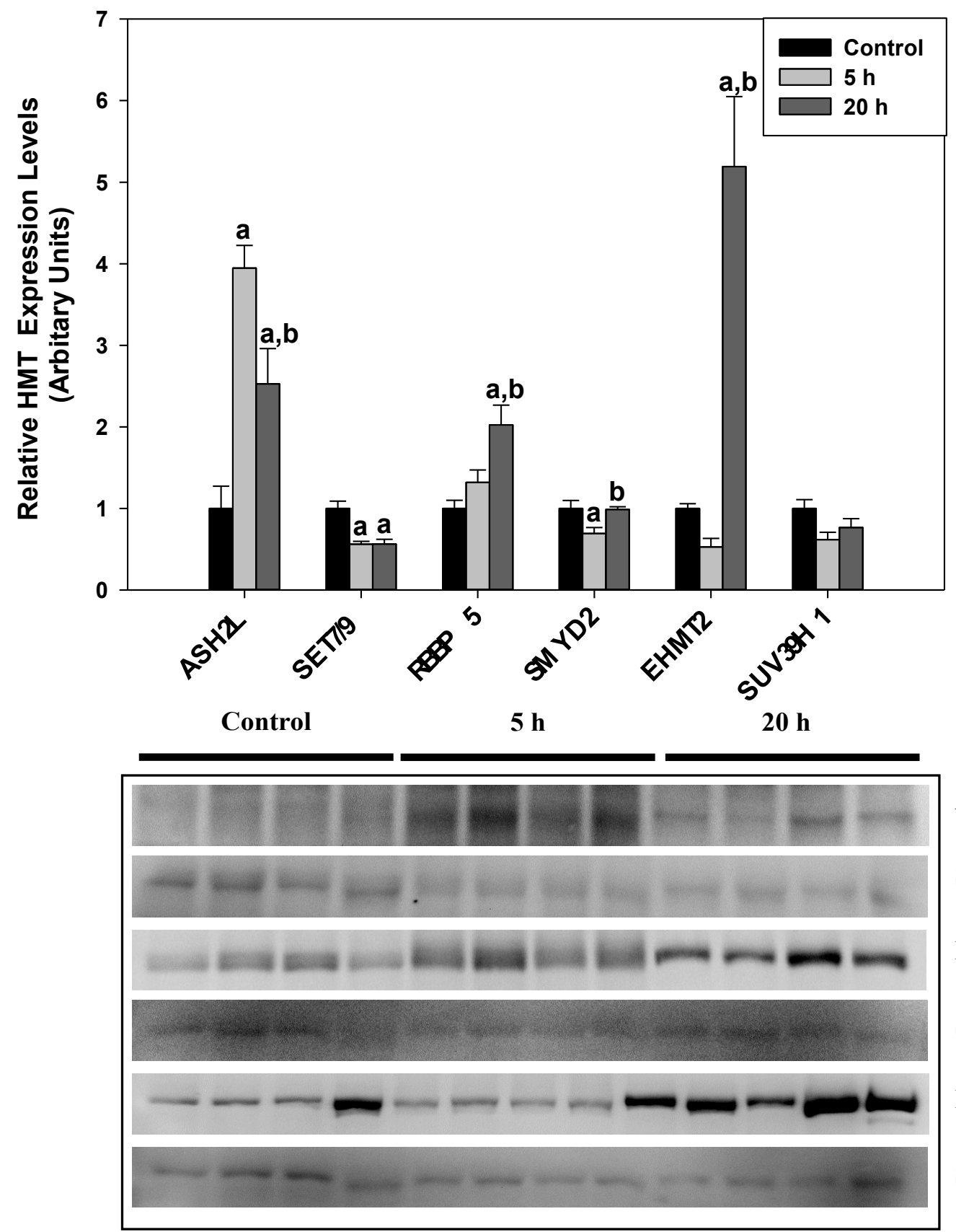

ASH2L

SET 7/9

RBBP5

SMYD2

EHMT2

SUV39H1

Figure 3. The relative proteins expression levels of five histone $\mathrm{H} 3$ methyltransferases in response to control, $5 \mathrm{~h}$, and $20 \mathrm{~h}$ anoxia exposure in the liver of T.s. elegans as determined by western immunoblotting. Other information as in Figure 2.

The enzymatic activity of HKMTs that methylate H3K4, H3K9, and H3K27

residues were measured in the liver fractions using three EpiQuick HKMT 
activity/inhibition assay kits purchased from Epigentek (Figure 4). Total enzymatic activity at $\mathrm{H} 3 \mathrm{~K} 4$ increased by $1.59 \pm 0.14$ and $1.59 \pm 0.25$ fold during $5 \mathrm{~h}$ and $20 \mathrm{~h}$ anoxia, respectively. Total enzymatic activity of $\mathrm{H} 3 \mathrm{~K} 9$ increased by $4.48 \pm 0.6$ fold during $20 \mathrm{~h}$ anoxia, but remained unchanged during $5 \mathrm{~h}$ anoxia when compared to control conditions. Contrary, total enzymatic activity of H3K27 remained unchanged during both experimental conditions.

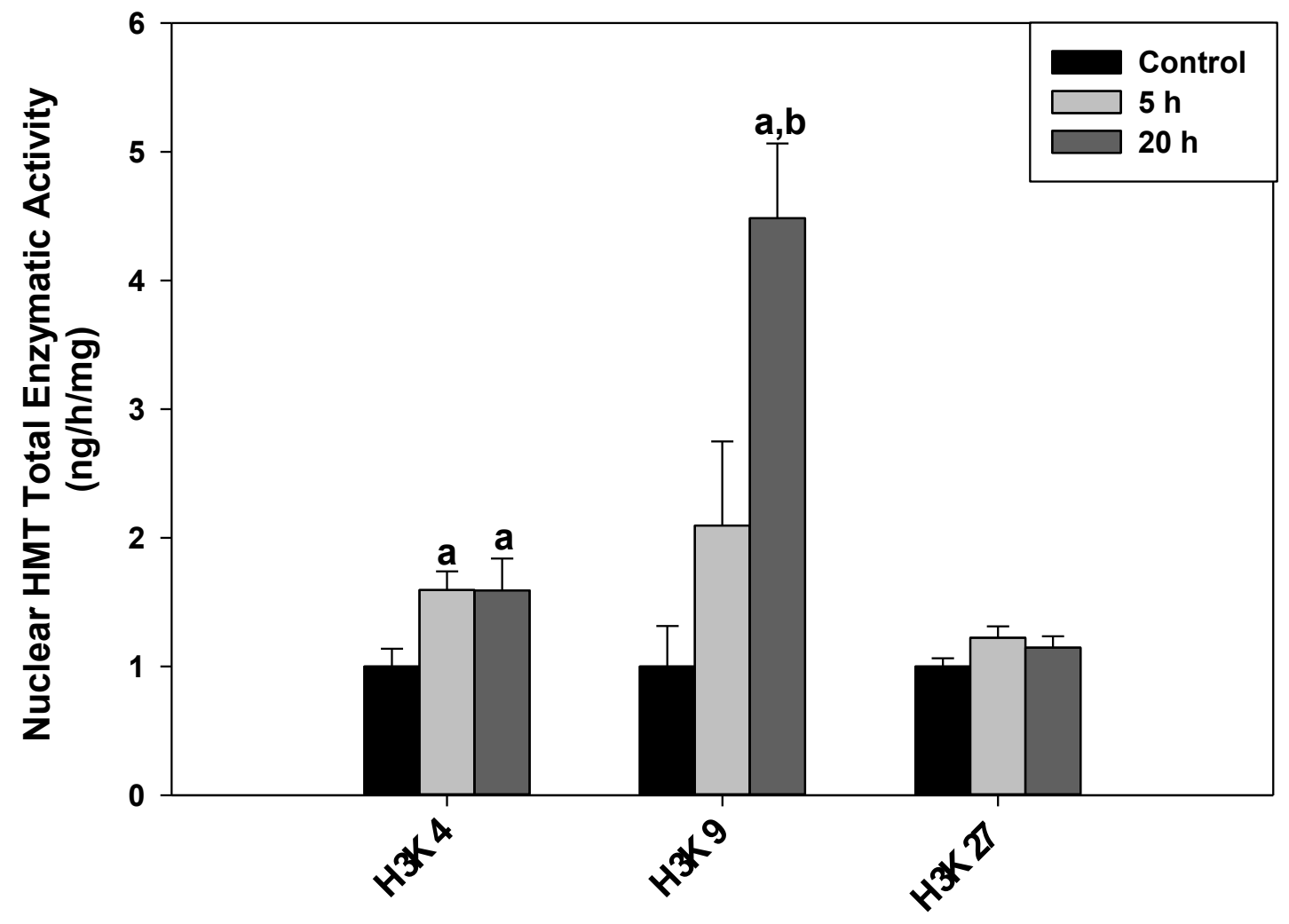

Figure 4. Total Histone methyltransferase enzyme activity (ng/h/mg of total soluble protein) on histone $\mathrm{H} 3 \mathrm{~K} 4, \mathrm{H} 3 \mathrm{~K} 9$, and $\mathrm{H} 3 \mathrm{~K} 27$ in the liver of T.s. elegans as determined by Epiquick HKMT activity/inhibition colorimetric assays from Epigentek. Other information as in Figure 2. 


\section{Discussion}

Freshwater turtles belonging to the Chrysemys and Trachemys genre are champion anaerobes that can survive approximately 90 days of continual anoxia at $3{ }^{\circ} \mathrm{C}$ and recover with minimal cellular injury (Jackson, 2000). The red-eared sliders (Trachemys scripta elegans) employ numerous, well-designed strategies to combat cellular consequences that are associated with anoxia with MRD being considered as the most important contributing factor (Hochachka, 1988; Hochachka and Lutz, 2001b; Jackson, 1968, 2000). T.s. elegans reduce their metabolic rate to $10 \%$ of normoxic values in response to long-term anoxia by strong coordinated suppression of all energy expensive cellular processes such as global gene expression, protein translation, proteolysis, cell cycle, apoptosis, gluconeogenesis, urea synthesis and reprioritizing the available ATP toward cellular processes that are needed for survival (K. Biggar et al., 2011; Krivoruchko and Storey, 2013a, 2010a, 2010b, Storey, 2007, 1996; K. Storey and Storey, 2004a; Storey and Storey, 1990b). Although extensive work has already been done on glycolytic controls (Bell and Storey, 2012; Brooks and Storey, 1989; N. Dawson et al., 2013; Neal J. Dawson et al., 2013; Mehrani and Storey, 1995a), transcriptional regulation (Bansal et al., 2016; Biggar and Storey, 2012b; Krivoruchko and Storey, 2013b; Zhang et al., 2013b), post-transcriptional regulation via miRNAs (Biggar and Storey, 2011, 2015, 2012b; K. K. Biggar et al., 2011), as well as post-translational regulation (K. Biggar et al., 2011; SP Brooks and Storey, 1993; Storey, 1996; Storey and Storey, 2007) of anoxia tolerance in red-eared sliders, epigenetic regulation of anoxia tolerance in particular, regulation of global gene expression through histone modification remains to be explored. 
Histone methylation, one of the more dynamic and intricate histone modifications, occurs on lysine and arginine residues of histone proteins and is catalyzed by enzymes belonging to three distinct HKMTs; the PRMT1 family, the SET domain proteins, and the non-SET domain proteins such as DOT1/DOT1L (S. L. Berger, 2002; Lachner et al., 2003; Sims et al., 2003; Vakoc et al., 2006). The dynamic nature of histone methylation arises from the fact that HKMTs can function as both negative and positive regulators of transcription depending on the site of modification (K4, K9, or K27) and the degree (mono, di, or trimethylation) of modification at each lysine site (Barski et al., 2007; Peter Cheung et al., 2000; Khorasanizadeh et al., 2004; Lachner et al., 2003). Furthermore, additional levels of complexity exist within histone lysine methylation; methylated histones can be used as binding sites for activator or repressor lysine methyl-binding proteins (Martin and Zhang, 2005; Vakoc et al., 2006). Consequently, the recruitment of methyl-binding transcriptional activators or repressor to the target lysine sites may play a vital role in transcriptional regulation especially in response to external stimuli and environmental stress.

Although, great progress has been made in understanding the functional importance of histone lysine methylation in experimental mouse models and human cell lines since its first discovery in 1964 (Murray, 1964), the dynamic regulation of histone methylation in response to anoxia tolerance and survival has not been explored in a natural model system that is anoxia tolerant. As such, this paper explores the dynamic changes in histone $\mathrm{H} 3$ lysine methylation as well as the corresponding HKMTs in response to $5 \mathrm{~h}$ and $20 \mathrm{~h}$ anoxia at three prominent transcriptional regulatory sties, H3K4me1, H3K9me3, H3K9mepan, and H3K27me1, in the liver of a champion 
anaerobe, the red-eared slider, to explore dynamic changes in histone lysine methylation following long-term anoxia exposure.

H3K4me1, a histone H3 methyl modification that is typically associated with poised and active enhancer regions and euchromatin (Eva Bártová et al., 2008; Lachner et al., 2003; Martin and Zhang, 2005; Schneider et al., 2004), surprisingly increased in expression (Figure 2) and two HKMTs that are known to actively methylate H3K4 site, ASH2L and RBBP5 (Lachner et al., 2003; Martin and Zhang, 2005; Schneider et al., 2004) also increased in expression in the liver during anoxia. On the contrary, SET7/9, an additional HKMT that monomethylates $\mathrm{H} 3 \mathrm{~K} 4$, decreased in expression in response to anoxia (Figure 3). The overall decrease in relative protein expression levels of SET7/9 could be a result of MRD in which protein translation is globally inhibited in the liver to conserve ATP (Storey, 2007; Storey and Storey, 1990b). Conservation and reprioritization of ATP is of utmost importance during times of anoxia, and consequently the anoxia-tolerant red-eared slider could be monopolizing ASH2L and RBBP5 to facilitate $\mathrm{H} 3 \mathrm{~K} 4 \mathrm{me} 1$ while suppressing the expression of SET7/9 during long-term anoxia to save energy. Furthermore, according to (He et al., 2015), the inhibition of SET7/9 improves reactive oxygen species (ROS) clearance from cells and elevates mitochondrial antioxidant functions. Therefore, the red-eared sliders may be depressing the expression of SET7/9 in the liver during anoxia in order to enhance the antioxidant defense and minimize ROS damage that is often associated with oxygen reperfusion. Correspondingly, antioxidant responses were reported to robustly increase during anoxia in the red-eared sliders (Hermes-Lima et al., 2001; Krivoruchko and Storey, 2010b, 2010c; Willmore and Storey, 1997). The relative protein expression level of SMYD2, 
another H3K4 targeted methyltransferase, decreased slightly during $5 \mathrm{~h}$ anoxia but returned to control levels during $20 \mathrm{~h}$ anoxia (Figure 3). SMYD2 is one of the HKMTs that actively monomethylate $\mathrm{H} 3 \mathrm{~K} 4$ as well as some prominent non-histone proteins, such as p53 and HSP90 (Egorova et al., 2010). The methylation of p53 at K370 has been shown to repress p53-mediated apoptosis in response to DNA damage as well as regulate the expression of downstream target genes such as p21, a cyclin-dependent protein kinase important for cell-cycle control (Huang et al., 2006; Sajjad et al., 2014). The methylation of HSP90 at K616 increases the stability of the HSP90 chaperone and facilitates cytoprotection (Donlin et al., 2012). Correspondingly, substantial increases in the antiapoptotic and heat shock protein responses have been previously reported in red-eared sliders in response to anoxia (Bansal et al., 2016; Krivoruchko and Storey, 2010a). Therefore, in order to prevent apoptosis and increase the viability of existing proteins in a low energy, stressed state, the red-eared slider may be maintaining the protein expression levels of SMYD2 during $20 \mathrm{~h}$ anoxia.

The overall increase in $\mathrm{H} 3 \mathrm{~K} 4 \mathrm{me} 1$ modification in the liver was further supported by a significant increase in enzymatic activity of all HKMTs that are known to methylate H3K4 in T.s. elegans in response to anoxia (Figure 4). The unexpected increase in H3K4me1, a sign of active euchromatin, during a low energy state may not necessarily indicate a global increase in transcription but rather could illustrate a more target-specific increase in gene expression. For example, mitochondrial superoxide dismutase1 (SOD1), a crucial antioxidant enzyme involved in combating oxidative damage by catalyzing the conversion of superoxide into oxygen and hydrogen peroxide (Dawson et al., 2015), is typically hypermethylated at $\mathrm{H} 3 \mathrm{~K} 4 \mathrm{me} 1$ sites in the promoter regions to facilitate 
transcription. An increased expression of lysine-specific demethylase-1 (LSD1) has been shown to directly affect the expression of SOD1 by actively removing H3K4me1 modifications in the SOD1 promoter regions (Guo et al., 2015; Zhong and Kowluru, 2011). Consequently, the overall increase in $\mathrm{H} 3 \mathrm{~K} 4 \mathrm{me} 1$ seen during anoxia in the liver of red-eared sliders may be due to enhanced expression of this modification in the active enhancer regions of cytoprotective genes that are needed for anoxia survival. In addition, although $\mathrm{H} 3 \mathrm{~K} 4 \mathrm{me} 1$ is typically associated with transcriptional activation, the overall change in gene expression of a cell does not depend on a single methyl modification, but rather an intricate association between DNA methylation/demethylation as well as numerous other covalent modifications that are part of "the histone code" determine the transcriptional outcome of targeted genes.

H3K9me3 and H3K9mepan modifications significantly increased during $20 \mathrm{~h}$ anoxia in the liver of red-eared sliders (Figure 2) and correspondingly the HKMT that actively methylates $\mathrm{H} 3 \mathrm{~K} 9$, EHMT2, also increased in expression during $20 \mathrm{~h}$ anoxia (Figure 3). Furthermore, a similar trend was seen in the enzymatic activity of all HKMTs that are known to methylate H3K9 site (Figure 4). Methylation of H3K9 (mono, di, or tri) is highly correlated with transcriptional repression from fungi to humans (Du et al., 2015; Lachner et al., 2003; Sims et al., 2003). H3K9me3 in particular, has been shown to facilitate heterochromatin formation and maintenance within the genome and is a binding site for HP1 in the promoter regions of actively transcribed genes (Bannister and Kouzarides, 2011; Lachner et al., 2003; Martin and Zhang, 2005; Sims et al., 2003; Vakoc et al., 2006). The binding of HP1 to the promoter regions of actively transcribed genes prevents the binding of transcription factors and as such, $\mathrm{H} 3 \mathrm{~K} 9$ not only serves as a 
mark for stable heterochromatin formation but may also function as a vital regulatory mechanism for target-specific gene expression (Martin and Zhang, 2005). Therefore, the anoxia-tolerant red-eared slider may be utilizing EHMT2 prominently to methylate H3K9 residues in the promoter regions of the genes that are deemed energy expensive to function or needless for anoxia survival. Furthermore, previous work done on N.crassa and $A$. thaliana suggests a functional link between histone and DNA methylation in which H3K9 methylation has been shown to recruit DNMTs (DNA methyltransferases) to the promoter regions of targeted genes loci and further repress transcription (Lachner et al., 2003). Correspondingly, DNA methylation has been shown to be a major regulator of gene expression in the liver during $5 \mathrm{~h}$ and $20 \mathrm{~h}$ anoxia in red-eared sliders ( $\mathrm{S}$ Wijenayake and Storey, 2016).

H3K27me1 is a highly conserved histone modification, that is associated with active transcription and euchromatin (Bannister and Kouzarides, 2011; Barski et al., 2007; Ferrari et al., 2014; Kim and Kim, 2012; Kimura, 2013). H3K27me1 $\mathrm{H} 3 \mathrm{~K} 27 \mathrm{me} 1$ is similar in function to $\mathrm{H} 3 \mathrm{~K} 4 \mathrm{me} 1$ in its pro-transcriptional activity, but have different expression patterns in the liver of red-eared sliders. H3K27me1 expression levels decreased significantly during $5 \mathrm{~h}$ and $20 \mathrm{~h}$ anoxia (Figure 3), yet remained unchanged in total enzymatic activity (Figure 4). The differential expression in H3K4me1 and H3K27me1 seen in this study could suggest different roles for each modification in the liver during anoxia. For example, as H3K4me1 may be involved in facilitating the expression of cytoprotective genes, whereas H3K27me1 expression may be repressed as part of MRD to limit ATP usage. Since H3K27me1 is typically found in the promoter regions of highly transcribed genes (Ferrari et al., 2014), it is possible that 
the red-eared sliders are decreasing the expression of H3K27me1 in the liver as part of the global reduction in gene expression; a prominent characteristic of MRD.

Liver was exclusively chosen for this analysis because the organ plays a crucial

role in anoxia tolerance and survival, not merely as the major site of glycogen storage and glycogenolysis, but also as a proliferative tissue that continues to function as a central regulator of MRD. According to (Buck et al., 1993), turtle hepatocytes robustly reduced the metabolic rate to $10 \%$ when compared to control conditions. As such, we were interested to see whether liver may be utilizing histone methylation for chromatin remodeling and to facilitate the expression of certain genes while strongly repressing others. In conclusion, this study proposes a role for histone lysine methylation in anoxia tolerance and survival in T.s. elegans with a potential role in both target-specific and global repression of genes in the liver during $5 \mathrm{~h}$ and $20 \mathrm{~h}$ anoxia.

\section{Acknowledgements}

I would like to thank Jan Storey for the editorial review of this manuscript. 


\section{References}

Bannister, A.J., Kouzarides, T., 2011. Regulation of chromatin by histone modifications. Cell Res. 21, 381-395. doi:10.1038/cr.2011.22

Bansal, S., Biggar, K.K., Krivoruchko, A., Storey, K.B., 2016. Response of the JAKSTAT signaling pathway to oxygen deprivation in the red eared slider turtle, Trachemys scripta elegans. Gene 593, 34-40. doi:10.1016/j.gene.2016.08.010

Barski, A., Cuddapah, S., Cui, K., Roh, T.-Y., Schones, D.E., Wang, Z., Wei, G., Chepelev, I., Zhao, K., 2007. High-resolution profiling of histone methylations in the human genome. Cell 129, 823-837. doi:10.1016/j.cell.2007.05.009

Bártová, E., Krejčí, J., Harničarová, A., Galiová, G., Kozubek, S., 2008. Histone modifications and nuclear architecture: A review. J. Histochem. Cytochem. 56, 711721. doi:10.1369/jhc.2008.951251

Bell, R., Storey, K., 2012. Regulation of liver glutamate dehydrogenase from an anoxiatolerant freshwater turtle. HOAJ Biol. 1, 1-3. doi:org/10.7243/2050-0874-1-3

Berger, S.L., 2002. Histone modifications in transcriptional regulation. Curr. Opin. Genet. Dev. 12, 142-148. doi:10.1016/S0959-437X(02)00279-4

Bickler, P.E., 2004. Clinical perspectives: neuroprotection lessons from hypoxia-tolerant organisms. J. Exp. Biol. 207, 3243-3249. doi:10.1242/jeb.00977

Biggar, K., Groom, A., Storey, K., 2011. Hypometabolism and turtles: Physiological and molecular strategies of anoxic survival, in: Nowakowska, A., Caputa, M. (Eds.), Hypometabolism: Strategies of Survival in Vertebrates and Invertebrates. Research Signpost, Kerala, pp. 57-94.

Biggar, K., Storey, K., 2011. The emerging roles of microRNAs in the molecular 
responses of metabolic rate depression. J. Mol. Cell Biol. 3, 167-175. doi:10.1093/jmcb/mjq045

Biggar, K.K., Kornfeld, S.F., Storey, K.B., 2011. Amplification and sequencing of mature microRNAs in uncharacterized animal models using stem-loop reverse transcription-polymerase chain reaction, Analytical Biochemistry.

doi:10.1016/j.ab.2011.05.015

Biggar, K.K., Storey, K.B., 2015. Insight into post-transcriptional gene regulation: stressresponsive microRNAs and their role in the environmental stress survival of tolerant animals. J. Exp. Biol. 218, 1281-1289. doi:10.1242/jeb.104828.

Biggar, K.K., Storey, K.B., 2012. Evidence for cell cycle suppression and microRNA regulation of cyclin D1 during anoxia exposure in turtles. Cell Cycle 11, 1705-1713. doi:10.4161/cc.19790

Brooks, S., Storey, K., 1993. De novo protein synthesis and protein phosphorylation during anoxia and recovery in the red-eared turtle. Am. J. Physiol. 265, R1380-6.

Brooks, S., Storey, K., 1989. Regulation of glycolytic enzymes during anoxia in the turtle Pseudemys scripta. Am. J. Physiol. 257, R278-R283.

Buck, L., Land, S., Hochachka, P., 1993. Anoxia-tolerant hepatocytes: Model system for study of reversible metabolic suppression. Am. J. Physiol. 265, 49-56.

Buck, L.T., 2004. Adenosine as a signal for ion channel arrest in anoxia-tolerant organisms. Comp. Biochem. Physiol. Part B Biochem. Mol. Biol. 139, 401-414. doi:10.1016/j.cbpc.2004.04.002

Cao, F., Chen, Y., Cierpicki, T., Liu, Y., Basrur, V., Lei, M., Dou, Y., 2010. An Ash2L/RbBP5 Heterodimer Stimulates the MLL1 Methyltransferase Activity 
through Coordinated Substrate Interactions with the MLL1 SET Domain. PLoS One 5, e14102. doi:10.1371/journal.pone.0014102

Cheung, P., Allis, C.D., Sassone-Corsi, P., 2000. Signaling to chromatin through histone modifications. Cell 103, 263-271. doi:10.1016/S0092-8674(00)00118-5

Dawson, N., Bell, R., Storey, K., 2013. Purification and properties of white muscle lactate dehydrogenase from the anoxia-tolerant turtle, the red-eared slider, Trachemys scripta elegans. Enzyme Res. 2013, 1-8. doi:10.1155/2013/784973

Dawson, N.J., Biggar, K.K., Storey, K.B., 2013. Characterization of fructose-1,6bisphosphate aldolase during anoxia in the tolerant turtle, Trachemys scripta elegans: An assessment of enzyme activity, expression and structure. PLoS One 8, e68830. doi:10.1371/journal.pone.0068830

Dawson, N.J., Katzenback, B.A., Storey, K.B., 2015. Free-radical first responders: The characterization of $\mathrm{CuZnSOD}$ and MnSOD regulation during freezing of the freezetolerant North American wood frog, Rana sylvatica. Biochim. Biophys. Acta - Gen. Subj. 1850, 97-106. doi:10.1016/j.bbagen.2014.10.003

Dillon, S.C., Zhang, X., Trievel, R.C., Cheng, X., 2005. The SET-domain protein superfamily: protein lysine methyltransferases. Genome Biol. 6, 227. doi:10.1186/gb-2005-6-8-227

Donlin, L.T., Andresen, C., Just, S., Rudensky, E., Pappas, C.T., Kruger, M., Jacobs, E.Y., Unger, A., Zieseniss, A., Dobenecker, M.-W., Voelkel, T., Chait, B.T., Gregorio, C.C., Rottbauer, W., Tarakhovsky, A., Linke, W.A., 2012. Smyd2 controls cytoplasmic lysine methylation of Hsp90 and myofilament organization. Genes Dev. 26, 114-119. doi:10.1101/gad.177758.111 
Dou, Y., Milne, T.A., Tackett, A.J., Smith, E.R., Fukuda, A., Wysocka, J., Allis, C.D., Chait, B.T., Hess, J.L., Roeder, R.G., 2005. Physical association and coordinate function of the H3 K4 methyltransferase MLL1 and the H4 K16 acetyltransferase MOF. Cell 121, 873-85. doi:10.1016/j.cel1.2005.04.031

Du, J., Johnson, L.M., Jacobsen, S.E., Patel, D.J., 2015. DNA methylation pathways and their crosstalk with histone methylation. Nat. Rev. Mol. Cell Biol. 16, 519-532. doi:10.1038/nrm4043

Egorova, K.S., Olenkina, O.M., Olenina, L. V, 2010. Lysine methylation of nonhistone proteins is a way to regulate their stability and function. Biochemistry $75,535-48$.

Ferrari, K.J., Scelfo, A., Jammula, S., Cuomo, A., Barozzi, I., Stützer, A., Fischle, W., Bonaldi, T., Pasini, D., 2014. Polycomb-dependent H3K27me1 and H3K27me2 regulate Active transcription and enhancer fidelity. Mol. Cell 53, 49-62. doi:10.1016/j.molcel.2013.10.030

Guo, Y., Yu, S., Zhang, C., Kong, A.-N.T., 2015. Epigenetic regulation of Keap1-Nrf2 signaling. Free Radic. Biol. Med. 88, 337-49. doi:10.1016/j.freeradbiomed.2015.06.013

He, S., Owen, D.R., Jelinsky, S.A., Lin, L.-L., Williams, C.M., 2015. Lysine methyltransferase SETD7 (SET7/9) regulates ROS signaling through mitochondria and NFE2L2/ARE pathway. Sci. Rep. 5, 14368. doi:10.1038/srep14368

Hermes-Lima, M., Storey, J.M., Storey, K.B., 2001. Antioxidant defenses and animal adaptation to oxygen availability during environmental stress, in: Storey, K., Storey, J. (Eds.), Cell and Molecular Responses to Stress, Volume 2. Elsevier Press, Amesterdam, pp. 263-287. doi:10.1016/S1568-1254(01)80022-X 
Herz, H.-M., Garruss, A., Shilatifard, A., 2013. SET for life: biochemical activities and biological functions of SET domain-containing proteins. Trends Biochem. Sci. 38, 621-639. doi:10.1016/j.tibs.2013.09.004

Hochachka, P.W., 1988. Metabolic suppression and oxygen availability. Can. J. Zool. 66, $152-158$.

Hochachka, P.W., 1986. Defense strategies against hypoxia and hypothermia. Science (80-. ). 231, 234-41.

Hochachka, P.W., Buck, L.T., Doll, C.J., Land, S.C., 1996. Unifying theory of hypoxia tolerance: molecular/metabolic defense and rescue mechanisms for surviving oxygen lack. Proc. Natl. Acad. Sci. U. S. A. 93, 9493-8.

Hochachka, P.W., Lutz, P.L., 2001. Mechanism, origin, and evolution of anoxia tolerance in animals. Comp. Biochem. Physiol. B. Biochem. Mol. Biol. 130, 435-59.

Hochachka, P.W., Rupert, J.L., Monge, C., 1999. Adaptation and conservation of physiological systems in the evolution of human hypoxia tolerance. Comp. Biochem. Physiol. A. Mol. Integr. Physiol. 124, 1-17.

Huang, J., Perez-Burgos, L., Placek, B.J., Sengupta, R., Richter, M., Dorsey, J.A., Kubicek, S., Opravil, S., Jenuwein, T., Berger, S.L., 2006. Repression of p53 activity by Smyd2-mediated methylation. Nature 444, 629-632. doi: $10.1038 /$ nature 05287

Hughes, C., Rozenblatt-Rosen, O., Milne, T., Copeland, T., Levine, S., Lee, J., Hayes, D., Shanmugam, K., Bhattacharjee, A., Biondi, C., Kay, G., Hayward, N., Hess, J., Meyerson, M., 2004. Menin associates with a trithorax family histone methyltransferase complex and with the hoxc8 locus. Mol Cell 13, 587-597. 
Jackson, D., 1997. Lactate accumulation in the shell of the turtle, Chrysemys picta bellii, during anoxia at 3 and $10^{\circ}$ C. J. Exp. Biol. 200, 2295-2300.

Jackson, D., 1968. Metabolic depression and oxygen depletion in the diving turtle. J. Appl. Physiol. 24, 503-9.

Jackson, D., Heisler, N., 1983. Intracellular and extracellular acid-base and electrolyte status of submerged anoxic turtles at $3^{\circ} \mathrm{C}$. Respir. Physiol. 53, 187-201.

Jackson, D., Toney, V., Okamoto, S., 1999. Lactate distribution and metabolism during and after anoxia in the turtle, Chrysemys picta bellii. Am. J. Physiol. 271, R409R416.

Jackson, D.C., 2000. Living without oxygen: Lessons from the freshwater turtle. Comp. Biochem. Physiol. Part A Mol. Integr. Physiol. 125, 299-315. doi:10.1016/S10956433(00)00160-4

Jackson, D.C., Taylor, S.E., Asare, V.S., Villarnovo, D., Gall, J.M., Reese, S.A., 2006. Comparative shell buffering properties correlate with anoxia tolerance in freshwater turtles. AJP Regul. Integr. Comp. Physiol. 292, R1008-R1015. doi:10.1152/ajpregu.00519.2006

Khorasanizadeh, S., Gerchman, S.E., Ramakrishnan, V., Travers, A., Muyldermans, S., Selker, E.U., Cheng, X., Burlingame, A.L., Wong, J., Tempst, P., Zhang, Y., 2004. The nucleosome: From genomic organization to genomic regulation. Cell 116, 25972. doi:10.1016/S0092-8674(04)00044-3

Kim, J., Kim, H., 2012. Recruitment and biological consequences of histone modification of H3K27me3 and H3K9me3. ILAR J. 53, 232-9. doi:10.1093/ilar.53.3-4.232

Kimura, H., 2013. Histone modifications for human epigenome analysis. J. Hum. Genet. 
58, 439-445. doi:10.1038/jhg.2013.66

Krivoruchko, A., Storey, K., 2013a. Activation of the unfolded protein response during anoxia exposure in the turtle Trachemys scripta elegans. Mol. Cell. Biochem. 374, 91-103. doi:10.1007/s11010-012-1508-3

Krivoruchko, A., Storey, K., 2013b. Anoxia-responsive regulation of the FoxO transcription factors in freshwater turtles, Trachemys scripta elegans. Biochim. Biophys. Acta - Gen. Subj. 1830, 4990-4998. doi:10.1016/j.bbagen.2013.06.034

Krivoruchko, A., Storey, K., 2010a. Activation of antioxidant defenses in response to freezing in freeze-tolerant painted turtle hatchlings. Biochim. Biophys. Acta - Gen. Subj. 1800, 662-668. doi:10.1016/j.bbagen.2010.03.015

Krivoruchko, A., Storey, K., 2010b. Regulation of the heat shock response under anoxia in the turtle, Trachemys scripta elegans. J. Comp. Physiol. B 180, 403-414. doi:10.1007/s00360-009-0414-9

Krivoruchko, A., Storey, K., 2010c. Molecular mechanisms of turtle anoxia tolerance: A role for NF-кB. Gene 450, 63-69. doi:10.1016/j.gene.2009.10.005

Lachner, M., O’Sullivan, R.J., Jenuwein, T., 2003. An epigenetic road map for histone lysine methylation. J. Cell Sci. 116, 2117-2124. doi:10.1242/jcs.00493

Lehnertz, B., Ueda, Y., Derijck, A.A.H.A., Braunschweig, U., Perez-Burgos, L., Kubicek, S., Chen, T., Li, E., Jenuwein, T., Peters, A.H.F.M., 2003. Suv39hmediated histone H3 lysine 9 methylation directs DNA methylation to major satellite repeats at pericentric heterochromatin. Curr. Biol. 13, 1192-200. doi:10.1016/S0960-9822(03)00432-9

Lutz, P.L., 1992. Mechanisms for anoxic survival in the vertebrate brain. Annu. Rev. 
Physiol. 54, 601-618. doi:10.1146/annurev.ph.54.030192.003125

Lutz, P.L., Milton, S.L., 2004. Negotiating brain anoxia survival in the turtle. J. Exp. Biol. 207, 3141-3147. doi:10.1242/jeb.01056

Martin, C., Zhang, Y., 2005. The diverse functions of histone lysine methylation. Nat. Rev. Mol. Cell Biol. 6, 838-849. doi:10.1038/nrm1761

Mehrani, H., Storey, K., 1995. Enzymatic control of glycogenolysis during anoxic submergence in the freshwater turtle Trachemys scripta. Int. J. Biochem. Cell Biol. 821-830, 821-830. doi:10.1016/1357-2725(95)00042-N

Murray, K., 1964. The occurance of epsilion-N-methyl lysine in histones. Biochemistry $3,10-5$.

Nakamura, T., Mori, T., Tada, S., Krajewski, W., Rozovskaia, T., Wassell, R., Dubois, G., Mazo, A., Croce, C.M., Canaani, E., 2002. ALL-1 is a histone methyltransferase that assembles a supercomplex of proteins involved in transcriptional regulation. Mol. Cell 10, 1119-28.

Peters, A.H.F.M., Mermoud, J.E., O’Carroll, D., Pagani, M., Schweizer, D., Brockdorff, N., Jenuwein, T., 2002. Histone H3 lysine 9 methylation is an epigenetic imprint of facultative heterochromatin. Nat. Genet. 30, 77-80. doi:10.1038/ng789

Sajjad, A., Novoyatleva, T., Vergarajauregui, S., Troidl, C., Schermuly, R.T., Tucker, H.O., Engel, F.B., 2014. Lysine methyltransferase Smyd2 suppresses p53-dependent cardiomyocyte apoptosis. Biochim. Biophys. Acta - Mol. Cell Res. 1843, 25562562. doi:10.1016/j.bbamcr.2014.06.019

Schneider, R., Bannister, A.J., Myers, F.A., Thorne, A.W., Crane-Robinson, C., Kouzarides, T., 2004. Histone H3 lysine 4 methylation patterns in higher eukaryotic 
genes. Nat. Cell Biol. 6, 73-77. doi:10.1038/ncb1076

Shi, Y., Whetstine, J.R., 2007. Dynamic regulation of histone lysine methylation by demethylases. Mol. Cell 25, 1-14. doi:10.1016/j.molcel.2006.12.010

Sims, R.J., Nishioka, K., Reinberg, D., 2003. Histone lysine methylation: a signature for chromatin function. Trends Genet. 19, 629-639. doi:10.1016/j.tig.2003.09.007

Storey, K., 2007. Anoxia tolerance in turtles: Metabolic regulation and gene expression. Comp. Biochem. Physiol. Part A Mol. Integr. Physiol. 147, 263-276. doi:10.1016/j.cbpa.2006.03.019

Storey, K., 1996. Metabolic adaptations supporting anoxia tolerance in reptiles: recent advances. Comp. Biochem. Physiol. Part B Comp. Biochem. 113, 23-35. doi:10.1016/0305-0491(95)02043-8

Storey, K., Storey, J., 2007. Tribute to P. L. Lutz: putting life on 'pause' - molecular regulation of hypometabolism. J. Exp. Biol. 210, 1700-1714. doi:10.1242/jeb.02716

Storey, K., Storey, J., 2004. Oxygen limitation and metabolic rate depression, in: Storey, K.B. (Ed.), Functional Metabolism. John Wiley \& Sons, Inc., Hoboken, NJ, USA, pp. 415-442. doi:10.1002/047167558X.ch15

Storey, K., Storey, J., 1990. Metabolic rate depression and biochemical adaptation in anaerobiosis, hibernation and estivation. Q. Rev. Biol. 65, 145-74. doi: $10.4172 / 2157-7625.1000224$

Vakoc, C.R., Mandat, S.A., Olenchock, B.A., Blobel, G.A., 2005. Histone H3 Lysine 9 methylation and HP1 $\gamma$ are associated with transcription elongation through mammalian chromatin. Mol. Cell 19, 381-391. doi:10.1016/j.molcel.2005.06.011 Vakoc, C.R., Sachdeva, M.M., Wang, H., Blobel, G.A., 2006. Profile of histone lysine 
methylation across transcribed mammalian chromatin. Mol. Cell. Biol. 26, 9185-95. doi:10.1128/MCB.01529-06

Venkatesh, S., Workman, J.L., 2015. Histone exchange, chromatin structure and the regulation of transcription. Nat. Rev. Mol. Cell Biol. 16, 178-189.

doi:10.1038/nrm3941

Wijenayake, S., Storey, K., 2016. The role of DNA methylation during anoxia tolerance in a freshwater turtle (Trachemys scripta elegans). J. Comp. Physiol. B 186, 333342. doi:10.1007/s00360-016-0960-X

Willmore, W., Storey, K.B., 1997. Antioxidant systems and anoxia tolerance in a freshwater turtle Trachemys scripta elegans. Mol. Cell. Biochem. 170, 177-85. doi:10.1023/A:1006817806010

Zhang, J., Biggar, K.K., Storey, K.B., 2013. Regulation of p53 by reversible posttranscriptional and post-translational mechanisms in liver and skeletal muscle of an anoxia tolerant turtle, Trachemys scripta elegans. Gene 513, 147-155. doi:10.1016/j.gene.2012.10.049

Zhong, Q., Kowluru, R.A., 2011. Epigenetic changes in mitochondrial superoxide dismutase in the retina and the development of diabetic retinopathy. Diabetes 60 , 1304-1313. doi:10.2337/db10-0133 


\section{CHAPTER 6}

\section{GENERAL DISCUSSION}




\subsection{Oxygen deprivation}

Prolonged exposure to oxygen deprivation is a lethal stress for most terrestrial vertebrates since they cannot tolerate and survive anoxia for longer than few minutes, mainly due to the vital role that oxygen plays as the final acceptor of electrons in the electron transport chain (ETC). Through oxidative phosphorylation, approximately 37 mol of ATP can be produced from a one mol of glucose (Brand, 2003). However, in the absence of oxygen, oxidative phosphorylation is entirely inhibited and anaerobic glycolysis becomes the sole source of energy production. Anaerobic glycolysis can only produce a net of $2 \mathrm{~mol}$ of ATP from catabolizing $1 \mathrm{~mol}$ of glucose and in doing so also generates end products such as lactate that can be cytotoxic (Jackson and Heisler, 1983; Jackson and Ultsch, 1982). Furthermore, a poor ATP yield will create an energy imbalance between the rate of ATP production and the rate of ATP utilization, leading to an energy crisis that disrupts or collapses various crucial ATP-dependent cell functions. For example, ATP limitation disrupts ion channel functioning and induces membrane depolarization, leading to subsequent influx of extracellular calcium into cells (Hochachka and Lutz, 2001a; Pérez-Pinzón et al., 1992; Storey, 2007). In turn, this uncontrolled influx of calcium can cause various cellular-based degenerative effects including DNA and RNA degradation, proteolysis, and apoptosis (Hochachka, 1988; P. W. Hochachka, 1986). As such, most terrestrial vertebrates cannot handle prolonged anoxia without incurring lethal cellular damage.

\subsection{Anoxia tolerance and metabolic rate depression}

Some invertebrates and ectothermic vertebrates have adapted physiological and biochemical adaptations against hypoxia and anoxia and can survive the lethal 
consequences that are associated with re-oxygenation (Gorr et al., 2010). Among terrestrial vertebrates, freshwater turtles belonging to Trachemys and Chrysemys genera, including Trachemys scripta elegans (red-eared sliders) and Chrysemys picta belli (painted turtles) in particular, are considered to be champion anaerobes; indeed, they are often used as medical models to derive therapeutics against anoxia-induced injuries in humans (Storey, 2007, 1996; Storey and Storey, 1992). Red-eared sliders, the experimental model of this thesis, can tolerate short-term anoxia that is associated with deep-dives in search of food as well as long-anoxia that is associated with winter hibernation at the bottom of ice-locked ponds (Gorr et al., 2010; P. W. Hochachka, 1986; Jackson, 1968; Storey and Storey, 1990b). These turtles have developed various physiological, biochemical, and molecular adaptations to survive anoxia including 1) increase fermentable fuel storage in the liver, skeletal muscle, and heart that can be used to generate ATP (Jackson, 1968; K. Storey and Storey, 2004a; Storey and Storey, 2007, 1990b; K. B. Storey and Storey, 2004; Ultsch and Jackson, 1982), 2) store and buffer plasma lactate buildup that can reach 150-200 $\mathrm{mM}$ after several months of anoxia (Davis and Jackson, 2007; Jackson et al., 2006a), 3) enhance cytoprotective and antioxidant defense mechanisms to combat reactive oxygen species (ROS) damage (Krivoruchko and Storey, 2013a, 2010a, 2010b, 2010c; Willmore and Storey, 1997), and finally to correct the imbalance between ATP production and ATP utilization, red-eared sliders can decrease the overall metabolic rate by $80-90 \%$ (Hochachka, 1988; Jackson, 1968; Storey and Storey, 1990b) when compared to normoxic conditions. Metabolic rate depression (MRD) is accomplished by shutting down all ATP-utilizing cellular processes that may hinder anoxia survival and reprioritizing the conserved ATP towards driving cellular 
processes that are needed for anoxia survival (Storey, 2007, 1996; Storey and Storey, 2007). One of the main cellular processes that experience global suppression during anoxia is gene expression. It is estimated that $1-10 \%$ of the total cellular energy is used by gene transcription, depending on the tissue (Rolfe and Brown, 1997). As such, this is a significant metabolic cost that must be reduced and stringently regulated during anoxiainduced hypometabolism. A strong decrease in global gene expression has been reported in a number of other anoxia-tolerant animals such as brine shrimp (Artemia franciscana) (van Breukelen et al., 2000), intertidal snails (Littorina littorea) (Larade and Storey, 2007), Crucian carp (Carassius carassius) (Rolfe and Brown, 1997), and North American wood frogs (Rana sylvatica) (Storey and Storey, 1992) as well as in states of aerobic hypometabolism such as hibernating golden-mantled ground squirrels (Callospermophilus lateralis) (Martin et al., 2000) and13-lined ground squirrels (Ictidomys tridecemlineatus) (Storey and Storey, 2010, 1990b).

Global gene expression can be regulated at the transcription level by regulating the accessibility of transcription factors to target promoter regions (Krivoruchko and Storey, 2013b, 2010c; Zhang et al., 2013a), at the post-transcription level through miRNA regulation of mature mRNA transcripts (Biggar and Storey, 2011, 2015, 2012b; Brooks and Storey, 1989), and at the post-translational level through post-translational modifications (PTMs) such as phosphorylation, acetylation, methylation, and SUMOylation of metabolic enzymes and membrane ion channels and receptors (Mehrani and Storey, 1995a, 1995b, 1995c; Storey, 2007; Storey and Storey, 2004a). Another prominent mechanism of global and localized transcriptional regulation is epigenetics, in 
which gene expression can be regulated at the DNA level through DNA methylation and post-translational modifications (PTMs) of the amino (N)- tails of core histones.

\subsection{Epigenetics}

Epigenetics is the study of heritable covalent modifications on DNA and PTMs of core histone proteins that directly regulate gene expression (Waddington, 2012, 1956). Epigenetic signatures are highly susceptible to changes in environmental stimuli and stress and convey more variability than genetic changes. It is possible that red-eared sliders are experiencing drastic changes in the epigenome during metabolic reorganization in response to anoxia. As such, similar to physiological and biochemical adaptations that allow anoxia tolerance in red-eared sliders, epigenetic adaptations may also play a vital part in anaerobiosis. Therefore, this thesis explored the four main aspects of gene regulatory epigenetics in response to control, $5 \mathrm{~h}$ anoxia, and $20 \mathrm{~h}$ anoxia in T.s. elegans: 1) DNA methylation mediated by DNA methyltransferases (DNMTs) and methyl-binding proteins (MBDs), 2) DNA demethylation mediated by ten-eleven translocation family (TET) of proteins, 3) balance between histone $\mathrm{H} 3$ acetylation/deacetylation, and 4) histone $\mathrm{H} 3$ lysine regulation by histone methyltransferases (HMTs). This thesis used a variety of molecular techniques, including total soluble protein extractions, western immunoblotting, genomic extractions, DNA dot blotting, cytoplasmic and nuclear fractionations, genomic $5 \mathrm{mC}$ assays, colorimetric, and fluorometric enzymatic assays to explore the overall epigenetic response to anoxia tolerance. In summary, the results suggest a prominent role for epigenetics in the global suppression of gene expression during anaerobiosis in red-eared sliders. 


\subsection{The interplay between epigenetics and metabolism}

It is an accepted notion that suppression of gene expression is based on the level of chromatin condensation and is a vital part of MRD in anoxic red-eared sliders. However, some of the most well-established chromatin modifiers, which are also epigenetic enzymes, including DNMTs, TETs, HATs (histone acetyltransferases), HDACs (histone deacetylases), and HMTs use metabolic cofactors such as Sadenosylmethionine (SAM), acetyl-CoA, and nicotinamide adenine dinucleotide $\left(\mathrm{NAD}^{+}\right)$ as well as intermediate metabolites such as $\alpha$-ketoglutarate $(\alpha-K G)$ to function (Etchegaray and Mostoslavsky, 2016; Janke et al., 2015; Katada et al., 2012). These metabolic cofactors and substrates directly influence the enzymatic activity of the chromatin modifiers and thereby indirectly regulate chromatin accessibility, leading to both overall and localized regulation of gene expression. As such, although transcriptional regulation may help establish a hypometabolic state during anaerobiosis in red-eared sliders (Hochachka, 1988; Storey, 2007, 1996; Storey and Storey, 1990b), the overall metabolic output also determines the level of chromatin reorganization and transcriptional output in the cell. Red-eared sliders may use this cyclical relationship to maintain a stable metabolic and transcriptional homeostasis.

\subsection{DNA and histone methylation}

The universal cofactor of both DNA methylation and histone methylation is the intermediary metabolite, SAM, which is derived from the condensation of the amino acid methionine and ATP, catalyzed by methionine adenosyltransferase (MAT) (Reytor et al., 2009; Vaquero et al., 2007a). Subsequently, S-adenosylhomocysteine (SAH) is produced as an intermediary by-product of SAM during methyltransferase reactions. SAH is a 
potent inhibitor of DNA and histone methylation, and as a result the SAM/SAH ratio serves as a biosensor of the metabolic state of a given cell at a given time. As such, in a low energy, anoxic state with limited ATP availability, the SAM/SAH ratio may influence the activity of DNA and histone methyltransferases and regulate chromatin accessibility according to the energy demands (Etchegaray and Mostoslavsky, 2016). Chapter 2 examined the dynamic changes in DNA methylation in response to anoxia in T.s. elegans liver, heart, and white skeletal muscle, whereas Chapter 4 explored the regulation of histone $\mathrm{H} 3$ lysine methylation in the liver of T.s. elegans. A robust increase in DNA methylation was seen in the liver and white skeletal muscle, indicating a potential downregulation of gene expression in response to $5 \mathrm{~h}$ and $20 \mathrm{~h}$ anoxia (Chapter 2). Histone $\mathrm{H} 3$ lysine methylation illustrated a promoter-specific response in the liver of red-eared sliders that could potentially aid in the selective upregulation of genes that are necessary for anoxia survival, while globally suppressing others to conserve energy (Chapter 4). Thus, the increase in $5 \mathrm{mC}$ levels on the DNA along with selective increases in repressive histone $\mathrm{H} 3$ methylation marks such as $\mathrm{H} 3 \mathrm{~K} 9$ could be a result of SAM/SAH ratios influencing DNMTs and HMTs to enforce a restricted chromatin state in a majority of gene promoters during anoxia in the liver of red-eared sliders. Furthermore, because gene expression during anoxia is not suppressed globally but rather in a target-specific manner, the increase in the permissive histone methylation mark, $\mathrm{H} 3 \mathrm{~K} 4 \mathrm{me} 3$, described in Chapter 5 could be part of the enhanced cytoprotection seen in red-eared sliders. Cytoprotective mechanisms such as antioxidants, heat shock protein response and unfolded protein response are robustly activated to combat potential ROS damage during the reoxygenation phase and stabilize the cellular proteome over prolonged periods of 
time when ATP availability for protein synthesis is impaired (Krivoruchko and Storey, 2013a, 2010a, 2010b, 2010c; Willmore and Storey, 1997).

\subsection{DNA demethylation}

Similar to DNMTs, the TETs also require metabolic intermediates and cofactors to function. TET-family of DNA demethylases utilize metabolic intermediates such as $\alpha$ $\mathrm{KG}$ in the presence of $\mathrm{Fe}^{2+}$ to catalyze the successive oxidation of $5 \mathrm{mC}$ into 5hydrozymethylcytosine, 5-formylcytosine, and 5-carboxylcytosine (Hahn et al., 2014; He et al., 2011; Ito et al., 2010a; S. Ito et al., 2011; Kohli and Zhang, 2013; Tahiliani et al., 2009). This is a step-wise method for removing stable $5 \mathrm{mC}$ residues from targeted DNA regions and enforcing a permissive chromatin state to enhance gene expression. Importantly, TET-activity is directly dependent upon the availability of $\alpha-K G$ and can be inhibited by TCA cycle intermediates such as fumarate and succinate, which are downstream of $\alpha-K G$ (Etchegaray and Mostoslavsky, 2016; Lu et al., 2012). Therefore, the rate of DNA demethylation is controlled by the overall metabolic output of the TCA cycle. As such, the significant decrease in TET-mediated DNA demethylation seen in the liver and white skeletal muscle during anoxia (Chapter 3) could potentially be attributed to the limited availability of TCA cycle intermediates in this state. Furthermore, $\alpha-\mathrm{KG}$ can be derived from either glucose or glutamine and is involved in several pathways (Lu et al., 2012). However, most anabolic pathways are suppressed during anoxia in red-eared sliders as part of the MRD (Storey, 2007, 1996; K. Storey and Storey, 2004a; Storey and Storey, 1990b). Therefore, it is possible that red-eared sliders carefully regulate the availability of $\alpha-K G$ to limit both DNA demethylation as well as ATP-requiring anabolic pathways during oxygen deprivation. 


\subsection{Histone acetylation and deacetylation}

Histone acetylation is catalyzed by histone acetyltransferases (HATs) that transfer acetyl groups from acetyl-CoA to lysine residues of histone and non-histone proteins. As such, the enzymatic activity of HATs directly depends on the intracellular levels of acetyl-CoA (P Cheung et al., 2000; Eberharter and Becker, 2002; Hebbes et al., 1988; Jenuwein and Allis, 2001). The interaction between HATs and acetyl-CoA exemplifies another vital interplay between metabolism and chromatin regulation, especially during periods of nutrient/ATP deprivation (Wellen et al., 2009). Acetyl-CoA is a molecular intermediate that feeds the TCA cycle and is generated from the catabolism of glucose and $\beta$-oxidation of fats. Acetyl-CoA is also a building block for anabolic synthesis of lipids, cholesterol, and amino acids (Janke et al., 2015; Lu et al., 2012). As such, the availability of acetyl-CoA that can be used for histone $\mathrm{H} 3$ acetylation depends solely on the overall metabolic output and ATP availability of the cells during MRD in red-eared sliders. As expected, histone $\mathrm{H} 3$ acetylation, that is typically associated with permissive chromatin and active transcription, decreased in the liver of red-eared sliders during short-term and long-term anoxia (Chapter 4). This was associated with an overall decrease in HAT expression and enzymatic levels. Put together, this may be an important characteristic of MRD in which acetyl-CoA production is limited due to an overall decrease in glycolytic rate and a complete shut down of $\beta$-oxidation of fats. Hence, a limited availability of acetyl-CoA as a consequence of altered pathways of fuel metabolism under anoxia may play an important part in suppressing HAT acetylation of histone H3, contributing to inhibition of gene expression, one of the major ATP consuming cell processes. 
Another major metabolic cofactor with prominent epigenetic functions is $\mathrm{NAD}^{+}$ (nicotinamide adenine dinucleotide). $\mathrm{NAD}^{+}$is the oxidized form of $\mathrm{NADH}$, and functions as an electron acceptor in redox reactions. $\mathrm{NAD}^{+}$is a vital part of many metabolic pathways (particularly catabolic ones), including glycolysis, $\beta$-oxidation of fats, TCA cycle, ETC, as well as functioning as an obligate cofactor for class III histone deacetylases, the sirtuin (SIRTs) proteins (Etchegaray and Mostoslavsky, 2016; Janke et al., 2015; Katada et al., 2012; Lu et al., 2012). The NAD ${ }^{+}$dependency of SIRTs is largely based on nutrient availability and the overall metabolic output of the cell. SIRTs that have been shown to exclusively localize in the nucleus, SIRT1, 6 and 7 (Finkel et al., 2009b), deacetylate transcriptionally relevant lysine residues and thereby couple the metabolic state with transcriptional regulation (Etchegaray and Mostoslavsky, 2016). The interplay between metabolism and $\mathrm{NAD}^{+}$-dependent SIRT enzymatic activity was supported by studies that illustrated a positive correlation between decreased $\mathrm{NAD}^{+}$levels and decreased SIRT1 activity (Etchegaray and Mostoslavsky, 2016; Yoon et al., 2001; Yoshino et al., 2011). The decreased SIRT1 protein expression levels seen in the liver of red-eared sliders (Chapter 4) might also be influenced by varying levels of NAD (H) pools in response to anoxia tolerance. This would be an interesting point to follow up, since adenylate pools are typically reduced under MRD. Furthermore, SIRT1 has been shown to deacetylate PGC-1 $\alpha$ and enhance gluconeogenesis and glucose output in the liver (Gerhart-Hines et al., 2007; Rodgers et al., 2005). Therefore, SIRT1 expression may be suppressed during anoxia in the liver of red-eared sliders as a way of preventing ATPconsuming hepato-gluconeogenesis. The protein expression level of another metabolically relevant sirtuin, SIRT6, decreased in response to anoxia (Chapter 6). 
SIRT6 deacetylates H3K9ac and H3K56ac to repress the expression of HIF-1 $\alpha$ driven glycolytic genes (Zhong et al., 2010). Therefore, reduced SIRT6 protein expression may be one factor that promotes glycolytic ATP production under anoxic conditions by potentially enhancing protein levels of crucial glycolytic enzymes. Furthermore, class I and II HDACs have been shown to increase robustly in their protein expression and enzymatic activity in the liver of anoxia-tolerant red-eared sliders (Krivoruchko and Storey, 2010d), whereas, by comparison, nuclear enzymatic activity of SIRTS decreased strongly (Chapter 4). Consequently, type I and II HDACs may have a more prominent function in transcriptionally silencing active histone lysine residues in the liver during anaerobiosis compared to $\mathrm{NAD}^{+}$- dependent SIRTs.

\subsection{Other factors involved in chromatin modifications}

However, the availability of a given metabolite cannot provide exclusive control of the enzymatic activity of chromatin-modifiers; for example, increased ATP availability in cells does not translate to an activation of all transcription factors and expression of all genes (Katada et al., 2012). Similarly, a hypometabolic state does not involve global suppression of all transcription, but rather selective genes either remain unchanged or are upregulated in expression during anoxia (Storey, 2007, 1996). Interactions between different DNMTs, TETs, and histone-modifying enzymes as well as interactions of these modifiers with DNA-binding factors also regulate enzymatic activity (Katada et al., 2012). This is similar to the results seen in Chapter 2 and 3, in which the increased expression of DNA methyl-binding proteins, MBD1 and MBD2, may have affected the DNA binding capability of TETs and thereby suppress DNA demethylation during anoxia. Furthermore, chromatin modifiers that use the same cofactor or metabolic 
intermediate, yet modify different substrates may compete with each other. This could be the case with DNMTs using SAM to catalyze DNA methylation (Chapter 2) or HMTs using SAM to catalyze histone and non-histone proteins methylation (Chapter 5) since in a low energy state SAM may not be ubiquitously available. Moreover, chromatin modifiers such as HATs, HDACs, and HMTs can be post-translationally modified and the modifications may affect their enzymatic activity and DNA and histone binding capability (Vaquero et al., 2007b; Wei et al., 2011), as in the case of GCN5

phosphorylation by DNA-dependent protein kinase (DNA-PK) (Barlev et al., 1998) and deacetylation by SIRT6 (Dominy et al., 2012). Both of these post-translational modifications (PMTs) regulate GCN5 enzymatic activity.

\subsection{Future directions}

Although this thesis provides a comprehensive outlook on the dynamic regulation of epigenetic mechanisms as part of MRD during anoxia tolerance, there are other avenues that can be explored to obtain a definitive cause and effect between epigenetic regulation and the expression or repression of target genes. Many in-depth physiological and biochemical studies have been done with red-eared sliders as models for potentially identifying therapeutic measures that could be used against hypoxia-induced injuries in humans. Multiple molecular pathways have already been explored in red-eared sliders; these include the activation of Hif-1 $\alpha$ (K. Biggar et al., 2011), the unfolded protein response (Krivoruchko and Storey, 2013a), antioxidant response (Krivoruchko and Storey, 2010b; Willmore and Storey, 1997), heat shock proteins (Krivoruchko and Storey, 2010a), transcription factors including NF-kB, FoxO and p53 (Krivoruchko and Storey, 2010a, Krivoruchko and Storey, 2013b; Zhang et al., 2013), characterization of 
cell cycle regulatory proteins (Biggar and Storey, 2012b), as well as the activation of ChREBP (Krivoruchko and Storey, 2014), and evidence of miRNA regulation of MRD (Biggar and Storey, 2011), along with post-translation regulation of glycolytic enzymes in various tissues (Dawson et al., 2013; Mehrani and Storey, 1995a, 1995b, 1995c, Storey, 2007, 1996, Storey and Storey, 2004a, 2004b, Storey and Storey, 2010, 1990). Thus, we have a comprehensive set of proteomics data outlining both transcriptionally active and repressive protein targets and pathways that can be further investigated with an epigenetics approach. Given that my thesis highlights global changes in both DNA methylation and histone modification (methylation and acetylation of transcriptionallyrelevant lysine residues of histone $\mathrm{H} 3$ ) in response to short (5 h) and long (20 h)- term anoxia, one useful next step will be to take a localized and target-specific approach to determine whether protein targets that have shown by previous studies to be differentially expressed, are in fact epigenetically regulated at the chromatin level. In particular, a focus on the promoter regions of transcription factors such as Hif- $1 \alpha$, FoxO, p53, NF- $\mathrm{kB}$, or cyclin 1 would reveal whether they are hypo- or hyper-methylated with $5 \mathrm{mC}$ marks. Bisulfite genomic sequencing could also be performed on the red-eared slider genome with gene identification based on the genome of the very closely-related anoxia-tolerant painted turtle (Bradley et al., 2013) .

Bisulfite sequencing is the current gold standard for quantifying and identifying $5 \mathrm{mC}$ at a single-base pair resolution. This method was first introduced in 1992 by (Frommer et al., 1992) and involves treatment of genomic DNA with sodium bisulfite in order to distinguish unmodified cytosines from $5 \mathrm{mC}$ in the genome. Cytosines in single and double-stranded DNA are converted to uracil after sodium bisulfite treatment, 
whereas $5 \mathrm{mC}$ modifications are immune to this conversion and remain unchanged. As such, using subsequent methylation-specific PCR (MSP) with primers designed for the promoter region of specific, target-genes, one can determine the level of methylation present and thereby determine the transcriptional outcome of those genes (Frommer et al., 1992; Li and Tollefsbol, 2011). There are also other methods that have been derived from the core principle of bisulfite sequencing including combined bisulfite restriction analysis (COBRA) and methylation-sensitive single nucleotide primer extension (Ms-SNuPE) that can be used to determine the level of localized, target-specific hypo/hypermethylation (Gonzalgo and Jones, 1997; Xiong and Laird, 1997).

Another high-throughput technique that can be used to map localized changes in epigenetic patterns is chromatin immunoprecipitation followed by sequencing (ChIPseq). ChIP-seq can be used to determine the level of post-translational modifications on the N-terminal tails of histone proteins with a single amino-acid resolution (Furey, 2012; Nakato and Shirahige, 2017; Park, 2009). ChIP-seq results can also be integrated with alternative types of genomic assays including gene expression, DNA methylation, and chromatin conformation to better understand the epigenetic landscape that includes a combinatorial set of reversible modifications to the DNA and histone proteins. In particular, this method could be used to further understand the discrepancy seen in Chapter 5, in which H3K4me1, a histone mark that is associated with open chromatin, along with a $\mathrm{H} 3 \mathrm{~K} 9 \mathrm{me} 3$ and $\mathrm{H} 3 \mathrm{~K} 9$ panmet, histone marks that are associated with closed chromatin, both increased in expression in response to anoxia. Consequently, ChIP-seq could help determine which gene loci are modified with the active methylation mark 
(H3K4me1) and which gene loci are modified with the repressive methylation mark (H3K9me3) in the liver epigenome of the red-eared sliders.

\subsection{Concluding remarks}

In conclusion, this thesis provides a novel outlook into the epigenetic regulation of anoxia tolerance in T.s. elegans. Each chapter explored a different aspect of epigenetics, including DNA methylation, DNA demethylation, histone acetylation/deacetylation, and histone lysine methylation in terms of MRD and the availability of metabolic cofactors and intermediate metabolites in different turtle tissues. Liver was chosen exclusively for two of the chapters due to the vital role that it plays in turtle anaerobiosis. Overall, the results demonstrated dynamic changes in both DNA methylation and histone acetylation and methylation levels in red-eared sliders during $5 \mathrm{~h}$ and $20 \mathrm{~h}$ anoxia. Furthermore, the overall metabolic output and the availability of ATP were postulated to be a main determinant of chromatin reorganization and assembly during anoxia.

\section{References}

Barlev, N., Poltoratsky, V., Owen-Hughes, T., Ying, C., Liu, L., Workman, J., Berger, S., 1998. Repression of GCN5 histone acetyltransferase activity via bromodomainmediated binding and phosphorylation by the Ku-DNA-dependent protein kinase complex. Mol. Cell. Biol. 18, 1349-58.

Biggar, K., Groom, A., Storey, K., 2011. Hypometabolism and turtles: Physiological and molecular strategies of anoxic survival, in: Nowakowska, A., Caputa, M. (Eds.), Hypometabolism: Strategies of Survival in Vertebrates and Invertebrates. Research 
Signpost, Kerala, pp. 57-94.

Biggar, K., Storey, K., 2011. The emerging roles of microRNAs in the molecular responses of metabolic rate depression. J. Mol. Cell Biol. 3, 167-175. doi:10.1093/jmcb/mjq045

Biggar, K.K., Storey, K.B., 2015. Insight into post-transcriptional gene regulation: stressresponsive microRNAs and their role in the environmental stress survival of tolerant animals. J. Exp. Biol. 218, 1281-1289. doi:10.1242/jeb.104828.

Biggar, K.K., Storey, K.B., 2012. Evidence for cell cycle suppression and microRNA regulation of cyclin D1 during anoxia exposure in turtles. Cell Cycle 11, 1705-1713. doi:10.4161/cc. 19790

Bradley, S., Minx, P., Warren, D., Shedlock, A., Thomson, R., Valenzuela, N., Abramyan, J., Amemiya, C., Badenhorst, D., Biggar, K., Borchert, G., Botka, C., Bowden, R., Braun, E., Bronikowski, A., Bruneau, B., Buck, L., Capel, B., Castoe, T., Czerwinski, M., Delehaunty, K., Edwards, S., Fronick, C., Fujita, M., Fulton, L., Graves, T., Green, R., Haerty, W., Hariharan, R., Hernandez, O., Hillier, L., Holloway, A., Janes, D., Janzen, F., Kandoth, C., Kong, L., de Koning, A., Li, Y., Literman, R., McGaugh, S., Mork, L., O’Laughlin, M., Paitz, R., Pollock, D., Ponting, C., Radhakrishnan, S., Raney, B., Richman, J., St John, J., Schwartz, T., Sethuraman, A., Spinks, P., Storey, K., Thane, N., Vinar, T., Zimmerman, L., Warren, W., Mardis, E., Wilson, R., 2013. The western painted turtle genome, a model for the evolution of extreme physiological adaptations in a slowly evolving lineage. Genome Biol. 14, R28. doi:10.1186/gb-2013-14-3-r28

Brand, M., 2003. Approximate yield of ATP from glucose, designed by donald 
nicholson: Commentary. Biochem. Mol. Biol. Educ. 31, 2-4.

doi:10.1002/bmb.2003.494031010178

Brooks, S., Storey, K., 1989. Regulation of glycolytic enzymes during anoxia in the turtle Pseudemys scripta. Am. J. Physiol. 257, R278-R283.

Cheung, P., Allis, C., Sassone-Corsi, P., 2000. Signaling to chromatin through histone modifications. Cell 103, 263-271. doi:10.1016/S0092-8674(00)00118-5

Davis, E., Jackson, D., 2007. Lactate uptake by skeletal bone in anoxic turtles, Trachemys scripta. Comp. Biochem. Physiol. Part A Mol. Integr. Physiol. 146, 299 304. doi:10.1016/j.cbpa.2006.10.034

Dawson, N.J., Biggar, K.K., Storey, K.B., 2013. Characterization of fructose-1,6bisphosphate aldolase during anoxia in the tolerant turtle, Trachemys scripta elegans: An assessment of enzyme activity, expression and structure. PLoS One 8, e68830. doi:10.1371/journal.pone.0068830

Dominy, J., Lee, Y., Jedrychowski, M., Chim, H., Jurczak, M., Camporez, J., Ruan, H.B., Feldman, J., Pierce, K., Mostoslavsky, R., Denu, J., Clish, C., Yang, X., Shulman, G., Gygi, S., Puigserver, P., 2012. The deacetylase Sirt6 activates the acetyltransferase GCN5 and suppresses hepatic gluconeogenesis. Mol. Cell 48, 900913. doi:10.1016/j.molcel.2012.09.030

Eberharter, A., Becker, P., 2002. Histone acetylation: A switch between repressive and permissive chromatin: Second in review series on chromatin dynamics. EMBO Rep. 3, 224-229. doi:10.1093/embo-reports/kvf053

Etchegaray, J.-P., Mostoslavsky, R., 2016. Interplay between metabolism and epigenetics: A nuclear adaptation to environmental changes. Mol. Cell 62, 695-711. 
doi:10.1016/j.molcel.2016.05.029

Finkel, T., Deng, C.-X., Mostoslavsky, R., 2009. Recent progress in the biology and physiology of sirtuins. Nature 460, 587-591. doi:10.1038/nature08197

Frommer, M., McDonald, L.E., Millar, D.S., Collis, C.M., Watt, F., Grigg, G.W., Molloy, P.L., Paul, C.L., 1992. A genomic sequencing protocol that yields a positive display of 5-methylcytosine residues in individual DNA strands. Proc. Natl. Acad. Sci. U. S. A. $89,1827-31$.

Furey, T., 2012. ChIP-seq and beyond: New and improved methodologies to detect and characterize protein-DNA interactions. Nat. Rev. Genet. 13, 840-852. doi:10.1038/nrg3306

Gerhart-Hines, Z., Rodgers, J., Bare, O., Lerin, C., Kim, S.-H., Mostoslavsky, R., Alt, F., Wu, Z., Puigserver, P., 2007. Metabolic control of muscle mitochondrial function and fatty acid oxidation through SIRT1/PGC-1alpha. EMBO J. 26, 1913-1923. doi:10.1038/sj.emboj.7601633

Gonzalgo, M., Jones, P., 1997. Rapid quantitation of methylation differences at specific sites using methylation-sensitive single nucleotide primer extension (Ms-SNuPE). Nucleic Acids Res. 25, 2529-31.

Gorr, T., Wichmann, D., Hu, J., Hermes-Lima, M., Welker, A., Terwilliger, N., Wren, J., Viney, M., Morris, S., Nilsson, G., Deten, A., Soliz, J., Gassmann, M., 2010. Hypoxia tolerance in animals: Biology and application. Physiol. Biochem. Zool. 83, 733-52. doi:10.1086/648581

Hahn, M., Szabó, P., Pfeifer, G., 2014. 5-Hydroxymethylcytosine: A stable or transient DNA modification? Genomics 104, 314-323. doi:10.1016/j.ygeno.2014.08.015 
He, Y.-F., Li, B.-Z., Li, Z., Liu, P., Wang, Y., Tang, Q., Ding, J., Jia, Y., Chen, Z., Li, L., Sun, Y., Li, X., Dai, Q., Song, C.-X., Zhang, K., He, C., Xu, G.-L., 2011. Tetmediated formation of 5-carboxylcytosine and its excision by TDG in mammalian DNA. Science (80-. ). 333, 1303-1307.

Hebbes, T., Thorne, A., Crane-Robinson, C., 1988. A direct link between core histone acetylation and transcriptionally active chromatin. EMBO J. 7, 1395-402.

Hochachka, P.W., 1988. Metabolic suppression and oxygen availability. Can. J. Zool. 66, $152-158$.

Hochachka, P.W., 1986. Defense strategies against hypoxia and hypothermia. Science (80-. ). 231, 234-41.

Hochachka, P.W., Lutz, P.L., 2001. Mechanism, origin, and evolution of anoxia tolerance in animals. Comp. Biochem. Physiol. B. Biochem. Mol. Biol. 130, 435-59.

Ito, S., D’Alessio, A.C., Taranova, O. V., Hong, K., Sowers, L.C., Zhang, Y., 2010. Role of Tet proteins in $5 \mathrm{mC}$ to $5 \mathrm{hmC}$ conversion, ES-cell self-renewal and inner cell mass specification. Nature 466, 1129-1133. doi:10.1038/nature09303

Ito, S., Shen, L., Dai, Q., Wu, S.C., Collins, L.B., Swenberg, J.A., He, C., Zhang, Y., 2011. Tet proteins can convert 5-methylcytosine to 5-formylcytosine and 5carboxylcytosine. doi.org 333, 1300-1303. doi:10.1126/science.1210597

Jackson, D., 1968. Metabolic depression and oxygen depletion in the diving turtle. J. Appl. Physiol. 24, 503-9.

Jackson, D., Heisler, N., 1983. Intracellular and extracellular acid-base and electrolyte status of submerged anoxic turtles at $3^{\circ} \mathrm{C}$. Respir. Physiol. 53, 187-201.

Jackson, D., Ultsch, G., 1982. Long-term submergence at $3^{\circ} \mathrm{C}$ of the turtle, Chrysemys 
picta bellii, in normoxic and severely hypoxic water: II. Extracellular ionic responses to extreme lactic acidosis. J. Exp. Biol. 29-43.

Jackson, D.C., Taylor, S.E., Asare, V.S., Villarnovo, D., Gall, J.M., Reese, S.A., 2006. Comparative shell buffering properties correlate with anoxia tolerance in freshwater turtles. AJP Regul. Integr. Comp. Physiol. 292, R1008-R1015.

doi:10.1152/ajpregu.00519.2006

Janke, R., Dodson, A., Rine, J., 2015. Metabolism and epigenetics. Annu. Rev. Cell Dev. Biol. 31, 473-496. doi:10.1146/annurev-cellbio-100814-125544

Jenuwein, T., Allis, C., 2001. Translating the histone code. Science (80-. ). 293, 10741080.

Katada, S., Imhof, A., Sassone-Corsi, P., 2012. Connecting threads: Epigenetics and metabolism. Cell 148, 24-28. doi:10.1016/j.cell.2012.01.001

Kohli, R., Zhang, Y., 2013. TET enzymes, TDG and the dynamics of DNA demethylation. Nature 502, 472-479. doi:10.1038/nature 12750

Krivoruchko, A., Storey, K., 2014. Activation of the carbohydrate response element binding protein (ChREBP) in response to anoxia in the turtle Trachemys scripta elegans . Biochim. Biophys. Acta - Gen. Subj. 1840, 3000-3005. doi:10.1016/j.bbagen.2014.06.001

Krivoruchko, A., Storey, K., 2013a. Activation of the unfolded protein response during anoxia exposure in the turtle Trachemys scripta elegans. Mol. Cell. Biochem. 374, 91-103. doi:10.1007/s11010-012-1508-3

Krivoruchko, A., Storey, K., 2013b. Anoxia-responsive regulation of the FoxO transcription factors in freshwater turtles, Trachemys scripta elegans. Biochim. 
Biophys. Acta - Gen. Subj. 1830, 4990-4998. doi:10.1016/j.bbagen.2013.06.034

Krivoruchko, A., Storey, K., 2010a. Molecular mechanisms of turtle anoxia tolerance: A role for NF-kB. Gene 450, 63-69. doi:10.1016/j.gene.2009.10.005

Krivoruchko, A., Storey, K., 2010b. Activation of antioxidant defenses in response to freezing in freeze-tolerant painted turtle hatchlings. Biochim. Biophys. Acta - Gen. Subj. 1800, 662-668. doi:10.1016/j.bbagen.2010.03.015

Krivoruchko, A., Storey, K., 2010c. Regulation of the heat shock response under anoxia in the turtle, Trachemys scripta elegans. J. Comp. Physiol. B 180, 403-414. doi:10.1007/s00360-009-0414-9

Krivoruchko, A., Storey, K., 2010d. Epigenetics in anoxia tolerance: A role for histone deacetylases. Mol. Cell. Biochem. 342, 151-161. doi:10.1007/s11010-010-0479-5

Larade, K., Storey, K., 2007. Arrest of transcription following anoxic exposure in a marine mollusc. Mol. Cell. Biochem. 303, 243-249. doi:10.1007/s11010-007-94688

Li, Y., Tollefsbol, T., 2011. DNA methylation detection: Bisulfite genomic sequencing analysis. Methods Mol. Biol. 791, 11-21. doi:10.1007/978-1-61779-316-5_2

Lu, C., Thompson, C., Ji, H., Zheng, Y., Liang, J., Huang, W., Gao, X., Aldape, K., Lu, Z., Riggins, G., 2012. Metabolic regulation of epigenetics. Cell Metab. 16, 9-17. doi:10.1016/j.cmet.2012.06.001

Martin, S., Epperson, E., van Breukelen, F., 2000. Quantitative and qualitative changes in gene expression during hibernation in Golden-mantled ground squirrels, in: Life in the Cold. Springer Berlin Heidelberg, Berlin, Heidelberg, pp. 315-324. doi:10.1007/978-3-662-04162-8_34 
Mehrani, H., Storey, K., 1995a. Effects of anoxia on protein phosphatase in turtle organs: purification and properties of protein phosphatase type-1 from turtle liver. Arch. Biochem. Biophys. 316, 836-843. doi:10.1006/abbi.1995.1112

Mehrani, H., Storey, K., 1995b. Enzymatic control of glycogenolysis during anoxic submergence in the freshwater turtle Trachemys scripta. Int. J. Biochem. Cell Biol. 821-830, 821-830. doi:10.1016/1357-2725(95)00042-N

Mehrani, H., Storey, K., 1995c. cAMP-Dependent protein kinase and anoxia survival in turtles: purification and properties of liver PKA. Molular Cell. Biochem. 145, 8188.

Nakato, R., Shirahige, K., 2017. Recent advances in ChIP-seq analysis: from quality management to whole-genome annotation. Brief. Bioinform. 18, 279-290. doi:10.1093/bib/bbw023

Park, P., 2009. ChIP-seq: Advantages and challenges of a maturing technology. Nat. Rev. Genet. 10, 669-680. doi:10.1038/nrg2641

Pérez-Pinzón, M.A., Rosenthal, M., Sick, T.J., Lutz, P.L., Pablo, J., Mash, D., 1992. Downregulation of sodium channels during anoxia: a putative survival strategy of turtle brain. Am. J. Physiol. 262, R712-5.

Reytor, E., Perez-Miguelsanz, J., Alvarez, L., Perez-Sala, D., Pajares, M., 2009. Conformational signals in the C-terminal domain of methionine adenosyltransferase I/III determine its nucleocytoplasmic distribution. FASEB J. 23, 3347-3360. doi:10.1096/fj.09-130187

Rodgers, J., Lerin, C., Haas, W., Gygi, S., Spiegelman, B., Puigserver, P., 2005. Nutrient control of glucose homeostasis through a complex of PGC-1a and SIRT1. Nature 
434, 113-118. doi:10.1038/nature03354

Rolfe, D., Brown, G., 1997. Cellular energy utilization and molecular origin of standard metabolic rate in mammals. Physiol. Rev. 77, 731-58.

Storey, K., 2007. Anoxia tolerance in turtles: Metabolic regulation and gene expression. Comp. Biochem. Physiol. Part A Mol. Integr. Physiol. 147, 263-276.

doi:10.1016/j.cbpa.2006.03.019

Storey, K., 1996. Metabolic adaptations supporting anoxia tolerance in reptiles: recent advances. Comp. Biochem. Physiol. Part B Comp. Biochem. 113, 23-35. doi:10.1016/0305-0491(95)02043-8

Storey, K., Storey, J., 2010. Metabolic rate depression: the biochemistry of mammalian hibernation. Adv. Clin. Chem. 52, 77-108.

Storey, K., Storey, J., 2007. Tribute to P. L. Lutz: putting life on 'pause' - molecular regulation of hypometabolism. J. Exp. Biol. 210, 1700-1714. doi:10.1242/jeb.02716

Storey, K., Storey, J., 2004a. Oxygen limitation and metabolic rate depression, in: Storey, K.B. (Ed.), Functional Metabolism. John Wiley \& Sons, Inc., Hoboken, NJ, USA, pp. 415-442. doi:10.1002/047167558X.ch15

Storey, K., Storey, J., 2004b. Metabolic rate depression in animals: transcriptional and translational controls. Biol. Rev. Camb. Philos. Soc. 79, 207-33.

Storey, K., Storey, J., 1992. Natural freeze tolerance in ectothermic vertebrates. Annu. Rev. Physiol. 54, 619-637. doi:10.1146/annurev.ph.54.030192.003155

Storey, K., Storey, J., 1990. Metabolic rate depression and biochemical adaptation in anaerobiosis, hibernation and estivation. Q. Rev. Biol. 65, 145-74. doi: $10.4172 / 2157-7625.1000224$ 
Storey, K.B., Storey, J.M., 2004. Metabolic rate depression in animals: transcriptional and translational controls. Biol. Rev. Camb. Philos. Soc. 79, 207-33.

Tahiliani, M., Koh, K., Shen, Y., Pastor, W., Bandukwala, H., Brudno, Y., Agarwal, S., Iyer, L., Liu, D., Aravind, L., Rao, A., 2009. Conversion of 5-methylcytosine to 5hydroxymethylcytosine in mammalian DNA by MLL partner TET1. Science (80-. ). 324, 930-5. doi:10.1126/science.1170116

Ultsch, G., Jackson, D., 1982. Long-Term submergence at $3^{\circ} \mathrm{C}$ of the turtle, Chrysemys Picta Bellii, in normoxic and severely hypoxic water: Survival, gas exchange, and acid-base status. J. Exp. Biol. 96, 11-28.

van Breukelen, F., Maier, R., Hand, S., 2000. Depression of nuclear transcription and extension of mRNA half-life under anoxia in Artemia franciscana embryos. J. Exp. Biol. 203, 1123-30.

Vaquero, A., Scher, M., Erdjument-Bromage, H., Tempst, P., Serrano, L., Reinberg, D., 2007a. SIRT1 regulates the histone methyl-transferase SUV39H1 during heterochromatin formation. Nature 450, 440-444. doi:10.1038/nature06268

Vaquero, A., Scher, M., Erdjument-Bromage, H., Tempst, P., Serrano, L., Reinberg, D., 2007b. SIRT1 regulates the histone methyl-transferase SUV39H1 during heterochromatin formation. Nature 450, 440-444. doi:10.1038/nature06268

Waddington, C.H., 2012. The epigenotype. Int. J. Epidemiol. 41, 10-13.

doi:10.1093/ije/dyr184

Waddington, C.H., 1956. Genetic assimilation of the bithorax phenotype. Evolution (N.

Y). 10, 1. doi:10.2307/2406091

Wei, Y., Chen, Y.-H., Li, L.-Y., Lang, J., Yeh, S.-P., Shi, B., Yang, C.-C., Yang, J.-Y., 
Lin, C.-Y., Lai, C.-C., Hung, M.-C., 2011. CDK1-dependent phosphorylation of EZH2 suppresses methylation of $\mathrm{H} 3 \mathrm{~K} 27$ and promotes osteogenic differentiation of human mesenchymal stem cells. Nat. Cell Biol. 13, 87-94. doi:10.1038/ncb2139

Wellen, K., Hatzivassiliou, G., Sachdeva, U., Bui, T., Cross, J., Thompson, C., 2009. ATP-citrate lyase links cellular metabolism to histone acetylation. Science (80-. ). 324, 1076-1080. doi:10.1126/science.1164097

Willmore, W., Storey, K.B., 1997. Antioxidant systems and anoxia tolerance in a freshwater turtle Trachemys scripta elegans. Mol. Cell. Biochem. 170, 177-85. doi:10.1023/A:1006817806010

Xiong, Z., Laird, P., 1997. COBRA: a sensitive and quantitative DNA methylation assay. Nucleic Acids Res. 25, 2532-4.

Yoon, J., Puigserver, P., Chen, G., Donovan, J., Wu, Z., Rhee, J., Adelmant, G., Stafford, J., Kahn, C., Granner, D., Newgard, C., Spiegelman, B., 2001. Control of hepatic gluconeogenesis through the transcriptional coactivator PGC-1. Nature 413, 131138. doi: $10.1038 / 35093050$

Yoshino, J., Mills, K., Yoon, M., Imai, S.-I., 2011. Nicotinamide mononucleotide, a key NAD+ intermediate, treats the pathophysiology of diet- and age-induced diabetes in mice. Cell Metab. 14, 528-536. doi:10.1016/j.cmet.2011.08.014

Zhang, J., Biggar, K.K., Storey, K.B., 2013. Regulation of p53 by reversible posttranscriptional and post-translational mechanisms in liver and skeletal muscle of an anoxia tolerant turtle, Trachemys scripta elegans. Gene 513, 147-155. doi:10.1016/j.gene.2012.10.049

Zhong, L., D’Urso, A., Toiber, D., Sebastian, C., Henry, R., Vadysirisack, D., 
Guimaraes, A., Marinelli, B., Wikstrom, J., Nir, T., Clish, C., Vaitheesvaran, B., Iliopoulos, O., Kurland, I., Dor, Y., Weissleder, R., Shirihai, O., Ellisen, L., Espinosa, J., Mostoslavsky, R., 2010. The histone deacetylase Sirt6 regulates glucose homeostasis via Hif1 $\alpha$. Cell 140, 280-293. doi:10.1016/j.cell.2009.12.041 


\section{APPENDIX A}

\section{LIST OF PUBLICATIONS}




\section{Published}

Wijenayake S., Tessier SN, Storey KB. 2015. Metabolic arrest during hibernation! Cardiac regulation of pyruvate dehydrogenase (PDH) in a hibernating ground squirrel (Ictidomys tridecemlineatus). Canadian Journal of Cardiology 31: S225.

Wijenayake S., Storey KB. 2016. The role of DNA methylation during anoxia tolerance in a freshwater turtle (Trachemys scripta elegans). Journal of Comparative Physiology B, 186: 333-342.

Gerber VEM., Wijenayake S, Storey KB. 2016. Anti-apoptotic response during anoxia and recovery in a freeze-tolerant wood frog (Rana sylvatica). PeerJ, 4: e1834.

Gorelick R., Fraser D, Mansfield M, Dawson JW, Wijenayake S, Bertram SM. 2016. Abrupt shortening of bird $\mathrm{W}$ chromosomes in ancestral Neognathae. Biological Journal of Linnean Society.

Wijenayake S., Al-attar R, Tessier SN, Storey KB. 2016. Hibernation vs Freezing: The tale of metabolic reorganization in winter. Cryobiology. 73: 427.

Wijenayake S., Tessier SN, Storey KB. 2017. Regulation of pyruvate dehydrogenase $(\mathrm{PDH})$ in the hibernating ground squirrel, (Ictidomys tridecemlineatus). Journal of Thermal Biology. 69: 199-205.

Tessier, SN., Zhang Y, Wijenayake S, Storey KB. 2017. MAP kinase signaling and Elk1 transcriptional activity in hibernating thirteen-lined ground squirrels. BBA Gen Subjects. doi: 10.1016/j.bbagen.2017.07.026. [Epub ahead of print].

Luu BE*, Wijenayake S*, Malik Al, Storey KB. 2017. Regulation of heat shock protein response in the African clawed frog (Xenopus laevis). Cell Stress and Chaperones. doi: 10.1007/s12192-017-0822-9. [Epub ahead of print].

\section{Submitted/ Under Review}

Wijenayake S., Hawkin LJ, Storey KB. Transcriptional consequence of histone H3 lysine methylation in response to long-term anoxia. Gene. Submitted. Submission ID. GENE- D-17-01733.

Wijenayake S., Luu BE*, Zhang J, Tessier SN, Quintero-Galvis JF, Gaitan-Espitia JD, Nespolo RF, Storey KB. Regulation of hibernation in the "living fossil", Dromiciops gliroides: the role of mitogen-activated protein kinase cascade. CBP. Submitted.

Wijenayake S., Luu BE*, Zhang J, Tessier SN, Quintero-Galvis JF, Gaitan-Espitia JD, Nespolo RF, Storey KB. Regulation of Pyruvate Dehydrogenase Complex and Metabolic Fuel Selection during torpor in the South American Marsupial, Dromiciops gliroides. CBP. Submitted. 
Luu BE*., Wijenayake S*, Zhang J, Tessier SN, Quintero-Galvis JF, Gaitan-Espitia JD, Nespolo RF, Storey KB. Characterization of the torpor-responsive Akt/mTOR pathway and protein translation machinery in the hibernating South American Marsupial, Dromiciops gliroides. CBP. Submitted.

Luu BE*., Wijenayake S*, Zhang J, Tessier SN, Quintero-Galvis JF, Gaitan-Espitia JD, Nespolo RF, Storey KB. Torpor activates pro-survival response pathways in the hibernating South American Marsupial, Dromiciops gliroides. CBP. Submitted.

\section{Completed Projects: To be Submitted in 2019 and Beyond}

Al-Attar RN, Wijenayake S, Storey KB. The role of pyruvate dehydrogenase regulation in the freeze-tolerant wood frog, Rana Sylvatica. TBD.

Wijenayake S., Storey KB. Characterizing the uncharacterized. The presence of humainlike protein, turtlin, in the anoxia tolerance red-eared slider. Peptides.

Hoyeck M., Wijenayake S, Storey KB. The role of Nrf and PPAR in antioxidant defense response in the liver and muscle of the dehydrated wood frog, Rana sylvatica.

Cryobiology.

Wijenayake S., Brooks C, Hoyeck M, Storey KB. Reversible protein phosphorylation of p53 in the liver and skeletal muscle of the frozen wood frog, Rana sylvatica. JEZ.

Wijenayake S., Szereszeski KE, Storey KB. Anti-apoptotic response in the brains of four model systems.

Childers C., Wijenayake S., Storey KB. The dynamic regulation of protein translation in response to high glucose conditions.

Al-Attar RN*, Wijenayake S, Storey KB. Reversible protein phosphorylation of PDH in response to high glucose conditions in Rana Sylvatica. TBD.

Hadj-Moussa, H., Wijenayke S, Storey KB. Regulation of NFkB during torpor-arousal in a master hibernator, the thirteen-lined ground squirrel.

The series of papers on Western and Eastern spadefoot toads Luminex multiplex analysis:

- Approximately four papers in total.

The remaining two chapters of the thesis:

- Histone acetylation and deacetylation in response to anoxia in the red-eared sliders (SIRTs and HATs).

- The role of DNA demethylation during prolonged anoxia (TETs). 
Moggridge JA*., Wijenayake S*, Luu BE, Quintero-Galvis JF, Gaitan-Espitia JD, Nespolo RF, Storey KB. Torpor-responsive microRNAs in the heart and brain of a coldadapted marsupial, Dromiciops gliroides.

Gerber A., Smyl-Joly J, Wijenayake S, Storey KB. Myocyte enhance factor 2A and 2C and red and white muscle maintenance in the anoxia tolerance red0eared slider, Trachemys scripta elegans. 


\section{APPENDIX B}

\section{COMMUNICATIONS AT SCIENTIFIC MEETINGS}


1. Wijenayake, S., Tessier, S.N., Storey, K.B.. 2017. No need to diet - just control your metabolism! Regulation of pyruvate dehydrogenase (PDH) in hibernating ground squirrels (Ictidomys tridecemlineatus). Canadian Society of Zoologists, Satellite Symposium: 50 years of comparative biochemistry - the legacy of Peter Hochachka. University of Manitoba, Winnipeg, MB, CAN. (Poster Presentation).

2. Wijenayake S., Al-attar R, Tessier SN, Storey KB. 2016. Freezing vs Hibernation; the tale of metabolic reorganization in winter. $53^{\text {rd }}$ Annual Meeting of the Society of Cryobiology, Ottawa, CAN (Oral Presentation).

3. Wijenayake S., Tessier SN, Storey KB. 2015. Metabolic arrest during hibernation! Cardiac regulation of pyruvate dehydrogenase (PDH) in a hibernating ground squirrel (Ictidomys tridecemlineatus). Canadian Cardiovascular Congress, Toronto, CAN (Poster Presentation).

4. Wijenayake S., Tessier SN, Storey KB. 2015. Hibernating to Survive Freezing! The story of how a small mammal (13-line ground squirrel) tackles the big problem of starvation and freezing, Annual Heart Research Day, Ottawa, CAN (Oral Presentation- Carolie Lalonde Innovation Award in Science).

5. Wijenayake S., Tessier SN, Storey KB. 2015. Metabolic Arrest during Hibernation! Cardiac regulation of pyruvate dehydrogenase (PDH) in hibernating ground squirrels (Ictidomys tridecemlineatus), Heart Research Day, Ottawa, CAN (Oral Presentation).

6. Wijenayake S., Tessier SN, Storey KB. 2015. No need to diet $\rightarrow$ Just control your metabolism! Regulation of pyruvate dehydrogenase (PDH) in hibernating ground squirrels (Ictidomys tridecemlineatus), 11th Annual Ottawa-Carleton Institute for Biology Symposium (OCIB), Ottawa, CAN (Best 2min thesis speed round Award).

7. Wijenayake S., Tessier SN, Storey KB. 2015. No need to diet $\rightarrow$ Just control your metabolism! Regulation of pyruvate dehydrogenase (PDH) in hibernating ground squirrels (Ictidomys tridecemlineatus), 11th Annual Ottawa-Carleton Institute for Biology Symposium (OCIB), Ottawa, CAN (Poster Presentation Best Poster Award).

8. Wijenayake S., Tessier SN, Storey KB. 2015. No need to diet $\rightarrow$ Just control your metabolism! Regulation of pyruvate dehydrogenase (PDH) in hibernating ground squirrels (Ictidomys tridecemlineatus), Chemistry and Biochemistry Graduate Research Conference, Montreal, CAN (Poster Presentation - Best Biochemistry Poster Award).

9. Wijenayake S., Storey KB. 2014. No Oxygen? $\rightarrow$ No Problem! Epigenetic mechanisms of anoxia tolerance: a role for DNA methylation. 10th Annual 
Ottawa-Carleton Institute for Biology Symposium (OCIB), Ottawa, CAN (Oral Presentation).

10. Wijenayake S., Storey KB. 2014. Heat shock protein response during dehydration in African clawed frog (Xenopus laevis). Chemistry and Biochemistry Graduate Research Conference, Montreal, CAN (Oral Presentation).

11. Wijenayake S., Storey KB. 2014. Epigenetic mechanisms of anoxia tolerance: a role for DNA methylation. Society for Experimental Biology, Manchester University, Manchester, UK (Poster presentation).

12. Wijenayake S., Storey KB. 2014. Epigenetic mechanisms of anoxia tolerance: a role for DNA methylation. American Aging Association, San Antonio, USA (Poster presentation).

13. Wijenayake S., Gorelick R. 2012. Extracellular invaders mediate DNA methyltransferase enzymes (MTases) to gain access to the host genomes. Evolution, Ottawa, CAN (Oral presentation).

14. Wijenayake S., Gorelick R. 2011. How did cytosine methylation acquire its gene regulatory function? Canadian Society of Zoologists (CSZ) $50^{\text {th }}$ annual symposium, Ottawa, CAN (Oral Presentation).

15. Wijenayake S., Gorelick R. 2011. How did cytosine methylation acquire its gene regulatory function? Canadian Society for Ecology and Evolution (CSEE) $6^{\text {th }}$ annual symposium, Banff, CAN (Oral presentation).

16. Wijenayake S., Gorelick R. 2011. DNA methyltransferase enzymes (MTases) may not enhance genomic protection against exogenous DNA invasions. 9th Annual Ottawa-Carleton Institute for Biology Symposium (OCIB), Ottawa, CAN (Poster Presentation). 


\section{APPENDIX C}

\section{DEPARTMENTAL SEMINARS AND GUEST LECTURES}


1. Wijenayake, S. 2017. Putting Life on 'Pause' Biochemical and Epigenetic Regulation of Stress Responses. Center for Regenerative Medicine and Stem Cell Therepy. University of California, San Francisco.

2. Wijenayake, S. 2017. Biochemical and Epigenetic Regulation of the Cellular Stress Response. National Research Council of Canada.

3. Wijenayake, S. 2016. Thermodynamics. Lecture in Biology 2200: Biochemistry, Department of Biology, Carleton University.

4. Wijenayake, S. 2016. Electron Transport Chain. Lecture in Biology 2200: Biochemistry, Department of Biology, Carleton University.

5. Wijenayake, S. 2015. Lipids and Membranes. Lecture in Biology 2200: Biochemistry, Department of Biology, Carleton University.

6. Wijenayake, S. 2015. Membrane Transport. Lecture in Biology 2200: Biochemistry, Department of Biology, Carleton University.

7. Wijenayake, S. 2015. Introduction to Metabolism. Lecture in Biology 2200: Biochemistry, Department of Biology, Carleton University.

8. Wijenayake, S. 2014. Carbohydrates. Lecture in Biology 2200: Biochemistry, Department of Biology, Carleton University.

9. Wijenayake, S. 2014. Lipids and Membranes. Lecture in Biology 2200: Biochemistry, Department of Biology, Carleton University.

10. Wijenayake S., 2012. DNMT's role in anoxia tolerance. Guest lecturer in Biology 4103: Population Genetics, Department of Biology, Carleton University.

11. Wijenayake S., 2011. Epigenetics. Guest lecturer in Biology 4103: Population Genetics, Department of Biology, Carleton University.

12. Wijenayake S., 2010. The science behind fingerprinting. Guest lecturer in Biology 1010: Biotechnology and Society, Department of Biology, Carleton University.

13. Wijenayake S., 2009. Chronic exposure to PCB and DDT increase the percent occurrence of kidney necrosis and liver hyperplasia in bottom feeding feral fish populations. Department of Biology, University of Ottawa (Oral and poster presentation).

14. Wijenayake S., 2009. The consumption of n-3 PUFAs, Eicosapentaenoic and Docosahexaenoic acid, enhances muscle performance. Department of Biology, University of Ottawa (Oral and poster presentation). 


\section{APPENDIX D}

\section{AUTHOR CONTRIBUTIONS}


Chapter 2: The role of DNA methylation during anoxia tolerance in a freshwater turtle (Trachemys scripta elegans) $\rightarrow$ By Sanoji Wijenayake and Kenneth B Storey.

- Published

- Author contributions:

Sanoji Wijenayake conceived, designed, performed the experiments, analyzed the data, and wrote the paper/chapter.

Kenneth B. Storey contributed reagents, and materials.

Chapter 3: Demethylate that DNA! Dynamic regulation of TET-mediated DNA demethylation in response to anoxia tolerance in a freshwater turtle, Trachemys scripta elegans $\rightarrow$ By Sanoji Wijenayake and Kenneth B Storey.

- $\quad$ Ready to be submitted

- Author contributions:

Sanoji Wijenayake conceived, designed, performed the experiments, analyzed the data, and wrote the paper/chapter.

Kenneth B. Storey contributed reagents, and materials.

Chapter 4: The dynamic regulation of histone $\mathrm{H} 3$ acetylation and deacetylation in response to prolonged oxygen deprivation in the champion anaerobe, Trachemys scripa elegans $\rightarrow$ By Sanoji Wijenayake and Kenneth B Storey.

- Ready to be submitted.

- Author contributions:

Sanoji Wijenayake conceived, designed, performed the experiments, analyzed the data, and wrote the paper/chapter.

Kenneth B. Storey contributed reagents, and materials.

Chapter 5: Regulation of histone lysine methylation in response to anoxia tolerance in a freshwater turtle, Trachemys scripta elegans $\rightarrow$ By Sanoji Wijenayake, Liam Hawkins, and Kenneth B Storey.

- $\quad$ Submitted to Gene. Submission ID. GENE-D-17-01733

- Author contributions:

Sanoji Wijenayake conceived, designed, performed the experiments, analyzed the data, and wrote the paper/chapter.

Liam Hawkins did western immnoblotting for the HMTs.

Kenneth B. Storey contributed reagents, and materials. 


\section{APPENDIX E}

\section{LIST OF ANTIBODIES}


F.1 Antibody information and catalog numbers and supplier information.

\begin{tabular}{|c|c|c|c|}
\hline Antibody & Type & Supplier & Catalog \#. \\
\hline DNMT1 & Polyclonal, Anti-rabbit & Genetex & GTX116011 \\
\hline DNMT2 & Polyclonal, Anti-rabbit & Genetex & GTX13892 \\
\hline DNMT3b & Polyclonal, Anti-rabbit & Genetex & GTX128157 \\
\hline MBD1 & Polyclonal, Anti-rabbit & Genetex & GTX110612 \\
\hline MBD2 & Polyclonal, Anti-rabbit & Genetex & GTX105622 \\
\hline TET1 & Polyclonal, Anti-rabbit & Genetex & GTX124207 \\
\hline TET2 & Polyclonal, Anti-rabbit & Genetex & GTX124205 \\
\hline TDG1 & Polyclonal, Anti-rabbit & Genetex & GTX110473 \\
\hline Histone-H3 & Polyclonal, Anti-rabbit & Cell Signaling & 4499 \\
\hline H3K14ac & Polyclonal, Anti-rabbit & Cell Signaling & 7627 \\
\hline H3K18ac & Polyclonal, Anti-rabbit & Cell Signaling & 13998 \\
\hline H4K56ас & Polyclonal, Anti-rabbit & Cell Signaling & 4243 \\
\hline HAT1 & Polyclonal, Anti-rabbit & Genetex & GTX110643 \\
\hline GCN5 & Polyclonal, Anti-rabbit & Cell Signaling & 3305 \\
\hline PCAF & Polyclonal, Anti-rabbit & Cell Signaling & 3378 \\
\hline Tip60 & Polyclonal, Anti-rabbit & Cell Signaling & 12058 \\
\hline CBP & Polyclonal, Anti-rabbit & Cell Signaling & 3379 \\
\hline SIRT1 & Polyclonal, Anti-rabbit & Active Motif & 39354 \\
\hline SIRT6 & Polyclonal, Anti-rabbit & Active Motif & 39912 \\
\hline SIRT7 & Polyclonal, Anti-rabbit & Genetex & GTX105732 \\
\hline ASH2L & Polyclonal, Anti-rabbit & Cell Signaling & 5019 \\
\hline SET7/9 & Polyclonal, Anti-rabbit & Cell Signaling & 2813 \\
\hline RBBP5 & Polyclonal, Anti-rabbit & Cell Signaling & 13171 \\
\hline SMYD2 & Polyclonal, Anti-rabbit & Cell Signaling & 9734 \\
\hline ЕНМТ2 & Polyclonal, Anti-rabbit & Cell Signaling & 3306 \\
\hline SUV39H1 & Polyclonal, Anti-rabbit & Cell Signaling & 8729 \\
\hline H3K4me1 & Polyclonal, Anti-rabbit & Abcam & ab8895 \\
\hline H3K9me3 & Polyclonal, Anti-rabbit & Abcam & Ab8898 \\
\hline H3K9pan & Polyclonal, Anti-rabbit & Active Motif & 39378 \\
\hline H3K27me1 & Polyclonal, Anti-rabbit & Active Motif & 39890 \\
\hline
\end{tabular}




\section{APPENDIX F}

\section{IMMUNOBLOTTING CONDITIONS}


Figure G1. Immunoblotting conditions used in the study.

\begin{tabular}{|c|c|c|c|c|c|}
\hline Antibody & $\begin{array}{c}\text { MW } \\
(\mathrm{kDa})\end{array}$ & Gel (\%) & Reactivity & [Primary] & [Secondary] \\
\hline DNMT1 & 184 & 6 & $\begin{array}{c}\text { Rabbit- } \\
\text { Polyclonal }\end{array}$ & $1: 1,000$ & $1: 8,000$ \\
\hline DNMT2 & 42 & 10 & $\begin{array}{c}\text { Rabbit- } \\
\text { Polyclonal }\end{array}$ & $1: 1,000$ & $1: 8,000$ \\
\hline DNMT3a & 120 & 8 & $\begin{array}{l}\text { Rabbit- } \\
\text { Polyclonal }\end{array}$ & $1: 1,000$ & $1: 8,000$ \\
\hline DNMT3b & 100 & 8 & $\begin{array}{c}\text { Rabbit- } \\
\text { Polyclonal }\end{array}$ & $1: 1,000$ & $1: 8,000$ \\
\hline MBD1 & 80 & 10 & $\begin{array}{c}\text { Rabbit- } \\
\text { Polyclonal }\end{array}$ & $1: 1,000$ & $1: 8,000$ \\
\hline MBD2 & 48 & 10 & $\begin{array}{c}\text { Rabbit- } \\
\text { Polyclonal }\end{array}$ & $1: 1,000$ & $1: 8,000$ \\
\hline TET1 & 244 & 6 & $\begin{array}{l}\text { Rabbit- } \\
\text { Polyclonal }\end{array}$ & $1: 1,000$ & $1: 8,000$ \\
\hline TET2 & 220 & 6 & $\begin{array}{l}\text { Rabbit- } \\
\text { Polyclonal }\end{array}$ & $1: 1,000$ & $1: 8,000$ \\
\hline TDG1 & 42 & 10 & $\begin{array}{c}\text { Rabbit- } \\
\text { Polyclonal }\end{array}$ & $1: 1,000$ & $1: 8,000$ \\
\hline Histone-H3 & 15 & 15 & $\begin{array}{c}\text { Rabbit- } \\
\text { Polyclonal }\end{array}$ & $1: 1,000$ & $1: 8,000$ \\
\hline H3K14ac & 17 & 15 & $\begin{array}{l}\text { Rabbit- } \\
\text { Polvclonal }\end{array}$ & $1: 1,000$ & $1: 8,000$ \\
\hline H3K18ac & 17 & 15 & $\begin{array}{c}\text { Rabbit- } \\
\text { Polyclonal }\end{array}$ & $1: 1,000$ & $1: 8,000$ \\
\hline Н4К56ас & 17 & 15 & $\begin{array}{l}\text { Rabbit- } \\
\text { Polyclonal }\end{array}$ & $1: 1,000$ & $1: 8,000$ \\
\hline HAT1 & 47 & 10 & $\begin{array}{l}\text { Rabbit- } \\
\text { Polyclonal }\end{array}$ & $1: 1,000$ & $1: 8,000$ \\
\hline GCN5 & 86 & 10 & $\begin{array}{l}\text { Rabbit- } \\
\text { Polyclonal }\end{array}$ & $1: 1,000$ & $1: 8,000$ \\
\hline PCAF & 87 & 10 & $\begin{array}{l}\text { Rabbit- } \\
\text { Polyclonal }\end{array}$ & $1: 1,000$ & $1: 8,000$ \\
\hline Tip60 & 53 & 10 & $\begin{array}{l}\text { Rabbit- } \\
\text { Polyclonal }\end{array}$ & $1: 1,000$ & $1: 8,000$ \\
\hline CBP & 268 & 6 & $\begin{array}{c}\text { Rabbit- } \\
\text { Polyclonal }\end{array}$ & $1: 1,000$ & $1: 8,000$ \\
\hline SIRT1 & $\begin{array}{l}110- \\
120\end{array}$ & 8 & $\begin{array}{l}\text { Rabbit- } \\
\text { Polyclonal }\end{array}$ & $1: 1,000$ & $1: 8,000$ \\
\hline SIRT6 & 39 & 10 & $\begin{array}{c}\text { Rabbit- } \\
\text { Polyclonal }\end{array}$ & $1: 1,000$ & $1: 8,000$ \\
\hline
\end{tabular}




\begin{tabular}{|c|c|c|c|c|c|}
\hline SIRT7 & $\begin{array}{l}45- \\
48\end{array}$ & 10 & $\begin{array}{c}\text { Rabbit- } \\
\text { Polyclonal }\end{array}$ & $1: 1,000$ & $1: 8,000$ \\
\hline ASH2L & 55 & 10 & $\begin{array}{c}\text { Rabbit- } \\
\text { Polyclonal }\end{array}$ & $1: 1,000$ & $1: 8,000$ \\
\hline SET7/9 & 40 & 12 & $\begin{array}{c}\text { Rabbit- } \\
\text { Polyclonal }\end{array}$ & $1: 1,000$ & $1: 8,000$ \\
\hline RBBP5 & 60 & 10 & $\begin{array}{c}\text { Rabbit- } \\
\text { Polyclonal }\end{array}$ & $1: 1,000$ & $1: 8,000$ \\
\hline SMYD2 & 50 & 10 & $\begin{array}{c}\text { Rabbit- } \\
\text { Polyclonal }\end{array}$ & $1: 1,000$ & $1: 8,000$ \\
\hline EHMT2 & 132 & 8 & $\begin{array}{c}\text { Rabbit- } \\
\text { Polyclonal }\end{array}$ & $1: 1,000$ & $1: 8,000$ \\
\hline SUV39H1 & 49 & 10 & $\begin{array}{c}\text { Rabbit- } \\
\text { Polyclonal }\end{array}$ & $1: 1,000$ & $1: 8,000$ \\
\hline H3K4me1 & 17 & 15 & $\begin{array}{c}\text { Rabbit- } \\
\text { Polyclonal }\end{array}$ & $1: 1,000$ & $1: 8,000$ \\
\hline H3K9me3 & 17 & 15 & $\begin{array}{c}\text { Rabbit- } \\
\text { Polyclonal }\end{array}$ & $1: 1,000$ & $1: 8,000$ \\
\hline H3K9pan & 17 & 15 & $\begin{array}{c}\text { Rabbit- } \\
\text { Polyclonal }\end{array}$ & $1: 1,000$ & $1: 8,000$ \\
\hline H3K27me1 & 17 & 15 & $\begin{array}{c}\text { Rabbit- } \\
\text { Polyclonal }\end{array}$ & $1: 1,000$ & $1: 8,000$ \\
\hline
\end{tabular}




\section{APPENDIX G}

\section{STEPS TAKEN TO ENSURE ANTIBODY SPECIFICITY FOR IMMUNOBLOTTING}


Several steps were taken throughout this thesis to ensure the antibody specificity for the target-proteins and to make certain the correct target-band was quantified to obtain the relative protein expression levels via western immunoblotting. They include:

1) NCBI online database was used to obtain the amino acid sequence of the target proteins using the red-eared slider and the western painted-turtle sequenced genomes and the molecular weight was predicted using EXPASy online bioinformatics software as described in appendix $\mathrm{H}$.

2) Since the two turtle genomes are sequenced, the available amino acid sequence of the target protein was aligned with the sequence of the epitope the antibody was made against to assess conservation. Antibodies made from epitopes with \% identity of $>70 \%$ was used for western immumoblotting.

3) If antibodies from different regions of the target protein was available from the company, antibodies from both regions were tested against red-eared slider tissues to determine consensus in primary antibody binding to the correct band at the correct MW.

4) A dilution curve of approximately $5,10,15,20,25,30 \mu \mathrm{g}$ of total soluble protein was conducted per protein target per tissue to determine the linear amplification range of the chemiluminescent signal prior to running the quantification runs.

5) The membranes were always blocked with either $2.5-10 \%$ milk for 30 min (depending on the antibody) or using high molecular weight polyvinyl alcohol (70,000-100,000 kDa range) at $1 \mathrm{mg} / \mathrm{mL}$ for $1-2 \mathrm{~min}$. The blocking step was done before probing with the primary antibody to minimize non-specific binding of the primary antibody to other protein targets. 


\section{APPENDIX H}

\section{BIOINFORMATICS- IMMUNOBLOTTING}


Following bioinformatics tools were used in all western immunoblotting experiments to determine the correct molecular weight (MW) of the protein targets in red-eared slider turtles. Note: the red-eared sliders (Trachemys scripta elegans) and another very closely related anoxia-tolerant freshwater turtle, the Western painted turtle (Chrysemys picta bellii) are both fully sequenced.

1) The amino acid sequence for the target proteins were obtained from NCBI (The National Center for Biotechnological Information) at https://www.ncbi.nlm.nih.gov/. An example is shown below illustrating the stepwise determinant of DNMT1 MW using the Western painted turtle genome.

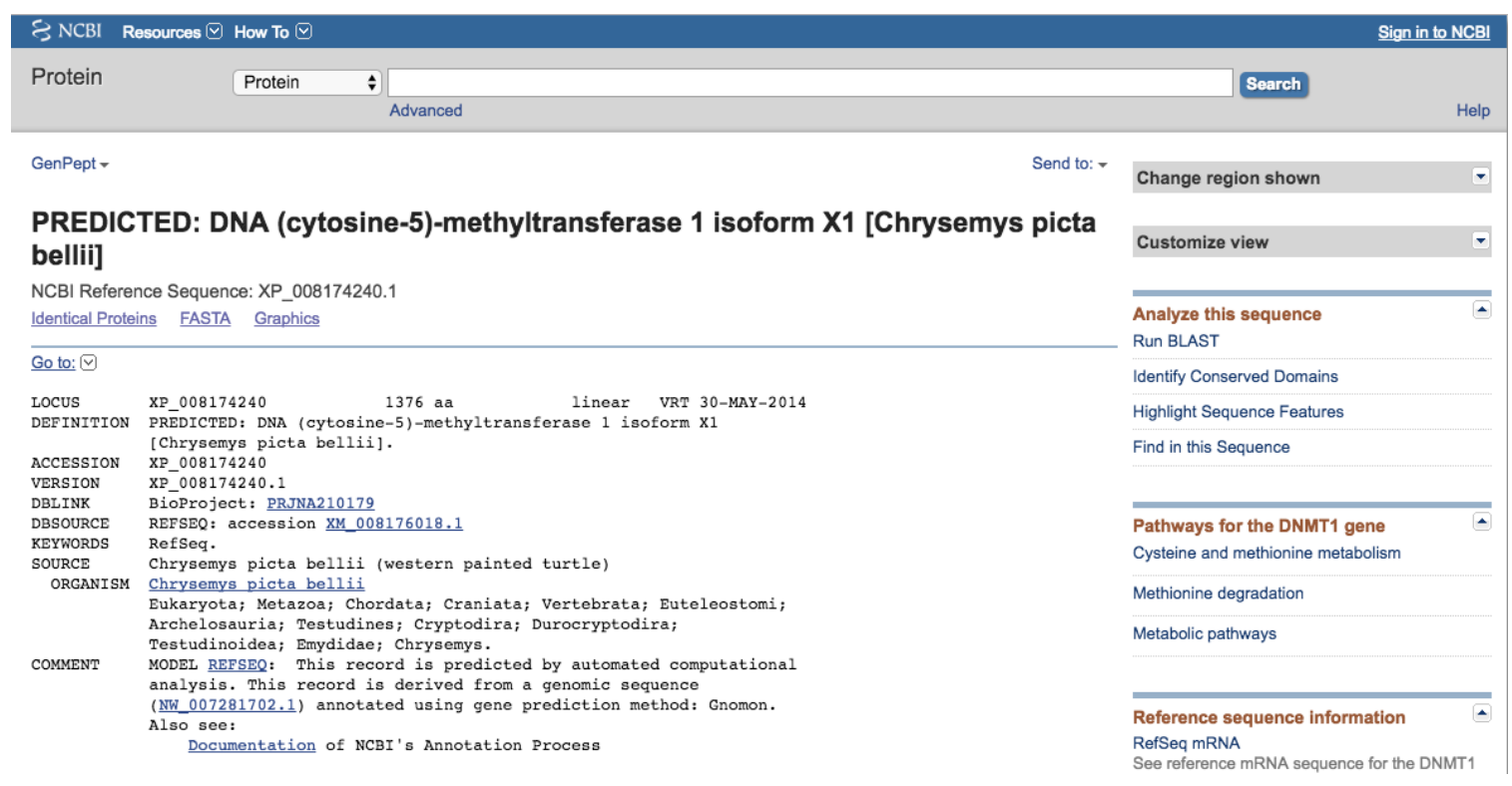


2) The coding sequence for DNMT1 was obtained.

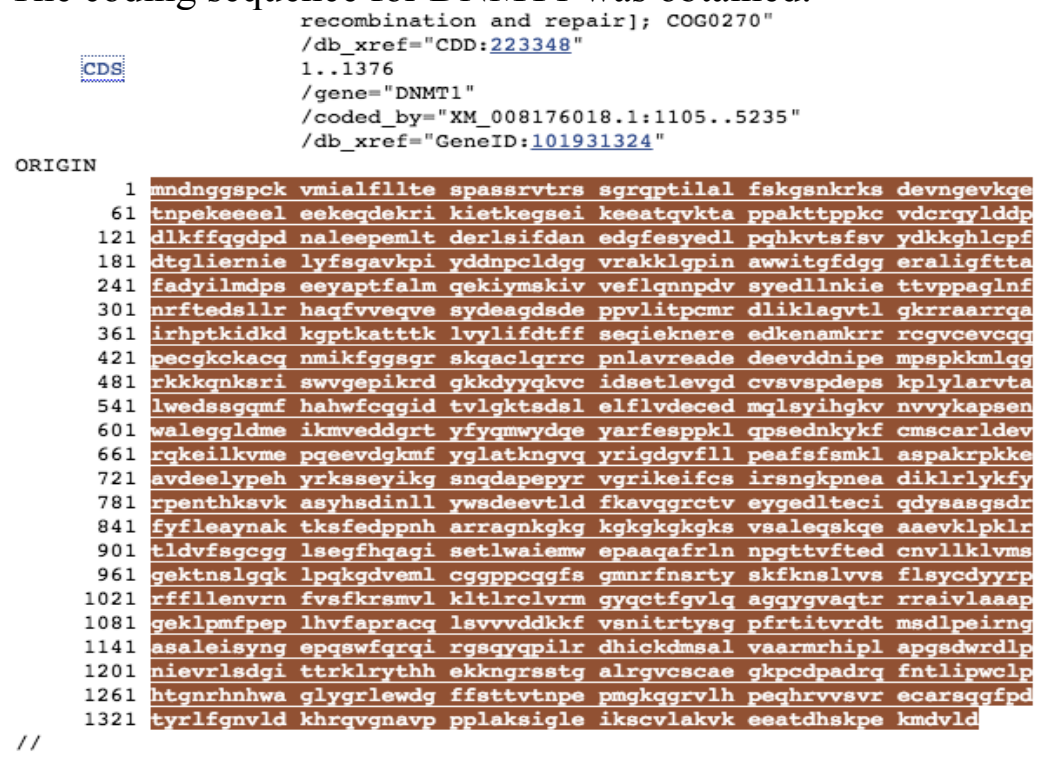

3) ExPASy Bioinformatics Resource Portal was used as described by Bjelleqvist et al., $(1993) \rightarrow$ Bjellqvist, B.,Hughes, G.J., Pasquali, Ch., Paquet, N., Ravier, F., Sanchez, J.-Ch., Frutiger, S. \& Hochstrasser, D.F. The focusing positions of polypeptides in immobilized $\mathrm{pH}$ gradients can be predicted from their amino acid sequences. Electrophoresis 1993, 14, 1023-1031.

Compute $\mathrm{p} / \mathrm{Mw}$ tool

Compute $\mathrm{p} / \mathrm{Mw}$ is a tool which allows the computation of the theoretical pl (isoelectric point) and Mw (molecular weight) for a list of UniProt Knowledgebase (Swiss-Prot or TrEMBL) entries or for user entered sequences [reference].

Documentation is available.

Compute p/Mw for Swiss-Prot/TrEMBL entries or a user-entered sequence

Please enter one or more UniProtKB/Swiss-Prot protein identifiers (ID) (e.g. ALBU_HUMAM or UniProt Knowledgebase accession numbers (AC) (e.g. P04406), separated by spaces, tabs or newlines. Alternatively, enter a protein sequence in single letter code. The theoretical pl and Mw (molecular weight) will then be computed.

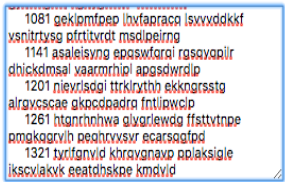

Or upload a file from your computer, containing one Swiss-Prot/TrEMBL ID/AC or one sequence per line: Choose File No file chosen

Resolution: $\bullet$ Average or $\bigcirc$ Monoisotopic

Click here to compute pl/Mw Reset

4) The MW of DNMT1 in the Western painted turtle was predicted to be $155.8 \mathrm{kDa}$ with a predicted pI of 6.40 . 


\section{APPENDIX I}

\section{WESTERN IMMUNOBLOT IMAGE}




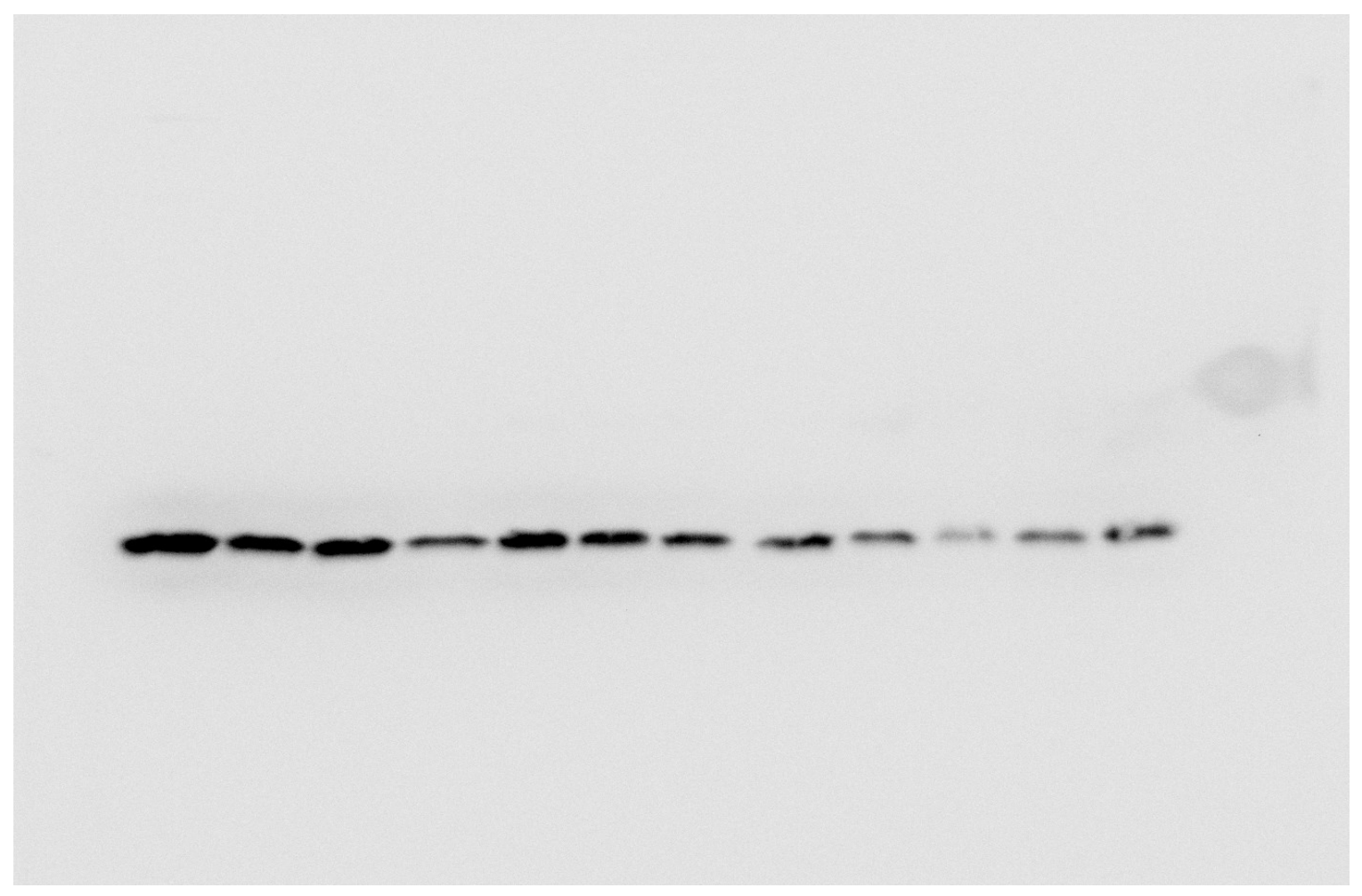

Figure I1. A enhanced chemiluminecense (ECL) image of a western immunoblot done in the liver of Trachemys picta elegans. $25 \mu \mathrm{g}$ of total soluble protein was resolved on a $12 \%$ SDS-polyacrylamide gel at $180 \mathrm{~V}$ and transferred on to a PVDF membrane for 90 min at $160 \mathrm{~mA}$. The blot was blocked with $5 \%$ milk for $30 \mathrm{~min}$ at room temperature on a plate rocker, incubated overnight with TET3 primary antibody $(1: 1000 \mathrm{v} / \mathrm{v})$ at $4{ }^{\circ} \mathrm{C}$, and incubated with anti-rabbit secondary antibody for $30 \mathrm{~min}$ at room temperature. 


\section{APPENDIX J}

\section{TECHNICAL INFORMATION ON CYTO-NUCLEAR EXTRACTS}




\section{The principal of cytoplasmic and nuclear extractions}

Cytoplasmic and nuclear extractions were used in this thesis to carefully separate the total soluble protein fractions that are localized in the nucleus from the proteins that are localized in the cytoplasm. This is particularly important when measuring the enzymatic activities of variable epigenetic modifiers such as histone methyltransferases (HMTs) and histone acetyltransferases (HATs) and deacetylases (HDACs), that can modify both histone and non-histone proteins. Therefore, to get a better understanding of the relative changes in only the nuclear-specific enzymatic activity of these epigenetic enzymes in Chapter 2, Chapter 3, Chapter 4, and Chapter 5, cytoplasmic and nuclear fractions were carefully separated and only the nuclear fractions were used. I have included a new and improved cytoplasmic and nuclear extraction procedure that can be done with $<50 \mathrm{mg}$ of tissue with minimal to no nuclear rupture below. The new method was used in Chapter 2 and Chapter 3. However, in Chapter 1 a slightly different protocol was that required a minimum of $500 \mathrm{mg}$ of frozen tissue to successfully separate cytoplasmic proteins from nuclear proteins. Note: both methods can be used to be successfully separate the two fractions without premature nuclear lysis and generate very similar results.

\section{The older cytoplasmic and nuclear extraction protocol}

$500 \mathrm{mg}$ of frozen liver samples were homogenized in cytoplasmic extraction buffer 1:2 (w:v) (10 mM Hepes pH 7.9, 10 mM KCl, 10 mM EDTA, 1 mM dithiothreitol (DTT), with a few crystals of PMSF and $10 \mu \mathrm{L} / \mathrm{mL}$ protease inhibitor cocktail with EDTA (Bioshop; Catalog \#. PIC001)) using a motor and pestle and kept on ice for 5 min. The samples were then centrifuged at $10,000 \mathrm{xg}$ for $10 \mathrm{~min}$ at $4{ }^{\circ} \mathrm{C}$ and the supernatant 
(cytoplasmic fractionation) were collected into new $1.5 \mathrm{~mL}$ microcentrifuge tubes. The pellet was resuspended in $150 \mu \mathrm{L}$ of nuclear extraction buffer (20 mM HEPES, $400 \mathrm{mM}$ $\mathrm{NaCl}, 1 \mathrm{mM}$ EDTA, $10 \%$ (v:v) glycerol, $1 \mathrm{mM}$ DTT with $10 \mu \mathrm{L} / \mathrm{mL}$ protease inhibitor cocktail with EDTA (Bioshop; Catalog \#. PIC001)). To enhance nuclear lysis, the pellet was homogenized with the pestle once more and the samples were placed horizontally on a rocking platform on ice for $1 \mathrm{~h}$. Post-incubation, the samples were centrifuged at $10,000 \mathrm{xg}$ for $10 \mathrm{~min}$ at $4{ }^{\circ} \mathrm{C}$ and the supernatant (nuclear fractions) were collected into new $1.5 \mathrm{~mL}$ microcentrifuge tubes. The protein concentrations were quantified as described in the total protein extraction section. The samples were normalized to a final concentration of $5 \mu \mathrm{g} / \mu \mathrm{L} .50 \mu \mathrm{L}$ of the stock cytoplasmic and nuclear fractions were mixed with 1:1 (v:v) with 2x SDS loading buffer (100 mM Tris-base, $4 \%$ (w:v) SDS, 20 $\%$ (v:v) glycerol, $0.2 \%$ (w:v) bromophenol blue, $10 \%$ (v:v) 2-mercaptoethanol) to a final concentration of $2.5 \mu \mathrm{g} / \mu \mathrm{L}$. These samples were used to test the degree of success in separating cytoplasmic and nuclear fractions by using western immunoblotting and probing both cytoplasmic and nuclear fractions with histone H3 antibody (Genetex; Catalog \#. GTX129546) diluted 1:1000 (v:v) in 1x TBST. 
The new cytoplasmic and nuclear protocol:

\begin{tabular}{c} 
Technical Bulletin MB518 - NEW Method \\
Isolation and extraction of cytoplasmic and nuclear extracts from $\leq \mathbf{5 0 ~} \mathbf{m g}$ of frozen \\
tissues \\
Sanoji Wijenayake (2016) \\
\hline
\end{tabular}

NOTE: This technical bulletin replace the previous technical bulletin on CytoNuclear extractions!

This is an in-house, optimized method that is based on an existing kit technology.

This protocol can be done using already available lab equipment and reagents.

In the past, successful isolation and extraction of total soluble proteins from cytoplasmic fractions without rupturing the nuclei was difficult and required large amounts of tissue. In particular, per n, one would require an upwards of $1 \mathrm{~g}$ of tissue.

This protocol can be done with approximately $\mathbf{5 0} \mathbf{~ m g}$ of tissue and if followed correctly will yield cytoplasmic and nuclear fractions with excellent quality.

\section{$\underline{\text { Required Buffers: }}$}

- 10X Buffer A: 100 mM HEPES; 100 mM KCl; 100 mM EDTA; 200 mM $\beta$-glycerol phosphate, $\mathrm{pH} 7.9$.

- 5X Buffer B: 100 mM HEPES; 2 M NaCl; 5 mM EDTA; 50\% (v/v) glycerol; $100 \mathrm{mM}$ $\beta$-glycerol phosphate, $\mathrm{pH} 7.9$

- 100 mM DTT

- Protease inhibitor cocktail from Bioshop

- Biorad solution

\section{Required Equipment:}

- Motor and pestle for homogenization

- A sonicator

- $2 \mathrm{~mL}$ tubes

- Desktop centrifuge that can reach 14, 000 rpms and a Spectrophotometer 


\section{Protocol:}

\section{Step 1:}

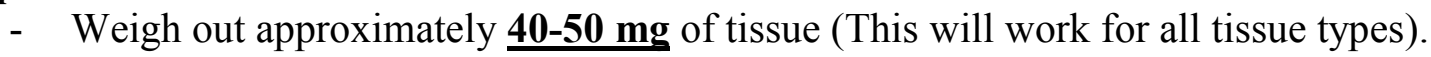

You will not need any more than this to obtain high protein yield with this method.

- Do not powder the tissue pieces before homogenization. Leave the tissue pieces in large chunks in 1.5 or $2 \mathrm{~mL}$ sample tubes. This is done to minimize manual handling of the tissues that can increase the likelihood of protein degradation and nuclear rupture.

- Prepare the buffers as listed above and be sure to pre-chill the buffers and homogenization pestle on ice before use (Note: use the custom-made, glass pestles in the Buffer room for these extractions).

- Chose the correct glass pestle to fit the sample tubes $\rightarrow 1.5 \mathrm{~mL}$ tubes will require a pestle with pointed-end, and $2 \mathrm{~mL}$ tunes require the round-end pestles.

- Dilute 10X buffer A into 1X with $\mathrm{DDH}_{2} \mathrm{O}$ and add $10 \mu \mathrm{L} / \mathrm{mL}$ of $100 \mathrm{mM}$ DTT and $10 \mu \mathrm{L} / \mathrm{mL}$ of protease inhibitor cocktail to the solution.

- When ready for homogenization, add $\underline{1: 5(w / v) \text { ratio of } 1 X \text { buffer } \mathbf{A}}$. In other words, for $50 \mathrm{mg}$ of frozen tissue, add about $250 \mu \mathrm{L}$ of $1 \mathrm{X}$ buffer $\mathrm{A}$.

- Homogenize your samples using gentle piston strokes - just 3-4 strokes needed for soft tissues like liver versus perhaps 6-8 for tougher tissues such as skeletal muscle. Hold the samples in a bucket of ice during homogenization.

- $\quad$ Rinse the homogenizer with methanol and water between uses; dry with a kimwipe. Repeat this for all the samples. 
- Incubate samples on ice for $25 \mathrm{~min}$ and centrifuge at $12,000 \mathrm{rpms}$ for $15 \mathrm{~min}$ at $4^{\circ}$ C.

- Remove the supernatant and store in new set of tubes $\rightarrow$ THIS IS YOUR

\section{CYTOPLASMIC EXTRACTS.}

\section{Step 2:}

- Do not dilute 5X buffer B before use. Buffer B has a high salt that is needed to lyse the intact nuclei.

- Add $100 \mathrm{mM}$ DTT and protease inhibitor cocktail at 1:1000 ratio to 5X buffer B before use.

- Then add about $250 \mu \mathbf{L}$ of $\mathbf{5 X}$ buffer $\mathbf{B}$ to each pellet. This is based on an average pellet size. However, if your pellet is larger, add more lysis buffer.

- Sonicate the samples to induce nuclear lysis. This is a very important step that enhance protein yield. DO NOT SKIP THIS STEP!

- Post sonication, incubate the samples on ice for $10 \mathrm{~min}$ to further increase protein extraction.

- Centrifuge the samples at $14,000 \mathrm{rpms}$ for $10 \mathrm{~min}$ at $4^{\circ} \mathrm{C}$.

- Extract the supernatant and store in separate tubes $\rightarrow \underline{\text { THIS IS YOUR }}$

\section{NUCLEAR EXTRACTS.}

\section{Step 3:}

- Quantify the amount of protein in both cytoplasmic and nuclear fractions using the BioRad assay. Dilute soft tissue lysates such as liver and kidney in 1:80 ratio with $\mathrm{DDH}_{2} \mathrm{O}$ and dilute tissues such as heart, brain, and skeletal muscle in 1:60 ratio with $\mathrm{DDH}_{2} \mathrm{O}$. Follow instructions for BioRad as described in Tech Bull EBO1B. 
- To validate the efficiency of your nuclear isolation and extraction, you need to run Western blots of your nucleic and cytosolic fractions and test them with an antibody to a protein that you know is only in the nucleus (i.e. Histone H3 using anti-Histone $\mathrm{H} 3$ antibody) or cytoplasm (i.e. creatine kinase using anti- creatine kinase antibody). Other cytoplasmic antibodies that could be used include glucose-6-phosphate dehydrogenase or maybe lactate dehydrogenase (**but see Ken or a senior student).

- KEEP A RECORD of these trials for each new tissue/animal - e.g. a nice blot picture showing Nuc and Cyt fractions stained for Histone H3 and/or quantified band densities - reviewers often ask for this proof.

- Once the quality of your separation of nuclear and cytoplasmic fractions is confirmed by this method, you can store the samples at $-80^{\circ} \mathrm{C}$ for further use.

\author{
Note: This protocol was modified from a commercially available kit $\rightarrow$ \\ EpiQuik Nuclear Extraction Kit (100 assays)




\section{APPENDIX K}

\section{ENZYMATIC ASSAY - MECHANISTIC DETAILS}


The commercially available epigenetic activity assays used in this thesis all used antibody-based detection systems for measuring the total enzymatic activity of DNMTs, TETs, HAT, SIRTs, and HMTs on a given substrate that is conjugated on to the bottom of 96-well plates. EpiQuick DNMT Activity/Inhibition Colorimetric Assay Ultra Kit from Epigentek (Catalog \# P-3009) used in Chapter 2 was used to outline the mechanism below.

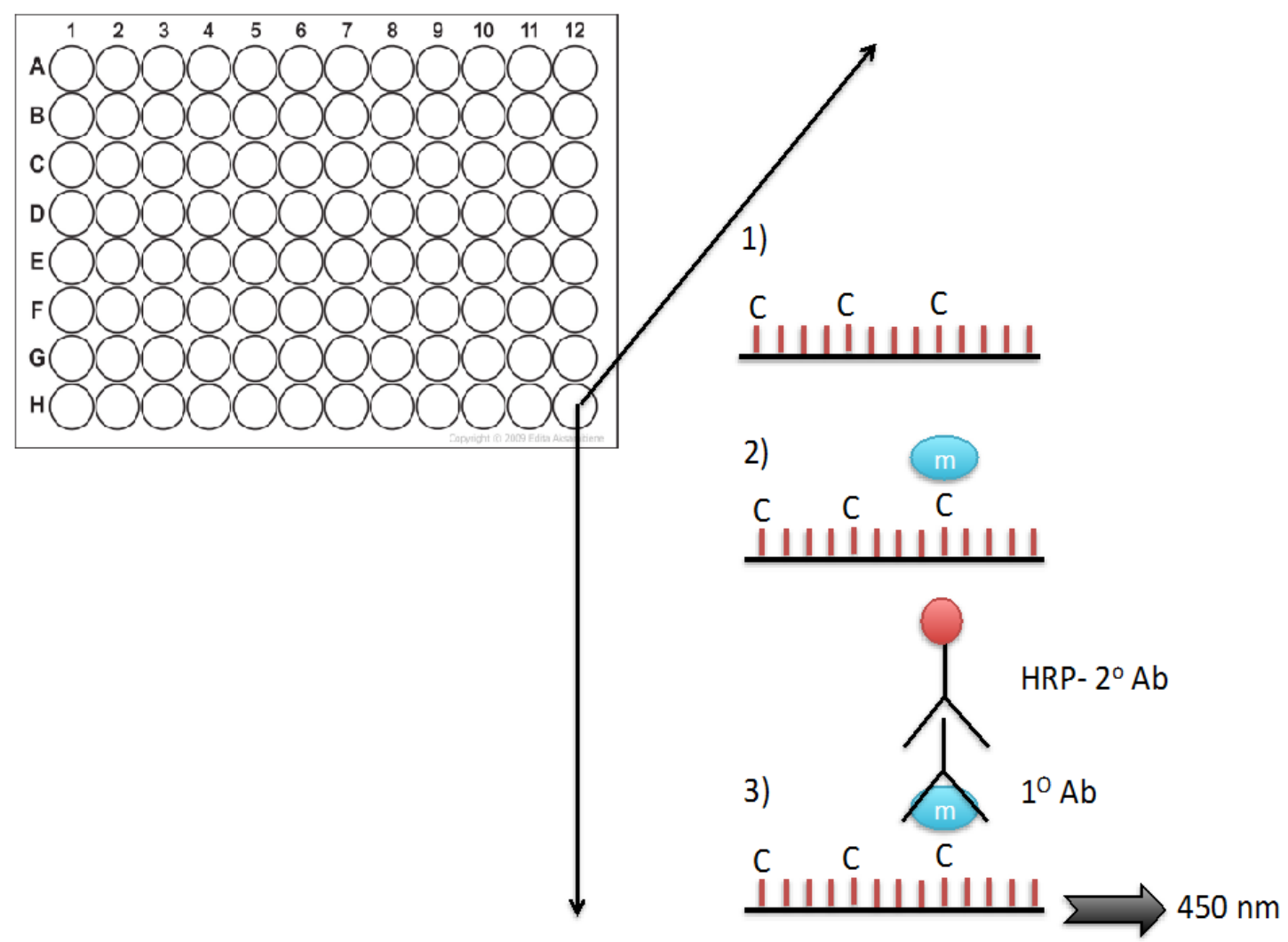

Figure J1. Principal mechanism of action of EpiQuick DNMT activity/inhibition colorimetric assay ultra-kit from Epigentek (Catalog \# P-3009). 1) Illustrate the oligonucleotide sequence enriched with cytosine residues that are conjugated to the bottom of the 96 -well plates. 2) Modification of the $5^{\text {th }}$ position of cytosine residues by DNMTs in the nuclear sample lysate. 3) Methylated marks are identified by a $5 \mathrm{mC}$ primary antibody, which is then bound by an HRP-tagged secondary antibody. 


\section{The overall principal and procedure for the DNMT activity assay}

The EpiQuiK DNA methyltransferase activity assay is designed to measure the total DNMT activity (DNMT1, DNMT3a, and DNMT3b) in a given protein lysate. In

brief, oligonucleotide sequences enriched with cytosine residues are stably coated on to the bottom of the strip wells. The wells are specifically targeted to have a high DNA absorption ability. Subsequently, DNMT enzymes from the added protein lysate then transfer a methyl group from Adomet to available cytosine residues. The methylated DNA is then recognized with an anti-5-methylcytosine antibody and HRP-conjugated secondary antibody. Finally, the amount of methylated DNA, which is proportional to DNMT activity, is measured colorimetrically or fluorometrically in an ELISA-like reaction. 


\section{APPENDIX L}

\section{THESIS DEFENSE SLIDES}




\section{No OXYGEN? NO PROBLEM!}

Epigenetic Mechanisms of Anoxia Tolerance in a Champion

Anaerobe, the Red-Eared Slider Turtle

(Trachemys scripta elegans)

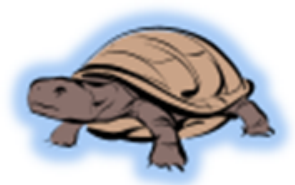

Ph.D. Thesis Defense

By:

Sanoji Wijenayake (Ph.D. Candidate)

Supervisor: Dr. Kenneth B Storey 


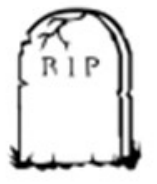

\section{Hypoxia \& Anoxia}

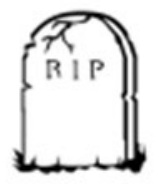

- Hypoxia: Low levels of oxygen

- Anoxia: Complete absence of oxygen

- The problem of low oxygen:

- Rate of ATP generation $\ll<$ Rate of ATP consumption

- Lipid and amino acid fuels become useless

- Glycolysis becomes the sole source of ATP (2 ATP/glucose)

- But glycolysis CANNOT supply enough ATP to sustain the cells unmodified needs

- Produce cytotoxic end products

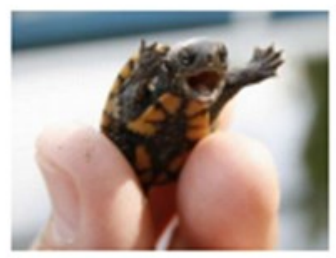




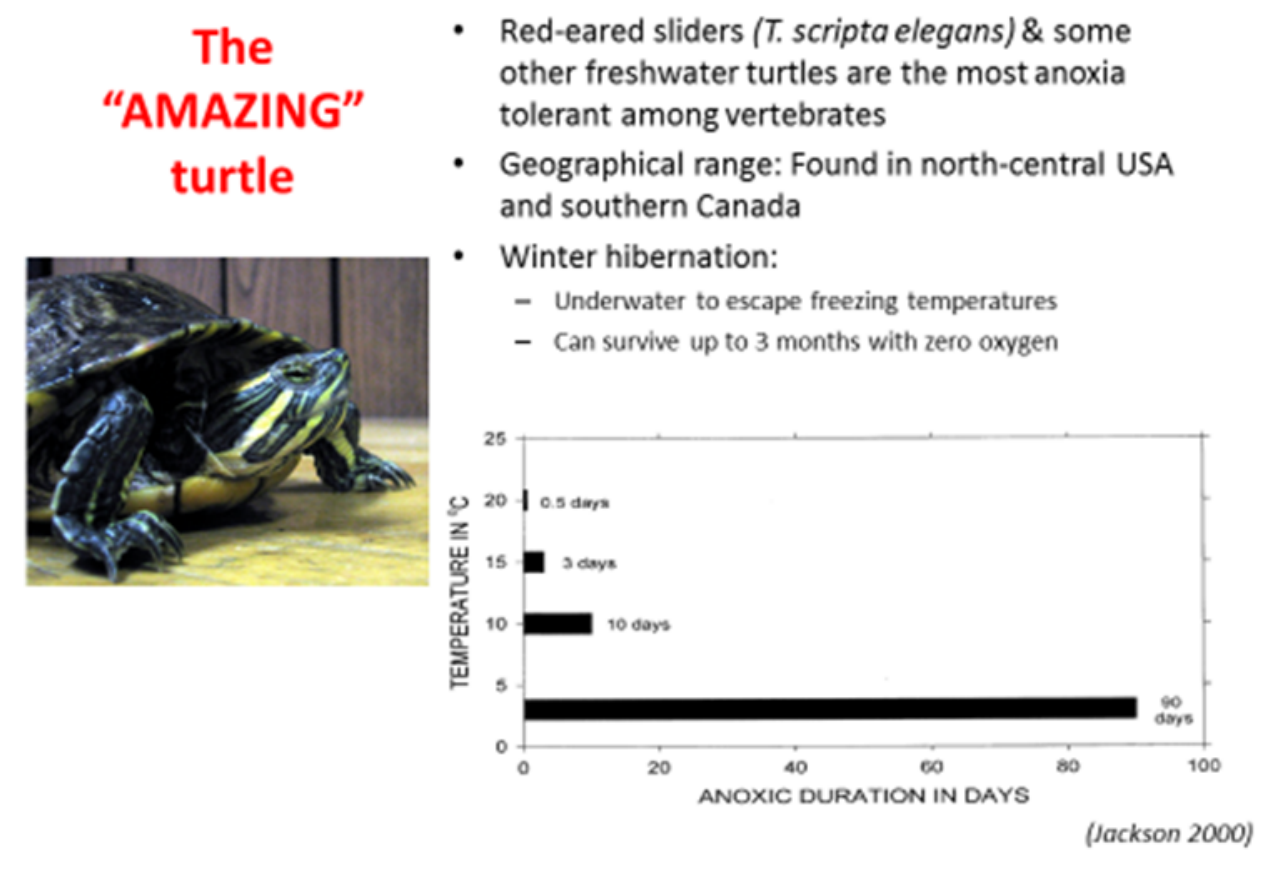




\section{Hypothesis}

When normal metabolic functions are disrupted by low oxygen conditions in the freshwater turtle (Trachemys scripta elegans), gene expression is regulated in a tissue-specific manner via epigenetic controls that include a combinatorial result of increased DNA methylation, decreased demethylation, and site-specific modifications of acetylation and methylation of histone $\mathrm{H} 3$.

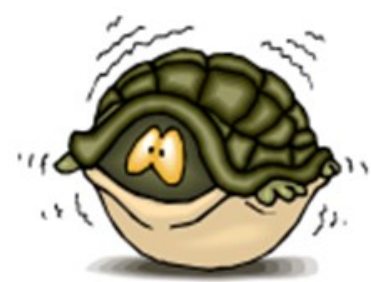




\section{Epigenetics}

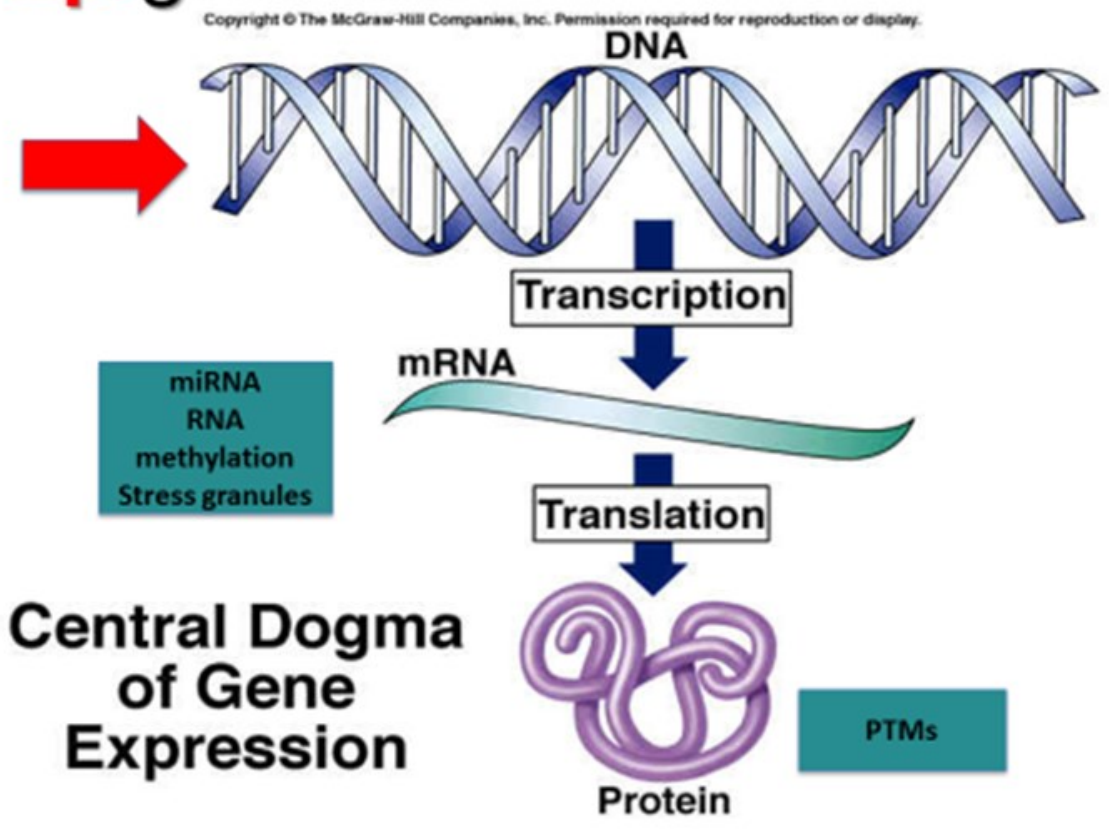




\section{Chapter 1: DNA methylation}

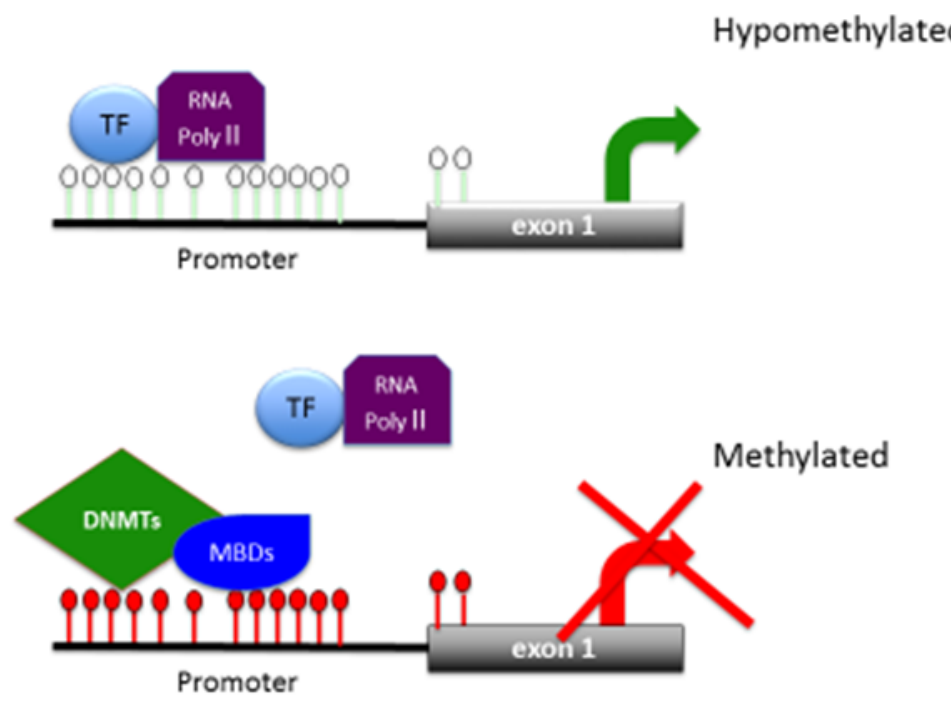




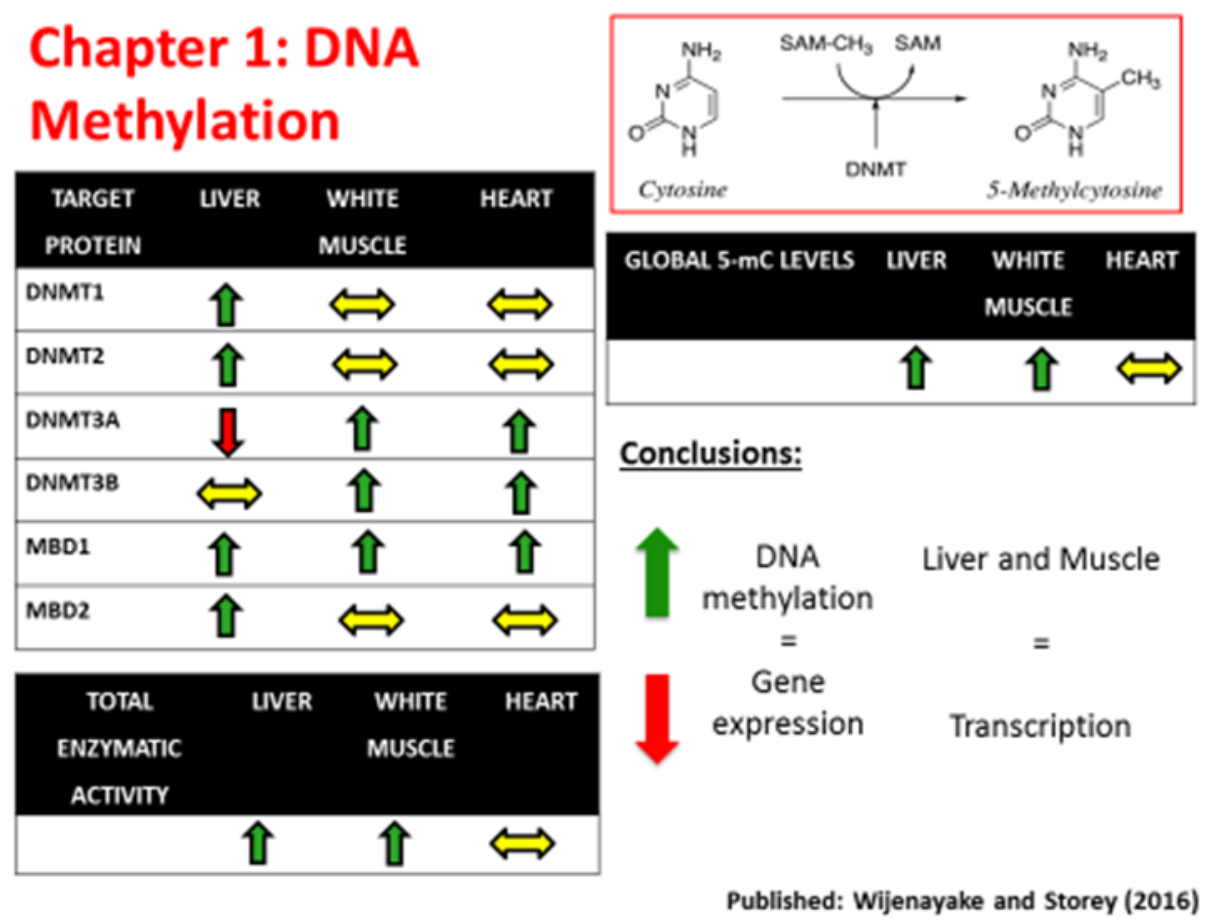




\section{TET-mediated Demethylation mechanism}

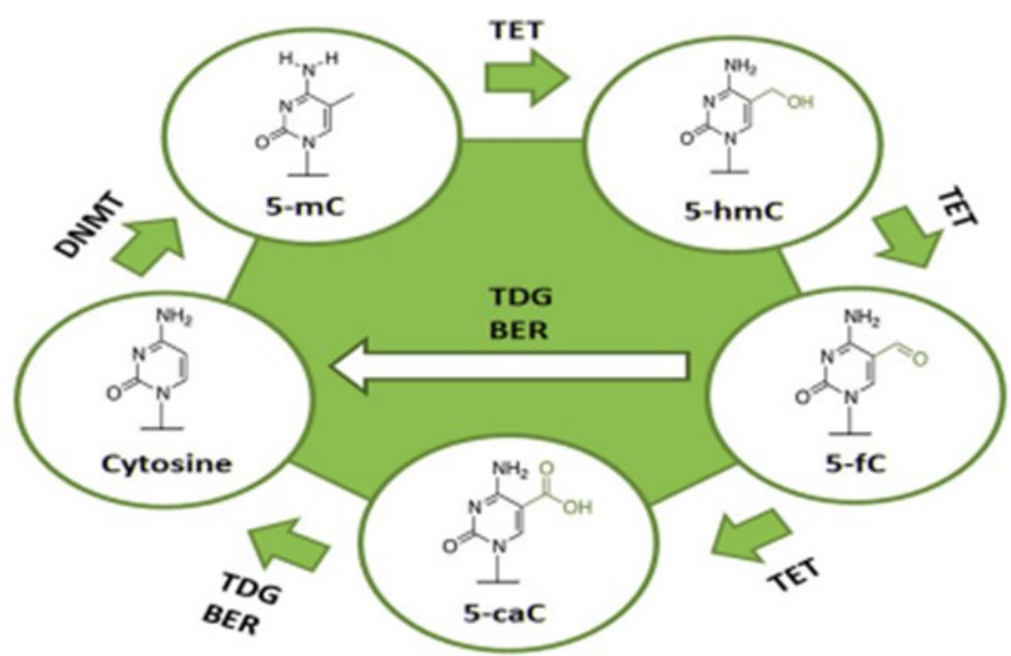




\section{Chapter 2: DNA Demethylation}

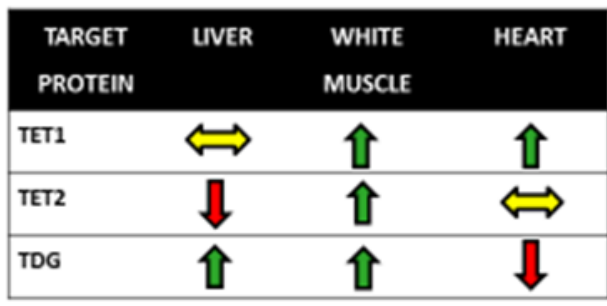

$\begin{array}{cccc}\begin{array}{c}\text { TOTAL } \\ \text { ENZYMATIC } \\ \text { ACTIVITY }\end{array} & \text { UVER } & \begin{array}{c}\text { WHITE } \\ \text { MUSCLE }\end{array} & \text { HEART } \\ & & & \\ & \Downarrow & \Downarrow & \Leftrightarrow\end{array}$

\begin{tabular}{|c|c|c|c|}
\hline $\begin{array}{l}\text { TARGET } \\
\text { PROTEIN }\end{array}$ & UVER & $\begin{array}{l}\text { WHITE } \\
\text { MUSCLE }\end{array}$ & HEART \\
\hline 5-hmc & & & $\Leftrightarrow$ \\
\hline $5-\mathrm{HC}$ & & & 1 \\
\hline $5-\operatorname{coc}$ & $\Leftrightarrow$ & П & $\Leftrightarrow$ \\
\hline
\end{tabular}

Conclusions:

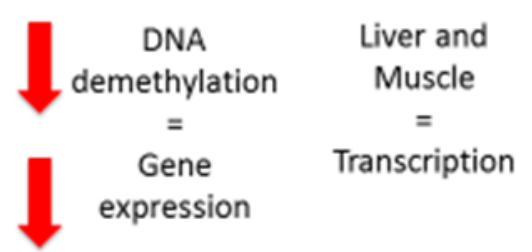




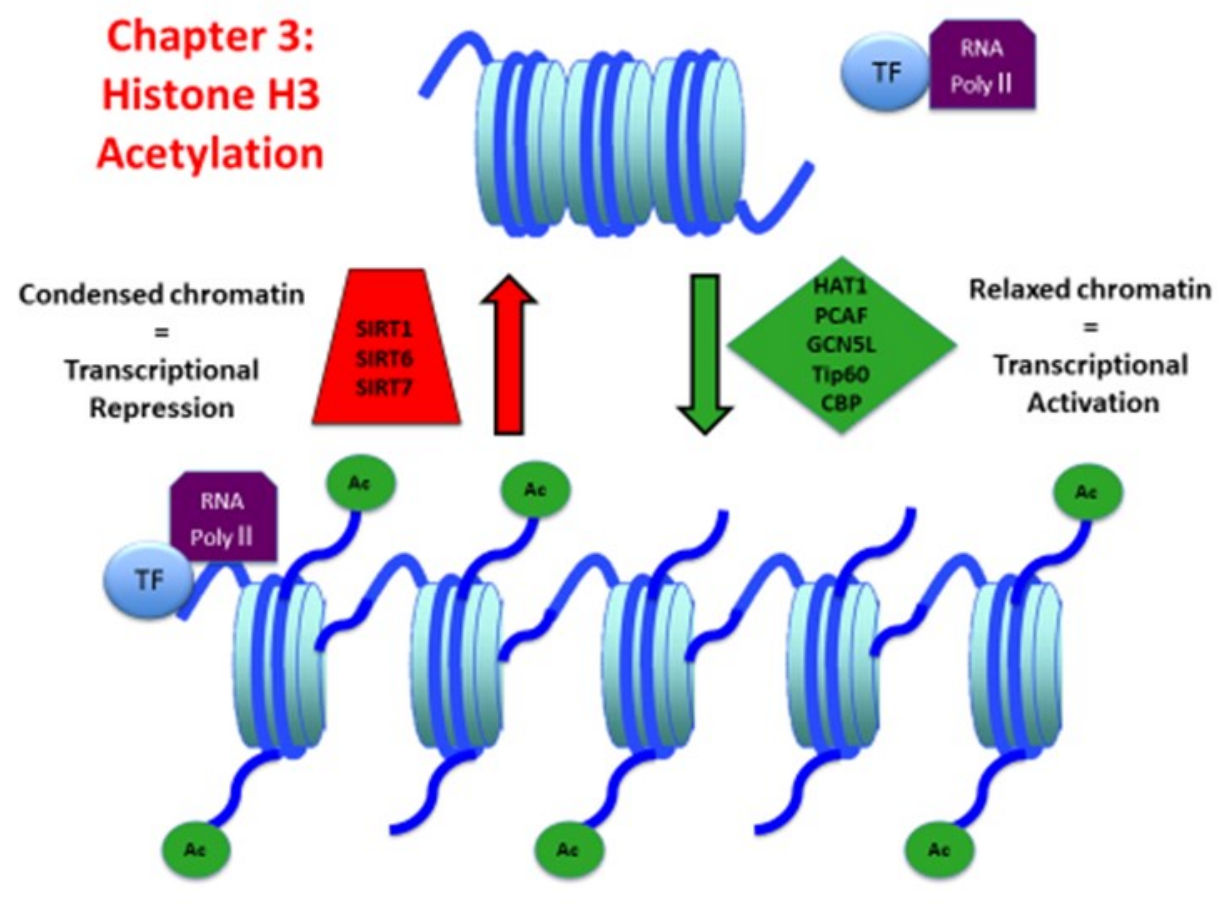




\section{Chapter 3-Acetylation and Deacetylation}

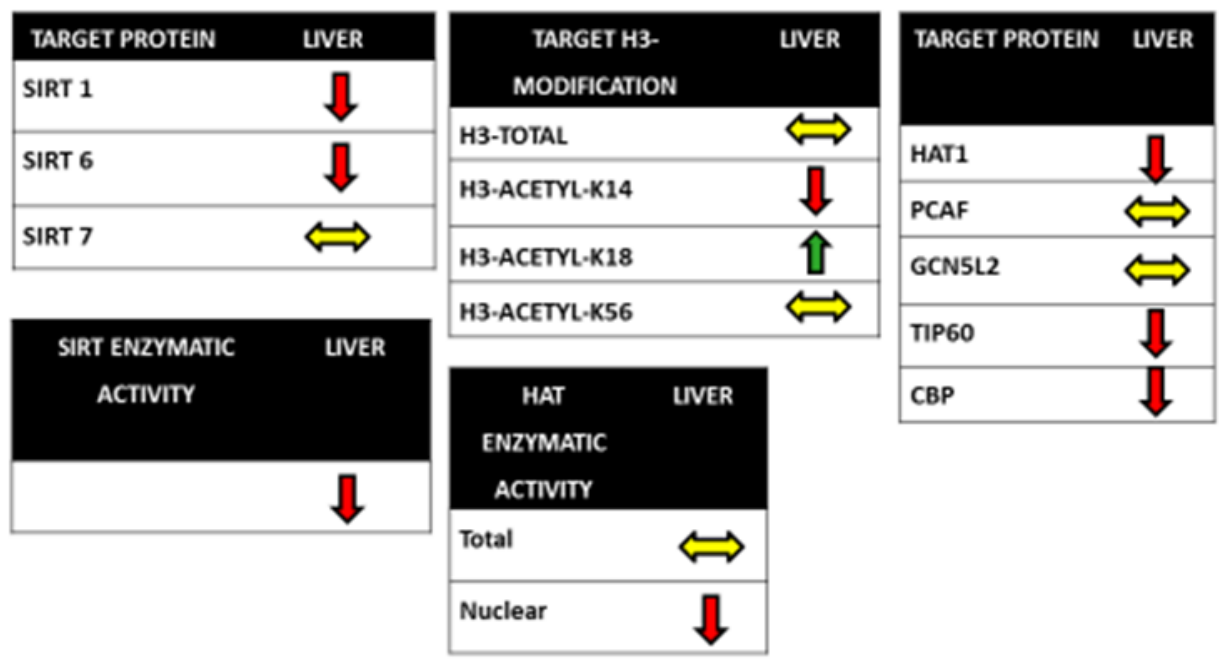




\section{HATs vs HDACs}

- Overall trends;

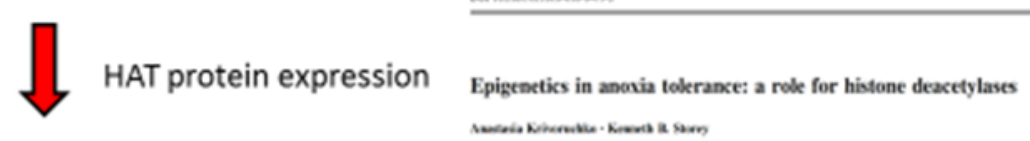

$\llbracket$ Nuclear HAT enzymatic activity

Nuclear SIRT Enzymatic activity 


\section{Chapter 4}
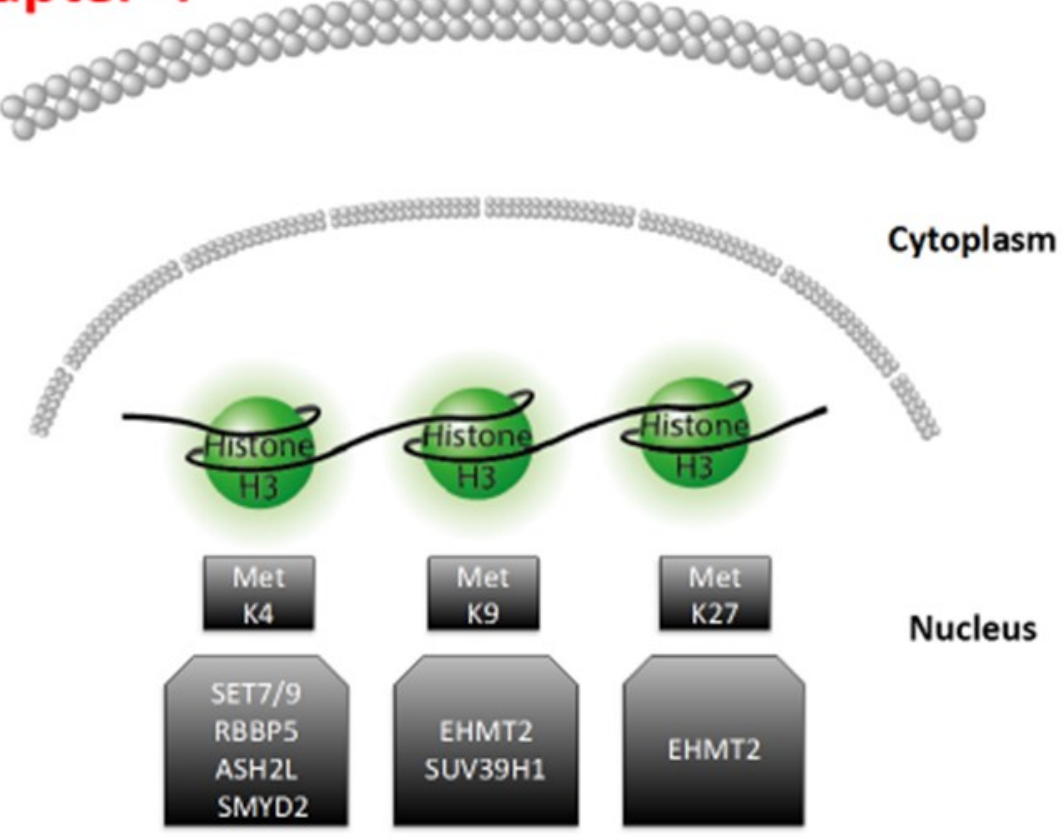

Nucleus 


\section{Chapter 4: Histone KMTs}

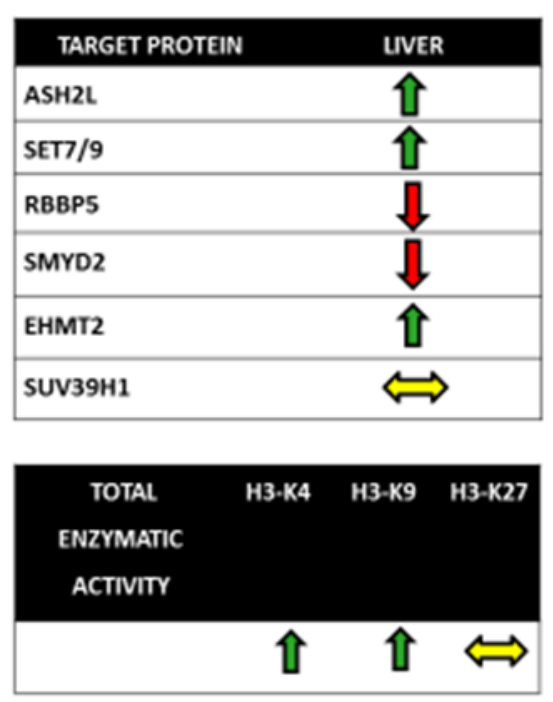

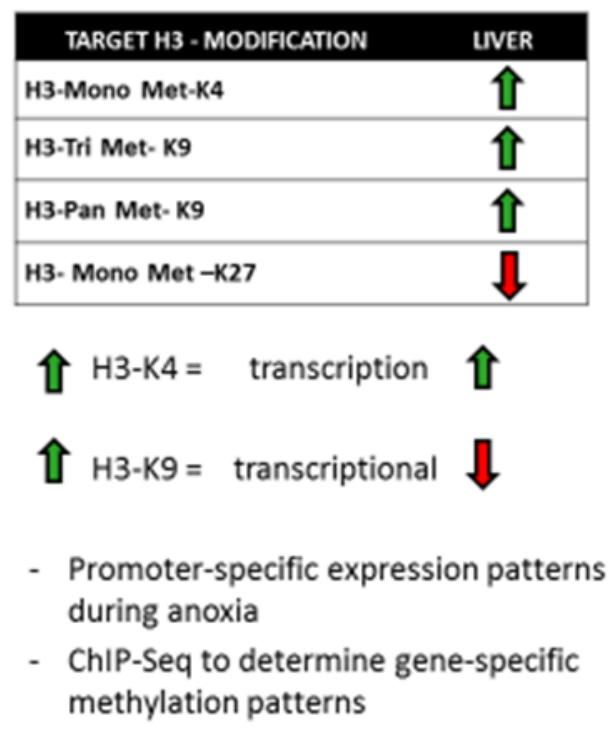




\section{What does all of this mean in terms of MRD and anoxia tolerance????}

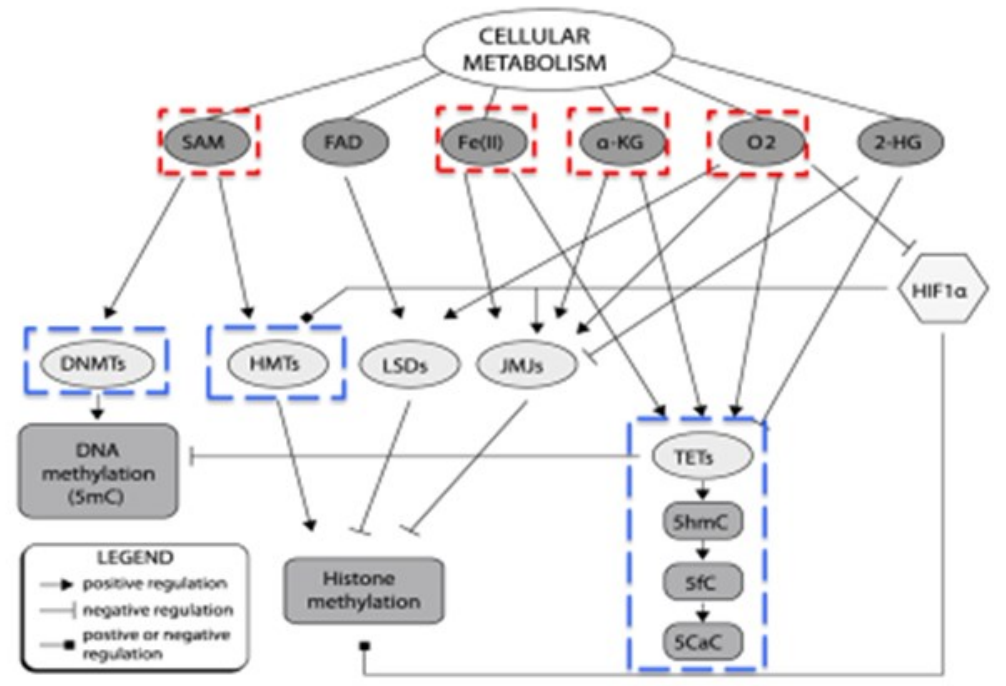


Overall, turtles use epigenetic reprogramming to remodel chromatin accessibility in response to anoxia

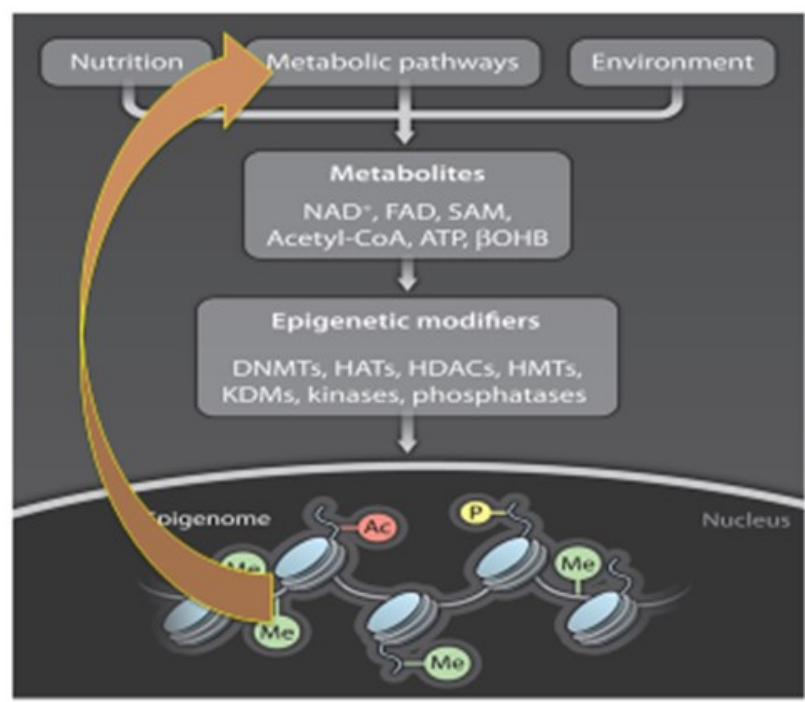

Paolo Sassone-Corsi Science 2013,339-148-150 


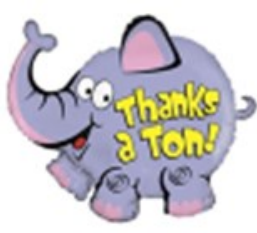

- Thanks to Dr. KB Storey \& JM Storey

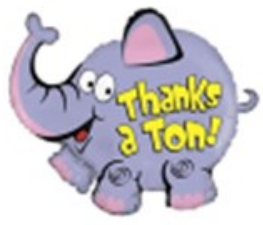

- Thanks to all Storey lab members

- Thanks to Dr. Jean-Michel Weber and Dr. Jim Cheetham

- Thanks to Dr. John H. White and Dr. Tyler Avis
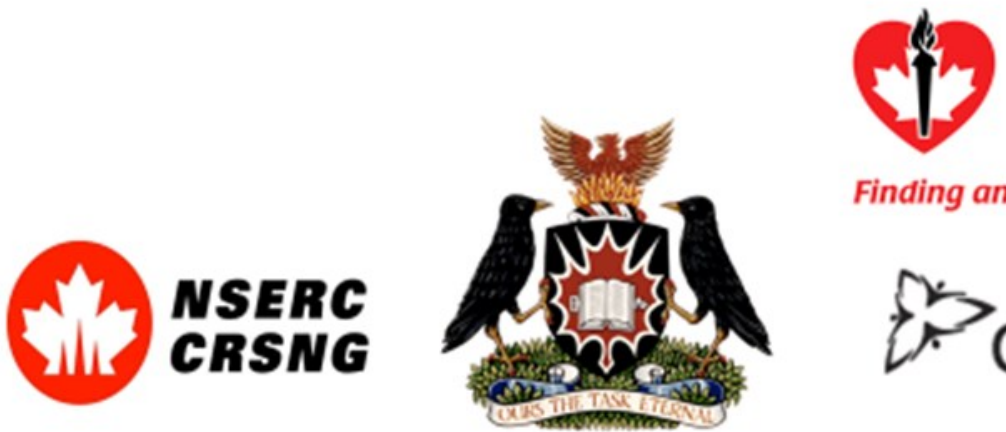

HEART \& STROKE FOUNDATION

Finding answers. For life.

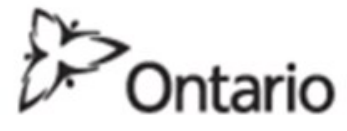


Extra Slides: Methods 


\section{Overall Methods}

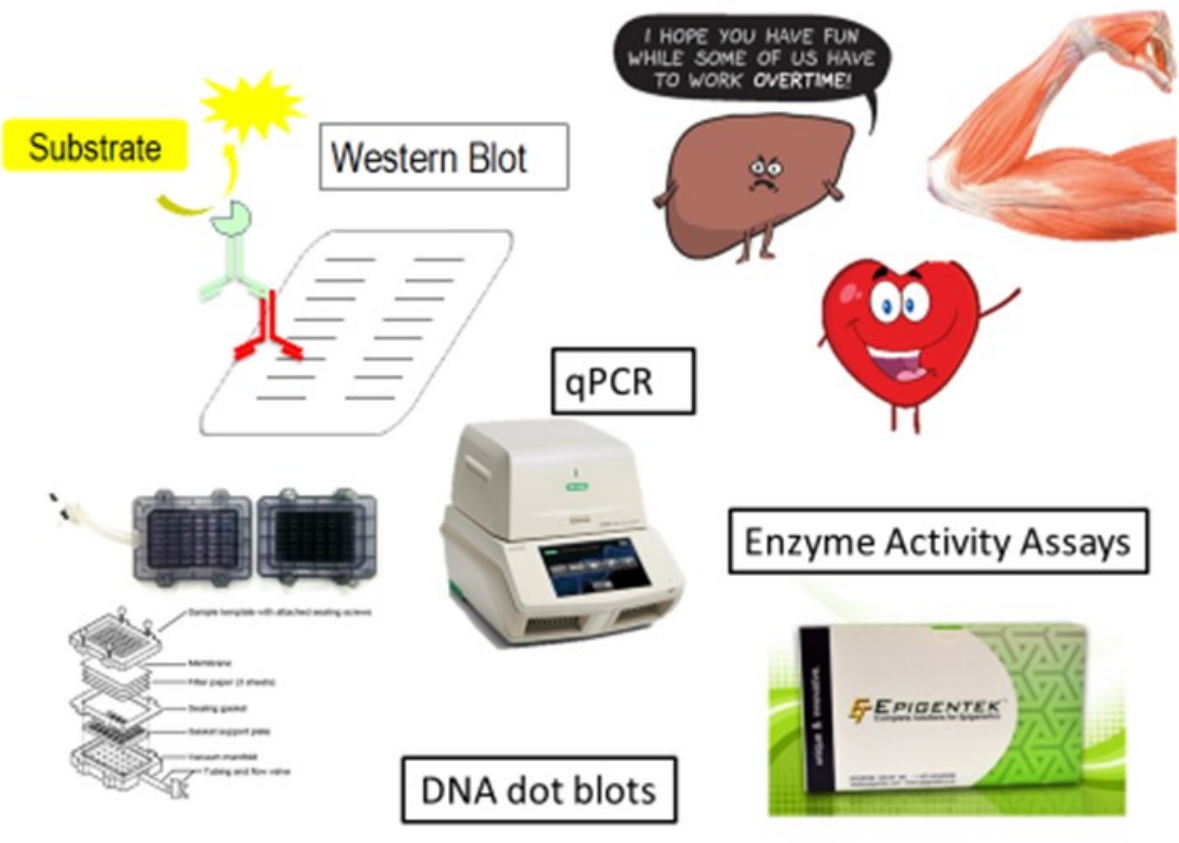




\section{Tissue Choices}

\section{- Liver}

- Largest organ

- Containsmajority of glycogen stores

- $90 \%$ reduction in metabolicrate

\section{- Heart}

- Exhibit high anaerobic capacity

- Contain $10 \%$ higher cardiac glycogen levels than any terrestrial vertebrates

- Containshigh expression levels of glycolytic enzymes (HK, PFK)

- White Muscle

- Primarily glycolytic, low levels of mitochondria

- Fast twitch muscles $\rightarrow$ Rapid actions

- Location: Neck and Forearms

\section{- Red Muscle}

- Primarily aerobic, high levels of mitochondria

- Slow-twitch $\rightarrow$ sustained work
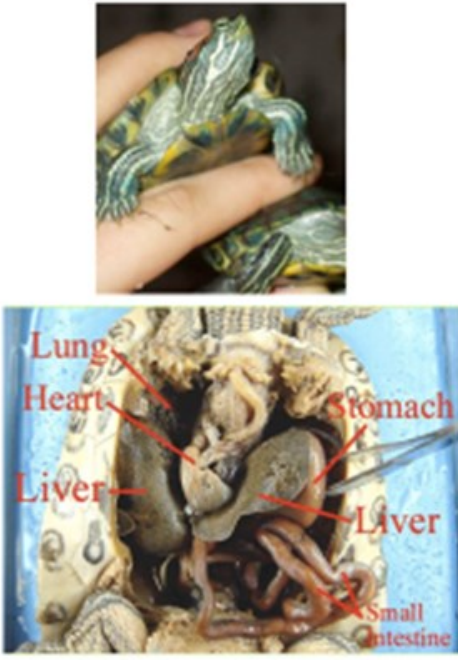


\section{Experimental Conditions}

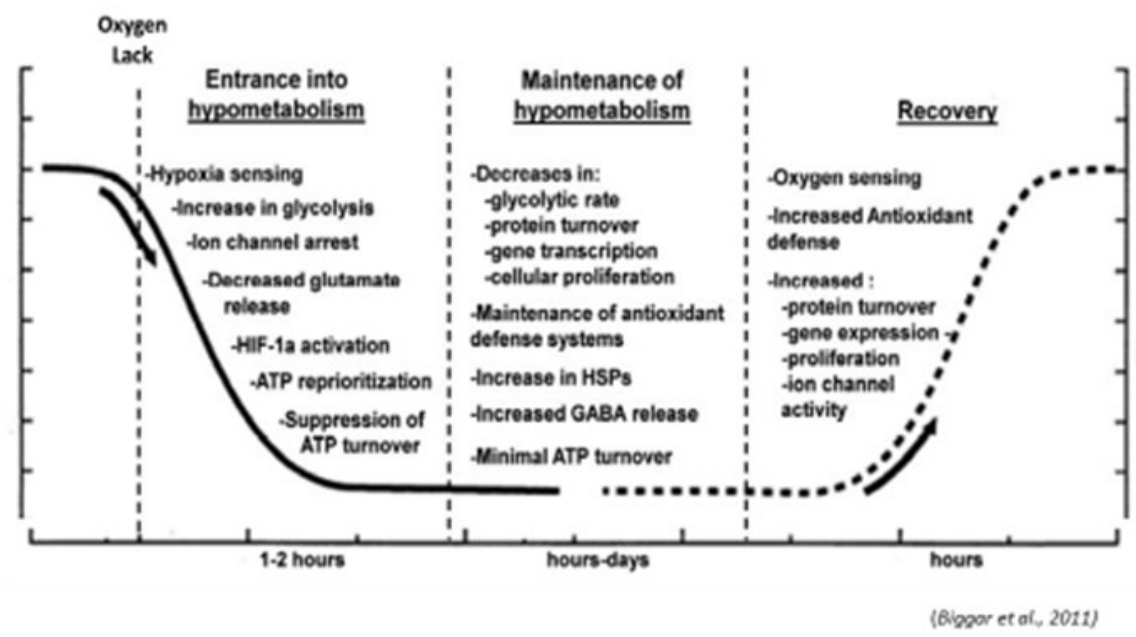




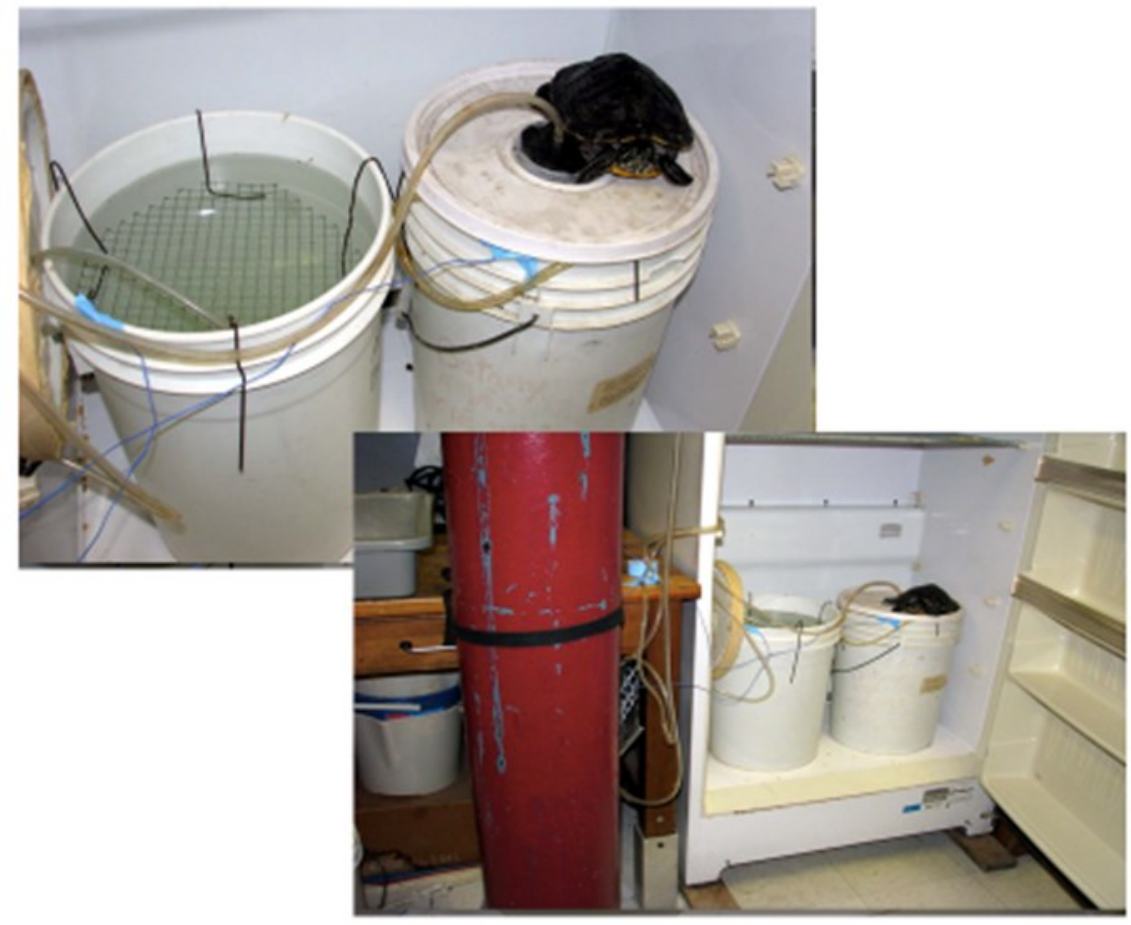




\section{Statistical Analyses}

- Type I error

- Incorrectly rejecting a true null hypothesis or committing a false positive

- p-value: The probability of committing a type I error

- My thesis $\rightarrow p<0.05$

- Two-tailed T-test: Compare two variables $(p<0.05)$

- One way ANOVA = Multiple comparisons $(p<0.05)$

- Resemble a F-distribution

- F-distribution is analogous to a normal distribution but compare more than 2 conditions

- Only indicate that there is an overall difference

- Need Post-hoc tests to determine which conditions are statistically significant and control for increasing type I error 


\section{Statistical Analyses}

- Tukey range test (HSD)

- Compared the means of every treatment to the means of all other treatments

- In a pairwise comparison, the test identifies two means that are more different than the SEM of all comparisons

- Formula:

$$
q_{s}=\left(Y_{a}-Y_{b}\right) / S E M
$$

- Advantages and Disadvantages:

- When the sample sizes are unequal and confidence intervals are needed, this is the best Post-hoc test to use. 
- Student-Newman-Keuls test (SNK)

- The test is based on a step-wise approach

- Sample means are ordered from the smallest to the largest and the difference was examined

- Similar in principal to the Tukey test BUT;

- Less conservative

- Likely to make a type I error with multiple comparisons

- Dunnet's test

- Compared all experimental conditions to the control

- This test cannot be used to do pairwise comparisons

Used SIGMAPLOT 11/12 software for statistical analyses 


\section{Bonferroni Correction}

- Highly stringent and conservative test at minimizing type I error

- Test each comparison at a significant level of $\alpha / n$

- Use $\rightarrow \alpha / n$

$-\alpha=$ the confidence interval (95\%)

$-n=$ the sample size $(n=4)$ 


\section{Other Anoxia Tolerant Strategies}




\section{Crucian Carp}

- Tolerate absolute anoxia at low temperatures (close to zero)

- Survive $\sim 140$ days without 02

- Employ a state of MRD

- Employ anaerobic respiration with ethanol as the end product

- Pyruvate (glycolysis) $\rightarrow$ Lactate

- Lactate (decarboxylated) $\rightarrow$ Acetaldehyde

- Acetaldehyde (hydrogenated) $\rightarrow$ ethanol

- Excretes the ethanol into the water DO NOT STORE

- No channel arrest with $\mathrm{Ca}^{2+}$ and $\mathrm{K}^{+}$

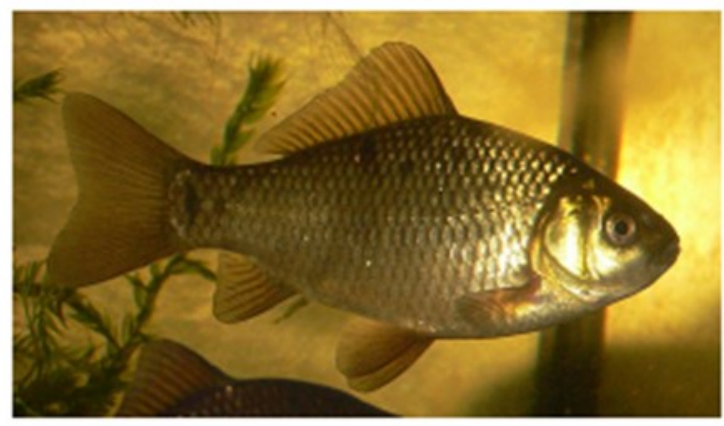

- No reduction of glutamate and maintain brain blood flow

- Still active during the anoxic stress 


\section{Goldfish}

- Tolerate hypoxia and complete anoxia for few days at $4 \mathrm{C}$.

- Experience MRD in response to anoxia

- Survive few days without 02

- Employ anaerobic respiration with ethanol as the end product

- Alcoholic fermentation in the muscle $\rightarrow$ lactate is catabolized to form ethanol and $\mathrm{CO}_{2}$

- Brain and heart use glycolysis to produce ATP

- Excretes the ethanol into the water DO NOT STORE

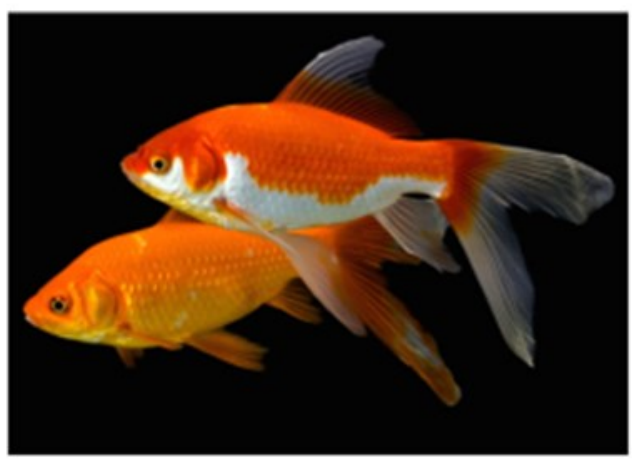

- Not active during long anoxic episodes 


\section{Epaulette shark}

- Tolerate hypoxia and at times anoxia at $25-30 \mathrm{C}$.

- Subjected to nocturnal low tides in coral reefs.

- Experience MRD in response to anoxia

- Survive few days without $\mathrm{O2}$

- Employ anaerobic respiration with ethanol as the end product

- Pyruvate (glycolysis) $\rightarrow$ Lactate

- Lactate (decarboxylated) $\rightarrow$ Acetaldehyde

- Acetaldehyde (hydrogenated) $\rightarrow$ ethanol

- Excretes the ethanol into the water

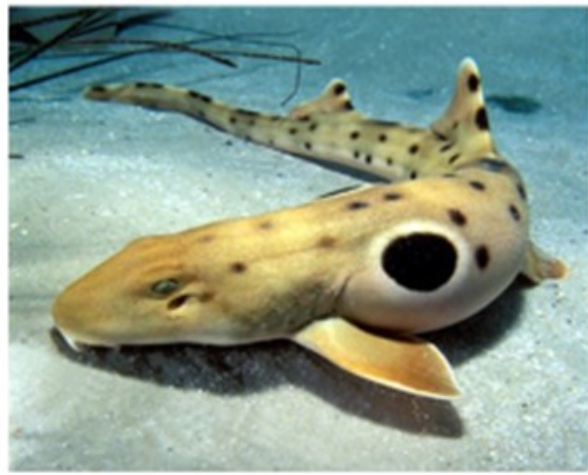
DO NOT STORE

- Not active during long anoxic episodes 


\section{African Naked Mole-rats}

- Experience chronic hypoxia all its life

- Cold-blooded and have long longevity

- Have low resting MR and high hemoglobin affinity for $\mathrm{O}_{2}$

- Extreme brain tolerance to anoxia

- Remain active during anoxic exposure

- And Retain body temperature

- Experience MRD $(>85 \%)$ at $<7 \% \mathrm{O}_{2}$

- Release large amounts of fructose to the blood and use that to drive glycolysis

- Fructose-based glycolysis

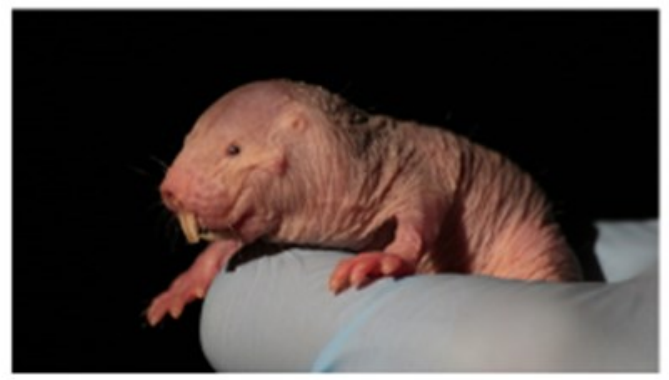




\section{Diving Mammals}

- Seals:

- Hypoxic for minutes to hours $(\sim 2)$ at a time

- Rely on endogenous stores of $\mathrm{O}_{2}$ in $\rightarrow$ hemoglobin in the blood or myoglobin in the muscles

- Cardiovascular adjustments

- Metabolic adjustments $\rightarrow$ DMR is lower than resting surface MR and increased during dive duration.

- Arterial blood oxygen tension is significantly lower than nontolerant mammals ( $7-10 \mathrm{mmHg}$ vs $25-40 \mathrm{mmHg}$ )
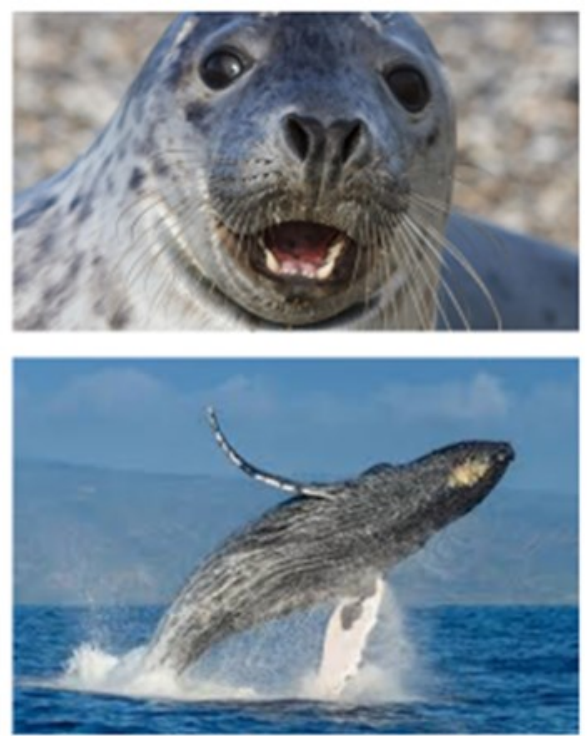
